CRITICAL PERSPECTIVES ON THE TRANSFORMATIVE POTENTIAL OF HIGHER EDUCATION IN AOTEAROA NEW ZEALAND

BY

CHELSEA MARIA GROOTVELD

\begin{abstract}
A thesis
submitted to the Victoria University of Wellington

in fulfilment of the requirements for the degree of

Doctor of Philosophy
\end{abstract}

Victoria University of Wellington

(2013) 


\section{He Karakia}

E tau nei ki runga i a tātou katoa te wairua o ngā mātua tīpuna

Nā rātou i whakatakoto te ara hei hīkoitanga mā tātou ngā uri

I whatatōkia ō tātou ngākau ki ngā tikanga hei aratakinga i a tātou

Kia ngākaunui ki te hāpai i a tātou mahi katoa

i roto i te pono i te tika, i te māramatanga

Me te aroha anō o tētahi ki tētahi

E Rongo whakairia ake ki runga kia tīna!

Tīna! Haumi e, hui e, Tāiki e!

Bestow upon us all the spiritual essence of the ancestors

For it was they who lay the pathway for us, their descendants;

(It was they) who implanted within our hearts the ancient customs to guide us in order that we be dedicated in uplifting (ourselves and others)

in all of our tasks. And that we do so in truth, in what is right, and with an enlightened vision, and with love to one another.

Oh Rongo, raise these words up high so that they become fixed permanent

Permanent, bound, firm! 


\section{He Mihi}

E tika ana ki te tuku mihi ki a rātou mā kua wheturangitia, rātou kua mene atu ki te pō, moe mai rā koutou.

Ko Hikurangi rāua ko Kapuarangi ōku maunga.

Ko Waiapu rāua ko Wainui ōku awa

Ko Umuariki tōku hapū

Ko Ruataupare rāua ko Torerenuiarua ōku marae

Ko Ngāti Porou, Ko Ngaitai, Ko Te Whānau a Apanui, Ko Te Whakatōhea me Tūhourangi ōku Iwi.

Ko Chelsea Grootveld tōku ingoa

Nei rā aku mihi ki a tātou te hunga ora

Tihē mauri ora e 


\begin{abstract}
The global economic recession has resulted in unprecedented levels of inequality among the masses and paradoxically extraordinary levels of wealth and fortune among an elite few. In Aotearoa New Zealand, there is a widely held belief among Māori that higher education provides the key to dismantling inequalities and a 'good education' will help in the making of a better life. This research study looks at how to create positive transformation for Māori through education by exploring the interrelationship between higher education, transformation and social class in contemporary Aotearoa New Zealand.
\end{abstract}

Based on semi-structured interviews with 30 'highly educated' Māori from diverse backgrounds, aged 25 to 46 years old, this thesis explores the perspectives and tensions that arise for contemporary Māori who are creating a landscape for themselves and their whānau (family), particularly how higher education is complicit in both the potential to transform and the potential to constrain transformation. At the end of the day, are highly educated Māori simply maintaining the status quo, or are they in fact building organic intellectuals with the capacity to create and effect positive transformation for the collective?

The research found that higher education success was a key enabler for transformation. Higher education opened doors and provided opportunities for participants to build critical consciousness and accrue material wealth as individuals in order to contribute to collective (whānau, hapū and Iwi) transformation. Only half of the participants identified with social class and therefore class consciousness was not a lever for transformation, rather it was at the level of whakapapa (genealogy) where transformative consciousness might be accelerated. Whānau is the critical transformation site and participants are leading transformative strategies in a range of dynamic ways, however, at present this action is uncoordinated. The findings showed scope for increased cohesion and collaboration in order to develop innovative strategies which draw on 'both' cultural and material wealth to address structural inequalities and enliven whānau, hapū, iwi and Māori transformative aspirations. 


\section{Acknowledgements}

First, to the individuals who agreed to be part of this study, thank you for opening your homes and workspaces to me and for trusting me to share your life stories and experiences on a subject as tricky as transformation and social class. It was a humbling experience to have interviewed you and spent many hours reviewing recordings and analysing transcripts in an attempt to express your stories with authenticity and respect.

Professor Wally Penetito, it was an honour to be supervised by you. Thank you for sharing your passion and depth of knowledge in Māori education, the sociology of education and social class analysis. You have encouraged me to pursue a kaupapa where few Māori academics have ventured. Thank you for having faith in my ability to do this research study justice. I also thank you for your patience and humour.

Dr Hazel Phillips, for your clarity, pragmatism, intellect and awhi. Thank you for modelling what it means to be a strong Māori female academic, mother, grandmother and wife. You have consistently challenged my thinking and encouraged me to push beyond my intellectual comfort zone. I am a better scholar for this.

To Hiria McRae, for your inspiration, support, baking, and sharing your specialist teaching knowledge. Tabitha McKenzie for your drive and motivation. Ria Tomoana, Te Aroha Hohaia and Greg van Passen for always showing interest in my research. Dee O'Carroll and Awanui Te Huia, for your intellect, love of travel and fine kai. Peter Sanders, for showing me what an effective filing system looks like. The international postgraduate students at Campbell House for reminding me how lucky I am to be studying in my homeland with my family alongside me.

To the staff of Te Kura Māori - Pine Southon and Belinda Cattermole, Dr Cherie Chu, Dr Joanna Kidman, Mere Marshall, Pania Te Maro, Rawiri Hindle, Dr Kabini Saga, and Fuapepe Rimoni for your inspiration and words of encouragement. To Sheila Law and Alix Klein for your patience and support. To the staff of the WJ Scott Library for your outstanding service. I must also acknowledge the Victoria University 
scholarships office, Faculty of Education, Fred Bishop and the Ministry of Education for their financial support. MAI ki Pōneke - thank you.

To the TriPōneke whānau (especially our kids) for providing balance and positivity in my life - Nicola Grace, Vanessa and Norm Broughton, Renaee Clark, Sally and Carl Goldsmith, Katy Te Amo, Natalia and Irai Edwin, Noni, Moana, Linda, Terry, Ann, Papa Jim, Anne, Ruthie, Di and Piripi, Gail, Lisa, Nicky, Belinda and Chris. To Heather, Wayne, Missy, George, Lee and Kiri Bird for instigating a kaupapa which has forever changed my life.

To my beautiful friends, old and new, in Aotearoa and abroad for your enduring support and love. A simple email and facebook message was always appreciated. Te rōpū mana Māori ki te kura o Te Rā for your sense of justice, resilience and faith.

To my whānau, you are a source of strength and unconditional love. Mum and Dad, for your support from afar. Mum Paki, for your endless support. Kelley, Simon, Aidan, Aunty Dob, Karley, Dave, Caleb, Lex and Leo, Koro and Helen, Matt and Pip, Rhondy, Delamere, Paku, Maxwell, Hammond-Woolcott, Hamawaki, Hori, EdwardsHammond, Debreceny, Hammond, Cope, Cooper, Grace, Guyton, Edwards, Hata, Masters, Mihaere, Mikaere-Hayes, Ellison, Aramoana, Ims, Porima, Sciascia, Tomoana and Wilson-Te Kanawa whānau - a special thanks to Anne Anituatua Delamere for your enduring grace and wisdom. To my grandfather, Te Wikiriwhi Tuahu Delamere, for your hardcase jokes and enduring wisdom.

To my children, Kahuroa Te Raana and Mihi-Terina Aiko. Thank you for grounding me and putting this PhD into perspective. I am looking forward to being more present to you both and having time to go scooter racing, build huts and read books.

Timoti - for your love, endurance, patience and faith in my ability to finish this PhD. You are my rock. You have encouraged me to pursue doctoral studies and supported me in every way conceivable to complete this task. I am a better person because of you. I look forward to returning the favour so that you can pursue your dreams and aspirations. 


\section{Preface}

This preface describes the conventions I have followed in the presentation of this thesis.

\section{Conventions}

I have included translations of Māori words in the text where necessary and also provided a comprehensive glossary of Māori terms used in this thesis. Translation from Māori to English has been provided to make this study more accessible to a wider audience.

In sections where narratives are presented I have used the symbol / to denote a pause in speech. I have used pseudonyms to replace people's names or small place names to protect the anonymity of participants. 


\section{Table of Contents}

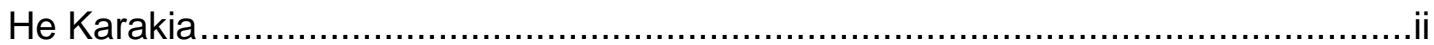

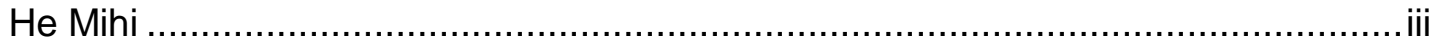

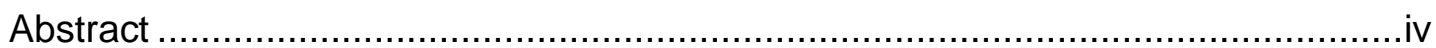

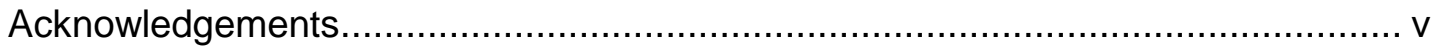

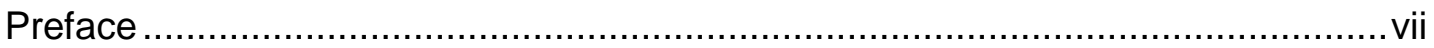

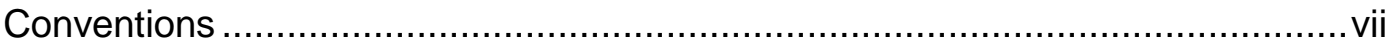

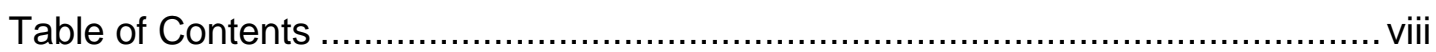

List of Tables and Figures...........................................................................

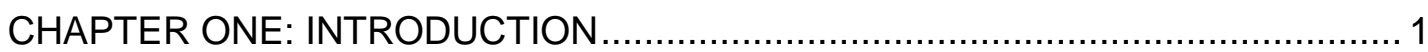

Education and Schooling in Aotearoa New Zealand ...................................... 1

Māori Experiences in Formal State Schooling: A Brief History ......................... 2

State of Māori Education......................................................................... 3

Māori and Higher Education ...................................................................... 3

Educational Inequalities: Culturalist and Structuralist Perspectives.................. 6

The Material Benefits of Higher Education (Jobs and Income) ...................... 10

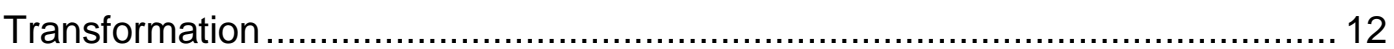

Higher Education: Building a Critical Consciousness? .................................... 13 
Class Consciousness

Social Class Perspectives

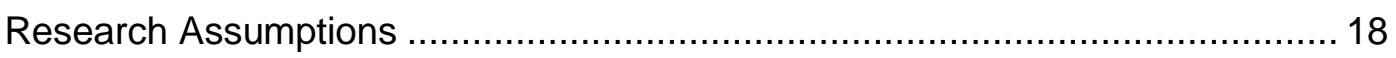

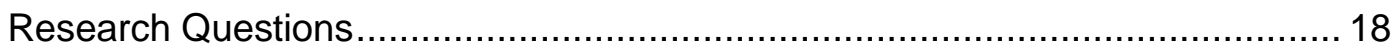

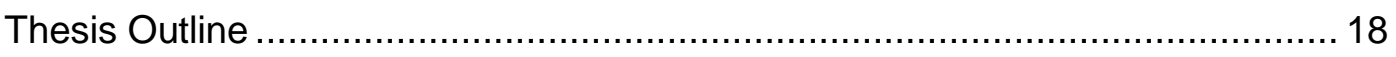

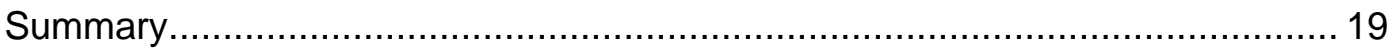

CHAPTER TWO: CONCEPTUAL POSITIONING PART ONE: LOCATING MYSELF

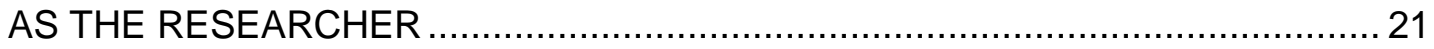

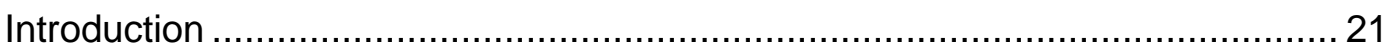

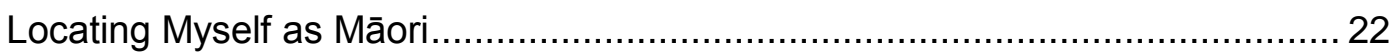

He Korowai Kuia - Matriarchal Support ................................................ 22

Ōku Matua - My Parents ................................................................ 24

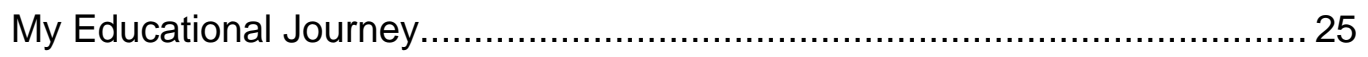

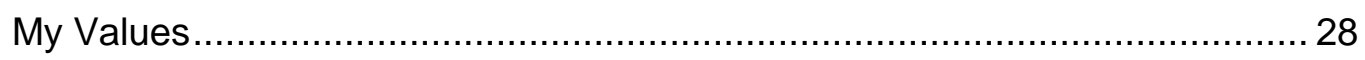

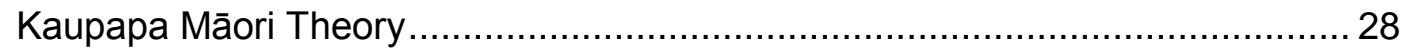

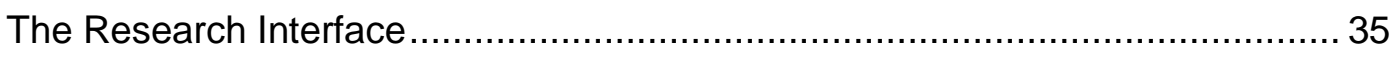

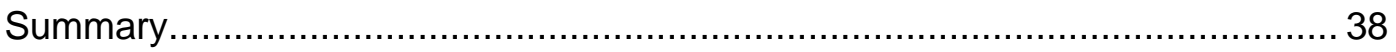




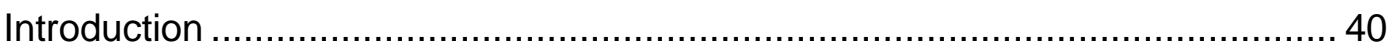

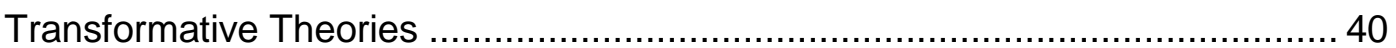

Indigenous Peoples and Colonisation ........................................................ 40

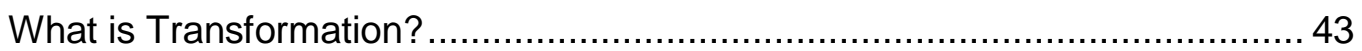

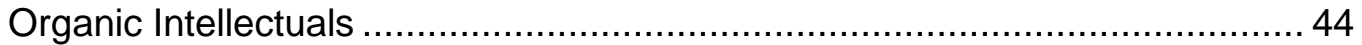

Kaupapa Māori and Transformative Theories.................................................. 47

The Transformative Potential of Social Class Perspectives ................................ 50

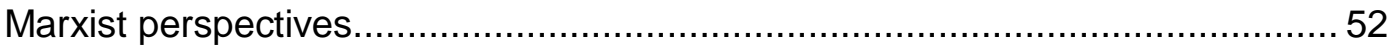

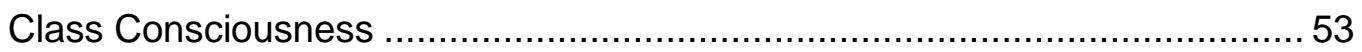

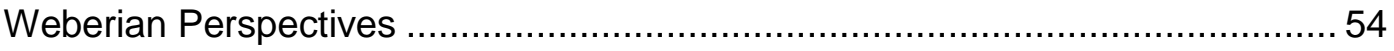

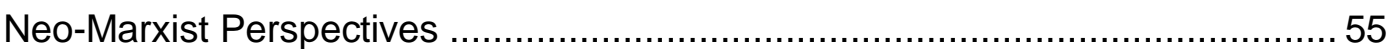

Neo-Marxist Perspectives on Class, Ethnicity and Race ………………........56

Neo-Marxist Perspectives and Culture....................................................... 58

Neo-Marxist Culturalist Class Perspectives.................................................... 60

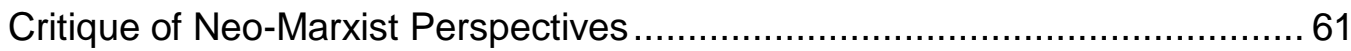

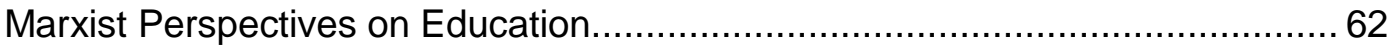

Social and Cultural Reproduction: Pierre Bourdieu........................................... 63 
Habitus

Cultural Capital 65

Fields 66

Summary

CHAPTER FOUR: BACKGROUND TO THIS STUDY 69

Introduction 69

Māori World View. 69

Whakapapa 72

Whakapapa and Hierarchy 73

Traditional Society and systems of hierarchies 74

Māori Political Economy. 77

Colonisation and Land Alienation 78

Social Class: Our Colonial Roots 79

Neo-liberal Political Economy 80

Political Economy 80

Neo-liberalism. 81

Neo-liberalism and Education 82

Growing Social Inequalities 82 
Global Economic Recession

Impact on Māori Wellbeing

Increased Child Poverty. 84

Māori Resistance. 85

Social Class-Related Research in Aotearoa New Zealand 87

Summary. 91

CHAPTER FIVE: METHODOLOGY 93

Introduction 93

Qualitative Mixed Methods Research 93

Participant Selection 94

Quantifying the Target Cohort. 94

Accessing the Target Cohort 96

Purposeful Sampling

Higher Education - One Indicator of the 'Middle Class' 97

Research Methods 98

Document Review. 99

Semi-Structured Interviews 99

Logistics and Planning .... 100 
Relationships and Participants Recruitment.

Pilot Interviews

Interview Timelines and Locations

Three-Phase Approach to Interviews

Participant Demographic Statistics

Age Range

Participants' Qualifications 105

Participants' Occupations 106

Participants' Gross Annual Income 108

Reo Proficiency 108

Children and Dependants 109

Kaupapa Māori Research Principles 110

Tikanga.

Whakawhanaungatanga

Manaakitanga

Mana

He Kanohi Kitea

Data Analysis 
Ethics

Whakamana i te tangata

Whakawhanaungatanga

Confidentiality

Cultural Advice

Informed Consent

Limitations

Summary.

CHAPTER SIX: FINDINGS

Introduction

What it Means to be Māori in Aotearoa New Zealand.

Values

Role of Education

Parents' Educational Experiences and Expectations 128

Place-Based Education and Cultural Wealth 129 
Higher Education

Brief Summary

Limited Material Wealth.

Class Consciousness

Social Class: Te Ao Māori Perspective

Social Class: Te Ao Hurihuri Perspective 139

Perceptions of Difference. 140

Giving Back and Whānau Expectations 142

Transformation at the Roots 143

Summary 145

Key Findings 146

CHAPTER SEVEN: MĀORI IN THE MIDDLE - CRITICAL PERSPECTIVES ON HIGHER EDUCATION, TRANSFORMATION AND SOCIAL CLASS IN AOTEAROA NEW ZEALAND.

Introduction 148

What is the Role of Higher Education Success in the Transformative Potential of Māori? 148

Formal Education Experiences..... 148

What Is the Transformative Potential of This Cohort?. 151 
Whānau Strategies

Iwi (Tribal) Strategies.

What Role Does Class Consciousness Play in Transformation in Contemporary Aotearoa New Zealand?

Class Ambivalence 156

Habitus in Te Ao Māori: Participants' Life-worlds 158

Cultural Wealth: A Māori Cultural Capital? 162

Do Māori Perceive Themselves in Social Class-based Ways? 168

Why Is This Topic Important? 169

Summary 171

CHAPTER EIGHT: CONCLUSION

Introduction 172

The Role of Education and Models of Transformation 172

Whakapapa (Geneology): An Enabler and Mobiliser 174

Highly Educated and Stuck in the Middle 174

Future Research and Directions

Policy Implications 176

Whānau and Hapū Transformation 176 $x v i$ 


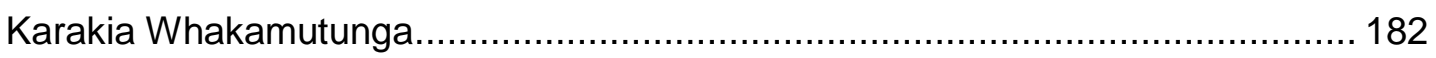

Glossary

References

Appendix A: Participant Interview Schedule.

Appendix B: Information Sheet for Interview Participants 222

Appendix C: Consent form for Interview Participants 224

Appendix D: Transcriber Confidentiality Form 225

Appendix E: Participant Matrix 226 


\section{List of Tables and Figures}

Figure 1: Theoretical Framework: The Interface Between Neo-Marxist and Kaupapa Māori Theory

Figure 2: Principles of Neo-Marxist Culturalist Class and Kaupapa Māori Theory.. 60

Table 1: Participant Interview Locations and Number of Interviews 103

Table 2: Participant Age Range 105

Table 3: Participant Highest Qualification 105

Table 4: Participant Occupations and Sector 106

Table 5: Participant Gross Annual Income 108

Table 6: Self-rated Reo Proficiency 109

Table 7: Number of Children/Dependants 109

Table 8: Oliver and Shapiro Cultural Wealth Model. 166

Table 9: Māori Cultural Wealth Model 166 


\section{CHAPTER ONE: INTRODUCTION}

This thesis is about Māori who have achieved in the formal education system and their perspectives on the relevance of living in a class-based society and what influence that has on transformative potential. It is about the perspectives and tensions that arise for Māori who are creating a landscape for themselves, particularly how higher education is complicit in both the potential to transform and the potential to constrain. At its heart, this research study is about creating positive change and transformation for Māori through education by exploring the interrelationship between higher education, social transformation and social class in contemporary Aotearoa New Zealand.

\section{Education and Schooling in Aotearoa New Zealand}

What is meant by education in the context of this research? 'Education' comes in many different shapes and sizes - formal, informal, place-based and academic with a multitude of benefits and outcomes to be enjoyed from each. For the purposes of this research, a Western view of education is applied. This means the focus is on the formal state schooling and education system (compulsory and tertiary) in Aotearoa New Zealand and the place of Māori within it. To be 'educated' within this system means to have attained qualifications in the schooling system. This means Western-based knowledge, curricula, pedagogies and cultural capital are privileged and normalised as the standard for what ought to be learned and more importantly what knowledge is valued in society (Apple, 1992; Bernstein, 1977; Young, 1975). What counts as education success means different things to different people and this research thesis is deliberate in its focus on Māori higher education success, defined as the attainment of postgraduate and/or higher qualifications. Education in this sense does not refer to 'mātauranga' Māori, a term often used to denote education from a Māori perspective imbued in the dynamic and complex body of externalised and codified knowledge (Royal, 2005). Such discussions, albeit intriguing, are beyond the scope of this research. This section begins with a brief historical overview of Māori experiences within the formal state schooling and education system. 


\section{Māori Experiences in Formal State Schooling: A Brief History}

The roots of the present-day New Zealand education system are deeply embedded in Western philosophies, epistemologies, world views and values (Penetito, 1984, 2002). The formal education system was transplanted to New Zealand by the colonial settlers from the British motherland and imposed on hapū and iwi with the establishment of the Native Schools in 1867 (Durie, 1998). The imperialist ideology and mindset of the day was to assimilate, educate and civilise the native peoples by eradicating their language and culture (Smith, 1999).Thus, education and schooling provided the perfect vehicle through which these assimilative objectives could be achieved (Simon, 1986). As pointed out by Dewes (1975), Māori formal education has, from its inception, been subject to Pākehā veto and control. It is no surprise therefore that generations of whānau, hapū, iwi and Māori communities have suffered as a result of practices and policies purposefully manufactured to colonise, subjugate and assimilate (Durie, 1998; Walker, 1996). To say the formal education system has failed Māori is an understatement. For the majority, their experiences within the formal education system have been a disaster (Penetito, 1988, 2010b). In its most recent annual report on Māori education entitled 'Ngā Haeata Mātauranga 2008/2009', the Ministry of Education acknowledges, to some degree, its systemic failure. It states: "Historically, the education system has been underperforming for Māori learners and their whānau, iwi and communities" (Ministry of Education, 2010).

Walker (1990) argued how for the majority of Māori to be 'educated' in the formal education system meant they had to leave their Māori identity, language and culture at the door. Unfortunately, this statement still holds true for many Māori students today. To be 'educated' means to endure an education system which reflects a world view, culture and set of values antithetical to one's own (Bishop and Glynn, 1999). While there have undoubtedly been successes like the establishment of te kōhanga reo (early childhood education language nests), the emergence of Māori medium education, and the development of wānanga at the tertiary level, the emergence of these "resistance initiatives" (Giroux, 1983:72) at the periphery was largely a reaction to increased frustration at the state schooling system as well as concern for the revitalisation of language and culture (Benton, 1989; Sharples, 
1988; Smith, 1990). Meanwhile, the system and the ideologies underpinning the system remain steadfast and intact.

\section{State of Māori Education}

In order to improve Māori educational outcomes significant challenges must to be addressed by the formal education system. As the current Minister of Māori Affairs and Associate Minister of Education, Dr Pita Sharples (as cited in Ministry of Education, 2010), states: "the challenge facing education today, the outcome of which will affect the future of all New Zealanders, is to create an education system that supports the right of Māori students to live and learn as Māori, to reach their potential, and go on to contribute to their whānau, iwi and our nation" (2010:4). In terms of key educational outcomes and indices, Māori are over-represented in stand-down, absenteeism and underachievement rates and under-represented in achievement rates. In short, Māori educational achievement-related statistics are abysmal. The superficial presentation of such negative statistics more often than not, intentionally or unintentionally, lays the blame firmly on the shoulders of Māori students and their whānau (family) and contributes to the ongoing promulgation of deficit attitudes and negative stereotypes about Māori student potential in education and schooling (Bishop and Berryman, 2006). If, however, we invert these statistics and view them through a different lens, we could argue that the 'system' has failed to fulfil the achievement and attendance potential of Māori students (Reid and Robson, 2006).

\section{Māori and Higher Education}

The history of Māori participation and achievement in higher education (also commonly referred to as tertiary education) in Aotearoa New Zealand is marred by successive government policies of assimilation, integration, multiculturalism and biculturalism (Penetito, 2002; Phillips, 2003; Tiakiwai, 2001). Against this policy backdrop, a legacy of Māori educational underachievement has unfolded (Durie, 1997; Irwin, 1992; Penetito, 2010b; Smith, 1990; Smith, 1999) in what has for the most part been a negative and humiliating process (Fuli, 1994; Tiakiwai and Teddy, 2003; Walker, 1999). The pioneering educational feats of Apirana Ngata, the first Māori university graduate, and his contemporaries at the turn of the century were 
negated by education policies of the day which actively discouraged Māori from pursuing a university education (Moon, 1993). Rather, Māori were seen as being most suited to technical and manual trades, and policies and practices were adjusted to support this view (Harker, 1990; Simon, 1990; Simon and Smith, 2001). According to Tiakiwai (2001) the achievements of the first group of Māori graduates "threatened Pākehā dominance and superiority" and this resulted in direct changes to suppress Māori access to higher education (2001:22). Simon (1990) explains how Ngata and his fellow students arrived "too soon" and showed they could "excel at a level of European education beyond that of the majority Pākehā (non-Māori European)", and thus were a direct threat to Pākehā dominance (1990:101). This racist hegemonic ideology set the scene for future Māori participation in higher education. Predictably, the government's exclusionary policies continued unabated as evidenced by the sharp decline in Māori graduates up until the 1960s and 1970s. Walker (1991) attributes the significant gap between the first and second wave of Māori university graduates to the "official agenda of suppressing Māori talent" (Walker, 1991:8). The dearth in empirically based research related to Māori achievement in higher education is therefore not surprising (Tiakiwai, 2001; Wilkie, 2006). Fitzgerald's (1977) seminal research on Māori university graduates, however, is one of the few pieces of research which looks at Māori achievement with a particular focus on cultural identity. His research showed the second wave of university graduates in the 1970s were able to avoid assimilation by adopting a behaviour and identity best described as biculturalism, that is, they possessed a strong sense of cultural and ethnic identity and were eager to protect and/or incorporate this micro culture into the larger macro New Zealand culture (Fitzgerald, 1974:179). Māori and indigenous peoples alike often describe higher education as a paradox (Carey, 2008; Ip, 2008). As Tiakiwai (2001) explains, this paradoxical experience is a struggle to "live dual existences", that is, "maintaining cultural identity and traditions on the one hand, while achieving Western standards of academic success on the other" (2001:1). Durie (2001) expands on this idea of dual existences and has cogently articulated the reality within which Māori live, that is, positioned at the interface between te ao Māori (the Māori world) and te ao whānui (the global world). He challenges educators, policymakers and researchers alike to seek to understand this reality by looking at the ways in which Māori world views and the world views of wider society impact on each other. 
As stated by Tiakiwai and Teddy (2003), despite the denigration suffered by Māori as a result of racist and assimilative educational policies, "Māori have engaged in a counter-hegemonic process to ensure an education system that is more reflective of Māori needs and aspirations" (2003:4). To this end, the current context for Māori in tertiary education has changed markedly. More Māori than ever before are studying in higher education, due in no small part to the establishment of whare wānanga (Department of Labour, 2009). So, how are Māori progressing in higher education relative to the wider population? Overall, New Zealanders are becoming more highly educated. In 2008, one in six people held a bachelor's degree or higher-level qualifications; this figure was one in ten people in 1988. While the proportions of Māori holding a bachelor's degree or higher-level qualification more than doubled in the 20-year period from 1988 to 2008, the proportions of the non-Māori population continue to increase at a much faster rate (Ministry of Education, 2009).

The current global economic recession has resulted in a corresponding increase in tertiary enrolments with many New Zealand universities oversubscribed (McCormack, 2010:2). In short, increasing numbers of people are seeking higher education qualifications faced by the reality of an increasingly competitive labour market, but paradoxically with no guarantee of employment once qualified (Strathdee, 2005). This phenomenon raises the question about what it means to achieve higher education success in a weakening labour market. Current developments would suggest the goalposts for entry into the labour market have shifted and a bachelor's degree does not hold the same value and currency. Thus, perhaps a more appropriate indicator of higher education success in today's context is having attained a postgraduate qualification (i.e. bachelor's degrees with honours, postgraduate diplomas and certificates, master's degrees and doctorates). Although statistics related to Māori participation indicate that Māori remain underrepresented in postgraduate study in comparison to non-Māori, there are positive signs with an overall growth in numbers (Ministry of Education, 2007b; Te Puni Kōkiri, 2006). Māori postgraduates are recognised as a pool of potential leaders who can contribute to the realisation of Māori aspirations and to the New Zealand economy (Durie, 2006; McKinley et al., 2007). Moreover, a Ministry of Education paper entitled 'Māori in Doctoral Study' points out that the number of Māori doctoral students steadily increased between 1994 and 2004, with the overall number of 
students enrolled nearly tripled from 77 in 1994 to 262 in 2004. Completions of doctoral degrees by Māori students also increased steadily from 11 in 1994 to 35 in 2004 (Ministry of Education, 2006).

\section{Educational Inequalities: Culturalist and Structuralist Perspectives}

Māori underachievement in education or, rather, the failure of the education system to deliver quality outcomes to Māori students and their whānau, is well documented and there are two dominant schools of thought as to the reasons behind this culturalist and structuralist perspectives. While there are stark differences between both perspectives, it is the interplay (dialectic) between them which is critical to this thesis and both need to be understood. For example, while neo-liberalism is based on structuralist orthodoxy, its implementation is very much culturalist and therefore the distinctions are not so clear cut. The tensions, complexities and contradictions that emerge as a result of the cultural/structural dialectic are precisely what this thesis attempts to highlight as I argue the need for both cultural and structural responses to address educational inequalities and create transformation.

The culturalist perspective is based on the idea that present-day educational disparities are the result of a racist and hegemonic education system which has systematically ignored Māori culture, world views and practices (see for example Bishop, 1998; Bishop and Glynn, 1999; Smith, 1999; Smith, 2000). The culturalist perspective is often viewed as subjective, personal, and draws on the strength and value of peoples and culture to formulate responses to address disparities. In the local education context, cultural responses have been implemented on two fronts. First, policies, programmes and interventions have been implemented within the system designed to shift mainstream attitudes, values, beliefs, behaviours, practices and pedagogies to improve cultural awareness, responsiveness and, in the longterm, Māori educational achievement. Second, kaupapa Māori responses were developed outside of the mainstream system, responses where kaupapa Māori world views, language, identity and culture are valued and at the centre of education programmes and interventions. 
Recent examples of cultural responses within the system include Te Kotahitanga a professional development model introduced in $33 \mathrm{New}$ Zealand secondary schools from 2004 to 2007 , its aim is to develop culturally responsive pedagogies to enhance Māori student achievement (Meyer, Penetito, Hynds, Savage, Hindle and Sleeter, 2010) and He Kakano - a strategic school-based professional development programme with an explicit focus on building culturally responsive school leadership, its aim is to support school leaders to support and enhance the social and cultural conditions necessary to bring about change for Māori students (Ministry of Education, 2013). Kaupapa Māori responses include Te Kōhanga Reo - total immersion te reo Māori whānau (family) programme for mokopuna (young children) from birth to six years of age (Waitangi Tribunal, 2012) and Kura Kaupapa Māori Māori language immersion schools where the philosophy and practice reflect Māori cultural values (Smith, L.T, 1992). In short, cultural responses to Māori educational inequalities are the dominant response funded by the Ministry of Education.

Conversely, structuralist theory is described as detached, objective, impersonal and concerned with patterns, hidden systems, processes and structures. The structuralist perspective argues that the underlying cause of Māori underachievement is 'socioeconomic', based on a lack of Māori access to, and participation in, New Zealand's capitalist economic system (Chapple, 2000; Nash, 1999b, 1999c; 2001; Openshaw and Rata, 2008; Poata-Smith, 2004a; Rata, 2000, Strathdee, 2013).

Poata-Smith (1996, 2004a, 2004b) is one of a handful of contemporary Māori academics who talks about social class and Māori from a structural perspective and argues against culturalist or what he refers to as ethnic-based policies and responses. Smith's insightful $\mathrm{PhD}$ thesis analysis traced the evolution of contemporary Māori protest and identifies three key epochs (Poata-Smith, 1996). First, the seeds of contemporary Māori activism (1967-1975); second, the Māori land rights movement (1975-1984); and third, the arrival of the new right and the emergence of 'cultural nationalism' (from 1984 onwards). One of the most important points he makes is that analyses of Māori movements must always be considered within the context of the nature of capitalism, that is, the "underlying social structures, political forces and ideologies of the capitalist society" (1996:98). 
Poata-Smith explains how a group of highly influential Māori elite leaders and thinkers espoused the 'cultural nationalism ideology' premised on the idea that immersion in one's Māori identity or Māoritanga could alleviate the ills of oppression. He asserts the emphasis on identity alone as the crucial determining factor in Māori oppression has been an "unmitigated disaster for the vast majority of working class Māori whānau" (Ibid:110). Furthermore, he states the cultural nationalism ideology "ignores the fundamental gap in differential access to economic and political power within and across Māori society" (Ibid:112). The emergence of the Māori elite during the establishment and negotiation of the Treaty of Waitangi settlements framework was critical as the state co-opted Māori elite into positions of prestige and wealth within the state structure. This resulted in Māori leaders who became distanced from the realities of flax-roots Māori. Poata-Smith concludes that the increasing use of Māori culture and identity as a strategy for dealing with Māori disadvantage and powerlessness has been one of the most significant developments in the evolution of Māori activism since the 1960s; however, it has done nothing to change material reality for the vast majority of Māori. Sykes (2010) also critiques the Māori elite and argues it is no coincidence this group has emerged alongside the distribution of capital into Māori communities as part of the Treaty Settlement Framework, and resulted in a new Māori hegemony (2010:9).

Poata-Smith's cogent analysis emphasised meaningful transformation can only come about through challenging and dismantling the underlying power structures of the capitalist society. Moreover, radical transformation at both a structural and political level is required in order to change the material lives of the majority of Māori working-class whānau. That said, so much of the debate in contemporary Aotearoa is dominated by issues of cultural identity, which although fundamentally important and central to Māori social wellbeing, detract from the material reality of the majority of working-class Māori who continue to live on the margins.

Differential access to economic and political power between a Māori elite and working-class Māori is at the heart of the analyses developed by Rata $(2000,2005)$ and Openshaw (2008), both non-Māori academics who present ideas congruent with aspects of Poata-Smith's thesis. 
Rata argues from a material theory perspective how neo-tribal capitalism has emerged as a "localised version of capitalism" in Aotearoa New Zealand (2000:34). She posits within the context of the Treaty of Waitangi settlements process, contemporary iwi (tribes) have become "economic corporations controlled by the emergent capitalist elite - neo tribal elite" far removed from the traditional iwi structure (2005:6). Neo-tribal capitalism is characterised by exploitative class relations of production and the concealing ideology of communal revival (Rata, 2005:6, Strathdee, 2013: 501). This notion is akin to Poata-Smith's concept of cultural nationalism (Poata-Smith, 2004b).

Moreover, Rata distinguishes between cultural theory, which argues that new tribal economies are characterised by determinant kinship communal relations (whakapapa), and material theory, which posits new tribal economy relations are in fact class relations. She insists that, despite the rhetoric, communal revival and neotribal ideology are firmly grounded in the economic interests of the emergent elite classes, as evidenced by the unequal wealth distribution and differential access to economic and political power within Māori society. She identified two features which distinguish neo-tribal capitalism from capitalism; first, the absence of private ownership and, second, class relations operating under the guise of communal social relations. In short, social class inequalities are masked by the ideology of communal revivalism.

Rata describes the professional middle class as the "comprador bourgeois" which has within two decades re-positioned itself as the contemporary elite, the owners, or at the very least the controllers of all capitalised resources originally claimed as reparations for historical injustices for all Māori (2005:9). Rata's analysis is grounded in an attempt to understand the nature of capitalism and the underlying capitalist structure. She is scathing in her attack on cultural theory which she argues is based on unfounded assumptions which remain largely unchallenged. Rata's ideas are controversial among Māori, and are subject to intense critique (see Wilkie, 2006). However, like Poata-Smith, her thesis offers a different and challenging, material-based perspective through which contemporary social inequalities and strategies for transformation can be analysed and debated. Moreover, as increasing numbers of iwi shift into post-Treaty of Waitangi settlement contexts, Rata's ideas 
provide a potent lens through which issues of power and class relations within contemporary iwi might be explored.

Throughout this thesis I argue that both structural and cultural responses are needed to create change and the dialectic and interface is where Māori are carving out a landscape and new space to effect transformation. We now turn our attention towards the relationship between higher education, jobs and income to analyse how they come together to impact on the material and lived realities of Māori.

\section{The Material Benefits of Higher Education (Jobs and Income)}

Education and, in particular, higher education is widely recognised as an important factor in determining a person's social and economic status (Nash and Harker, 1997; Lauder and Hughes, 1990a). This argument is supported by Campbell (2007) who contends within a modern-day context, school and higher education have played an increasingly important role in the processes of determining a person's occupation, levels of potential wealth and power (2007:128). Thus, occupation has a direct relationship with material living standards for both Māori and non-Māori employed populations (Krishnan et al., 2002). A report produced by Te Puni Kōkiri (2010) entitled 'Benefits of Education for Māori' emphasises the flow-on effects of being highly educated. They state "Māori with higher levels of qualifications are more likely to be employed and earn higher incomes" (2010:1). In addition, the report highlights the health benefits of being highly educated and points out how Māori with higher qualifications are also more likely to live longer (Ibid). Furthermore, statistics from the most recent Household Labour Force Survey support the view that tertiary-qualified Māori earn more than Māori without qualifications, have lower unemployment rates, and are more likely to be employed in higher-skilled occupations (Ministry of Education, 2005; Statistics New Zealand, 2009a).

Income is an important measure of progress in the lives of Māori individuals and whānau because how much people earn has a significant impact on their economic and social wellbeing (Te Puni Kōkiri, 2009b). In 2008, the median hourly earnings of Māori with a bachelor's degree or a higher qualification were 70 percent higher than 
for Māori with no qualification. Tertiary qualifications offer a buffer against unemployment as Māori people with bachelor's degrees or higher qualifications have a lower unemployment rate than those without a qualification (Ibid). The kind of jobs that Māori work in is also an important measure of Māori wellbeing. Māori remain over-represented in the lower-skilled occupations and under-represented in the higher-skilled occupations (Department of Labour, 2009). This signals a huge waste of Māori talent and potential (Te Puni Kōkiri, 2009b). Rob McLeod, a Māori entrepreneur, businessman, and member of the Business Round Table postulates how shifting this large group of unemployed and low-wage employed Māori to work commensurate with their abilities and aspirations is worth an estimated tens of billions in return to the national economy (McLeod, 1999 as cited in McCormack, 2010:6). Moreover, Te Puni Kōkiri (2011) highlights how the demographic trend within the Māori population, that is, the structurally youthful Māori population located alongside a significantly older non-Māori population, provides a window of opportunity referred to as 'collateral demographic dividend' which has the potential for conversion to an economic dividend (2011:7). In short, over the next two decades as successive waves of baby boomers enter retirement, they will be replaced by a successively smaller and younger cohort in the labour market. This creates the space for a disproportionate number of Māori to enter and fill the labour market, and raises questions about what is being done to educate, train, support and prepare young Māori to fulfil this role in the future.

The evidence presented shows a strong correlation between higher education, jobs, income and status. Moreover, the global economic recession has increased demand for tertiary qualifications and exacerbated the level of competition and pressure. With a high youth population combined with the lowest proportion of school leavers transitioning to higher education (Ministry of Education, 2008), Māori are once again in a precarious position. In the search for answers as to why, despite generations of policy interventions, the majority of Māori continue to live on the margins, a materialist, class-based analysis provides a useful lens to explore why these social and educational inequalities persist and exposes the tenacious link between social class, education and occupation outcomes (Dale, 2000; Lauder and Hughes, 1990b; Lauder et al., 1999; Nash, 1999a; Nash and Harker, 1992). 


\section{Transformation}

Despite generations of systemic failure resulting in widespread Māori educational underachievement, it is still widely assumed by Māori that education will get us ahead and transform us as a collective or society (Smith, 2000). The view that education can be used as a vehicle for transformation (social mobility thesis) for the collective differs from the popular new-right meritocratic thesis, which asserts success and advancement is based on effort plus individual ability in order to achieve. Conversely, the transformative view recognises that we do not all start on a level playing field and how myriad factors like ethnicity, culture, gender and class intersect and have an impact on mobility and transformation.

Fundamentally, transformation is premised on the notion that the status quo is unacceptable and that change starts from within (Smith, 2004). This idea is supported by Smith (2003a) who argues transformation has to be won on at least two fronts; a confrontation with the coloniser and a confrontation with ourselves. This is what Smith calls the "inside out model of transformation" which he likens to Paulo Freire's notion that we must first free ourselves before we can free others (Freire, 1973, 1977). Freire's ideas around the transformative power of education are central to this thesis; however, as Richard Shaull eloquently illustrates in his preface to Freire's book, Freire was well aware that education was by no means a neutral process:

"Education either functions as an instrument which is used to facilitate the integration of the younger generation into the logic of the present system and bring about conformity to it, or it becomes 'the practice of freedom', the means by which men and women deal critically and creatively with reality and discover how to participate in the transformation of their world." (Shaull, 2000 as cited in Freire, 2000:34).

The idea of education as 'the practice of freedom', a lever of change and upward mobility is important, but in the journey towards transformation Shaull's narrative reminds us that it is equally important to ensure the agents of change be the change, and not conform to the status quo. Being the change is about resistance 
and agency - in other words for Māori to take control of their own lives to achieve their aspirations. The potential for higher education to be complicit in both the potential to transform and constrain is a key tension explored in this thesis. To this end, Smith suggests that transformation involves engagement in a cyclical process of conscientisation, resistance and transformation. People can start at different points within each process, but ultimately transformation involves the dynamic interplay between the three. In addition, Smith has identified six critical sites of struggle in assisting indigenous communities and peoples to transform, namely, the need to understand and respond to:

- The unhelpful divide between indigenous communities and the academy;

- The new formations of colonisation including economic formations;

- The politics of distractions and to become more proactive;

- The construction of the ultimate vision;

- The struggle for the academy to reclaim the legitimacy and validity of our own language, knowledge and culture; and

- The state to encourage state apparatus to work for indigenous peoples.

This research study seeks to touch on each of the six identified sites, but with a particular focus on the relationship between higher education and transformation. How does higher education success contribute to transformation, what role might social class play in terms of building transformative potential, particularly given the potential for higher education to be complicit in the maintenance of the status quo.

\section{Higher Education: Building a Critical Consciousness?}

This research touches on social class as an important tool for analysis to understand the transformative potential of highly educated Māori, but it is not central 
to this thesis. Rather, the question is whether higher education promotes a critical consciousness in which to challenge and transform or whether it embeds/embroils its participants into a 'false consciousness' in other words perpetuating the status quo. Thus, to understand class consciousness it is necessary to understand the notion of consciousness to develop a critique of the status quo. Second, I will introduce the idea of class consciousness and its usefulness as a tool. Third, I will explore social class, its whakapapa (origins) and history.

\section{Consciousness}

Consciousness is defined in a myriad of ways based on a range of world views and perspectives, and it is not my intent to provide an in-depth phenomenological discussion about the structure of consciousness. Put simply, the Oxford English dictionary defines consciousness as 'a person's awareness or perception of something' or 'the fact of awareness by the mind of itself and the world'. Within the context of this research study, consciousness is about building a critique of the status quo. If Māori are to transform, there must be an awareness that change is needed.

From a Māori world view, the idea of consciousness is depicted throughout Māori cosmology and creation stories. There are many tribal variations to these stories and the cosmological chant below recited by Te Kohuora of Rongoroa (Salmond, 1991 ) is one variation which captures the taxonomy of consciousness from a Māori world view:

Nā te kune te pupuke - From the conception the increase

Nā te pupuke te hihiri - From the increase the thought

Nā te hihiri te mahara - From the thought the remembrance

Nā te mahara te hinengaro - From the remembrance the consciousness

Nā te hinengaro te manako - From the consciousness the desire 
Similarly, Reverend Māori Marsden, esteemed Māori scholar depicts the growth of wisdom and knowledge in the verse below (Royal, 2003):

Te Mahara (primordial memory)

Te Hinengaro (subconscious wisdom)

Te Whakaaro (seed wisdom)

Te Whē (consciousness)

Te Wānanga (achieved wisdom)

The critical point is how consciousness is valued and embedded in Māori cosmology, philosophies and a Māori world view. Like many peoples throughout the world, the pursuit of higher levels of consciousness has long been part of Māori practices and tradition. Kaupapa Māori theory draws on this knowledge base and is described as "a conscience raising theory of liberation that empowers individuals with a critical consciousness" (Mahuika, 2008:3). The challenge therefore is to critique the status quo by not only turning a critical eye to the structures and systems which might "oppress" but also to turn this critical consciousness inward to look at Māori structures and systems as an inhibitor to transformation.

\section{Class Consciousness}

The derivations and implications of class consciousness for my thesis are discussed in Chapter Three, however the relevance of this concept to my thesis is about how it might be used as a tool and lever for transformation. Class consciousness can be defined as the beliefs that a person holds regarding one's social class or economic rank in society, the structure of their class, and their class interests (Wright, 2000). Therefore, if a class consciousness exists among the research cohort there could 
be potential to build structural class-based responses and strategies which challenge unequal power relations in contemporary Aotearoa New Zealand, to complement cultural-based responses.

\section{Social Class Perspectives}

Social class has been off the research agenda, out of vogue, in this country for the past two decades as academics, educationalists and policymakers alike have sought alternative explanations for growing social, economic and educational inequalities between Māori and Pākehā (non-Māori) in New Zealand. Branded by many as deficit theorising and Eurocentric economic determinism, social class was relegated to the netherworlds of locally based policy, research and analysis (Thrupp, 2008). Nonetheless, this thesis argues positive transformation for Māori must include a structural analysis of the capitalist economic system within which these inequalities are embedded. This approach resonates with the ideas posited by Māori scholar and Professor of Māori Education, Wally Penetito, who argues the policy pathway forward for Māori education must incorporate both cultural and structural analyses. Based on his experiences studying anti-racist and multicultural education in London and his analyses of the implications for Māori education, he noted how one issue became clear as day:

"Māori education policies that addressed cultural elements (language, religion, and customs) to the detriment of structural elements (regulations, codes, accountabilities, power relations) would be doomed to fail." (Penetito, 2010b:33)

Thus, social class offers a structuralist perspective through which issues such as critical consciousness, transformation, power, ideology, racism and hierarchy can be explored. It creates the theoretical space to critique the supposed 'egalitarian' society we live in, as well as pose questions about the potential it offers in terms of creating transformative solutions.

In this thesis I will argue how social class is complex and contested given the intersections of gender, race, ethnicity and culture, the old orthodox theories and 
contemporary neo-Marxist theories. Within a local context I will discuss how as a societal organising principle, social class was inevitable given the history of colonisation in Aotearoa New Zealand (Belich, 2007). For example, the process of colonisation imported a class consciousness through entrepreneurs looking to claim lands (Belich, 1989), missionaries seeking converts and extending the protestant ethic (Simon, 1998), adventurers escaping the doldrums of $19^{\text {th }}$-century Britain (King, 2003) and many other disenfranchised citizens wanting to reinvent their own forms of social stratification to advantage themselves. This new land offered an escape from the rigidity of the British class system, to be replaced by a new class system, a system which largely dismissed the cultural wealth, knowledge, systems and beliefs of the Māori inhabitants (Belich, 2001). Thus, there is a New Zealand form of social class that is similar to the British with the differentiating edge between both systems blurred, but just as predictable in its effects.

New Zealanders, for the most part, do not like to talk about social class because it differentiates and exposes the realities of material difference, even though the contrast between social groups is becoming increasingly visible - if you are looking for it (Black, 2005). Given this reticence to discuss or even acknowledge social class exists today, there is not surprisingly a paucity of local empirical-based social class research, and therefore, by default, even less Māori-centred research. The idea of a Māori middle class, provocative as it may seem, gained prominence among mainstream New Zealand when Courtney (2008) published an article entitled "Māori in the Middle" in a national magazine, North and South. The article presented Māori in a new light - highly educated, career-oriented, well paid, mobile and 'successful', antithetical to the stereotypical portrayal of Māori presented in mainstream media (Reweti, 2006). As an educated Māori woman and researcher, the article piqued my interest and raised a number of questions about how Māori perceive social class and its relevance to their life-worlds. Thus, the idea of class consciousness is explored to see whether a class-based consciousness exists and, if so, how this might be used as a vehicle or mechanism to collectivise a group of highly educated and well-resourced Māori to create transformation. 


\section{Research Assumptions}

This research is based on three key assumptions. First, transformation requires both structural and cultural critique, analysis, responses and perhaps more importantly, action. Second, higher education is complicit in both the potential to transform and the potential to constrain transformation. Third, social class is an important tool for analysis, to complement kaupapa Māori and transformative theory, but it is not the focal point of Māori transformative potential.

\section{Research Questions}

The overarching research question is: What is the role of higher education in the transformative potential of highly educated Māori?

In order to fully answer the main research question, first it was necessary to answer and explore a secondary question:

- What role does class consciousness play in transformation in contemporary Aotearoa New Zealand?

This secondary research question raised supplementary questions which needed to be explored:

- Do Māori perceive themselves in social class-based ways?

- How do Mãori perceive and understand social class as it relates to their lifeworlds?

\section{Thesis Outline}

This thesis is divided into eight chapters. Chapter One provides the context and rationale for the study, sets out the problem and identifies the central research question. Chapter Two examines the conceptual positioning of this thesis. This chapter outlines the two parts that make up this conceptual position and describes part one which is about the research standpoint, my location as a Māori researcher 
and how kaupapa Māori and transformative theory inform and are used in this study. Chapter Three presents part two of the conceptual positioning and explores transformative theory, class consciousness and social class.

Chapter Four presents the background to this study, which provides a link between the theoretical component and the empirical research. It explores hierarchies in Aotearoa New Zealand (traditional and contemporary) and Māori experiences of these in both traditional (pre-European) and contemporary contexts. This chapter is about the relevance of living in a class-based society and what influence that has on transformative potential.

Chapter Five outlines how the conceptual positioning has been operationalised in the current study. Chapter Six presents the findings of the qualitative study of 30 highly educated Māori and provides a prologue for the discussion presented in Chapter Seven which critically discusses how the research findings answer the research question and sub-questions. This chapter weaves together the participant narratives and the literature to highlight the implications of this study. Chapter Eight contains the conclusions of this study.

\section{Summary}

This chapter provides an overview of the research study, its importance and relevance to Māori transformative responses and the key areas covered by the research. It starts with a brief history of education and schooling in Aotearoa New Zealand and highlights the intergenerational failure of the education system to provide quality outcomes for Māori. The tension between culturalist and structuralist perspectives and responses is discussed to emphasise the important role this dialectic plays throughout the thesis.

The idea of a highly educated Māori cohort is presented as potential agents of change and transformation. To date, just what Māori think about social class and its relevance to their life-worlds is unclear and the effects of social class on the consciousness and practice of Māori has not been fully explored. This study argues for the creation of transformative strategies which draw on social class analyses as 
a tool to help understand structural inequalities from a Māori point of view and, more importantly, to move beyond simply describing these to talk about what to do and how to effect change and transformation for Māori, by Māori, using both culturalist and structuralist responses. 


\section{CHAPTER TWO: CONCEPTUAL POSITIONING PART ONE: LOCATING MYSELF AS THE RESEARCHER}

\section{Introduction}

This chapter is Part One of two. Part Two follows in the next chapter (Chapter Three). Both chapters form my theoretical positioning which embodies everything about this research study.

The original research proposal had a strong social class focus; however, as the research progressed the emphasis on social class shifted. Based on what my research participants were saying to me, transformation and change became the focal point and pivotal to this research while social class was used as a critical lens to theorise transformation and change. The nature of the topic and the fact that so little had been written about class consciousness and social class from a Māori cultural perspective meant the expansive theoretical landscape underpinning social class had to be explored. This was a challenging task given the complexities, tensions and conjectures in the field. Clear boundaries were established to ensure I was not subsumed by the sheer volume of class-based literature and while there will most certainly be gaps in the literature covered, this thesis does not attempt to cover everything. Rather, the focus is on building an understanding of the key concepts and ideas deriving from social class-based theories to inform transformation. The end result is that this study has a three-part theoretical component as expressed in the conceptual position presented in the next three chapters.

Part One presents my political and cultural point of view as a Māori woman and researcher. It is about my story and standpoint and describes how kaupapa Māori theory informs how I read and understand the world and the literature.

Part Two (Chapter Three) explores transformative theory, its underpinnings and principles and how these weave with kaupapa Māori theory to provide a platform for theorising and creating change. This chapter also looks at the idea of class 
consciousness by unpacking social class, its theoretical roots, key tenets, assumptions, contradictions and relevance in contemporary society.

Part Three (Chapter Four) builds the bridge between the theoretical and empirical components of this research study. It explores hierarchies, old and new, and the imposition of a western political economy in both traditional and contemporary contexts. It also outlines what the literature says about social class in Aotearoa New Zealand and the context within to illustrate how social class is embedded in the local context, in the everyday lives of Māori.

\section{Locating Myself as Māori}

As identified in my pēpeha (outlined in the mihi) I'm a proud descendant of the Ngāti Pōrou, Ngaitai, Whānau a Apanui, Whakatōhea and Tūhourangi tribes of Aotearoa New Zealand. I also have Dutch and French ancestry. The story behind this thesis invariably started long before I was born and begins with my ancestors and my parents. Their collective struggle to be treated with humanity and respect on their own land has carved the pathway for me to pursue doctoral studies and it is only right that this thesis begins with their 'his- and her-stories' (Irwin, 1990, 1992).

\section{He Korowai Kuia - Matriarchal Support}

I was fortunate to grow up surrounded by strong matriarchal figures - women who excelled in both te ao Māori and te ao hurihuri during periods in Aotearoa New Zealand's history when attitudes about the role and position of women in society were archaic at best (Evans, 1994). For Māori women this experience was exacerbated by the compound effect of both sexism and racism (Awatere, 1984; Te Awekotuku, 1991). When put into a historical and contemporary context, the achievements of my female ancestors are a rich source of inspiration which continue to shape my political and cultural perspective today. For the sake of brevity I only have the opportunity to highlight four women, but there are many more and I acknowledge their contributions (albeit not name them) here. 
Both of my grandmothers were staunch, hardworking, no-nonsense type woman with firm roots and connections to their papakāinga (ancestral homeland). My father's mother, Ngaio Morrow nee Grace (deceased), was a staunch and astute Ngāti Porou woman. A long-time member of the Māori Women's Welfare League, she possessed a gift for retaining and reciting whakapapa (genealogy) and was renowned for her fiery temper. My mother's mother, Charlotte Tuhikura Delamere nee Hata (deceased), was a proud Ngaitai and Te Whakatōhea woman. She was a trained primary school teacher, excelled in tennis and basketball and was the pōu (centre-post of tribal meeting house) who kept our whānau together. My grandmothers showed me what it means to be a resilient, intellectual, strong and proud Māori woman.

Similarly, my kuia (maternal great grandmother), Tiaria Wikiriwhi, descended from the Tūhourangi tribe in Rotorua and was the granddaughter of Te Paea Hinerangi Gray or Guide Sophia, world renowned guide at Lake Tarawera. Tiaria married my great grandfather, Weihana Delamere, and lived among his people in Te Whānau a Apanui. Weihana attended Te Aute College, and was a community leader, lawyer and advisor to Sir Apirana Ngata. Due to Weihana's high standing in the community and because Tiaria was an 'outsider' with two children from previous relationships, she faced hostility from whānau and the community. She navigated these tensions with a steely resolve and by all accounts was an indomitable force in our whānau and the local community.

My kuia (grandfather's sister), Anne Anituatua Delamere, is another important role model who even in passing remains a source of strength, grace, determination and inspiration in my life. She joined the New Zealand Air Force in the 1950s and was one of a handful of Māori women to graduate from university during the 1970s with her Diploma in Social Work. She made significant contributions to health and social services for Māori in the Mātaatua and Wellington region and was recognised for this when awarded the Queen's Service Medal (QSM) in 2004. These women epitomise mana wahine (indomitable strength and wisdom) and have carved the pathway for me as a young Māori women and mother living in contemporary Aotearoa New Zealand to be able to pursue opportunities they could only dream of. 
My attention turns to my parents, their life and education stories and how these have shaped and influenced my world view.

\section{Ōku Matua - My Parents}

My father, Raniera Grootveld, is the son of Cornelius Grootveld, a Dutchman who immigrated to New Zealand in the early 1950s. Cornelius was by all accounts an erudite, educated and well-read man with a love of the arts and in particular the opera. He married my grandmother, Ngaio Grace, and together they had three children (she also had two older children from previous relationships). My grandparents divorced when my father was 5 years old and both he and his older brother were taken by my great-grandparents to be raised in Ruatoria, a small coastal village on the East Coast of Aotearoa New Zealand, in the heartland of Ngāti Porou. My father's childhood anecdotes are filled with stories of hard manual labour, a strict and disciplined 'grandpa' (war veteran), loving 'nanny', generous aunties and cousins. There was little in terms of material possessions or wealth and they lived off the land. It was a tough upbringing, but one which taught my father discipline, resourcefulness and resilience. In terms of schooling, he was one of the last students to attend Tuparoa school - a small sole-charge school where he excelled in science and maths. He attended Ngata Memorial College and then onto Gisborne Boys' High School where he left aged 16 years old with four school certificate subjects (above average for Māori students at that time), bound for Wellington in search of a job in the big city. My father's educational journey was about an academically bright, young Māori boy with a culturally rich, disciplined and materially humble upbringing, but whose full academic potential was never realised.

My mother, Anne Anituatua Delamere, grew up in Ōpotiki and is the second youngest of five children. Her father, Wikiriwhi Te Tuahu Delamere, is from Te Whānau-a-Apanui and Te Arawa and married Charlotte Tuhikura Hata. My mother's childhood anecdotes are filled with stories of domestic duties, hard-working parents, disciplined grandparents and lots of extended whānau. Like the majority of Māori families in the community, material wealth and possessions were limited, but they were always well fed and knew how to harvest fruit and vegetables, catch eels, fish and collect seafood. My mother attended Ōpotiki Primary School and Ōpotiki 
College and left secondary school with a few school certificate subjects aged 17 years old. She moved to Wellington to work and live with her aunty, Anne Delamere, and flatmate at the time, Miria Simpson. My mother's education story was about a bright, but shy, young Māori girl who left school as soon as she could in search of a job and opportunities in the city.

My parents were part of the Māori urbanisation wave which hit Wellington during the 1950s, 1960s and 1970s (Barcham, 1998). Jobs were plentiful in the cities and Māori filled a need for cheap labour in manual-oriented roles (Grace, Ramsden and Dennis, 2007). Dad worked as a lineman and mum as a data entry operator at Herd Street Post Office. They met and fell pregnant relatively early in their life; mum was 20 years old and dad 21 years old when I was born. Part of my parents' story is about leaving one's roots and whānau in search of employment and a better life in the city. The other part is about an education system that never really expected them as Māori students to succeed academically. My parents were not brought up as native speakers of te reo Māori. My mother's parents were punished for speaking Māori at school and therefore it was not the language of the home. My father was exposed to more language through his grandparents, but did not further his learning of te reo beyond his childhood years.

For as long as I can remember my father worked long hours in physically taxing jobs (drain-laying, laying down phone cables and lawn-mowing). Our family was very much working class in that our entire livelihood always depended on my father's wages. My parents were not politically active in an explicit sense, but valued education as a powerful tool in the making of a better, materially comfortable way of life. They set high standards and pushed me to study and achieve academically and were significant in my pathway towards attaining my $\mathrm{PhD}$.

\section{My Educational Journey}

I was born in Wellington, but spent the majority of my childhood in Titahi Bay, a small urban seaside community in Pōrirua. Almost every school holiday, however, was spent in Ōpotiki at my grandparents' house. As a whānau we regularly went to the marae in Torere for tangihanga, weddings, reunions and church. Thus from a 
very young age I developed a strong sense of place and connection to my grandparents' home and our marae. From 2 years of age I attended an inner city crèche in Wellington. This was during the early 1980s when the benefits of early childhood education were largely unknown and as a consequence my parents were often questioned about the damage and negative impact the crèche had on my development. However, with no whānau available to take care of me and a desire to buy their own house, this was the only way my parents could both work to try and get ahead in life. Only in hindsight can I see what a bold and brave decision this was. Thus, from a very young age I learnt to be independent.

I started primary school at Clyde Quay School, a large multicultural inner city school in Mount Victoria, Wellington. I enjoyed school from the outset because I loved to read, sing, learn and compete. When I was 7 years old my parents bought their first home in Titahi Bay, and now in hindsight I can appreciate what a significant financial achievement this was given the high interest rates at the time and dad's relatively low wage. I always thought we were poor because we never had extra cash to buy a nice car, flash clothes or McDonalds, but I never went hungry and to be fair, how many poor people own a home?

At Titahi Bay primary school I was put up a class after scoring high in aptitude tests and excelled academically. I was bright and had a passion for learning and competition. I also joined athletics and possessed a natural talent in running, jumping and most sports. At intermediate my passion for learning waned as I was exposed to a new cohort of peers and social code. I learnt that in order to survive socially, being brainy and bright wasn't cool, so I read less and just did enough to pass, but not excel in tests. In terms of secondary education I wanted to attend Queen Victoria Māori Girls College in Auckland where my kuia, Anne Delamere, was educated, but mum and dad couldn't afford it nor did they have the networks or know how to access information about potential scholarships, so I went to the local college. I started college in the third form (year 9) bilingual class and loved the close-knit whānau (family) context. My parents made a conscious choice to enrol me in the bilingual class to learn te reo Māori. I was not brought up with te reo in the home, but never felt this was an issue as I was raised to be proud of who I am and where I come from. At college my sporting talents transferred to netball which 
became a huge part of my life, but academically I continued to do enough to be above average in most of my subjects. In my seventh form year I was selected to be head girl. I left secondary school with a B bursary and enrolled at Victoria University to study towards a Bachelor of Arts Degree in Education and Māori.

One of the striking memories I have about my secondary education was the number of Māori and Pasifika friends who dropped out or were kicked out of school along the way. I knew then that something just didn't add up. From a class of 30something Māori students in year 9, to only five of us left in year 13 - and me the only one studying bursary. This was not about naughty Māori kids with behavioural issues and whānau who didn't care. This was about a system that excluded students and whānau, many (not all) teachers with deficit attitudes, an underresourced, low-decile school, a curriculum based on Western knowledge, a lack of positive Māori academic role models, and students who were bored and could not see the value and relevance of academic learning. In my opinion what set me apart from my peers, many of whom were far brighter than me, was that I was obedient, acquiescent, listened to my teachers and enjoyed academic-style learning. I thrived when asked to do tests and enjoyed competition. I also had parents who pushed me to study and do well at school. University was never a part of my world view and it was only through listening to and talking with my Pākehā friends that university became a goal because I wanted to prove to myself and them that Māori can do anything.

My university years were about discovering a whole new way of learning and knowing, about thinking critically, exploring my identity as Māori and establishing strong networks with friends. I enjoyed studying at university because it was a cultural melting pot with students from diverse cultural and ethnic backgrounds as well as a diverse range of subjects. I graduated with a Bachelor of Arts degree in Māori and Education in 1997 aged 20 years old. In 2005, I graduated with my Master's Degree in Education with merit and in 2009 I was accepted to study towards my $\mathrm{PhD}$ in Education. The $\mathrm{PhD}$ journey is still very much about proving to myself and to the world that I as a Māori woman can achieve success in the uppermost echelons of academia. It is about my parents and my tīpuna and the sacrifices they made so that I could walk this journey. It is about my children and 
grandchildren and being a strong role model so they will know that anything is possible. It is about being a catalyst and agent of change in my whānau so that I can use my academic degree for the benefit of my people. This small collection of his- and her-stories and my story show how my cultural context and the collective experiences of my kuia, tīpuna and parents shape my political and cultural point of view.

\section{My Values}

I was socialised into a collective ethic which means I feel a deep-seated responsibility to lead, contribute and help others in my whānau to shine. I also wholeheartedly believe education can be used as a vehicle to empower and transform. The key values instilled in my whānau are: manaakitanga - to look after people, to be hospitable and make people feel welcome; whanaungatanga - to keep family connections strong, to put whānau first; perseverance - to never give up and strive for your goals; and hauora - to value and practise good health. These are values I bring with me into the research process. I support Māori-driven, Māoricentred and Māori-focused research, which means I'm critical of research which purports to be for or about Māori, but has minimal Māori input and engagement. This is who I am in relation to the research and why kaupapa Māori theory resonates with me as a Māori researcher and why it has been selected as the foundation to my conceptual position.

\section{Kaupapa Māori Theory}

Kaupapa Māori existed long before Māori academics coined the term, and has its origins in a history that reaches back thousands of years (Penehira, Cram and Pipi, 2003; Rangihau, 1977). Sharples (1988) contends kaupapa Māori is rooted in 'old knowledge' based on Māori spiritualism and traditionalism belonging to another time. Similarly Nepe (1991) suggests the difference between kaupapa Māori theory and other traditions is that they derive from different epistemological and metaphysical foundations. For Smith (1999) it is precisely this different epistemological base which shapes the way Māori see the world, organise themselves, ask questions and seek solutions (1999:188). From this 'old world' 
source contemporary kaupapa Māori discourse emerged as evidenced in the work of preeminent Māori philosophers, tohunga, orators and scholars like Te Rangihīroa Buck, Apirana Ngata, Rev Māori Marsden, John Rangihau, Mira Szaszy, Anne Anituatua Delamere, Eva Rickard, Whina Cooper and Katarina Mataira to name but a few.

Kaupapa Māori is a theory and practice that is often misconstrued, misunderstood and misinterpreted by Māori and non-Māori alike. Walker, Eketone and Gibbs (2006) point out the confusion around kaupapa Māori is exacerbated by protagonists who resist precise definitions and argue instead that it is both more and less than a paradigm, a form of resistance and agency, and a methodological strategy (2006:333). The resistance and emancipatory aims of kaupapa Māori are further supported by Mahuika (2008) who states kaupapa Māori is a theory and practice of "active resistance to the continued colonisation of Māori people and culture" (2008:12).

There is, however, a general consensus about the key tenets or principles of kaupapa Māori theory and practice. For example, Smith (1997) identified a set of six principles which sit at the core of kaupapa Māori theory and intervention. While his list has been embellished by Māori academics and practitioners over the years, the original principles form the backbone of kaupapa Māori theory. The six principles are:

- Tino rangatiratanga - The self determination principle;

- Taonga Tuku lho - The cultural aspirations principle;

- Ako Māori - The culturally preferred pedagogy principle;

- Kia piki ake i ngā raruraru o te kāinga - The socioeconomic mediation principle;

- Whānau - The extended family structure principle; and 
- Kaupapa - The collective philosophy principle.

The six principles have influenced my research design and methodology in direct and indirect ways, but in particular the resistance and transformative aims of kaupapa Māori theory resonated with the research project. For example, Smith (2003b:11) looks at how kaupapa Māori theory and its foundation principles fulfil the following functions in terms of Māori resistance, transformation and conscientisation:

- It promotes the validity and legitimacy of Māori language, knowledge and culture and creates the political space to enable the legitimate study and continuance of Māori language, knowledge and culture;

- It is positioned as Māori-centred, but also speaks cross-culturally in the sense of making space for Māori language, knowledge and culture existence;

- It is concerned with economics and structural change and attempts to take account of unequal 'power relations' and dominant subordinate politics;

- It is transformative in its aims;

- It attempts to challenge existing theory as being culturally and interest laden;

- It supports the use of all existing theory (by Māori) providing that it can positively support Māori advancement; and

- It recognises that indigenous struggle is neither singular nor homogenous and that there is a need to 'struggle' on several levels and in several sites, often simultaneously. 
Thus, kaupapa Māori theory provided a potent emancipatory theoretical tool to analyse contemporary Māori perspectives on transformation and class consciousness. It is my standpoint that Kaupapa Māori is not meant to 'replace' existing theory and merely establish a dominant advantage, rather it will coexist alongside existing theories which support Māori advancement and transformation. In this context I use support to encapsulate theories which not only validate, substantiate, resonate with and affirm a Māori world view and cultural practices, but also theories which rigorously critique kaupapa Māori theory and challenge kaupapa Māori theorists to look critically within, reflect and adopt differing theoretical positions in order to strengthen kaupapa Māori theory.

So how do kaupapa Māori principles and aims translate into a research context and why is there a need for kaupapa Māori research? According to Walker et al (2006), kaupapa Māori research emerged as part of a broader movement by Māori to question, contest and challenge "Western notions of knowledge, culture and research" (2006:331). Walker (1987) concurred and highlighted how kaupapa Māori theory and research developed as a result of an emerging political consciousness. This movement of the people was evidenced by the proliferation of Māori protest and resistance movements during the 1970 s and 80 s, designed to liberate and emancipate Māori through social and political activism (King, 1996; Poata-Smith, 1996, 2004a, 2004b).

From a research perspective, this dynamic period was also marked by growing concerns among Māori communities about the abuse of power, authority and control by researchers, predominantly non-Māori, "doing research to Māori" (Smith, 1997). In other words Māori were having research done to them with minimal influence on the research agenda, framework, methodology, outcomes and benefits (Irwin, 1994; Kidman, 2007). Consequently the misappropriation of Māori language, culture and knowledge was a common feature of the research landscape (Gibbs, 2001; Walker, 1990). Frustrated by Western-based frameworks of analysis and ideologies, which did little to support Māori aspirations for transformation, Māori educationalists started to articulate a kaupapa Māori perspective and world view (Bishop, 1999; Wilkie, 2006). 
Kaupapa Māori commentators agree that kaupapa Māori is research that "seeks to make a positive difference to the researched, their whānau, hapū, Iwi and Māori society" (Smith, 1999:191). Penetito (2006) discussed tikanga in research and identified te reo (language), place and the rituals enacted by Māori (e.g. mihimihi and tikanga) as the core components of a Māori context of research - these are what makes a kaupapa Māori agenda and flavour in the context of research. The growing need to make these components explicit, he argued, is because more Māori and non-Māori are getting involved in research and asking what is kaupapa Māori research? How is it different? What does it mean for me as a researcher?

The importance of relationships in kaupapa Māori research is highlighted by Cram (2006) who suggested kaupapa Māori research is primarily about the relationship between the researcher and the researched. The goal is not to gather data; rather it is about the relationship being something that underpins the research $-\mathrm{a}$ relationship that is ongoing and enduring (Bishop, 1996).

I have selected kaupapa Māori theory as a theoretical lens for three reasons. First, kaupapa Māori is about me as a Māori researcher engaging in research with Māori participants, with the intent of providing benefits to Māori (Bishop, Berryman and Richardson, 2002; Smith, 1999). As highlighted by Pihama et al. (2002) and Irwin (1994), kaupapa Māori is concerned with the empowerment of Māori people and culture and is about being Māori, researching Māori, and being accountable to Māori. For me, kaupapa Māori theory was a natural and logical theoretical choice. I am Māori with a deep-seated commitment to contributing to transformation for whānau, hapū and iwi.

According to Moewaka-Barnes (2000), kaupapa Māori theory has significant implications for data collection, analysis and reporting and therefore demands a close examination of how I interpret and understand the experiences of the participants. This analysis process relies heavily on my own knowledge and world view and it is critical that I am explicit about who I am and the values I bring to the research process (McNeill, 2008). The concept of reflexivity is important here in that how I make sense of the world is based on my relationships and values. In other words, I will never be a passive participant in the research process and there is no 
possibility of me achieving a position of detachment (Denscombe, 2004). It is difficult to justify a position in research that is subjective because of the problem of relativity, that is, there can be no truth, only estimates of it. On the other hand, there can be no objectivity either because all humans are culture-bound to some degree (see for example Bourdieu, 2000). As a Māori researcher my attempts to get at the truth about this research study requires that I position myself. This does not mean being neutral, nor does it mean being biased. What I am trying to do is to be open and fair which are in themselves subjective entities.

The second reason why I chose kaupapa Māori theory was because I wanted to use a theory that privileged and illuminated Māori voices, realities and experiences without overlaying Western constructs and interpretations of knowledge, culture and identity which have traditionally silenced Māori voices (Barrington, 2008; Simon and Smith, 2001; Walker, 1990). The imposition of researchers onto the researched is well documented. For example, Bishop and Glynn (1999) pose critical questions about how the researcher positions themselves during the research process in relation to five key areas: initiation, benefit, representation, legitimation and accountability (Bishop, 1996:22). This framework was used throughout the development of this thesis to ensure I made conscious and informed decisions about my position as researcher as well as the position of the participants. It encouraged me to move beyond my own research agenda towards an approach based on the needs, interest, priorities and aspirations of my research participants. For example, in the data analysis phase I continually questioned how the participants' realities and voices were being represented and how their agency was reflected. This process involved ongoing discussion with my supervisors to ensure the participants' voices were represented fairly and authentically.

Third, I wanted to contribute to the evolution of kaupapa Māori by using it as both a theory and practice, to add to the knowledge base supporting kaupapa Māori and to incorporate knowledge and mātauranga from my own iwi. Smith (2006) described kaupapa Māori research methodology as something that is meaningful to the researcher derived from a te ao Māori knowledge base. For example, one might use a whakapapa (genealogy) model, a whakataukī (proverb) model, or a model based on waiata (song) as a template for one's own process or conceptual model to help 
make sense of the research. Accordingly, the conceptual framework for this research is informed by the following whakataukī which originates from my Ngaitai iwi (tribe) in Torere, Eastern Bay of Plenty:

He iti kōpara pioi ana te tihi o te kahikatea

The small bellbird who alights on the topmost branch of the kahikatea tree will set it swaying.

This whakataukī is grounded in mātauranga ā iwi, that is, the knowledge of my tribe, Ngaitai. It is placed based (Gruenewald, 2003; Smith and Sobel, 2010) in that it highlights the significance of the koppara bird and the kahikatea tree in the local Torere area and draws on both to inspire and educate Ngaitai descendants. For the purpose of this research this whakatauki sharpens the focus on success and transformation through education. More importantly, however, it suggests individual success can ignite and contribute to collective success (however that might be defined) to change the status quo. It frames the research within a Māori world view, a Ngāitai world view, but does not disregard the enormity of the underlying structural inequalities that exist. In fact, it challenges us to seek, understand and face these challenges head on so that more bellbirds might fulfil their potential.

Like most theories and discourse, however, kaupapa Māori has its detractors and opponents. Rata (1991, 2000, 2004a, 2005) has argued against kaupapa Māori in education and suggested identity politics have been used to promote a Māori ruling elite that has created oppressive oligarchic capitalist structures, like those in the Western world, in a new form of class oppression which she refers to as neo-tribal capitalism. She argues the neo-tribal ideology runs counter to democracy and will not result in any real long-term benefits for the majority of Māori. Poata-Smith (1996, 2004b) and Sykes (2010) also critique the emergence of a Māori tribal elite and argue politics of identity and kaupapa Māori approaches have been used to privilege the Māori middle class and oppress the Māori working class. 
Furthermore, kaupapa Māori critics point towards a one-size-fits-all theoretical approach, which assumes Māori are homogenous and ignores the complex and multiple intersections of iwi identities and lived realities (Barcham, 1998; Lopez, 1998). Even its proponents point towards shortcomings, for example Waitaere-Ang (1998) talks about the visible and invisible tensions that arise when Māori researchers talk about themselves and the degree to which Māori researchers are explicit about the level of institutionalisation they themselves bring to the research process. Thus, kaupapa Māori theory and practice continues to evolve alongside Māori communities in response to the ever-changing global world (te ao hurihuri).

The ideas presented provide signposts and touchstones for those engaging in research with Māori in the present, which in turn inform and add to the kaupapa Māori knowledge base for future generations. My intent is to use kaupapa Māori theory and practice to support and enhance my research so that it might contribute to Māori transformation. Kaupapa Māori is as much a political standpoint as it is a cultural one, and one that invokes both contemporary and traditional knowledge and practices. In other words, it creates and enables spaces for drawing on a range of theories to understand te ao Māori. This is important given that te ao Māori, for better or for worse, exists within te ao hurihuri and this is something that cannot be ignored. To this end, no singular theory can provide all of the answers and it was with this in mind that class-based theories and perspectives are explored in the next chapter.

\section{The Research Interface}

This thesis is philosophically positioned at the interface between culturalist and structuralist perspectives. Kaupapa Māori theory (Smith, 1997; Smith, 2003b) and transformative theory (Gramsci, 1971, 2005; Smith, 2003b) provide the foundation theories, and neo-Marxist perspectives (Crompton, 1996, Devine, 2000) are drawn on to analyse transformation through a structuralist lens. The primary focus is on how to create transformation using both cultural and structural responses and therefore the role of neo-Marxist perspectives is to provide a secondary analytical lens to augment kaupapa Māori and transformative theories. 
Each theory and perspective is based on a set of values and body of knowledge that is valid, legitimate and important in its own right. The intent was three-fold: first, to create a dynamic and potent lens to theorise, describe and create transformation; second, to guide the research approach and design, and strengthen the overall research; and third, to provide a fresh perspective on the relevance of class in the transformative pursuits of Māori in a contemporary Aotearoa New Zealand context.

The interface between indigenous and Western world views and knowledge systems is increasingly being explored by indigenous researchers, educationalists, academics, scientists, students and teachers alike (Barnhardt and Kawagley, 1999, 2004; Battiste, 2002; Cunningham, 1998; Kidman, Abrams and McRae, 2011). Driven by a desire to use traditional knowledge to inform contemporary life-worlds, this new space draws on two world views, two bodies of knowledge, to create new knowledge and benefits for indigenous peoples while maintaining the integrity of each paradigm (Durie, 2004; Meyer, 2001). Within a contemporary Aotearoa New Zealand context the interface between kaupapa Māori world views and knowledge systems and Western science and education paradigms continues to grow as Māori explore opportunities for creativity and knowledge expansion (Edwards, 2010; McKinley, 2001, 2005; Mercier, 2007; Royal, 2002; Smith, 2005;). However, Māori have a long history of drawing on Western knowledge and technologies and adapting both to suit their purpose and needs (Jones and Jenkins, 2011).

So why the need for a research interface? The Western research space has long been a site of contest and struggle for the indigenous pursuit of self-determination (Smith, 1999). Exploring the interface is in part a response to this oppressive space which has systematically marginalised and 'othered' indigenous knowledge systems and world views (Fanon, 1963; Kawagley, 1995; Said, 1978). Conversely the research interface is about indigenous peoples carving out new space that attends to indigenous needs and aspirations. It is about shifting indigenous world views and knowledge systems from the periphery to the centre of research endeavours (Barnhardt and Kawagley, 2005). As Durie (2004) explains, the interface is a space for creativity where two knowledge systems sit alongside each other for mutual gains and benefits: 
“...There are an increasing number of indigenous researchers who use the research interface between science and indigenous knowledge as a source of inventiveness. They have access to both systems and use the insights and methods of one to enhance the other. In this approach, the focus shifts from proving the superiority of one system over another to identifying opportunities for combining both." (2004:8).

The practical application of this process, however, is not as simple as it might seem. Smith (2008) for example describes the space between research methodologies, ethical principles, regulations and human subjects as "tricky ground, complicated and changeable", a space that "plays tricks on both the researchers and the researched" (2008:85). Similarly, Edwards (2010) argues the unequal relationship between both knowledge systems must be taken into account. Thus, the interface is about repositioning and negotiating boundaries, creating and moving space in the academy for indigenous voices to be heard (Smith, 2008:91).

Within a contemporary research context, a wide range of research for Māori is carried out and can be mapped along a continuum based on varied degrees of Māori involvement, control and accountability. To this end, Cunningham (2000) has developed a useful taxonomy for Māori research to help locate researchers and research projects and their likely contribution to the Māori knowledge base and Māori development (2000:65). Four essential types of research for Māori were identified: research not involving Māori, research involving Māori, Māori-centred research and kaupapa Māori research. What distinguishes Māori-centred research from kaupapa Māori research is the dual accountability which rests on the researcher and the degree of control Māori have over the research project. It is also important to distinguish between research at the interface, research for Māori and mātauranga Māori research, i.e. research that is carried out entirely within the realm and context of Māori knowledge and Māori methodological approaches (Durie, 2004; Royal, 1998, 2002). So how does one operate at the interface? Durie (2004) proposed four principles to guide research at the interface, namely, mutual respect, shared benefits, human dignity and shared discovery. While fairly self-explanatory, in short, these principles acknowledge different perspectives and world views, 
common goals and aspirations, regard and respect for people involved in the research and a focus on the future (2004:17).

Edwards' (2010) PhD thesis builds on Durie's scholarship and draws on both mātauranga Māori and Western science paradigms to theorise positive aging for Māori. His $\mathrm{PhD}$ research presents an inquiry paradigm matrix designed specifically to create space for mātauranga Māori to sit alongside Western science as a credible and relevant paradigm for research in contemporary Aotearoa New Zealand. To do this, Edwards aligned te ao marama with ontology, whakapapa with epistemology and kaupapa rangahau with methodology and in doing so shifted the tensions between the two knowledge systems from a philosophical level to a practical level, to the site of application (2010:56). Edwards explains:

"Bringing two separate knowledge systems together at the interface should not be confused with attempting to equate them. It is instead an exercise for recognising distinctiveness and complementarity and their combined ability to provide richer insights into phenomena observable through disciplined inquiry, that is, research." (2010:60).

Edwards' (2010) thesis resonates with the conceptual positioning presented in this research. Kaupapa Māori and transformative theory were selected because each is concerned with raising critical consciousness at both an individual and collective level, they are strengths based and focused on empowerment and disrupting the status quo. Neo-Marxist perspectives provide an analytical lens to build understanding about the root causes, underlying structures and assumptions underpinning social and classed inequalities and how these impact on the lived experiences of Māori. It is about the 'complementarity' of these knowledge systems and the production of mutual benefits.

\section{Summary}

In this chapter I have located myself as a Māori woman and researcher. I have made explicit the values that inform who I am and what I bring to this research study. I have shown how the experiences of my kuia and parents have influenced 
and shaped my cultural and political perspectives and outlined how my educational journey is as much a political journey, a form of activism in its own right. I have aligned who I am with kaupapa Māori theory and how this is used to inform how I analyse, think about, plan, carry out and discuss this research. I have also examined the research interface and what this space looks like within the context of this kaupapa. The next chapter takes a deeper look at transformative theory and explains how its principles and goals are central to this thesis and how it weaves with kaupapa Māori theory to move beyond simply explaining structural and cultural inequalities, towards mapping a way forward to show how to create change. The chapter also looks at social class theories, particularly the emergence of neoMarxist perspectives, and how these might contribute to theorise and create both cultural and structural transformation responses and strategies. Based on my analysis of the literature, a working definition of social class is presented to show how social class is used in this research study. 


\section{CHAPTER THREE: CONCEPTUAL POSITIONING PART TWO: TRANSFORMATIVE THEORY AND SOCIAL CLASS PERSPECTIVES}

\section{Introduction}

In this chapter I explore the theoretical roots of transformative theory and social class perspectives. When I began this thesis I had a strong focus and emphasis on social class; however, my research participants expressed social class was not such a key feature in their diverse realities. Thus, my focus shifted to transformation and while social class perspectives are important to understand, they are not central to this thesis. I start this chapter by exploring what transformation means from indigenous perspectives and how transformative strategies might be enacted within the context of contemporary colonisation in Aotearoa New Zealand. Second, I look at social class and its theoretical roots in order to contextualise contemporary understandings of class consciousness. My intent is to understand what social class is, how it came about, its relevance today, but in particular how a collective classbased consciousness might be used as a lever to facilitate Māori transformation.

\section{Transformative Theories}

Theories underpinning indigenous transformation are inextricably linked to indigenous experiences, perspectives and struggles. For Māori, like many other indigenous peoples, this experience is significantly shaped and influenced by the enduring effects of colonisation. How colonisation has impacted Māori educational outcomes and the Māori political economy is discussed in Chapter One and Chapter Four of this thesis, and it is not my intent to repeat these discussions. What is important is how colonisation has impacted individual and collective critical consciousness and aspirations to transform.

\section{Indigenous Peoples and Colonisation}

What are the defining characteristics of indigenous peoples? According to the United Nations there are over 370 million indigenous peoples spread across 70 countries in the world. Given this level of diversity there is no single definition of 
indigenous people; however, there are commonly accepted identifiers. First, indigenous peoples are just that, indigenous to the lands they inhabit and thus have an enduring, placed-based existence (Alfred, 2005). Second, their existence is woven together by distinct social, cultural, economic, political and spiritual systems, language, culture and beliefs (United Nations, 2010). Third, indigenous peoples themselves identify what and who are indigenous peoples as highlighted by Martinez Cobo (1986/7) in his ground-breaking longitudinal study on indigenous struggle. He states:

"On an individual basis, an indigenous person is one who belongs to these indigenous populations through self-identification as indigenous (group consciousness) and is recognized and accepted by these populations as one of its members (acceptance by the group). This preserves for these communities the sovereign right and power to decide who belongs to them, without external interference." (Ibid: 379-382).

While there are vast differences among indigenous peoples, they share a common struggle against colonisation in its various guises and forms. Alfred and Corntassel (2005) elaborate on what shapes this shared colonial experience.

"...the struggle to survive as distinct peoples on foundations constituted in their unique heritages, attachments to their homelands, and natural ways of life is what is shared by all indigenous peoples, as well as the fact their existence is in large part lived as determined acts of survival against colonising states efforts to eradicate them culturally, politically and physically". (2005:597).

Thus, colonisation is not a historical process which happened to indigenous peoples centuries ago, it is enduring and ever-present, a process described by esteemed African scholar Franz Fanon as an ongoing dialectic.

"Colonialism is not merely satisfied with holding a people in its grip and emptying the native's brain of all forms and context. By way of perverted 
logic, it turns to the past of the oppressed people, and distorts, disfigures, and destroys it. This work of devaluing pre-colonial history takes on a dialectical significance today." (Fanon, 1963:210)

The critical point to take from Fanon's thesis is how the colonisation process seeks to strip the colonised at every level conceivable in order to progress the colonisers' imperialist agenda. This dehumanising process is manifest in many ways; however, indigenous scholars concur that one of the most powerful effects colonisation has is on the mind - how colonised peoples view themselves and their connection to the world.

“Colonialism's...most important area of domination was the mental universe of the colonised, the control, through culture, of how people perceived themselves and their relationship to the world." (Ngugi Wa Thiong'o, 1986:16)

The negative impact colonisation has had on indigenous peoples' ability to dream, aspire, transcend and transform cannot be overstated. Prodigious indigenous scholars Edward Said and Paulo Freire both talk about the importance of freeing one's own mind before one can free others, the necessity to engage, reflect and critique one's own consciousness before one can contribute to building collective consciousness. This idea is further supported by Alfred and Corntassel (2005) who argue indigenous pathways of authentic action and freedom struggle start with "people transcending colonialism on an individual basis" (2005:612). Similarly, Smith's (2003) inside-out model is premised on the notion that transformation has to be won on at least two broad fronts: a confrontation with the coloniser and a confrontation with 'ourselves'.

In the context of contemporary colonialism (sometimes referred to as post-colonial imperialism), indigenous peoples attempt to resist the effects of these powerful forces to renew themselves politically and culturally. Māori are no different from any other indigenous peoples in their resistance, renewal and regeneration pursuits. To develop this transformative agenda, critical questions emerge about how to resist 
further dispossession and disconnection when the effects of colonial assaults on indigenous existence are so pronounced in the lives of all indigenous peoples, including Māori.

\section{What is Transformation?}

For the purposes of this research transformation is theorised in five ways. First, transformation is about building a critical consciousness among Māori at an individual level to transcend colonialism. Second, it is about asserting selfdetermination and freedom - tino rangatirantanga. Third, it is about how higher education might be used as one vehicle to build critical consciousness to create a sustained commitment to transformation, because quite simply the status quo is not good enough. Fourth, it is about mapping ways to show how to create transformation, rather than just describe and theorise transformation. Finally, it is about using both culturalist and structuralist responses to achieve this.

Within a local contemporary higher education context, Ngā Pae o Te Maramatanga - New Zealand's Indigenous Centre of Research Excellence (2012) suggest indigenous transformation is best facilitated by unleashing the creative potential of Māori peoples (2012: 3). Examples of this creative potential include kōhanga reo, kura kaupapa, wānanga, Māori business and entrepreneurship, Māori television and cultural creativity, all of which is underpinned by indigeneity, described as a dynamic and mutually enhancing kinship-based relationship with the natural world, derived from a traditional and indigenous world view. At an iwi (tribal) level, indigenous aspirations for transformation and change are expressed in a number of ways based on the distinct cultural practices, traditional knowledge and language of that particular iwi (tribe).

Similarly, the indigenous transformative agenda is expressed across a range of fields and disciplines and a plethora of frameworks articulate these transformative pursuits. For example, Alfred and Corntassel (2005:613) outline five mantras of a resurgent indigenous movement, namely:

- Land is life - reconnect with the geography of our indigenous heritage; 
- Language is power - regenerate in a conceptual universe formed through indigenous language;

- Freedom is the other side of fear - confront our fears head-on through spiritually grounded action;

- Decolonised diet - grow our own food and regenerate our health;

- Change happens one warrior at a time - achieve transformation by directguided experience in small, personal, groups and one-on-one mentoring.

These pathways are designed to be put into practice by every indigenous person in their own way, in response to the colonial context of their lived realities and provide a useful framework for mapping transformative strategies. In relation to this thesis, the mantra (to create change one warrior at a time) is particularly relevant as we explore the potential for higher education to facilitate transformation through the creation of engaged Māori intellectuals committed to creating change one warrior at a time.

\section{Organic Intellectuals}

In his seminal PhD thesis, Smith (1997) draws on Gramsci's notion of the 'organic intellectual' (Gramsci, 2005) to promote the idea of building a critical mass of highly educated Māori who possess a consciousness about their indigenous roots and responsibilities to lead Māori social, economic and educational transformation (Smith, 2003). Gramsci was a Marxist and his struggle was, as he saw it, a class one. The implication that this cohort is highly educated, well paid and resourced is clear. Thus, higher education success becomes a critical part of the transformative agenda.

Gramsci's ideas around transformation and the role of the organic intellectual are pivotal to this thesis. He believed in the innate capacity of human beings to understand their world and to change it and demanded that revolutionaries or agents of change be critical (Mayo, 1999). Gramsci posited how transformation was 
an ideological struggle that required raising awareness and consciousness, but perhaps more important was the creation of a socialist consciousness that arose from people's everyday lives and realities (Gramsci, 1971:10). In other words, the catalysts for transformation would emerge from the working classes themselves, grounded in working-class life-worlds and realities, but brought together by a collective consciousness and motivation to create change.

Gramsci's definition of the intellectual expands beyond traditional ideas, whereby he posits that all men (and presumably women) have intellect and use it, but not all are intellectuals by social function. What he means by this is someone who sews a button on a coat is not referred to as a professional seamstress, nor the person who bakes a loaf of bread at home an artisan bread-maker. Accordingly he identified two types of intellectuals: first, the traditional intellectual (i.e. professors and clergymen) who see themselves, and are viewed by society, as autonomous and independent of the ruling class. Gramsci argued this group is in fact tied to and assists the ruling group in society. Second, the organic intellectuals, a group that grows organically from their own life-worlds and experiences to critique their and their fellow class members' position (Giddens, 1997).

Gramsci's concept of hegemony refers to the permeation of an entire system of values, attitudes, beliefs and morality throughout society that helps to support the status quo in power relations (Gramsci, 1971). Hegemony is sustained through consent, whereby the system becomes part of the everyday consciousness of the population, part of common sense, and the natural order of the way things are and should be (Watkins, 1992). The use of consent and coercion to sustain hegemony is critical as highlighted by Gitlin (1980):

“Hegemony is a ruling class's (or alliance's) domination of subordinate classes and groups through the elaboration and penetration of ideology (ideas and assumptions) into their common sense and everyday practices; it is the systematic (but not necessarily or even usually deliberate) engineering of mass consent to the established order. No hard and fast line can be drawn between the mechanisms of hegemony and the mechanisms of 
coercion... in any given society, coercion and hegemony are interwoven." (1980:178)

So how do we overcome hegemony? Gramsci viewed organic intellectuals as agents of change who play a critical role in leading a counter hegemony to overthrow the ruling class and undermine existing social relations. The development of a counter hegemony required two things: first, a significant number of traditional intellectuals to join the cause, and second, the creation of working class intellectuals actively participating in practical life. The critical points to take from Gramsci's thesis are how the organic intellectual must be grounded in the life-world of the working class, be critical and conscious of the need for change and transformation at an individual and collective level, work with and alongside traditional intellectuals to be the change, and avoid conformity and the coercive powers of the ruling class. These points are fundamental to this thesis.

In contrast to critics of a Māori neo-tribal elite (see Poata-Smith, 1996 and Rata, 2000) Graham Smith's provocative idea about the emergence of organic Māori intellectuals has exciting potential. It positions a highly educated Māori cohort in a positive and transformative light, as one part of a bigger solution to dismantle and disrupt the status quo. An important distinction to make is how the neo-tribal elite described by Poata-Smith and Rata differ from the participants in this study. For example, this cohort is younger, not (yet) in positions of economic and political power and privilege, and self-identify as being distinct from the Māori elite. This cohort is in a sense 'stuck in the middle', between their working-class roots and a neo-tribal elite. Their 'stuckness' could simply be a function of their maturity or lack of it, but it is probable this will not last. This is a group that has the cultural and social capital to do things when they are ready and therefore align with the notion of organic Māori intellectuals.

Transformative literature reminds us it is not enough to be committed to change, one must be the change. Therefore transformation demands excellence in and cognisance of both indigenous ways of knowing and being as well as Western ways. It is about bridging both worlds, but being grounded in the indigenous. 
For example, within a Hawaiian context, scholar Julia Kaomea highlights some of the tensions and differences between what the academy might expect from its scholars and what indigenous Hawaiian communities expect.

"While the academy expects its members will speak from theory, Native Hawaiian communities expect that their members will speak from experience. While the academy expects that research relationships will be detached and objective. Native Hawaiian communities expect that these relationships will be intimate and enduring. While the academy expects that its members will contribute to the scholarly community through rigorous intellectualism, Native Hawaiian communities expect that their members will contribute through vigorous activism." (Kaomea, 2004:28)

The critical points to take from Kaomea's poignant words is how the role of the organic intellectual is not simply to theorise and problematise from within the academy, the organic intellectual must be connected, engaged, relational and committed to activism within an indigenous world view. It is as much about being and doing indigenous as it is about theorising and describing the indigenous. As the plethora of local and global research around social transformation and change shows us, the task and pursuit of the organic intellectual is somewhat easier said than done. However, this thesis seeks to explore the possibilities and potential of this group of highly educated Māori to show how change and transformation might be put into action one warrior at a time.

\section{Kaupapa Māori and Transformative Theories}

How kaupapa Māori and transformative theories have been weaved together in this research study is illustrated in Figure 1 which presents the research theoretical framework. The framework is based on two foundation theories - kaupapa Māori and transformative theory and shows how they connect and how the research will operate at the interface. It also shows how neo-Marxist perspectives will be used as a secondary lens, with a focus on class consciousness as a lever for transformation. The conceptual framework is framed by a Ngaitai (tribe) whakatauki (proverb) which positions the research within a Māori world view, a Ngaitai world view. 
Figure 1: Theoretical Framework: The Interface Between Kaupapa Māori, Transformative Theory and Neo Marxist Perspectives

He iti kōpara pioi ana te tihi o te kahikatea

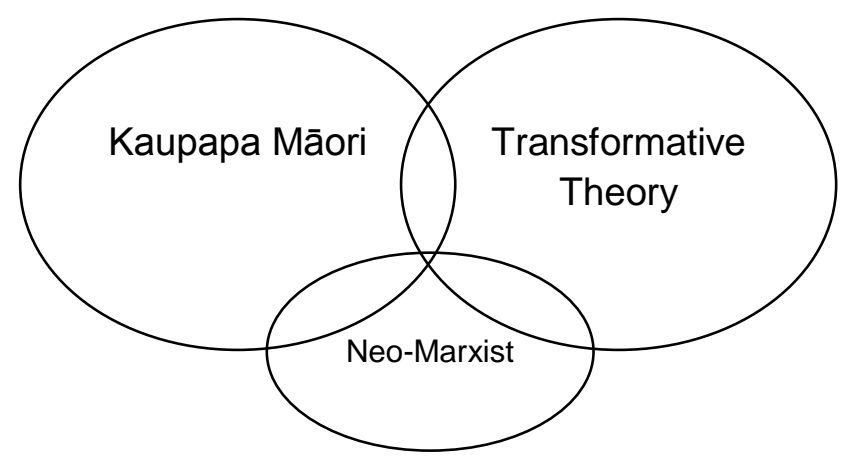

Figure 2 presents the principles of the two foundation bodies of knowledge and how they coalesce to inform how the research was theorised and conducted. 


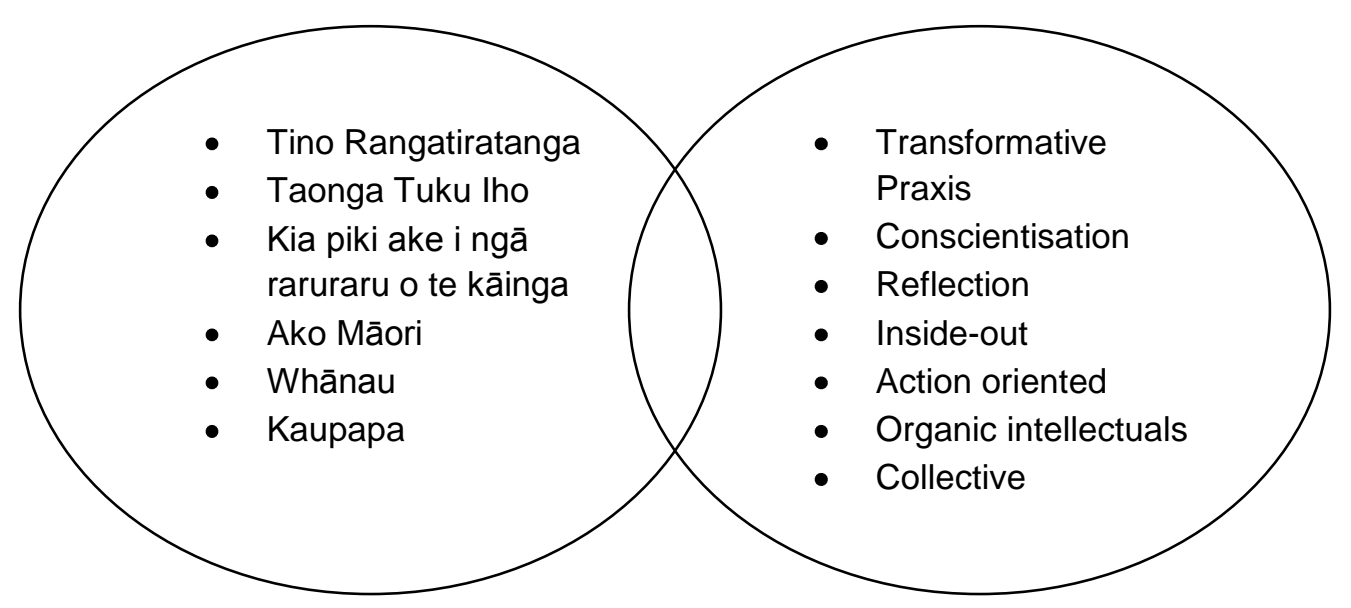

The principles of kaupapa Māori theory outlined in the left circle in Figure 2 illustrate how this research is about Māori determining their own pathways to transformation (tino rangatiratanga) based on a Māori world view, language and cultural practices (taonga tuku iho) and drawing on culturally preferred pedagogies (ako Māori), but cognisant of the structural and economic context within which Māori life-worlds are played out (kia piki ake I ngā raruraru o te kainga), the power of the collective (kaupapa), but importantly the power of family (whānau) as a key transformative site.

The transformative principles outlined in the right circle in Figure 2 complement and challenge kaupapa Māori theory. For example, transformative praxis is about research for change, it involves a dynamic interplay between action and reflection, between knowing and doing, it is the intertwining of research and practice (Given, 2008). Conscientisation challenges Māori to cultivate a critical consciousness, to 'reflect' on both theories and practice, to look within and free ourselves in order to free others (inside-out model) and be 'action oriented'. Transformation at the individual level enables Māori to cohere and galvanise a dynamic cohort of 'organic Māori intellectuals' to act as part of and for the benefit of the 'collective'.

The emphasis is on the intersection of the two foundation bodies of knowledge and their principles - kaupapa Māori and transformative theory. It is also about how 
structuralist neo-Marxist perspectives might be applied to inform new analyses of transformation. Durie's (2004) principles for engagement at the research interface (i.e. mutual respect, shared benefits, human dignity and shared discovery) also inform this conceptual positioning.

\section{The Transformative Potential of Social Class Perspectives}

The notion of class consciousness is central to my thesis - what it is, its derivations and implications for transformation. In order to talk about class consciousness I need to locate this discussion within the class discourse by reviewing relevant literature. The sheer volume of class-based literature means a comprehensive discussion about the historical and theoretical roots of social class is beyond the scope of this discussion, nor given the focus on transformation, is a lengthy review needed. Rather, the intent is to broaden our understanding of social class by looking at the key principles and tenets underpinning social class, particularly in relation to the effects of social class on the consciousness and practice of Māori and what social class might offer to support transformation.

Social class is a highly contested, complex and contradictory concept that is more often than not ill-defined, misconstrued and misunderstood. The idea of class presents the harsh material reality of social difference and hierarchy (Nash and Harker, 1992) and for this reason many people feel uncomfortable when talking about class. This is particularly true in societies like Aotearoa New Zealand where the classless egalitarian society myth is both pervasive and intergenerational (Bedggood, 1980; Dale, 2000; Lauder and Hughes, 1990a). Nonetheless, it is a truism that every society has some form of social stratification or hierarchy and this is only one way social class is considered. Following Williams (1983:68): "A class is sometimes an economic category, including all who are objectively in that economic situation. But a class is sometimes (and in Marx more often) a formation in which, for historical reasons, consciousness of this situation and the organisation to deal with it have developed."

In its crudest form, social class has been described as "the term used within Marxism and critical theory to describe the structural relationship between capital 
and labour" (Bell and Carpenter, 1994:116). While this description is indeed accurate, it is not particularly useful in terms of deepening my understanding of the multiple characteristics and complexities which make social class all of this and more.

Hatton (1998) suggests social class is a "dynamic and evolving process, rather than a category, that is based on real life groupings constantly under construction; getting organised; divided; broken down; and remade" (1998:233). Campbell (2007) agrees and identifies four assumptions underpinning social class. First, social classes are in a constant process of formation and dissolution, with schools contributing to that process. Second, classes exist in relation to one another, competing for wealth and power. Third, classes are constituted by real people in families and other collectives. Finally, the practices and cultures of classes and class relations can be both empowering and disempowering depending on the social context (2007:32). For Meadmore (1999) social class is a 'principle' which organises society and the mechanism by which "power, privilege, and inequality are distributed and institutionalised" (1999:60). Meanwhile, Pearson and Thorns (1983) cogently argued class is a product of a capitalist society. Within a contemporary context, however, social class takes into account not only wealth, occupation and income, but also cultural values and practices (Ball, 2003; Devine et al., 2005; Power, 2000). Bell and Carpenter (1994) view social class as a way of thinking about constantly changing and dynamic relationships between opposing social groups (1994:1170). For Skeggs (2004) contemporary understandings of social class must shift from a position whereby class is about location and positionality to a space where the key issue is the degree of flexibility and fluidity available to individuals.

Social class is but one of many complex social phenomena which impact in processes of social reproduction, and is neither the key nor sole determinant of one's life chances. For example, ethnicity, 'race', culture and gender also intersect to shape people's realities. Protagonists agree, however, the material reality is a person's social class origin usually has a great deal to do with how easy it is to do certain things in the making of a life (Campbell, 2007:151; Jones and Davis, 1988a). Thus, social class provides a powerful theoretical framework through which social 
reproduction and the creation of social inequalities can be analysed and critiqued (Ball, 2003; Savage, 2003; Wright, 2000). The focus on social classes, therefore, is not to try to fit people neatly into boxes or categories; rather it is to build an understanding of how social classes work in relation to one another (Meadmore, 1999:57). In order to ground my conceptual understanding of social class I must look to its theoretical roots, which are firmly entrenched in Marxist perspectives.

\section{Marxist perspectives}

Karl Marx's traditional economic-based social class theory provides the genome for neo-Marxist perspectives such as critical theory, conflict theory, and more recently new culturalist-based approaches (Ball, 2000; Bottero, 2004; Reay, 2006; Savage, 2003). Traditional Marxist perspectives were cultivated during the middle of the $19^{\text {th }}$ century amid the industrial revolution in Europe. Within this context, Marx observed widespread poverty, deprivation and inequalities among the 'working' population, and theorised that industrial capitalism had resulted in the creation of a new classbased society. Marxist perspectives posit that in order to understand social structures and social inequalities we must first understand the economic processes and structures that underpin the capitalist society (Bedggood, 1980; Pearson and Thorns, 1983; Sharp, 1980). For Marx, class represents, above all else, the relationship individuals have to the 'means of production', that is, the ways in which things are produced and the system of exchange and distribution (Wright, 2000). Class, therefore, is an amalgam of people who are in the same relationship to the means of production (Nash and Harker, 1992).

Marxist perspectives suggest the most critical feature of any system of production is who owns and controls it. Marx saw capitalist society as ultimately divided into two mutually opposed groups whose interests were irreconcilably divergent. First, the capitalists/bourgeoisie (ruling class) commonly referred to as the owners of production and, second, the proletariat (working class) or the owners of labour. The interests of capital and the interests of wage labour were diametrically opposed and this exploitative relationship is a critical feature of Marxism. Bell and Carpenter (1994) argue the exploitative relationship between the owners of capital and the owners of labour is an inevitable part of labour capitalist production and Marxist 
theory therefore shows how social class relations are based on "conflict, inequality and exploitation" and how these elements are "built into the structure of the economic system" (1994:113).

Similarly, Wright (2005) views exploitation as the key ingredient which most sharply distinguishes Marxist perspectives on class from other traditions. He states: "this exploitation centred concept provides theoretically powerful tools for studying a range of problems in contemporary society" (2005:5). In short, exploitation is tied to labour as people only have their labour to sell and are never paid in full for the work that they do. Therefore, in the labour market during times of economic depression, labour value is at its lowest, and within the context of Aotearoa New Zealand, Māori are affected more so than Pākehā in this scenario due to their relatively vulnerable position in the New Zealand labour market (Henare, Puckey and Nicholson, 2011).

\section{Class Consciousness}

The notion of class consciousness was central to Marx's thesis and he made the distinction between 'class in itself', which is defined as a category of people having a common relation to the means or production, and a 'class for itself', a stratum of people organized in active pursuit of its own interests (Borland, 2008). He was particularly concerned with the emancipation of the proletariat (working class) through the development of a revolutionary class consciousness. This involved a number of discrete elements: first, consciousness of class membership; second, consciousness of class interests; third, the will to advance these interests; and finally, a realisation of what this involves. Overarching all of these elements was the perception by the working class that their position was an unsatisfactory one, one of exploitation, inequalities and deprivation. In relation to contemporary Māori lifeworlds the implications of these ideas is that in order for class consciousness to act as a tool and enabler for transformation, Māori should be conscious of social class and identify themselves in terms of class membership; have common interests within this class-based stratum; have the motivation and impetus to drive these interests; and strategies to achieve these interests. 
Marx emphasised the notion of false consciousness when trying to understand why the working class did not revolt against their exploitation. He went on to say at some point the working class would revolt once they realise their subjugation. This is similar to the idea espoused by Foucault (1980) that oppression creates the seeds of resistance and action. He states: "there are no relations of power without resistance" (1980:142), thus supporting the idea that revolutions are indeed created on the margins of society.

The notion of false consciousness has been heavily critiqued because it casts the working class as not being agentic, that is not being able to change the material conditions of their lives. Consequently, critics describe Marxist perspectives as economic determinism (Conway, 1987; Hargreaves, 1982; Hickox, 1982) because it didn't go far enough in terms of going beyond the pathology of simply describing inequalities towards building theories and strategies which showed how to create action-based transformation. Thus, critical theorists, post-structuralists and postmodernists emerged in response to the theoretical limitations provided by Marxist perspectives. As Wright (2005) and others point out, although there is no consensus in any of the core concepts of social class analysis, what defines the tradition is capitalist oppression and the language within which debates around power, inequalities, domination and exploitation are waged (2005:5).

\section{Weberian Perspectives}

The second most influential social class theorist is Weber, who added to Marxist perspectives in pivotal ways. According to Weberian perspectives, the basis of class formation shifts from the Marxist focus on ownership, towards power and control. This allows for more complex stratification patterns including the role of the middle class and education and schooling in social class production (Campbell, 2007; Pearson and Thorns, 1983). In short, Weber's major contribution was to see social class in terms of status (which includes aspects of social reality such as educational qualifications) rather than purely in terms of one's relationship with capital.

In this sense class is broken down into and related to occupational groups with distinct status differences. In contrast to Marxist perspectives, the focus is on these 
status 'differences' rather than structural 'similarities'. Put simply, Weber argued that social classes are fragmented by different interests rather than unified by them as Marx had theorised. Class therefore is not the most important nor sole determinant of the social structure. Weber considered the importance of the middle class and argued the middle class position between the working and ruling class means they share some of the attributes of both. Despite the differences between Marxist and Weberian perspectives (see Giddens, 1997) for the purposes of this research, the key point to note is both approaches emphasise the importance of position in the occupational structure as a key determinant of other social relationships that individuals and groups engage in (Dale, 2000). Traditional Marxist perspectives are often described as deterministic, defunct and out of touch with the reality of contemporary social and economic structures. In recent times, it has for the most part been overshadowed by post-modern theories which seek to analyse social inequalities through a social, gendered and culturally based lens, rather than solely an economic one.

\section{Neo-Marxist Perspectives}

Contemporary critics of class point towards theoretical exhaustion (Pahl, 1993) and the weakness of class identities in modern-day society as clear evidence that class analysis is dead. As highlighted by Bottero (2004) even supporters of class point towards fragmentation (Crompton, 1996), attenuation (Morris and Scott, 1996) and its minimalist nature (Devine, 1998). The advent of the new right and neo-liberal ideologies, combined with the current global economic recession, has resulted in dramatic changes to the context within which social inequalities are lived and experienced. Increasingly questions are raised about how and why these inequities continue to be played out, and more importantly what theoretical tools we have in our intellectual arsenal to challenge the underlying capitalist system and structures.

What do Marxist perspectives seek to achieve in modern-day society and how relevant are Marxist perspectives today? In response to the first question, the following statement by Cole (2008) captures the central aim of Marxism: 
"The fundamental aim of Marxism is the overthrow of the anarchic, exploitative, and eco-destructive system of world capitalism and its replacement by world socialism and equality. To build a socialist world is a task of gargantuan proportions, but one that Marxists believe is eminently achievable." (2008:i).

In response to the second part of the question, protagonists agree that while the Marxist perspective provides an elaborate and systematic theoretical framework for class analysis, it does not adequately account for the composition of contemporary Western capitalist societies (Wright, 2000). There is, however, a general consensus among protagonists that class persists. Some would say that classed identities are not highly visible in contemporary society, while others would argue this is simply not true. For example, within Aotearoa New Zealand one just has to go to Wellington suburbs like Cannons Creek and Waitangirua and then drive 5e minutes down the road to Whitby to see class is alive, visible and real.

Neo-Marxist perspectives apply a Marxist critique of capitalism and theory of social class to a broader range of social and cultural phenomena in contemporary society (Wright, 2005). While neo-Marxist perspectives mark a shift from traditional Marxist perspectives, the legacy of Marxism remains in the questions that emerge and analyses to be investigated about macro society issues, for example, how does society work? How is wealth produced? Who benefits the most from what is produced? What social and economic processes continue to lead to inequalities? (Campbell, 2007). In other words, the Marxist focus on conflict, power, struggle, tension and inequalities remain an integral component of neo-Marxist perspectives.

\section{Neo-Marxist Perspectives on Class, Ethnicity and Race}

Traditional Marxian perspectives do not adequately account for the intersection of class, ethnicity, culture and race. Such theoretical limitations resulted in the expansion of Marxist analysis and the emergence of neo-Marxist perspectives which sought to incorporate experiences of ethnicity, race and culture into social class analyses (Cole, 1989; Miles, 1980). 
Some scholars argue that it is important to understand the impact of both social class and ethnicity in processes of social reproduction (Strathdee, 2013). For example, Pitcher (2012) describes the complex relationships that exist between capitalism and racism and points out there is considerable debate about whether or not ethnicity, race and diversity serve to support capitalism by diverting attention away from inequality that is a form of production. Similarly, Zizek (1997) argues multiculturalism has served to distract critical energy from a critique of capitalism and, thus, plays a supporting role in the extension and maintenance of capitalism. As he states, multiculturalism is the "cultural logic of multinational capitalism" (1997:28). In other words, Zizek posits the State promotes multiculturalism because it helps legitimate the role it plays in supporting capital accumulation. What both Pitcher and Zizek emphasise is that both race and capital play important roles in the production of inequality.

How does neo-Marxist theory define race? Race as a concept derived from physical anthropology (Darwin, 1859; Hook, 2009) and was used as a rough proxy for genes, culture and status to capture the social classification of people in a race-conscious society (Robson and Reid, 2001). The relevance and usefulness of race in modernday society is a point of conjecture and there is a marked absence of race analyses in traditional Marxist theory. Cole (1989) argues Marx was blind to gender and race, though he points out Marx did write about the levels of racism directed at the Irish (1989:128). For Cole racism has substance, but race is a problematic concept. He agrees with Miles (1982) who argues against the notion there are distinct 'races' for three reasons: first, "the extent of genetic variation within any population is usually greater than the average difference between populations; second, although the frequency of occurrence of different gene forms (alleles) does vary from one 'race' to another, any particular genetic combination can be found in almost any 'race'; and third, due to inter-breeding and large scale migrations, the distinctions between 'races' identified in terms of dominant genes (polymorphic) frequencies are often blurred" (as cited in Cole, 1989:127).

According to Jenkins (1997) race has long been identified as a concept lacking scientific credibility, and is neither a valid genetic or biological construct. Cole (1989) agrees and posits race is an "ideological construct" and for this reason struggles are 
not 'race' struggles, but these struggles take place within the context of "class boundaries; all ideological and political struggles are in fact class struggles" (1989:123). For Cole, in order to understand the intersection between 'race' and class from a Marxist perspective, we must start with an analysis of the material processes themselves by looking at the relationship between: a) state and capital; b) capital and labour; and c) the way in which racism is ideologically constructed. This three-pronged approach provides a useful starting point for considering the nature of race and class from a Marxist perspective. The idea of race as a social construct which facilitates racism is supported by Jones (2000) who argues against race as a biological construct that reflects innate differences, but a social construct that captures the impact of racism. In summary, neo-Marxist perspectives view race is an ideological not biological construct.

\section{Neo-Marxist Perspectives and Culture}

How do neo-Marxist perspectives account for culture? While the literature does not exclude discussions about ethnically based cultures and their relationship to the economic structure, nor does it at this point in time include it. The focus is on other forms of culture, some of which seem to transcend class boundaries. For example, traditional features which distinguished people from one another on the social hierarchy are no longer as apparent, and the forces of identity formation that were once so strongly located in the economic system are weakening. In theory what this means is working class cultures are no longer transmitted across generations between families and people are free to create their own class positions. As part of this, new cultural forms are emerging, for example the green movement and feminism, which do not have a direct relationship to the mode of production. The counter view posits these changes are superfluous and do not change workers' relations to the means of production and thus capitalism continues to function unabated and unopposed.

Stuart Hall, cultural theorist and sociologist, makes important contributions towards neo-Marxist cultural perspectives (Hall, 1980, 1992, 1996, 1997). For decades his influential theories have challenged traditional ideas about what constitutes culture and helped transform popular culture into an area of serious academic enquiry (Hall 
and Du Gay, 1996). Hall emphasised how "culture is a critical site of social action and intervention, where power relations are both established and potentially unsettled" (Procter, 2004:2). He distinguished between popular culture and high culture and argues it is at the site of popular culture where everyday struggles between dominant and subordinate groups are fought, won and lost. Thus, culture is both a process and site of ongoing struggle (Hall, 1980). His philosophy exposes the politics of culture and the relations of power that exist in society in a particular moment, and perhaps more importantly how subordinate groups might own that cultural space from the dominant group, however briefly (Hall, 1992:11). It is also about critiquing relations of power within the context of the capitalist society at that particular time. In short, Hall offers a frame of analysis that demands a critical view of culture, the power relations operating within that culture, and the capitalist context within which that culture is embedded.

Furthermore, in a potent critique of neo-liberal perspectives on internationalisation in higher education in New Zealand, Jiang (2011) provides important insights into what culture means from a neo-Marxist perspective and opens space for discussions around the relationship between ethnically based cultures and social class. He states:

"The neo Marxist pursuit of social justice begins with the basic assumption that no culture should be unfairly privileged. In general, neo Marxism operates from a philosophical base that involves a respect for different cultures. It highlights the need for equality among different cultures and furthermore does this by critiquing the neo-liberalism that is embedded in capitalism... Neo Marxism is anchored in principles of equality and fairness." (2011:390)

Thus, principles of social justice, equality and fairness sit at the heart of neo-Marxist perspective and inform the way in which culture is used in neo-Marxist culturalist class perspectives. It could also be argued the idea that no culture is unfairly privileged is precisely the same argument that neo-liberals have made and continue to make against Māori scholarships and support systems in education. Thus, 
perhaps the key point of difference is that neo-Marxist perspectives (at least from a theoretical perspective) operate from a value base which respects cultural diversity.

\section{Neo-Marxist Culturalist Class Perspectives}

Neo-Marxist culturalist class perspectives is an emerging field which seeks to better account for the changing face of class relations, identities and cultures in contemporary Great Britain. Culture is referred to in its broadest sense and includes the culture of classes, society, schools and institutions (Savage, 2003). While the literature does not refer to ethnically based cultures, the analyses which emerge help to build our understanding of the dialectics and tensions created when social class, ethnicity, culture and capital collide in contemporary contexts.

Led by British sociologists, this perspective looks at how in various settings of social life, processes of inequality are routinely produced and reproduced and how this involves both economic and cultural practices (Reay, 1998; Savage, 2003; Skeggs, 2004). Bottero (2004) argues this new approach has "refashioned class analysis by placing a much greater emphasis on processes of culture, lifestyle and taste" (2004:986). The focus therefore is on how class is "lived in gendered and raced ways" (Reay, 1998:272). This approach allows for more subtle and nuanced analyses of how social class works to complement the macro analyses which have dominated the ways in which social class was traditionally analysed (Ball, 2003; Devine et al., 2005). Cultural identity is at the heart of the new approach with a focus on how cultural processes are embedded within specific kinds of socioeconomic practices. For example, the fusion of economic and cultural elements no longer requires class identities to form in a distinct way as explained by Devine and Savage (2000) cited in Bottero (2004):

"What establishes the relationship between class and culture (i.e., what establishes the classed nature of cultural dispositions) is not the existence of class consciousness, or the coherence or uniformity of a distinct set of cultural dispositions. Rather, the relationship is to be found in the way in which cultural outlooks are implicated in modes of exclusion and/or domination." (Devine and Savage, 2000: 195). 
In other words, people do not have to explicitly recognise class issues or identify with class processes, but what is required is for specific cultural practices to be bound up with the reproduction of hierarchy. Therefore the emphasis is on the classed nature of particular social and cultural practices. In relation to this research, this approach puts the focus on the social and cultural practices particular to a highly educated Māori cohort.

Savage (2000) asserts class cultures can be usefully viewed as modes of differentiation rather than as types of collectives, where 'class' processes operate through individualised distinction rather than in social groupings (Savage, 2000:102). The old model of class is replaced by a focus on how class location is bound up with social identity. Individualisation, however, does not entail the death of class, but rather a shift in how class operates, for "while collective class identities are indeed weak, people continue to define their own individual identities in ways which inevitably involve relational comparisons with members of various social classes", representing "the reforming of class cultures around individualized axes" (Savage, 2000:xii).

For Savage (2000) as cited in Bottero (2004) the paradox of class is that "the structural importance of class to peoples' lives appears not be recognized by the people themselves. Culturally, class does not appear to be a self-conscious principle of social identity, however it appears to be highly pertinent" (Savage, 2000:xii). Neo-Marxist culturalist perspectives provide the space to talk about the relationship between racism, class, culture and capitalism. It forces one to look at why society is built on a level of racism that continues to privilege one group of people and marginalise another group. It asks questions about power, rights and values in society. As Reid (2006) has eloquently argued, until we get to the heart of these structural issues, Māori health and education outcomes will not change and transformation will be nothing but a dream (Reid, 2006).

\section{Critique of Neo-Marxist Perspectives}

Critics of this neo-Marxist culturalist approach point towards over-emphasis on the importance of culturalist-idealist (as opposed to structuralist-materialistic) analysis, 
and a disregard for the complexities and variations in different forms of capital and its relationships with state, government, education, teachers and teacher education (Hill, 2001:45). For example, Hill argues how different factions of capital - for example, manufacturing and finance capital, multinational and national capital, Atlantic and Euro-centred capital, post-Fordist and Fordist capital - intersect with daily life in different and complex ways:

"The culturalist approach underestimates the ultimate and effective unity of capital in Britain regarding the extent and effectiveness of state intervention in making schooling and teacher education unashamedly fit for capital, with the consistent attempts at repressing social democratic, socialist and liberal progressive ends of education. This casts doubts on their claims about the relative autonomy of education state apparatuses and agents." (2001:145).

The key point Hill (2001) makes is the education system is not autonomous - it intersects and is influenced by the complex movements of different forms of capital within the present-day political economy. This intersection impacts on everyday lives in both seen and unseen ways. According to Skeggs (2004) class struggle is alive and well in England. Critics of her work argue the use of 'struggle' in contemporary analysis is an outdated concept of social class; however, she argues that class is as much about symbolic struggle which is as relevant today as it ever was. She states:

"Class formation is a dynamic produced through conflict and fought out at the level of the symbolic. To ignore this is to work uncritically with categories produced through this struggle which always (because it is a struggle) exists in the interest of power." (2004:5).

\section{Marxist Perspectives on Education}

In her book entitled 'Knowledge, Ideology and the Politics of Schooling: Towards a Marxist Analysis of Education', Sharp (1980) critiques liberal bourgeoisie social theorists (e.g. Weber, Veblen, Durkheim, Mannheim, Bernstein and Bourdieu). She vehemently argues that they all fail to adequately comprehend the nature of 
capitalism and, in doing so, provide an incomplete framework to analyse social inequalities in schooling and education. In short, she posits schools are part of the structures of the capitalist state and if we are to deepen our understanding and analyses, we must first understand the economic system within which these structures were created. Sharp maintains that this structural analysis will invariably involve developing a theory of education which must include a theory of ideology. For Sharp, ideology refers to a range of social practices which reproduce and transform in ideological form the social relationships of production. Ideology reproduces capitalist modes of production and reflects a situation of domination. Sharp suggests the root of ideology lies in the structures and processes of society and is a material level of social practice which is to a great extent "unconscious; embodied in social routines, rituals and existence" (1980:86). The idea that ideology is imbued and embedded at an unconscious level is the reason why it is so difficult to change. Similarly, Mannheim (1936) argues ideology is a form and instrument of social reproduction. While Giddens (1997) posits ideology is "shared ideas or beliefs which serve to justify the interest of the dominant groups" (1997:583). The common message is ideology is powerful, insidious and difficult to change. Sharp's insightful analysis emphasises two key points. First, that in order to fully analyse social inequalities in schooling and education, a Marxist framework must imbue a sound understanding and analysis of the nature of capitalism within contemporary society. Second, this framework must include a theory of education and central to this is a theory of ideology. Thus, the relationship between social class and education is undoubtedly complex, but as Bell and Carpenter (1994) among many others emphatically state, the education system has "always been involved in reproducing class inequalities" (1994:112).

\section{Social and Cultural Reproduction: Pierre Bourdieu}

Bourdieu's contribution to the field of social class is significant. His theory of social and cultural reproduction is based on his attempts to explain the differences in educational outcomes in France. Bourdieu's thesis is underpinned by the assumption that societies are hierarchically divided into classes and structures maintained and legitimated by 'symbolic violence' - the unconscious mode of cultural and social domination (Bourdieu, 1973). This process happens through the 
imposition of values, ideas and practices which serve the interests of the dominant group and regulate those who come to believe that their domination is the natural order, the norm.

Bourdieu's argument of class becomes broader than Marxian analysis. He argues there are other attributes of class that need to be acknowledged. Bourdieu says it is not just about the relations of production, economics, income, status and occupation; rather, class is determined as much by our life-worlds which are culturally embedded and anchored in specific ways in how we see and interact with the world - part of a culture. It is about the little things - music, what you read, how you travel - all of which are indicators of this culturally embedded life-world. Therefore, class does not just arise as a result of economic determinism, but out of a whole lot of things. Bourdieu challenges us to embrace these cultural components of class. In this view, class is a whole way of being, a range of dispositions, ways of acting and sensibilities. Bourdieu's thesis is based on a number of central ideas like habitus, cultural capital and fields, which will now be explored in relation to this research.

\section{Habitus}

Bourdieu views power as something that is culturally and symbolically created through a dynamic interplay between structure, agency and fields. The main way this happens is through habitus. The concept of habitus is a mix of social and cultural and is defined as socially learnt skills, dispositions, norms, tendencies, sensibilities and ways of acting which guide behaviour and thinking and are taken for granted, experienced and acquired in everyday life. In other words, habitus is a culturally embedded life-world. Habitus is not the result of free will nor determined by structures or context, but by the interplay between the three over time (Bourdieu, 1984). Bourdieu is always trying to account for agency in a constrained world as well as trying to show how both agency and structure are implicit in each other (see Harker and May, 1993).

It is important, following Bourdieu (see Giroux, 1982:7) to understand habitus as a mediating link between objective structures (e.g. language, schools, families), social 
processes and reproduction. They tend to produce dispositions or attitudes, which in turn structure social experiences that reproduce the same or similar objective structures. The participant narratives provide a rich evidence base through which habitus can be explored. Given the relatively successful educational outcomes achieved by the cohort it will be interesting to look at commonalities and contradictions within the group to build a sense of what it means to have grown up as Māori within a particular habitus.

\section{Cultural Capital}

Cultural capital arises from habitus. Habitus marks us; cultural capital denotes how it is used. Cultural capital is not the sole preserve of the dominant class culture. All groups develop a cultural capital based on what is intrinsically valued in that particular life-world. For example, a Māori cultural capital might comprise proficiency in te reo me ōna tikanga (language and customs), depth of mātauranga (traditional knowledge) and tangible connections to one's own marae (homeland community). It is about one's own world and interaction with the wider world and includes both the cultural and social - what is of value and worth? What values are instilled? What interests, sensibilities, dispositions, values and practices does one possess? Bourdieu argued that cultural capital could not be transmitted between social class groups.

Cultural capital can be defined as the forms of knowledge, skills, education, language, dispositions and advantages that a person has that gives them higher status in society (Bourdieu, 1984). The critical point to take from Bourdieu's thesis is that we inherit these forms of cultural capital from our family background and resources. It is learned through our social and cultural interactions.

With regard to education, the nuclear family transmits the knowledge, attitudes and values needed to succeed in the educational system and therefore cultural capital theory is a way of explaining cultural differences which underpin and reproduce social class (Meadmore, 1999). It is important to note that the cultural capital of the dominant class is reflected and reproduced in schools. In Aotearoa New Zealand, 
this means the cultural capital of Māori, Pasifika, Asian and other cultures is overshadowed by a Pākehā, Western-based cultural capital.

Bourdieu distinguishes between three types of capital:

- Embodied capital - norms, practices and the dispositions we live by;

- Institutional capital - the markers that set us apart, i.e. qualifications and credentials as well as the values placed on these markers; and

- Objectified capital - the physical markers that distinguish us, for example in a Māori context this might be the wearing of tā moko (Māori tattoo), moko kauae (female tattoo on the jawbone) or a pounamu (a greenstone), i.e. objects which display, derive from and symbolise te ao Māori.

These types of capital operate in complex ways and are relevant because they essentially equate to power. The more capital one possesses across each of the three types of capital, the more powerful that person will be.

\section{Fields}

To understand how people behave, it is important to know and understand in what kind of power relations they take part. Bourdieu's notion of fields is relevant because it provides a way to understand the tensions inherent in social relations and also helps to identify what Bourdieu refers to as 'sites of struggle'. A field or 'site of struggle' can be thought of as a type of social arena or context where people (agents) manoeuvre, jostle and struggle for resources. This is the site where conflict between groups with their own values, practices and dispositions are played out. This conflict or struggle is at its heart about the legitimation of cultural capital, that is, the ongoing struggle to have one's cultural wealth and cultural identity valued and recognised.

Social class, education, upbringing and past choices all determine in part the behaviour of a person in the field, where they strive to either preserve or transform the status quo. Where a person (agent) tries to transform the rules of the field 
(doxa) struggle ensues, as those who try to maintain power, control and status fight against agents of change. One example of this is the tension between mono-cultural classrooms and Māori students who resist and challenge the rules of the classroom by enacting their learnt dispositions, ways of thinking and acting as well as calling on attributes of cultural capital, e.g. language, tikanga and taonga. As a result of this cultural mismatch, struggle ensues and those in power work to bring these students in line with the mono-cultural classroom rules and ethos (Bishop and Berryman, 2006). The participants in this study highlight the constant struggle between two fields - te ao Māori and te ao hurihuri and the inevitable tensions and conflicts that arise in the acquisition of Pākehā cultural capital within a Māori context and vice versa. The struggle is physical, symbolic, cultural and social.

So how does class analysis relate to the idea of fields? Within this context class is a war of positioning and de-legitimising, Bourdieu's concept of fields helps us to make sense of this battlefield. The idea of habitus as a mediating link also comes into play again. The struggle is to validate (where there is a conflict) one's own cultural capital. The system of 'symbolic violence' applies, but it does not automatically or mechanically impose on the disadvantaged or oppressed. A violence that is symbolic is no less destructive than one material in nature. According to Robbins (2000:xi), Bourdieu argues that it is one of the defining characteristics of the human condition for people to be situated within culture. Culture is enacted by everyone. It is a game in which there are no non-participating spectators.

\section{Summary}

This chapter started by exploring indigenous perspectives on transformation, the underlying principles and intent as well as the ways in which transformation is manifest in contemporary contexts. The move from individual transformation to collective/class-based theories of transformation is also explored and the idea of the organic intellectuals leading transformative pursuits on a small scale at the local level holds exciting potential for this thesis. How kaupapa Māori and transformative theories are used in this research study is also outlined. 
Next, the discussion focused on class consciousness and what this might offer Māori as part of a transformative agenda. Class consciousness is an important concept which sits at the heart of Marxist social class perspectives. In order to create transformation, a collective consciousness must be created aimed at disrupting and overthrowing the status quo. A review of selected literature was presented to show how social class is a complex and evolving process which has an effect on the structural and material lives of people in many seen and unseen ways. Social class perspectives have evolved but hold fast to the basic premise of Marxism; social class is about the relationships that people have to the means of production, characterised by power, domination, status and control. While the neoMarxist literature does not explicitly account for ethnically based cultures nor does it exclude them. As a diverse range of perspectives, the social class literature challenges us to build an understanding of the nature of the capitalist society, its underlying ideologies, assumptions and structures and how these intersect with race, ethnicity, gender and culture. . 


\section{CHAPTER FOUR: BACKGROUND TO THIS STUDY}

\section{Introduction}

This chapter is about the structural and cultural context we are all embedded in, what has influenced Māori as individuals and as a collective, and what processes promote and inhibit positive transformation. The discussion is broken into four parts. First, to ground my conceptual understanding of Māori experiences, I explore Māori world views and the underlying philosophies and concepts which shape this view. Second, I focus on how this world view shaped traditional (pre-European) social structure, whether hierarchy processes were in place and in what ways these processes connected to a Māori political economy. Third, my analysis shifts towards the impact of colonisation on the Māori social structure and political economy and explores the emergence of a 'classless' egalitarian society

\section{Māori World View}

The analysis of contemporary Māori experiences and perspectives on social class must be grounded in an understanding of traditional Māori social structure which is firmly embedded in a Māori world view (Royal, 2003).

In his cogent analysis of te ao Māori (the Māori world), Reverend Māori Marsden (1992a) describes world view as:

“...the central systematisation of conceptions of reality to which members of its culture assent, and from which stems their value systems. The world view lies at the very heart of a culture, touching, interacting with, and strongly influencing every aspect of that culture." (1992:3).

For Marsden mythology forms an integral part of mātauranga Māori (Māori knowledge). He challenges the modern orthodox views that such stories are fanciful folly and argues myths and legends are purposeful constructs which capture and 
embody Māori views of the world, reality and the inter-relationships between the creator, the universe and man (Ibid:5). Walker (1992) shares this sentiment and suggests:

In a culture that lives and grows, there need be nothing outmoded or discredited about mythology. Properly understood, Māori mythology and traditions provide myth-messages to which the Māori people can and will respond today." (1992:170)

Similarly Buck (1949) posits a Māori world view provides an explanation about the evolution of existence beginning with the supreme god lo. It is the story of creation, the creation of the world, the creation of the gods and the creation of humankind. Mikaere (2001) and King (2003), however, use the term 'Māori cosmogony' to describe the Māori view of how the world began and acknowledged how this world view provides a blueprint for Māori life, blending together the spiritual and natural worlds.

A report entitled 'Te Kāwai Ora' written by Penetito, Yates, Selby, Wikaira, Reid, Higgins, Taipana and Irwin (2001), the Māori Adult Literacy Working Party, used the term 'epistemology' to talk about Māori world views. Epistemology in its most narrow form can be defined as the study and theory of knowledge and justified belief (Pearsall, 1999), in other words knowing about Māori knowledge. The report highlighted the differences between the Māori world view (epistemology), Māori reality (ontology) 'being Māori', and kaupapa Māori (methodology) 'doing things the Māori way'. Thus, there is no single Māori world view, Māori reality or Māori way of being; rather Māori world views, realities and ways of being are multiple and complex, understood and expressed at the whānau, hapū and iwi level (2001:9).

According to Walker (1990) Māori operate in and understand the world ontologically. For example, whakapapa is an ontological device with regards to cosmogony, identity and place. Thus, there is an interconnection between epistemology and ontology - you cannot have one without the other. For example, an epistemological question always has an ontological question behind it, and in some ways any 
question that asks about the relevance of something is ontological, is rooted in a reality.

The importance of the Māori world view and how it is manifest through cultural concepts is articulated by Penetito (2005b) who states:

"The world is considered value bound (aroha, manaakitanga). We learn those values from the social world (whakawhanaungatanga/kinship). We internalise them and they become part of us (whakapapa, reo). They cannot be set aside (mana/power authority, tapū/scared and prohibited. We come to know the social world as being essentially relativist and where multiple realities are the norm. Everyone has his/her story to tell and variation is the reality (tikanga)." (2005b:49)

Cultural concepts express Māori world views and the range of concepts used to define and describe a Māori world view might differentiate slightly, but fundamental concepts like whakapapa, reo, tikanga, mana, tapū, aroha and manaakitanga sit at the heart of this view (Marsden and Henare, 1993; Ministry of Justice, 2001; Pere, 1979, 1994;).

In her seminal conceptual work used widely in the education sector, Pere (1988) identified key principles of mātauranga Māori which together enable Māori world views to be explored. Her conceptual model known as 'Te Wheke' (the Octopus) provides a framework to explore Māori epistemology at a range of levels. Te Wheke has three hearts: whakapapa, tikanga and manaakitanga, and ohaoha which are supported by eight kāwai (tentacles or principles): whanaungatanga (community), whatumanawa (emotions), mana ahua ake (authenticity), mauri (respect), wairua (spirituality), te ao tūroa (physical environment), hinengaro (knowledge), and taonga tuku iho (traditional knowledge). Similar models have also been developed by a range of Māori philosophers, scholars and practitioners (see for example, Mataira, 1980). 
At a practical level Pohatu (2003) asserts that, when activated, Māori world views immediately place Māori thinking, knowledge and application at the centre (2003:1). For Harmsworth (2010) a Māori world view is premised on the belief there is a natural order to the universe with an overarching principle of balance.

\section{Whakapapa}

The centrality of whakapapa to a Māori world view is a common thread in Māori and Pākehā literature (Karetu, 1992; King, 2003; Mahuika, 1992; Marsden, 1992b; Mead, 2003; Pere, 1988). Whakapapa binds and connects through the interrelationship of all living things - this holistic approach is a key marker of Māori world views.

According to Buck (1949), te ao Māori was based on whakapapa and on the belief and value systems set at that time passed down through the generations in a genealogical sequence descending from Rangi-awatea and Papa-tua-nuku. Thus, traditional Māori social structure comprised whānau (family), hapū (sub-tribe) and iwi (tribe) kinship groups, descendants of a common ancestor linked together by whakapapa. Terms like 'genealogy' and 'lineage' are often applied to understand whakapapa, but Māori commentators agree that whakapapa is all of this and more.

Mead (2003) asserts whakapapa is a "fundamental attribute and gift of birth. It is the social component of the ira, the genes... Whakapapa provides our identity within a tribal structure and later in life gives the individual the right to say, 'I am Māori'... In short, whakapapa is belonging." (2003:42)

Te Rito (2007) defines whakapapa is a 'paradigm' which operates at various levels: "a genealogical narrative, a story told layer on layer, ancestor on ancestor up to the present day" (2007:1). Thus, whakapapa is literally the process of laying one thing on another. Whakapapa is used to connect with or differentiate oneself from others in both a material and spiritual sense.

The link to the spirit world is important and differentiates whakapapa from other constructs of human genealogy. For example, Hudson, Ahuriri-Driscoll, Lea and Lea 
(2007) define whakapapa as the "foundation of traditional Māori social structure which perpetuates a value base that locates people through their relationships to the physical and spiritual world" (2007:43). They suggest whakapapa is "the ultimate catalogue' which not only defines the relationship between people, but links all other things. They argue this linking of humans, elements and organisms, as well as the ecological and morphological relationships, distinguishes whakapapa from a typical scientific taxonomy (2007:1).

In her poignant analysis of Kai Tahu tribal identity, O'Regan (2001) describes how whānau, hapū and iwi were bound by the common thread of whakapapa which linked the individual to the wider world:

"Whakapapa was the basis of group affiliation and therefore fundamental to social organisation. Whakapapa set one's role and place within a hierarchical society, therefore acting as a determining factor in leadership. As a symbol of identity, whakapapa was unsurpassed." (2001:50)

\section{Whakapapa and Hierarchy}

The importance of whakapapa in determining one's social standing in traditional society is supported by Metge (1976) who argues whakapapa was once the "key to social rank, however today whakapapa is only one of several factors determining social status in Māori society" (1976:128).

According to Katene (2010) traditional communities recognised two main classes of leaders, āriki/rangatira (chiefly) and tohunga lines. Chieftainship was regarded as a birthright and the measure of the leader was the sum total of one's chiefly genealogical ties. Similarly Mead (2003) argues while every Māori person is born with whakapapa which is part of a person's birthright, there is no common starting point, every person is different and everyone has a unique position in the social system. To this end, Mead identified 'te moenga rangatira' as an important ranking device, which still has relevance and validity in today's society. Te moenga rangatira can be defined as the chiefly marriage bed and reflects the importance attributed to the progeny of chiefs and the status afforded to chiefly offspring. 


\section{Traditional Society and systems of hierarchies}

Jarden (1992) and Poata-Smith (2004a) argue Western constructs of hierarchies based on social class were never part of traditional Māori society; rather communal life was supported by leadership, collectivism and a subsistence lifestyle. That said, it is a truism that each society has some form of hierarchy or stratification and traditional Māori society is no different.

There is a general consensus amongst historians that Aotearoa New Zealand was settled by Māori around 1350 AD (King, 2003). The orthodox historical discourse talks about the epic migratory journey of the 'Great Fleet', a cohort of waka which set sail from the ancestral homeland Hawaiiki to settle in Aotearoa. King (2003) challenges this orthodoxy and questions the validity of the sources that originally promulgated the 'Great Fleet' migration story. He argues early European ethnographers promoted the great fleet 'story' in a bid to appeal to European audiences. However, the underlying substance is questionable particularly when scarce evidence of a collective waka migration exists within Māori oral traditions. Rather he suggests individual waka or a small-scale fleet travelled to Aotearoa from Eastern Polynesia for the purposes of migration (Ibid:43). The migration of waka, however big or small, meant waka captains and tohunga (the chosen ones) were at the time of first settlement the primary form of leadership. As time passed, however, and the population expanded, this leadership shifted into other social groupings, namely, whānau, hapū and iwi.

In her comprehensive analysis of the dynamics of iwi tribal organisation from c.1769 to c.1945, Ballara (1998) argues the images of tribal structures as depicted in historical literature derive from a long history of "superficial observations of Māori by Europeans" (1998:19). Influenced by early ethnographers like Elsdon Best, she posits rigid and static structural models of kinship were promulgated whereby Māori kinship and social stratification comprised iwi (tribe), hapū (sub-tribe), whānau and extended whānau.

For Ballara the hapū was an important social and political unit during this period and a focal point for social division and hierarchy: 
"Each hapū was believed to have a chief who also has his place in a tribal hierarchy; the apex of this hierarchy was the ariki or paramount chief... All hapū were in turn divided into whānau/extended whānau within each of these categories was a graduated hierarchy of status, for example, ariki (paramount chief); rangatira (chief); kaumātua (senior member).” (1998:18)

Thus a clear system of graduated hierarchy operated within each hapū and Ballara argues Māori political and social systems were dynamic, not static and rigid (as promulgated by early ethnographers), but continually modified like Māori technology in response to phenomena like environmental change and population expansion (1998:21).

According to King (2003), by the $16^{\text {th }}$ century the iwi (tribal) unit had become the primary social and political unit across most of New Zealand due to population expansion, the demise of big game hunting and scarcity of crops. While no capitalist economic system existed in pre-European times, some academics refer to the divisions and hierarchy in traditional Māori society in class terms. For example, Buck (1987) talks about the 'class division' in traditional times comprising the chiefly class and the commoners, that is, the ware (low born) or tūtūā (1987:337). The precarious social standing of the tūtūā is explained by Mead (2003) who argues tūtūā did not qualify to be treated as human beings, because as slaves they had lost their birthright and in turn their right to be treated the same as other members of the hapū (2003:39). Mead explains while class divisions of traditional times no longer exist and are not recognised, the social divisions of the past have flattened out and there is one class called Māori (lbid:38).

Furthermore, King (2003) explains that for all the differences of status within te ao Māori - for example between ariki and rangatira, between rangatira and commoner, between tohunga and those who were not chosen, between slaves and everybody else, between men, women and children - pre-European Māori society was relatively homogenous in the sense that basic concepts and values of the culture were recognised and accepted from one end of the country to the other (2003:81). 
Te ao Māori is often viewed as collective and inclusive, and people are able to break down barriers because of values within tikanga, even though there is a clear hierarchy, but it is not seen as a hierarchy. So is Māori a stratified society or hierarchy and furthermore is it possible to have hierarchy without believing whoever is above is necessarily more important than those below?

According to a Māori leadership report commissioned by Te Puni Kōkiri (1992), the leader was only as good as the people he or she was leading. Thus, leadership was defined by the group's interest and legitimation of that leader. This mode of leadership signals a complex web of power relations and tikanga and suggests hierarchy may be the wrong word to explain these forces. For example, the teaching of esoteric knowledge through wānanga and the power and status afforded to kāhui ariki lineage are indicators of elements of hierarchy, but within Māoridom there are other narratives that say one could short circuit that process (Marsden, 2003).

Metge (1976) described how the power wielded by chiefs was mediated by the collective: by virtue of their rank and wealth, the chiefs exercised great influence, but their power was "far from absolute"; rather they "depended on the voluntary support and service of their kinsfolk, which they had to hold by good leadership and liberality" (1976:11).

The recognition of hierarchy and power in te ao Pākehā by Māori chiefs during the early settlement period in New Zealand is discussed by Jones and Jenkins (2011). They explain how over time Māori chiefs began to see a differentiation between Governor Gray and the missionaries and had already decided that the missionaries were tūtūā (commoners) so immediately hierarchicised them. The chiefs worked out that the people who held the real power were the ones who owned the land back in England, which encouraged them to look at the commercial side of society. Consequently entrepreneurship blossomed and while the place of religion and the Bible were important, neither compared to the power, status and appeal the English gentry and men living in castles represented to the chiefs. 
Scholars talk about 'class' and 'hierarchy' in traditional society almost interchangeably. The traditional hierarchy system was based on whakapapa and embedded in a Māori world view. This system differed from social class in that there was no capitalist economic system in place and therefore no exploitative relations of productions, no capitalists, no bourgeoisie or proletariats. Instead a complex web of power relations and tikanga operated within a whakapapa-based system of graduated hierarchy. As highlighted by Ballara (1998), however, this system was not static or rigid, but dynamic, evolving and malleable to the lived realities and external forces of the day.

\section{Māori Political Economy}

Traditional Māori social structure was inextricably linked to a Māori political economy. According to Metge (1976), the whole of traditional Māori life was firmly based on an annual cycle of food gathering, a subsistence lifestyle governed by the seasons and elements. Best (1941) describes the traditional Māori subsistence lifestyle as a form of communism whereby the wellbeing of the collective was privileged over the rights of the individual. Firth (1959: 135-141 as cited in Mead, 2003) challenges this point and argued that, although the individual appeared to exist only as a part of a group, the influence of Māori communism was overstated. He points towards an abundance of evidence which suggests the individual was not lost in the interests of the collective, for example, rivalry between persons, utu (reciprocity), koha (contribution), quarrels over land and property rights, gluttony, greed and idleness indicate a "sphere of action determined primarily by individual interests" (1959:138). Mead (2003) concludes that it was indeed possible in 1827 to be a Māori individual (2003:37).

In her systematic analysis of Māori and Pākehā political economic relationships in the Far North 1860-1940, Puckey (2006) reframes Māori participation in the Pākehā economy and asserts Māori were integral to the economy and not peripheral as the history books might suggest. In particular she acknowledged the economic contribution of Māori to the informal economy (shadow economy) in rural areas, in addition to contributions to the formal economy. 
Puckey identified two defining economic epochs in the Māori political economy: a) pre-1860 and b) 1860-1940. During the first epoch Māori and early settlers were engaged in a shadow economy built on the substance of a pre-colonial system which she refers to as a 'rural informal economy'. This system was unregulated, unmeasured and consequently largely dependent on social relations. This shadow economy, however, contributed significantly to the national economy (2006:32).

The second epoch (1860-1940) marked the influx of Europeans and resulted in the radical transformation of the Aotearoa New Zealand economy via the introduction of regulations which changed the ways in which Māori participated in the Pākehā economy. For example, there was not one rule for all, but differentiated regulations which clearly distinguished between the coloniser and the colonised (2006:33). Offshore sealing and, later on, shore-side whaling dramatically altered the contours of the economic landscape (King, 2003). However, Puckey argues the onset of colonisation and imposition of a Pākehā political economy did not result in the displacement of the rural informal economy; instead economic transformation was more of a hybrid in rural areas. Thus, Māori and Pākehā economic systems were highly integrated (2006:430). Puckey points towards overwhelming evidence that suggests Māori were entrepreneurial and actively sought opportunities to engage with Pākehā in business on their own terms:

"Māori had choices about how they related to the Pākehā economy, ranging along a continuum from full engagement to complete disengagement. Along the continuum were negotiated positions, such as formulating terms of engagement and attempts to convert unacceptable practices." (2006:430)

Thus the traditional Māori political economy was transformed into a hybrid economy whereby Māori shifted in and out of the shadow (informal rural) and formal economies.

\section{Colonisation and Land Alienation}

Land alienation is a key strategy implemented by colonising states in order to disempower and disenfranchise the colonised and progress colonial imperatives. 
The impact of land alienation (land sold, stolen, legislated away or otherwise) on the material lives of Māori early on in colonial settlement cannot be overstated (Ballara, 1982). Many scholars would argue the inequalities experienced by Māori today link back to this process. Land was the key to Māori subsistence living, the broader Māori and settler political economy, and of course to Māori identity (Walker, 1987). There are many whakatauki (proverbs) which emphasise the strong connection and place-based existence Māori, like other indigenous peoples, have to the land. For example, 'Whatungarongaro te tangata toi tū te whenua' (As people disappear from sight, the land remains) and 'He wahine he whenua, e ngaro ai te tangata' (By women and land, men will perish).

While Māori were indeed active in commercial development and entrepreneurial activities prior to and during the early stage of colonisation, Māori ability to maintain their active negotiation of the developing economy was severely restrained due to land alienation, but also to legislative restraints with regard to their participation in the economy, for example legal restrictions on Māori commercial fish farming/oyster beds (Williams, 1999; Jackson, 1993). In short, Māori who were able to maintain their involvement in the shadow economy were the lucky ones, but for many, like Taranaki iwi, land was confiscated and many Māori became wanderers looking for work (Stokes, 2008). It could be argued that early on in the settling of Aotearoa, hierarchies and class divisions were established between Māori and settlers. There is a litany of examples of unsuccessful Māori responses and challenges, for example Parihaka (Scott, 2004) and Whakatōhea (Walker, 2007).

\section{Social Class: Our Colonial Roots}

Social class and classed identities have not featured strongly in Aotearoa New Zealand due to a strong and pervasive sense of egalitarianism which can be traced back to our colonial roots (Belich, 2001; King, 1996; Orange, 1987). The historical resistance to class-based societies derived from the idea that new societies like New Zealand and Australia could escape the rigidities of the British feudal system (Campbell, 2007; McGregor, 1997). Pearson and Thorns (1983) argue that, within this context, emerged a strong notion of egalitarianism (1983:17). Dale (2000) suggests "kiwi egalitarianism" is a defining feature of New Zealand national identity, 
that is, "to deny the existence of class or class structure" (2000:108). Lauder and Hughes (1990b) agree and explain that New Zealanders perceive their country as egalitarian where everyone gets a "fair go" (1990b:43). Similarly, Jones and Jenkins (2011) suggest the relations between Māori and Pākehā were defined early in the encounters between Māori and colonial settlers, and therefore the fair go belief equally comes out of the discourse of 'he iwi kōtahi tātou' - we are one people along with the humanist ideals that underpinned treatying with natives. The powerful egalitarian rhetoric persists despite the voluminous body of evidence which indicates quite clearly that social inequalities in Aotearoa New Zealand are becoming stark (OECD, 2008). Within a contemporary setting, these inequalities are supported and perpetuated by the neo-liberal political economy.

\section{Neo-liberal Political Economy}

It is a truism that we are all (for better or for worse) inextricably linked to the global capitalist economic system (Friedman, 1962). This economic system intersects with all spheres of our life - social, cultural and political to create what is commonly referred to today as the neo-liberal political economy. A comprehensive discussion about the neo-liberal political economy is beyond the scope of this research study, nonetheless the key principles and implications of neo-liberalism and a political economy are briefly discussed to contextualise the forthcoming discussions and analyses. In particular, the focus is on how a neo-liberal political economy has impacted on Māori education, life outcomes and Māori ability to transform.

\section{Political Economy}

Political economy, in its most basic form, is the study of the role of economic processes in shaping society and history. It is also described as an inter-disciplinary subject combining the insights and tools of history, political science, economics and sociology (Delong, 2007). Rudd and Roper (1997) suggest a political economy approach includes the inter-relationship between the state, the economy and society. Thus, as Mosco (2009) aptly describes, political economy is a "broad-based and variegated approach to social analysis" (2009:36). It is about social change and history, social relations, power relations governing the production, distribution and 
exchange of resources, control and survival. For the purposes of this research, political economy encompasses all of the above and is shaped, for better or for worse, by neo-liberalism, the ideology underpinning our current capitalist economic system which impacts on our everyday lives structurally, economically, socially and culturally.

\section{Neo-liberalism}

Neo-liberalism is an ideology based on the advocacy of privatisation, marketisation, de-regulation and structural adjustment (Peters, Fitzsimons and Marshall, 1999). Various terms are often used interchangeably to describe neo-liberalism, for example, structuralist orthodoxy, globalisation, neo-liberal globalisation and the new right, all of which as Bargh (2002) highlights encompass policies and practices that are very similar, if not the same. The emergence of neo-liberalism across the world was swift and pervasive. According to Small (2009) the speed at which neoliberalism spread was such that "within a generation neo-liberalism came to dominate and define the ways that most countries in the world organized their economies, social policies and the ways in which they related with other countries" (2009:2). Thus, in the early 1980s, New Zealand with its relatively small population and thin (one parliament) government was considered a useful testing ground for the introduction and implementation of neo-liberal policies (Fitzsimons, 2000). Underpinned by its one-size-fits-all approach to reform, the neo-liberal project gave rise to competitive individualised models of social and economic organisation to replace social democratic models (Codd, 1999). Bargh (2007) supports this idea and defines neo-liberalism as "those practices and policies which seek to extend the market mechanism into areas of the community previously organised and governed in other ways" (2007:1). This process involves entrenching three central tenets of neo-liberalism: free trade, free mobility of capital, and a reduction in the scope and role of the state (Ibid: 3 ). For the purposes of this research study, the neo-liberal political economy refers to the inter-relationship between the state, the neo-liberal economy (underpinned by neo-liberal ideology) and society. It is about social relations and in particular the power relations governing the production, exchange and distribution of resources. 


\section{Neo-liberalism and Education}

When put in to action, the neo-liberal agenda resulted in major education, health and welfare system reforms in Aotearoa New Zealand, part of an ongoing process which continues to this day (Gordon and Whitty, 1997). Within an education context, Smith (2006) argues neo-liberalism reform is marked by a discourse of "education as a marketplace" whereby parents and students are consumers and clients and teachers and schools are self-managing providers of services (Smith, 2009:248). Moreover, Apple (2001) suggests within the neo-liberal educational framework, curriculum knowledge is a 'commodity' that can be traded for social incentives such as wellbeing and social status. The hallmarks of the neo-liberal educational agenda included resurgence in standardised testing; user-pays regimes, merit pay for teachers and privatisation. Much has been written about the detrimental impacts of such neo-liberal policies on educational outcomes in New Zealand and across the globe (see for example, Apple, 2001; Hughes and Lauder, 1991; Klees, 2008; Lauder and Wylie, 2011). As Codd (1999) cogently argues, economic imperatives more often than not supersede educational imperatives in the neo-liberal agenda.

\section{Growing Social Inequalities}

Māori represent about 15 percent of the population of Aotearoa New Zealand, while the majority group (NZ Europeans) constitute some 66 to 67 percent of the population. According to Statistics New Zealand (2008) the 'ethnic mosaic' of New Zealand's population is changing with Māori, Asian and Pacific populations making up a greater proportion of the overall New Zealand population. With a more youthful age structure and higher fertility rates, these three ethnic populations are likely to grow at a much faster pace than the European and Other populations (2008:4).

Under the umbrella of neo-liberalism Māori social, economic and educational inequalities have soared (Phillips and Mitchell, 2010; Robson, 2007; Te Puni Kōkiri, 1998). Māori are substantially over-represented in a wide range of negative social and economic indices. These include higher levels of unemployment, lower median incomes, lower life expectancy, higher rates of incarceration and poorer health and educational outcomes (Ministry of Social Development, 2010). 
An even more precarious picture is painted when these negative statistics are viewed through a social class and inequality lens (Laugesen and Black, 2010; United Nations Development Programme, 2009). For example, according to Roper (1997), class inequality and social polarisation in New Zealand have accelerated in the last two decades. An OECD report entitled Income Distribution and Poverty in 2008, reported that while inequality in New Zealand has fallen since 2000 (reversing a long-term trend where over the last two decades New Zealand had the fastest growing rate of inequality in the entire OECD) it is still well above the OECD average. Meanwhile, poverty (meaning people who live on less than half the median income) has risen since 2000, and is now at the OECD average. Moreover, from 1985 to 1995, real household incomes of lower- and middle-income groups fell, whereas rich households saw their real incomes rise (OECD, 2008). In short, research and statistics clearly show how in Aotearoa New Zealand today the rich are getting richer and the poor are getting poorer.

\section{Global Economic Recession}

The growing chasm between 'rich and poor', the 'haves and have nots' is part of a global phenomenon exacerbated by the ongoing global financial crisis also known as 'the 2007 economic recession' which first hit New Zealand in the March 2008 quarter and resulted in a 3.4 percent drop in gross domestic product (GDP) and rise in unemployment figures (Treasury, 2010; Statistics New Zealand, 2009c). Local research into the impact of the global financial recession on Māori has not surprisingly focused more on economic implications. For example, a report by $\mathrm{Te}$ Puni Kōkiri (2009) analysed the implications of the recession for the Māori economy. The report showed how historically recessions have had a disproportionately negative impact on Māori compared to non-Māori because of where Māori are located in the labour market and industry sectors (2009:2). With a high proportion of Māori employed in lower skilled, lesser paid occupations, i.e. construction and manufacturing industries, Māori are particularly vulnerable to global economic developments, more so than non-Māori. This level of economic vulnerability has a corresponding negative effect on Māori incomes, Māori housing and Māori health and educational outcomes. 


\section{Impact on Māori Wellbeing}

Research into the impact of the recession on Māori wellbeing showed how the gap in the subjective wellbeing of Māori and New Zealand Europeans widened during the recession between 2005 and 2009 (Sibley, Harre', Hoverd and Houkamau, 2011). Based on two national postal samples taken before (2005) and during (2009) the financial crisis the research showed how NZ European scores on the personal wellbeing index (PWI) were near identical across the two samples, while Māori scores, which were already lower than NZ European scores in 2005, decreased further in 2009. The report argues this gap in wellbeing widened because NZ Europeans, as a social group, experience material advantages which form a systemic buffer that protects their personal wellbeing against the negative impact of an economic recession. Conversely, Māori, who had already experienced systemic disadvantage, did not have this buffer, and therefore the effects of the 2007/10 global financial crisis impacted their personal wellbeing to a greater extent (Sibley et al., 2011:103). In short, those who earn less and have a lower level of education and poorer health have fewer buffers to protect against the impact of tough economic times on personal happiness and wellbeing.

\section{Increased Child Poverty}

The health and wellbeing of a country's children, arguably its most vulnerable cohort, is also an important measure of progress and prosperity. Within the context of the global economic recession (driven by neo-liberalism) child poverty has emerged as a pressing and alarming issue in Aotearoa New Zealand. An OECD report on child outcomes ranked Aotearoa New Zealand $28^{\text {th }}$ out of 30 OECD nations based on measures which included child mortality, health and education indicators. In addition, a recent child poverty report entitled 'He Ara Hōu - A Pathway Forward', explored the nature of the factors contributing to Māori and Pasifika child poverty. The report identified a disproportionate level of Māori and Pasifika children living in poverty with Māori and Pasifika children representing over half of the 200,000 children living below the poverty line. Its authors highlight the tenacious link between poverty and poor health, social and educational outcomes, and suggest if present trends in Māori and Pasifika child poverty continue, we are witnessing the development of a 'Brown underclass' (Chapple, 2000; Henare, 
Puckey, Nicholson, Dale and Vaithianathan, 2011). To this end, Dr Hone Kaa, spokesperson for Every Child Counts (ECC) and chair of Te Kāhui Mana Ririki (Māori Child Advocacy Organisation) argues the notion of a brown underclass has been around for the past decade; however, the economic recession has exacerbated the split between rich and poor (Every Child Counts, 2011).

Thus, despite decades of social and economic policies, strategies and what Popper (1977) refers to as piecemeal interventions, the gap between working class and middle class Māori, Māori and non-Māori in educational, social, political, economic and personal wellbeing has not only persisted, but increased (Chapple et al., 1997; Jensen et al., 2006; The New Zealand Institute, 2010). Given that the future generation of taxpayers in New Zealand will comprise a greater proportion of Māori, there is a clear and urgent need to look seriously at how the growing social inequalities between Māori and non-Māori can be transformed, not just for Māori, but for the future prosperity of all New Zealanders (Spoonley and Pearson, 2004; Te Puni Kōkiri, 1998). Within the context of the current global financial recession, current research and statistics indicate there is a strong likelihood these inequalities will continue unabated, if they are not challenged with vigour.

\section{Māori Resistance}

Māori have a long and proud history of resistance and resilience (Poata-Smith, 1996; Walker, 1987, 1990Poata-Smith). According to Bargh (2007), neo-liberal practice and policies, driven by an imperative to extend the market mechanism into all spheres of life, pose a direct threat to indigenous ways of life and world views (2007:15). Similar sentiments are shared by Smith (1999) and Sykes (2007) who point towards neo-liberalism as a form of colonisation or re-colonisation. Rata (2010) acknowledges how the global neo-liberal political framework has "profound effects" on social organisation at the local level (2010:4). It is therefore no surprise the Māori response to neo-liberalism has been one of resistance or the fight for 'tino rangatiratanga' (self-determination) which has taken a range of forms expressed in a variety of social, cultural, political, educational and economic contexts (Marshall, Peters and Smith, 1991; Te Punga Somerville, 2007). 
One of the more visible examples of Māori resistance is expressed through organised protest and activism. In her book entitled 'Hīkoi', Harris (2004) showcases the rise of Māori political consciousness depicted in a photographic history which traces 40 years of Māori protest. Of particular note in the past decade was the hīkoi (protest march) against the proposed Foreshore and Seabed Act 2004, which culminated in around 50,000 people, mostly Māori, marching onto Parliament grounds on 5 May 2004. The political significance of the hīkoi was such that Harris argues it became a profound example of Māori "transcending tribal differences" and highlighted the powerful and unifying effect of shared issues as the "footfalls of Māori activism continue to imprint society and politics - ake ake ake" (2004:151). The hīkoi is one powerful example of resistance, and there are countless more. Resistance is an ongoing process; it is not static or discrete, nor is it confined to the realm of visible, organised (or disorganised) protest and activism, nor what the media chooses to present. Resistance is carried out in everyday lives, through as Certeau (1984) describes "acts of making do", shaping and reshaping power relations. Smith (2006) builds on this idea of resistance within the context of unequal power relations and summarises the lessons learnt by Māori as a result of neoliberal reforms. She argues:

"Māori communities can be active agents of, and partners in, change processes. Engagement and participation has been contentious, disappointing, frustrating and tiring. However, engagement has also been worthwhile because gains can still be made. It is always about compromise in the context of unequal power relations." (2006:258)

Significant challenges are presented by the neo-liberal political economy in the context of educational inequalities and in the establishment of a quasi market education system. The literature shows how the neo-liberal political economy and global financial recession have resulted in unprecedented levels of Māori hardship, poverty and inequalities across a range of social, economic and educational indices. Transformative solutions which include structural responses aimed at disrupting unequal power relations and the structures that perpetuate, reproduce and maintain the status quo are needed now more than ever. 


\section{Social Class-Related Research in Aotearoa New Zealand}

Despite resistance to a class-based identity, New Zealand is nevertheless a society with deep divisions and inequalities. Social class has been used to understand and theorise educational inequalities by a number of ley educationalists which include Peter Ramsay, Eric Braithwaite, Mark Olssen and Colin Lankshear. In these studies structural explanations are prioritised over cultural explanations.

Peter Ramsay's research into social transformation, reproduction and the role schools play in such processes in the context of working-class schools in New Zealand is a key foundational text. Ramsay argued New Zealanders believe class (particularly when depicted in Marxist terms) is an alien concept imported by foreign academics and trade unionists. He attributes this to why so many in his research sample were able to talk about ethnic oppression, but not class oppression, despite the fact that "New Zealand without question is increasingly a class based society" (1983:314). An important point to take from his thesis is how the touchstone of transformation in New Zealand is ethnicity and its relationship to class. Thus, the relevance and impact of social class in everyday lives is more often than not masked by ethnic-based discussions.

Colin Lankshear's research on language and literacy (reading and writing) was innovative because he looked at the concept of freedom as liberation (as espoused by Paulo Freire) in relation to literacy, schooling and revolutionary change (Lankshear, 1987). Transformation was at the heart of this work and resulted in the emergence of a 'new literacy' with the advent of digital technologies and the internet. A key focus was on how these literacies could be adapted and adopted by educators to create change in the schooling system.

Esteemed scholar Mark Olssen's research on higher education policy and political philosophy is world renowned. He is deeply critical of outdated political philosophies, including Marxism, and argues new philosophies are needed to address $21^{\text {st }}$-century problems. Olssen views education as the essential ingredient in building nation states to respond to the forces of globalisation and neo-liberalism 
which he claims are direct threats to community and democracy (Olssen, Codd and O’Neil, 2004).

Two landmark studies focused specifically on social class in Aotearoa New Zealand are the Christchurch School Leavers Survey (see Lauder and Hughes, 1990) and the Smithfield Project (see Lauder et al., 1999). The Christchurch Leavers Survey focused on measuring academic ability, success in secondary school examinations and the occupational destinations of 2,500 Christchurch school leavers in 1982. The survey collected data on the students' socioeconomic background based on the Elley Irving Scale of socioeconomic status (SES) to test the meritocratic thesis that those of equal measured ability have equal life chances regardless of social background. The survey evidence showed a strong association between SES and school success, that the association is independent of possible differences in ability, and there is a similar association between SES and post-school destination. In other words, there is a strong association between social class and educational and occupational outcomes. The survey found that most school leavers from upperclass families went to upper-class destinations and most school leavers from working-class families went to working-class destinations. The key conclusion reached was that social class has a major impact on school performance and subsequent occupational destinations (Lauder and Hughes, 1990a).

The Smithfield Project (Lauder et al., 1999) examined the nature, operation and effects of school markets in two large cities. The findings showed that the education market increased the likelihood of middle-class children attending successful schools, because they have greater resources and are able to exploit the market to their own advantage (1999:126). Overall, the study concluded that the tactics used by middle-class parents show that "education markets serve to exacerbate the exclusion of working class and Māori students" (1999:135) and thus benefit the middle class.

Nash and Harker $(1992,1997)$ have also undertaken significant research in this area. Most notable are two projects: Access and Opportunity Project and Progress at School Project. Based on their analyses of the household survey component of the project, which included a sample of 1,400 families, including children aged 5-15 
years, they analysed the relationship between cultural capital and Progressive Achievement Test (PAT) reading comprehension scores. They argue that it is 'material resources' that should be seen as the effective cause of socially differentiated educational performance (1992:19). Furthermore, they suggest the family is the "potent agent in the generation of social differences in education" (1992:3) and that parental expectations are class-specific. For example, a workingclass parent might dream for their child to be a doctor, but this dream is mitigated and to a large extent restricted by the material resources at their disposal.

Nash and Harker (1992) conclude that, given the limited material resources working-class families have, they cannot compete with the superior resources of the middle class, and therefore any changes to the educational system itself would be superfluous. Put in this context they state "working class parents might be thought to do rather well for their children" (1992:18).

Wylie (1988) looked at how unfair the education system is in terms of educational outcomes or achievement. Like Lauder et al., she used socioeconomic status (SES) rather than social class as a term to categorise students and analysed 10 years of achievement data from 1978 onwards. The overall finding was that the school system was unfair in terms of outcomes to approximately 60 percent of the student population. This 60 percent comprised Māori, girls and women; students from lowsocioeconomic status homes; Pasifika; other ethnic minorities; the disabled; and rural dwellers. Because Māori fit into more than one of these categories, they are not surprisingly over-represented in this marginalised group.

Brosnan (1987) conducted research into the nature of the Aotearoa New Zealand occupational structure and the position of Māori within it in what is one of the few Māori-focused, class-related pieces of research. He analysed and compared data related to the shifts in the occupational structure base from 1956 to 1981 and identified a massive over-representation of Māori among blue-collar workers, i.e. manual and low-skilled labourers. He describes the blue-collar workers as prime recruits for an underclass characterised by "a lack of resources, near or total powerlessness, and little upward social mobility" (1987:47). Brosnan's data showed there had been little upward mobility for Māori and concludes that the large 
concentration of Māori in manual work is not only a huge waste of talent, but totally unacceptable (1987:55). While the data is somewhat dated and the nature of the occupational structure has changed significantly today, more recent labour market data indicates little has changed with Māori still over-represented in manual, lowskilled occupations (Department of Labour, 2009; Te Puni Kōkiri, 2009c).

A study conducted by Marie, Fergusson and Boden (2008) investigated the roles of Māori cultural identity and socioeconomic status on Māori educational outcomes by analysing 25 years of longitudinal data from the Christchurch Health and Development Survey. Based on a mixed method approach, their findings suggest that Māori educational underachievement can largely be explained by disparities in "socio economic status during childhood" (2008:183). They openly challenge the dominant view that educational disadvantage rests with cultural processes that are specific to Māori; rather they suggest the link between ethnicity and educational achievement is more a case of children from disadvantaged socioeconomic backgrounds doing less well in the context of the Aotearoa New Zealand education system. Furthermore, they argue that while a range of educational policy initiatives have been developed on the back of the cultural factors approach "there is little direct evidence to show that cultural factors directly contribute to Māori educational disadvantage" (2008:193). The caveats around this research are it is health-focused and specific to an urban setting with a relatively small Māori population. Furthermore, the research design and methods were not attuned to cultural difference or diversity and therefore the findings should be viewed with these insights in mind.

Two common features of the Aotearoa New Zealand-based, class-related studies are: a) small Māori sample sizes and b) a dearth in empirical research carried out by Māori academics. In short, there is an urgent need for increased Māori scholarship in this field. According to Thrupp (2007), social class is as relevant in contemporary Aotearoa New Zealand as it ever was, particularly for Māori:

“Māori are also part of the class structure and yet class doesn't get much mention in Māori discourses, yet both ethnic and class cultures count and hopefully one day when Māori are having to fight their corner less we will 
see work which can genuinely bring together theory and research across these two areas." (2007:79).

The reticence by Māori to engage in social class analysis has a historical underpinning. For example, early class writings focused on economic determinism, a school of thought which argued economic relations were the sole determinant of social relations. Moreover, race and gender perspectives were for the most part invisible in class analyses.

Nash (2010) argues wherever a group is colonised there are power relations and struggle, particularly within the context of education. These power relations are embroiled, cultural, social and geographical. Social class therefore is not just about education and income, but a whole lot of factors involved in how one sees oneself and how others see one. As outlined in the Introduction chapter to this thesis, Poata-Smith (1996, 2004a, 2004b) is one of a handful of Māori scholars to talk about social class and offer critical analyses of culturalist-based perspectives and policies. Similarly, Rata (2005) and Strathdee (2013) are highly critical of ethnicitybased educational policies and the emergence of a neo-tribal elite.

\section{Summary}

The analysis of traditional Māori social structure and political economy shows a graduated system of hierarchy was firmly in place governed by whakapapa and tikanga and underpinned by Māori world views (epistemology) which sit at the heart of Māori culture. The system of hierarchy was based on whakapapa whereby status was attributed to āriki/rangatira (chiefly) and tohunga lines, while ware (commoner lines) and tūtūā held no status in traditional society. That said, traditional social structure was dynamic and fluid and adapted to the ever-changing social, political and environmental landscape on which Māori realities were lived. For example, food scarcity and population increases had a major influence on traditional social structure.

Traditional Māori political economy was a subsistence economy based around the seasons and the need to hunt, plant, harvest and store food for survival. Thus, 
social class in its purest form did not exist, but divisions in status largely determined by whakapapa were critical to social hierarchy and structure. The arrival of the first Pākehā settlers (pre-1860) resulted in the emergence of a shadow rural informal economy whereby Māori and Pākehā worked alongside each other and social relations were critical to its success.

From 1860 onwards the influx of European settlers and the imposition of a Pākehā political economy resulted in the emergence of a hybrid Māori political economy - a mix of formal Pākehā economy and the rural informal shadow economy. Thus, over time, as the effects of colonisation began to impact on every facet of Māori social, political and economic life, the relationship of Māori to the means of production within a newly formed capitalist society was significantly influenced by the racist colonial ideologies of the day (Jackson, 1997). While some Māori continued to successfully contribute and participate in the shadow rural economy, the majority were marginalised by the new formal economy.

Contemporary local research and scholarship reveals a paucity of Māori-focused materialist/class-based research. Few Māori academics venture into the realm of materialism-based explanations for social inequalities. Rather, explanations are dominated by culture-based theories and approaches. Those who do provide materialist explanations offer important insights into the complex intersection between class, race/ethnicity and social inequalities. 


\section{CHAPTER FIVE: METHODOLOGY}

\section{Introduction}

This chapter outlines how the research was carried out, the methods used to collect data and how the data was analysed and interpreted. My intent is to show how my conceptual positioning informed every aspect of this research study - the choices made and the rationale for these. In particular I will outline how kaupapa Māori research principles and ethics were used and how important this was in terms of creating the space to capture rich and authentic narratives from the research participants.

\section{Qualitative Mixed Methods Research}

This research is qualitative. According to Strauss and Corbin (1990), qualitative research seeks to understand peoples' lives, behaviours, stories, experiences and world views, as well as the ways organisations function, social movements operate, but perhaps more importantly the interactional relationships between all of these. This focus on relationships, lived experiences and realities (Maxwell, 2005) appealed and was considered the best fit for what I wanted to achieve in this research, namely, to use a research approach which illuminated contemporary Māori experiences of and perspectives on transformation and social class using the participants' life-worlds, realities and voices (Phillips, 2003; Lather, 2006; Lawson and Garrod, 1994). A mixed-methods research design was used (Creswell, 2009; David and Sutton, 2004) and data was collected through two sources. First, relevant quantitative and qualitative documents were reviewed and, second, semi-structured interviews were carried out with key informants. An in-depth discussion on each method is provided from page 114 onwards. 


\section{Participant Selection}

This research thesis is focused on higher education and transformation. Thus, being highly educated was the key indicator to select participants and was defined as 'having a postgraduate diploma or certificate, honours, master's or doctorate degrees and/or a professional degree to account for Māori professionals such as health professionals, lawyers, scientists and accountants who may not have a postgraduate qualification'. Accordingly, the two key selection criteria were:

1. Māori whakapapa (participants self-identify as Māori); and

2. Highly educated (participants have a postgraduate qualification or higher and/or a professional degree).

Five sub-criteria were also used based on a need to capture a diverse range of highly educated Māori who represented a) a mix of rural and urban communities, b) public and private sector employment, c) occupations, d) ages and e) gender balance.

\section{Quantifying the Target Cohort}

According to Statistics New Zealand (2007), the highest qualifications reported by Māori in the 2006 census were:

- 2,535 (0.8 percent) had postgraduate and honours degrees;

- 2,241 (0.7 percent) had master's degrees; and

- 387 (0.1 percent) had doctorate degrees.

Therefore, the total number of Māori with a postgraduate qualification or higher is 4,963 representing 1.6 percent of the total Māori population. 
Quantifying the number of Māori with professional degrees is problematic because occupational statistics are not classified by individual occupations, such as lawyers, medical doctors and accountants. Rather, Statistics New Zealand classifies occupations according to industry and occupation using the Australia and New Zealand Standard Classification of Occupations (ANZSCO). The occupation classification system is based on nine key high-level occupation groups (Statistics New Zealand, 2009b). According to Statistics New Zealand's descriptors, two of these high-level groups, Legislators, Administrators and Managers and Professionals comprise highly skilled jobs carried out by people who have a bachelor's degree as a minimum qualification (Ibid).

Labour market statistics produced in 2009 showed that 8.3 percent $(23,705)$ of the total Māori labour force population $(285,600)$ is classified in the Legislators, Administrators and Managers occupation group, and 11.5 percent $(32,844)$ are in the Professionals group (Department of Labour, 2009). Interestingly, there has been significant growth (almost 4 percent) in Māori employment in higher-skilled occupations over the past 5 years. While this classification system provides highlevel data and gives a sense of the total Māori cohort in highly skilled occupations $(56,549)$, it is not particularly useful in terms of identifying those members with postgraduate qualifications or higher and/or professional qualifications.

Statistics from key professional associations and societies were collected as indicative data. For example, the Māori Law Society website stated it represented the interests of over 350 practising Māori lawyers in New Zealand (Te Huinga Roia Māori, 2010). This figure will not account for all Māori lawyers, practising and nonpractising, in New Zealand, but provided a starting point.

According to the most recent regulated Māori health workforce statistics, in 2008 there were 4,136 Māori active in a range of occupations including Medical Practitioners - Registered Doctors, Nurses, Midwives; Physiotherapists and Psychologists, to name but a few (Ministry of Health, 2010). Meanwhile, according to the National Māori Accountants (Ngā Kaitatau Māori o Aotearoa, 2007) homepage, it represents over 150 individual members. 
The indicative data suggested the following approximate numbers:

- Māori Lawyers (350);

- Māori Health Professionals (4,136); and

- Māori Accountants (150).

There were potentially between 4,600 and 5,000 Māori in the professional degrees cohort which, combined with the Māori with the postgraduate qualifications, honours, master's or doctorate degree cohort outlined on page 109, equated to a target population of approximately 10,000 people.

\section{Accessing the Target Cohort}

It was originally intended that a multistage procedure would be used to target relevant groups or organisations that hold Māori graduate data as a conduit to contacting Māori graduates. However, after discussions with representatives from relevant institutions and agencies including Ngā Pae o te Maramatanga (Centre of Research Excellence), the New Zealand Vice-Chancellor's Committee, Ministry of Education and Te Puni Kōkiri (Ministry of Māori Development), it was decided this approach would be time-intensive with little to no guarantee of success. Moreover, relevant professional and academic support groups and networks such as the MAI network (national support network for Māori PhD students) and Pūkenga Tukutuku (Māori scholar network) and MANU AO (Māori Academic Network) were unable to act as a conduit due to Privacy Act restrictions. In addition, the administrator of the New Zealand Educational Theses (NZET) Database was contacted to find out whether information about the ethnicity of authors is captured - it was thought that the database may provide a potential vehicle for accessing a random pool of Māori graduates. Unfortunately, however, the administrator advised that this information was not provided by the institutions that submitted theses. Thus, purposeful sampling (Marshall, 1996) was used to access the target cohort. 


\section{Purposeful Sampling}

According to Patton (1990), purposeful sampling is designed to locate informationrich key informants and starts by asking well-positioned people, who know a lot about topic xyz? Who should I talk to about topic xyz? (1990:176). There are about 16 different types of purposeful sampling and for this research 'snowball sampling' or what I refer to as 'kumara-vine sampling' was used. Kumara vine refers to the colloquial expression Māori use when talking about sharing or spreading news through their networks, similar to the phrase 'grape vine'. This sampling type appealed because it provided the space to draw on a large pool of professional and personal networks: my own, my two supervisors' and those of my initial participants.

The initial participant list comprised 50 names. This list was whittled down to 35 as I worked with my supervisors to achieve a balance of participants using the selection criteria. The participant list was amended as initial participants were interviewed and asked to suggest other people who might a) be interested in the research topic and b) provide an interesting or unique perspective. About a third of participants (10 people) were recruited using this technique. Another point to consider was how to mitigate the academic and educational bias of my supervisors and myself. Thus a conscious decision was made to find Māori working and living in spheres outside 'the norm'. The goal was to interview a sample of 30 participants who fulfilled the requirements of the selection criteria as well as being manageable in terms of time and resources, rather than selecting a representative sample size. To this end, 30 Māori with diverse higher education and professional qualifications and from a variety of backgrounds and professions were interviewed.

\section{Higher Education - One Indicator of the 'Middle Class'}

While targeting the middle class was not the focus of this research, education credentials are one of three key indicators used to measure social class. The literature tells us that education, occupation and income are three key determinants of the middle class (Nash, 2010). The Elley Irving (EI) scale of socioeconomic status (SES) is the traditional measure of class used in New Zealand. Based on census data, the scale proposed six social strata based on 1) education, 2) income and grouped by 3) occupation (Elley and Irving, 1972). Davis, Mcleod, Ransom and 
Ongley (1997) built on the Elley Irving scale and proposed the New Zealand Socioeconomic Index of Occupational Status (NZSEI) - a linear scale of ranked occupation based on age, income and education aggregated into six discrete groupings known as socioeconomic status (SES). The Elley Irving Scale and the NZSEI are two standard measures of SES which are used as proxy measures for social class in New Zealand.

Although precise definitions of 'middle class' are blurred, in addition to standard measures of class like El and NZSEI scales, there is a general consensus about common middle-class characteristics. For example, middle-class people commonly have a comfortable standard of living, significant economic security, considerable work autonomy and rely on their expertise to sustain themselves (Gilbert, 1998). Moreover, contemporary research on Māori identities has been extended to create space for an emerging middle class. For example, Cunningham, Stevenson and Tassell (2005) identified four types of Māori identities based on data collected from the Te Hoe Nuku Roa longitudinal study. The identity types are: conservative, integrated, pluralistic and isolated. The pluralistic category was created specifically to capture the identities of the emerging Māori middle class, which they describe as "a group comfortable in both mainstream New Zealand and the Māori world and importantly a group whose outcomes are relatively better than many of their Māori and Pākehā peers" (Cunningham et al., 2005).

The point of this discussion was to highlight how, although traditional measures of social class i.e. EI and NZSEI scales were not used to select the research cohort, the focus on higher education credentials meant the majority of participants were well paid and in higher status occupations and therefore might be thought of as having a high level of socioeconomic status and, by proxy, be part of the emergent Māori middle class.

\section{Research Methods}

The data for the proposed research was collected using two methods:

- Document Review (quantitative data); and 
- Semi-Structured Interviews.

The rationale behind and how each method was applied is briefly explained below.

\section{Document Review}

A review of relevant descriptive statistical data, beyond what was captured in the initial literature review, was carried out to ensure the qualitative data was augmented by statistical evidence and to inform the development of the interview schedule. The following frameworks, indexes and surveys were reviewed:

- New Zealand Socio Economic Index - NZSEI (Davis et al, 1997);

- Elley Irving Scale (Elley and Irving, 1976);

- New Zealand Household Labour Force Survey (HLFS); and

- Social Inequality in New Zealand: International Social Survey Programme.

Additional statistical reports were sourced from Te Puni Kōkiri, Statistics New Zealand, Massey University (1999, 2010), Ministry of Education, Department of Labour, Ministry of Social Development, New Zealand Vice-Chancellor's Committee (2008), OECD and United Nations. The reports provided the empirical evidence that informed my own understanding of the capitalist economic system from a political, national and global perspective and helped shape the economic context within which this research is located.

\section{Semi-Structured Interviews}

Semi-structured interviews were selected as the data collection method because they provided a balance of flexibility and structure, a happy medium between structured and unstructured interviews (Patton, 2002). For example, the semistructured interviews provided a level of flexibility which allowed me as the interviewer to be less concerned with the order topics were covered, and provided 
the interviewees the space to explore thoughts and ideas they considered important within the context of the discussion (Creswell, 2009). The intent was to provide a safe space for participants to openly share their life stories, life-worlds and aspirations for the future. This demanded a level of trust on both sides based on a clear understanding of what was expected of the participants, how their stories would be used and in turn what they could expect from me as the interviewer.

While the initial intent was to have a conversation with my participants based on my interview schedule, but guided by their rhythm and points of interest uninhibited by structure and order, I recognised the need to respect and acknowledge the mana and authority of my participants by treating the interview process with due respect and professionalism. In the context of my research, this meant privileging and elevating the interview process above a normal everyday conversation and forced me to lift my game in terms of both planning and preparation. At times this was extremely difficult because of the existing relationships I had with many of the participants. More often than not, the time before the interview and after involved a lot of 'catch up'. Silverman (2000) argues how interviews and conversations are similar in many ways, but there are distinct differences. For example, an interview is based on a set of assumptions and understandings about the context and situation which are not normally associated with a casual conversation. Similarly, Denscombe (2003) highlights three key differences between the interview and a conversation. First, participants consent to be part of the interview. Second, their words are officially 'on the record', and third, the agenda for the discussion is set by the researcher (2003:164). Denscombe warns the superficial similarity between an interview and a conversation can generate an illusion of simplicity, fraught with hidden dangers. To counter these challenges, he recommends good planning, proper preparation and sensitivity to the complex nature of interaction during the interview itself (lbid).

\section{Logistics and Planning}

The semi-structured interviews therefore involved careful practical and logistical planning, for example, confirmation and reminder emails were sent to participants with interview dates and times and venue details; interview schedules were sent 
prior to the interview when requested by participants (NB: only a few participants requested a copy of the schedule prior to the interview and it was my preference not to provide the schedule because I did not want to pre-empt the discussions and disrupt the natural flow of conversation). A series of 31 semi-structured interviews were carried out with a purposeful sample of the Māori middle class. The target was to carry out 30 interviews; however, an additional interview was required because it was discovered at the end of one interview that a participant had not fully completed their postgraduate studies and therefore did not fit the selection criteria for the target cohort.

\section{Relationships and Participants Recruitment}

Participants were invited to participate in the research using a range of media, including social networking website facebook, email and face-to-face interactions. In particular, facebook provided a useful and less formal medium for making contact with potential participants, many of whom I already had an existing relationship with, and also helped garner interest in the research. Facebook was used to make initial contact with just over 25 percent of my participants. Relationships played a critical role in participant recruitment and coordination. I was overwhelmed by the speed at and ease with which I was able to reach agreement and organise interviews, particularly given the extremely busy lives the participants lead. For example, within one week of contacting my first phase of participants, I had confirmed and organised my first 10 interviews. I am confident that in the absence of existing relationships this process would have taken longer, but also acknowledge the research topic probably sparked a level of curiosity and intrigue among participants.

\section{Pilot Interviews}

Two pilot interviews were carried out to test the flow, rigour and timeliness of the interview schedule. This practice proved invaluable and changes were made to the interview schedule based on participant feedback to improve flow and clarity. The pilot interviews also provided an opportunity to have my interviewing skills critiqued and I am indebted to the pilot participants for their free and frank comments about my initial interviewing shortcomings. In particular, the art of pausing and avoiding talking over the top of interviewees were two areas identified for improvement. The 
first phase of participants demonstrated a level of patience and wherewithal for which I am extremely grateful.

\section{Interview Timelines and Locations}

The 30 interviews were carried out in three phases over a period of 4 months starting in February and ending in May 2011. A total of four interviews in Christchurch were rescheduled due to the tragic Canterbury earthquake which struck the week before interviews were planned. Fortunately, all four participants were unharmed and two interviews were rescheduled in Wellington. The other two participants remained in Christchurch and were understandably focused on getting their lives and whānau back in order, so the decision was made to seek other participants to replace them. The interviews were conducted at either the participant's place of occupation or their home. A total of 17 interviews were carried out at the participants' home, three interviews at an office space on papakāinga and ten interviews at the participants' place of occupation, usually an urban office space.

The high number of home-based interviews posed many practical challenges. For example, background noise had to be managed as best as possible. Moreover interruptions from whānau, tamariki and mokopuna added another dimension to the interviews. These occurrences were part of the lived context of participants and fortunately sound quality was not compromised. The other interesting difference between the home- and work-based interviews was the level of formality in terms of dress and setting. Participants interviewed at work were dressed in business attire and the majority interviewed during their lunch break in a conference or meeting room. These participants appeared to be focused and attuned to the interview and were keen to contribute as much as they could within their available timeframe. Interestingly, all of the work-based interviews ran well over the allotted time. Conversely, those at home were dressed casually and interviewed throughout the day - mornings, lunchtimes and early evenings - in a range of locations including the dining room, study, lounge, spare room, deck, lawn or front yard. Not surprisingly, these interviews were more relaxed and casual. 


\section{Three-Phase Approach to Interviews}

The initial phase of interviews was carried out during February and March 2011 and encompassed participants living across the greater Wellington region from Wellington City, Titahi Bay and Horowhenua. The first interview was conducted on a farm on the outskirts of Levin (a town in the Horowhenua district) with the eldest of the research cohort, a native te reo speaker, proficient in tikanga and mātauranga. This seminal interview set the tone and tikanga for the succeeding interviews, and it is only in hindsight that I recognise how fortuitous and privileged I was to begin the data collection phase this way, guided by a humble, knowledgeable and humorous man. The tikanga (process) set down that day was as follows: we began with a whakatau (informal welcome), mihimihi (sharing of pēpeha), kōrero (interview), kai (shared food), kōrero (interview) and mihi whakamutunga (farewell and closing words). This tikanga provided the blueprint for how all other interviews were conducted. The second phase of interviews involved travel to Hāwera, Hawkes Bay and Ōhākune as well as further interviews in Wellington City. The third and final phase was carried out in Auckland, Lower Hutt, Ōtaki, Paekākāriki and the final interview in Waikanae. The targeted communities and number of interviews carried out in each community are highlighted in the table below.

Table 1: Participant Interview Locations and Number of Interviews

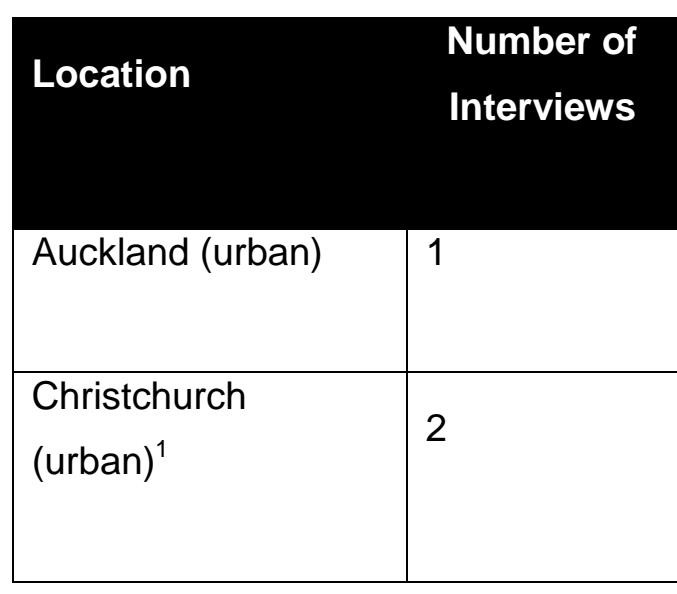

\footnotetext{
${ }^{1}$ Conducted in Wellington
} 


\begin{tabular}{|l|l|}
\hline $\begin{array}{l}\text { Horowhenua (semi- } \\
\text { rural) }\end{array}$ & 1 \\
\hline $\begin{array}{l}\text { Napier/Hastings } \\
\text { (urban) }\end{array}$ & 4 \\
\hline North Shore (urban) & 1 \\
\hline $\begin{array}{l}\text { Oeo/Hāwera } \\
\text { rural/papakāinga) }\end{array}$ & 4 \\
\hline $\begin{array}{l}\text { Ōhākune (urban) } \\
\text { (urban) }\end{array}$ & 2 \\
\hline Ōtaki (semi-urban) & 1 \\
\hline $\begin{array}{l}\text { Paekākāriki (semi- } \\
\text { urban) }\end{array}$ & 1 \\
\hline Petone (urban) & 1 \\
\hline Waikanae (urban) & 1 \\
\hline
\end{tabular}

Refer to Appendix A for a copy of the interview schedule.

\section{Participant Demographic Statistics}

This section presents a broad range of participant demographic statistics designed to provide a general overview of key statistics. Given the small sample size (30 
participants), cross-analysis of different variables is not viable; however, a more comprehensive qualitative-based participant matrix is outlined in Chapter 6.

\section{Age Range}

Participant ages ranged from 25 to 46 years, with almost two-thirds aged between 35 and 44 years old.

Table 2: Participant Age Range

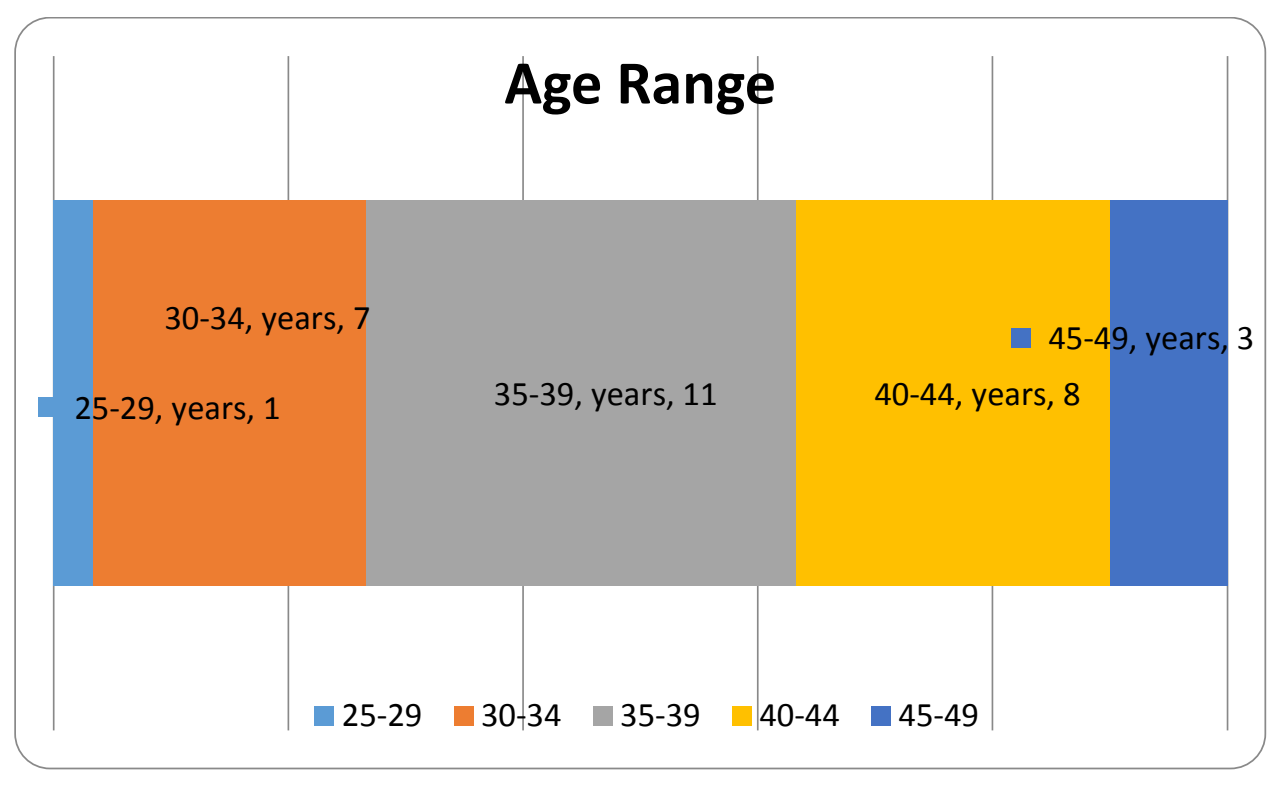

\section{Participants' Qualifications}

As per the participant selection criteria, participants were highly qualified, with over one-third holding a master's degree or higher as their highest qualification.

Table 3: Participant Highest Qualification

\begin{tabular}{|l|l|}
\hline Qualification & Participant(s) \\
\hline $\begin{array}{l}\text { MD - Doctor of } \\
\text { Medicine }\end{array}$ & 1 \\
\hline
\end{tabular}




\begin{tabular}{|l|l|}
\hline $\begin{array}{l}\text { PhD - Doctor of } \\
\text { Philosophy }\end{array}$ & 2 \\
\hline Master's Degree & 9 \\
\hline $\begin{array}{l}\text { LLB/Barrister and } \\
\text { Solicitor of the } \\
\text { Zealand Court of New }\end{array}$ & 5 \\
\hline LLB & 2 \\
\hline Honours & 7 \\
\hline PG Diploma & 4 \\
\hline
\end{tabular}

\section{Participants' Occupations}

Participants are currently employed in a range of occupations in the public and private sector. One-third is self-employed. Most occupations are within kaupapa Māori organisations or are Māori-specific roles. One participant was taking time out from her business development career in the private sector to be a home-maker.

Table 4: Participant Occupations and Sector

\begin{tabular}{|c|c|c|}
\hline Public Sector & Private Sector & Self-employed \\
\hline $\begin{array}{l}\text { Chief Executive Officer } \\
\text { (Iwi Rūnanga) }\end{array}$ & Associate (Law Firm) & $\begin{array}{l}\text { Contractor (Social Policy } \\
\text { and Research) }\end{array}$ \\
\hline $\begin{array}{l}\text { General Practitioner (Iwi } \\
\text { Health Service) }\end{array}$ & $\begin{array}{l}\text { Chartered Accountant } \\
\text { (Private Business) }\end{array}$ & $\begin{array}{l}\text { Contractor (Local Govt, } \\
\text { Policy and Research) }\end{array}$ \\
\hline
\end{tabular}




\begin{tabular}{|c|c|c|}
\hline $\begin{array}{l}\text { GIS Technician (Crown } \\
\text { Entity) }\end{array}$ & Partner (Law Firm) & $\begin{array}{l}\text { Contractor (Television \& } \\
\text { Iwi) }\end{array}$ \\
\hline $\begin{array}{l}\text { Lecturer - Creative Arts } \\
\text { (University) }\end{array}$ & $\begin{array}{l}\text { Project Manager (Iwi } \\
\text { Trust) }\end{array}$ & $\begin{array}{l}\text { Director (Kaupapa Māori } \\
\text { Research and Strategy) }\end{array}$ \\
\hline $\begin{array}{l}\text { Liaison Officer - Māori } \\
\text { (University) }\end{array}$ & $\begin{array}{l}\text { Senior Manager } \\
\text { (Accounting Firm) } \times 2\end{array}$ & $\begin{array}{l}\text { Contractor (Public Health } \\
\text { Research) }\end{array}$ \\
\hline $\begin{array}{l}\text { Manager (Regional Sports } \\
\text { Trust) }\end{array}$ & $\begin{array}{l}\text { Senior Consultant (Māori } \\
\text { Business) }\end{array}$ & Contractor (Health Sector) \\
\hline $\begin{array}{l}\text { Researcher - Māori } \\
\text { Health (University) }\end{array}$ & & Director (Evaluation) \\
\hline $\begin{array}{l}\text { Researcher - Māori } \\
\text { Development (University) }\end{array}$ & & $\begin{array}{l}\text { Director (Māori Language } \\
\text { and Education) }\end{array}$ \\
\hline $\begin{array}{l}\text { Secondary Teacher } \\
\text { (Māori Boarding School) }\end{array}$ & & Home-maker \\
\hline $\begin{array}{l}\text { Scientist - Marine Biology } \\
\text { (Crown Institute) }\end{array}$ & & $\begin{array}{l}\text { Managing Director (Māori } \\
\text { Language and Education) }\end{array}$ \\
\hline $\begin{array}{l}\text { Senior Lecturer - Māori } \\
\text { Environmental Planning } \\
\text { (University) }\end{array}$ & & \\
\hline $\begin{array}{l}\text { Senior Manager } \\
\text { (Wānanga) }\end{array}$ & & \\
\hline
\end{tabular}




\begin{tabular}{|l|l|l|}
\hline Senior Policy Analyst - & & \\
Māori Language (Govt & & \\
Dept) & & \\
\end{tabular}

\section{Participants' Gross Annual Income}

Over two-thirds of participants earn more than $\$ 80,000$ gross annual income. Of these, one-third earns more than $\$ 100,000$ per annum.

Table 5: Participant Gross Annual Income

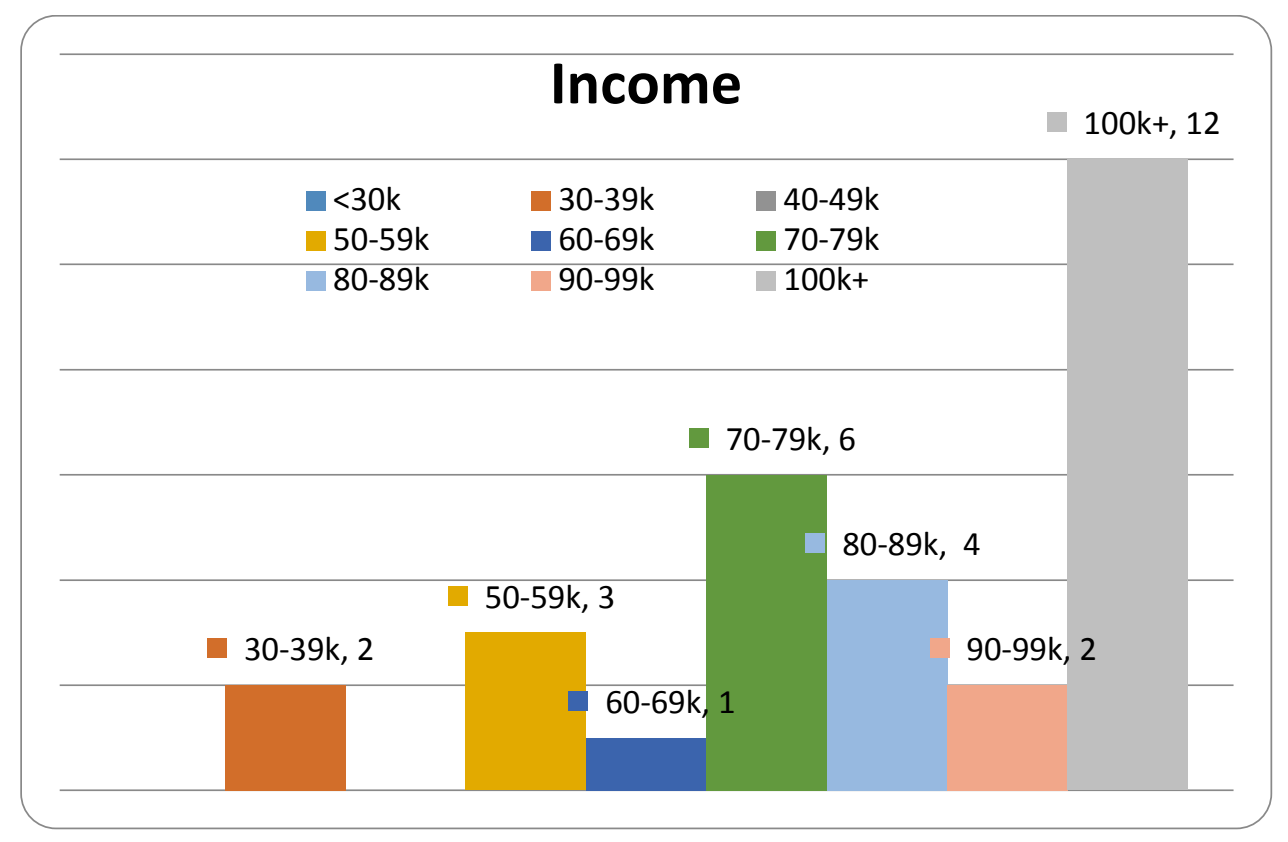

\section{Reo Proficiency}

Participants were asked to self-rate their reo proficiency. One-third rated as proficient or higher. The majority, however, rated themselves as intermediate. 
Table 6: Self-rated Reo Proficiency

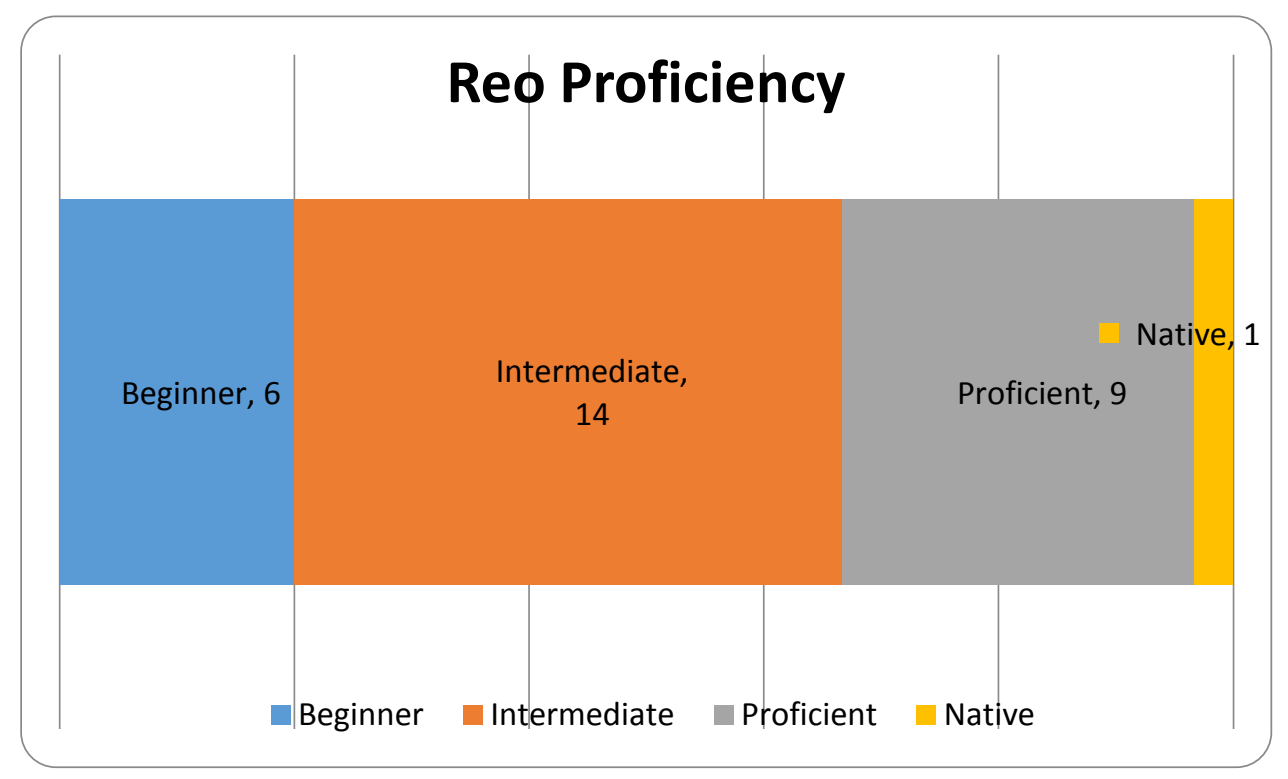

\section{Children and Dependants}

Over two-thirds of participants had children/dependants. Of these, almost half had three or more children/dependants.

Table 7: Number of Children/Dependants

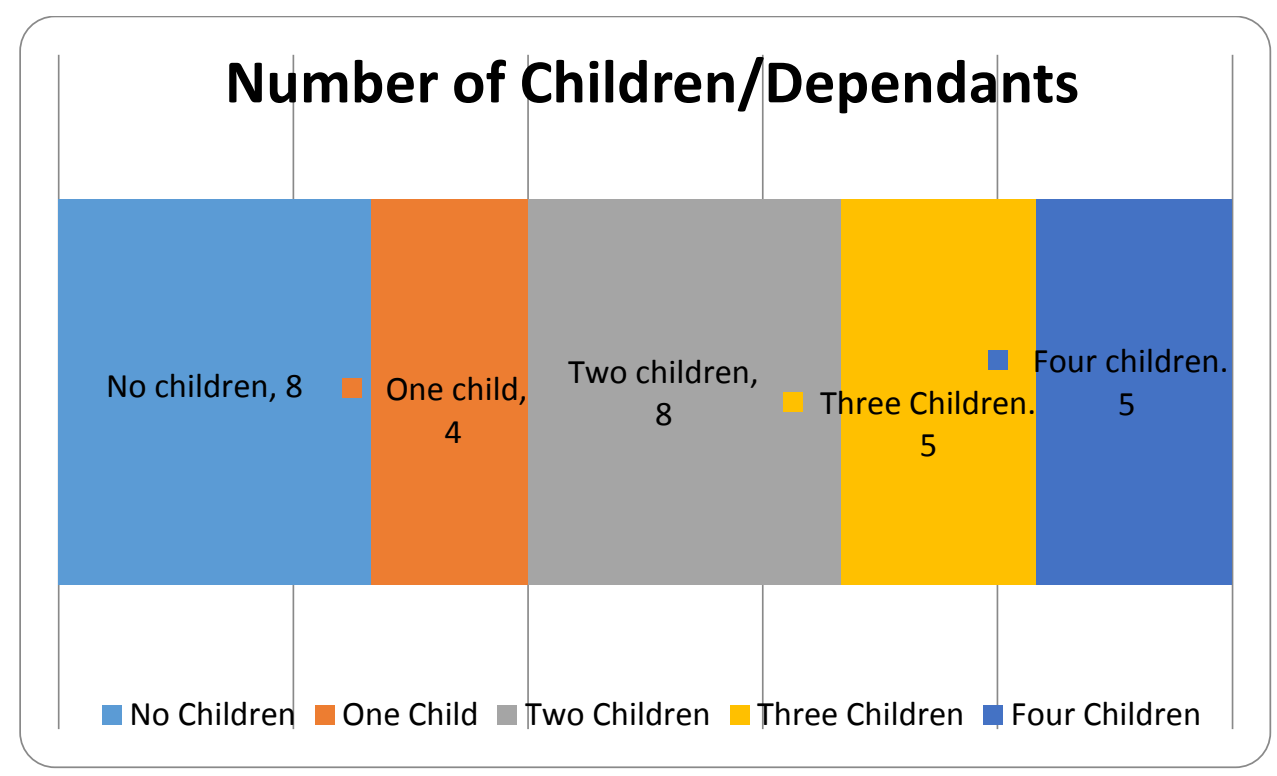


In summary, the key points to note are that this cohort is highly qualified, earn relatively high incomes, work in a variety of public and private sector jobs which are Māori-focused or involve some degree of engagement with Māori, and have a relatively high level of proficiency in te reo.

\section{Kaupapa Māori Research Principles}

The research practice was guided by a set of five principles commonly referred to as 'kaupapa Māori' principles. This was a logical choice given that kaupapa Māori is the heart of my theoretical framework and therefore shapes, informs and weaves throughout this research endeavour.

The five principles were:

- Tikanga;

- Whakawhanaungatanga;

- Manaakitanga;

- Mana; and

- He Kanohi Kitea.

\section{Tikanga}

Tikanga refers to guidelines around what is 'right'. It can also be described as rules, methods, approaches, customs, habits, rights, authority and control (Pere, 1988). Tikanga gives clear cultural guidelines about how we treat each other (Mead, 2003). In practical terms it meant that certain processes were followed when conducting the interviews. For example, a mihimihi (greeting) was shared with each participant and I explained who I am as the researcher, as well as my iwi affiliations in my pēpeha (self-introduction). Interestingly, this process revealed many previously unknown whakapapa connections with some of the participants and from the outset 
helped locate me as the researcher within a te ao Māori context. For those who wished, a karakia (prayer) was shared and at the end of each interview a brief mihi whakamutunga (final greeting) closed the interview process. Participants were offered the opportunity to speak in te reo and at times many participants used a mix of English and te reo. For the most part my te reo ability coped and I was able to engage, converse and understand what was being said. If I was unable to understand, I sought further clarification from the participant.

\section{Whakawhanaungatanga}

Described by Bishop (1998) as "the process of establishing whānau relationships, literally by means of identifying, through culturally appropriate means, your bodily linkage, your engagement, your connectedness, and therefore, an unspoken but implicit commitment to other people" (1988:203). The importance of whakawhanaungatanga cannot be overstated because it is the focus on relationships that is one of the key distinguishing features of kaupapa Māori research (Penetito, 2010b). I am connected to all participants either directly through my own whakapapa and networks, or indirectly through those of my supervisors. This connection runs far deeper than a standard researcher and participant type relationship, because within a kaupapa Māori context these relationships bestow on the researcher a cultural, moral, ethical and professional duty to tiakina (take care of) the knowledge participants have shared throughout all phases of the research process and beyond. In short, the relationships connect me to the participants and do not end simply because the research findings are disseminated (Pipi, Cram, Hawke et al., 2004). The relationships are enduring and therefore demand an open, honest, nurturing and caring approach.

\section{Manaakitanga}

This principle is about taking a collaborative approach to research and reinforces the view that research must be a reciprocal process (Bishop, 1996). It means that I acknowledged learning and expertise exists in both the research participants and me in equal measure. In practical terms this meant I tried to involve and engage the participants in the research project from the initial point of contact. For example, the initial invite was sent out with a full information sheet about the research inviting 
participants to ask questions, seek clarification or have a kōrero about the research. Many of the participants chose to do so and I had conversations with over half the research cohort via face-to-face contact, email or phone prior to the interview.

At each interview I took kai (food) - morning or afternoon tea, lunch or dessert - as a koha to participants. I wanted to give more, but my participants expressed thanks and gratitude for the opportunity to be interviewed. Many talked about how privileged they felt and others talked about how being interviewed was a novelty because in their line of work they were usually the interviewer or lead researcher. All participants were invited to review their transcripts for accuracy and provide feedback. A few chose to do so, but the majority emailed and advised they had no comments and were comfortable with the transcript.

\section{Mana}

I openly acknowledge my own biases as a Māori female researcher. I am conscious of the power and mana that holding a research position invokes and tried to mitigate this by engaging in a mana-enhancing process with my research participants whereby I respected and cared for their mana and at all times looked for ways to draw on this in positive and empowering ways. For example, during the interview process I tried to give participants the space to weave their own stories, placing them in a position of power and authority. This was a challenge, particularly in the earlier interviews when my interview technique was still developing. I quickly learnt to be comfortable with silences and extended pauses and resisted trying to fill the space with more talk and questions. I also learnt to roll with the flow of the kōrero and not to get caught up with trying to stick rigidly to my interview schedule and question order. Consequently, each interview took on a life of its own, with its own rhythm and beat. Some participants started at question one and catapulted ahead to talk about themes I wanted to cover in my final questions, while others wanted to get straight into talking about social class and transformation. This destroyed any preconceived notion I had that the transcripts would follow a tidy sequential order and therefore make sorting and coding a relatively straightforward and simple exercise. 
In a practical sense, this approach meant I carried a responsibility, commitment and obligation to do justice to the research participants' voices, to ensure the findings and analysis speak to their realities, and their voices were portrayed and represented authentically and accurately - as determined by them. This was a significant challenge particularly during the data analysis phase because I had to constantly check that I was not superimposing my own voice, values and ideas over the top of the participants' voices. My supervisors played an important role in reviewing the ways in which I coded, analysed and made sense of the data to be sure the authentic participant voice came through. This meant whole chunks of data from interview transcripts were analysed to provide a depth and richness of context, rather than cutting out pertinent sequences of narrative devoid of context (Czarniawska, 2004).

I also sent out a pānui (update) to the participants updating them on where the research process was at and presented some of the emerging findings for comment and feedback. I received mostly supportive comments, but also critical feedback, which I was pleased about. This feedback was incorporated into my analysis and emerging findings.

\section{He Kanohi Kitea}

According to kaupapa Māori methodologies the principle of 'He Kanohi Kitea' or engaging in face-to-face interactions with research participants is best (Cram and Pipi, 2000). All interviews were carried out in person, face to face and follow-up discussions were also held with a number of participants who were keen to hear about the research progress and emerging findings.

\section{Data Analysis}

The raw data included digital recordings of 30 semi-structured interviews, 30 interview transcripts, interview notes and interview reflections. All interviews were recorded digitally and interview notes were taken focused on background and contextual material, key points to emerge as well as gaps and weaknesses in the interview schedule. Interview reflections were also typed, focusing on how to improve my interview performance to ensure I was collecting substantive 
information to be able to answer my research questions. It was envisaged that the interviews would take no more than 60 minutes. However, on average, each interview was just over 90 minutes in duration.

I transcribed a total of 16 interviews and received a grant to pay for an external transcriber to finish the remaining 15 interviews. My supervisors encouraged me to transcribe as many interviews as possible within my allocated timeframe, and in hindsight I am grateful for this advice. The process was arduous and timeconsuming because of the interview durations, but rewarding in the sense that I got to know my data on a deeper level. Consequently, the transcription process is an integral part of my analysis and research methodology. This approach is supported by Riessman (1993) who suggested transcription is in itself a critical part of the data analysis process. To balance the analysis process, I also listened to digital recordings of the 15 interviews that I did not transcribe and took interview notes to supplement the interview transcripts. As part of my feedback process I sent a PhD update newsletter to participants in early November 2011 along with an invitation to peruse, review and confirm the interview transcripts. A total of five participants requested copies of transcripts. The transcription approval process was fully completed at the end of November 2011.

\section{Defining the Scope}

The sheer volume of data captured meant clear parameters were set to help cut extraneous themes, which were tagged and parked for future research, journal articles and presentations. The process of alignment involved an ongoing iterative process of reading, distillation and cross-referencing the data alongside the key themes and thesis statement to ensure sufficient data was collected to be able to answer the research question. Emergent research areas are presented in the final chapter of this thesis.

\section{Coding and Thematic Analysis}

Data was indexed in multiple ways to identify key themes. I chose thematic analysis because it was a method of analysis I was experienced in using and also because it provided a level of flexibility in that it is not tied to any existing theoretical 
frameworks, for example grounded theory (Glaser,1992), so it can be used within different theoretical frameworks (Braun and Clarke, 2006). This approach was considered a good fit in relation to my theoretical framework.

Boyatzis (1998) described thematic analysis as a method for identifying, analysing and reporting patterns or themes within data. According to Braun and Clarke (2006), however, thematic analysis is widely used, but more often than not poorly defined, in that there is no clear agreement about what it is and how you go about doing it. To this end, they developed a useful and practical six-phase process, underpinned by the literature, to guide researchers on how to do and use thematic analysis. Although intended to be sequential, the process was time-intensive and iterative. My supervisors had advised this was necessary and to be expected and encouraged me to get intimate with the data, to read, re-read and then read again, to look critically at the tensions and struggles inherent in the narratives, as well as the commonalities, contrasts and contradictions.

The six-phase iterative process of analysis used involved the following:

- Familiarising myself with the data: 16 transcripts were transcribed and 15 interviews were listened to. The transcripts were read, re-read, edited and formatted to ensure consistency in preparation for coding. Participants were also given pseudonyms.

- Generating initial codes: The transcripts were read and coded in a systematic fashion. For example, a set of high-level themes were identified and organised loosely around the broad thematic areas covered in the interview schedule, i.e. habitus, social class, education and transformation.

- Searching for themes: I used three criteria developed by Owen (1984) to identify the themes. First, recurrence: at least two threads of the discourse reflected the same thread of meaning even though different words might be used. Second, repetition: key words, sentences or phrases were repeated in at least two parts of the discourse and third, forcefulness: changes in 
volume, inflection, positioning, e.g. putting an idea as number one in a list, long pauses, introductory phrases or follow-up phrases e.g. "So what I really mean is..." or "That's what I think". Chunks of narrative relevant to each theme were identified, cut and pasted into analysis tables to ensure the rich context was not lost.

- Reviewing themes: The identified themes were checked in relation to the coded extracts (analysis tables) as well as the entire data set to generate a thematic map of analysis.

- Defining and naming themes: A process of ongoing analysis was carried out which involved reading and re-reading narratives to ensure the voices of the participants (in their narratives) were reflected in each theme. The specifics of the themes were fleshed out in relation to the overall analysis.

- Producing reports: A set of draft discussion papers were written based on the emerging themes from the narratives with links made to the literature. $A$ total of four papers were submitted to my supervisors for comment and review. As a result of the peer review process, the first and second level of themes were supported, challenged and critiqued and a third level of themes were also identified. The draft papers were edited based on the feedback from supervisors and used to inform various chapters of this research thesis. In addition, a set of writing conventions were developed based on the work of Nash (1997) to guide the presentation of narratives in a clear, coherent and consistent form.

As a result of this six-step thematic analysis process, a set of key findings emerged. These findings were refined based on a process of cross-referencing whereby the narratives were re-read alongside the key findings and the thesis statement to ensure coherency and authenticity. The findings were then presented to my supervisors for comment and review. 


\section{Ethics}

The research is framed within a kaupapa Māori methodology which has significant implications for the code of ethics that was followed in the development of this thesis. Ethics are implicitly related to a culture's values and beliefs and this cultural value set provides the lens through which ethical considerations are viewed (Hudson, 2004). For Māori, ethics are about tikanga (Mead, 2004). Therefore, tikanga provided the ethical framework within which this research was carried out. In practice this meant tikanga was used in a range of instances as outlined in the examples below.

\section{Whakamana i te tangata}

At times during the interviews I was privy to deeply personal and sensitive details about the research participants' lives and experiences. I was humbled that the participants trusted me enough to share such private details and therefore felt it important to make them feel safe. To this end I assured participants that all information provided was confidential to my supervisors and I, that their kōrero would be treated with respect, and that they were in control of the flow of the kōrero and could stop or change tack whenever they felt appropriate. Equally it was important that I kept myself safe throughout the interview process. This involved taking time out to reflect on each interview as well as saying a small karakia (prayer) at the beginning and end of each interview. What I found fascinating was that I thought I knew most of the participants in terms of who they are and where they come from, but this really was a superficial layer of knowing, and each interview revealed a deeper level of understanding about each person that humbled me to the point where I felt committed to protect and honour their mana and experiences shared with me.

Talking about success can sometimes be more difficult than talking about trials and tribulations, and the concept of 'whakahīhi' and the ideas encapsulated in the following whakataukī: 'Kāore te kumara e whakakī ana i tāna reka' - The kumara does not speak of its own sweetness - is applicable here. It is often difficult for people to talk about their own achievements, rewards and material wealth without being perceived to be arrogant and/or conceited. The important point to note was 
that at all times I tried to uplift and whakamana my participants by listening intently and providing a safe space for them to talk freely about their achievements. For some participants it was a struggle to talk about such things or if they did they tended to downplay such achievements. As an interviewer it was important to read the verbal and physical cues of participants, to learn when to push and when not to, to learn when to listen and when to dwell in the silence. In doing so, the interview process was a mutual process of respecting and uplifting mana.

\section{Whakawhanaungatanga}

The existing relationships and familial connections I had with most of the participants had significant implications on the research relationship particularly in terms of responsibility and power relations. I acknowledged both the 'insider' and 'outsider' position that I had with participants - the advantages and disadvantages of both positions are widely acknowledged (McNeill, 2008). For example, I did not assume that because I am Māori and had established relationships with most participants that I would automatically 'connect' and be viewed as an 'insider'. For some participants I was an insider because of my whakapapa (iwi, hapū, whānau), gender and/or current relationship, while for others I was an outsider. What was important was that I acknowledged the relationship and connected with each participant, stated clearly my responsibilities to them, and made space for a diversity of Māori experiences, identities, "contradictions, complexities and conundrums" (Webber, 2009:2) to emerge.

\section{Confidentiality}

During the research, confidentiality was tested because of the level of interest generated by the research topic as well as the relatively small nature of Māori networks and in particular the target cohort. This meant participants often asked who was being interviewed next or where I was travelling to next, or they mentioned they had bumped into so and so who said they were being interviewed. This is the nature of engaging in research with Māori and in particular a middle-class cohort. I was also privileged to interview two married couples, which was interesting and humorous on many levels, particularly in regard to their different responses to questions around career objectives, future aspirations for self, whānau and iwi. One 
participant, in humour, requested that his wife not be able to view his interview transcript. These issues were dealt with upfront and I explained that privacy and confidentiality prevented me from sharing who was involved in the research and that transcripts would only be sent to participants if requested.

\section{Cultural Advice}

Throughout the research process I drew on the expert cultural advice of my two supervisors, both of whom have a vast depth and breadth of research experience with Māori and within Māori communities. We would meet monthly kanohi ki te kanohi (face to face) as well as exchange papers, dialogue and discussion via email. The face-to-face meetings in particular were an integral part of the research endeavour. They provided me with a space to share ideas, thoughts, muses and frustrations, seek clarification and guidance and inspire and keep me moving forward with the research project.

\section{Informed Consent}

Informed consent was gained from all interview participants. Refer to Appendix B for a copy of the research information sheet and Appendix $C$ for a copy of the informed consent forms. Confidentiality of the information was maintained and the privacy of participants protected by maintaining anonymity throughout all phases of the research process.

\section{Limitations}

Two key limitations of this research study were:

- Participant selection criteria; and

- The exploratory nature of this study.

The first limitation of this research was the participant selection criteria, which was based on two key criteria: a) whakapapa or self-identifying as Māori and b) holding a postgraduate qualification and/or professional qualification. In addition, five 
secondary criteria were also applied to garner a diverse range of participants: a) location, b) occupation type, c) qualification type, d) age and e) gender. The two key criteria inevitably meant this research drew on a relatively small pool of Māori and when the secondary criteria is considered, that pool became even smaller.

Undoubtedly a Māori cohort exists that does not possess formal qualifications, but is successful in terms of income, occupation and career, and they are excluded from this research. Their journey would be an important and interesting research venture, particularly the focus on Māori entrepreneurship and making one's own way up the material wealth ladder without formal qualifications (see for example Mataira, 2000; Tapsell and Woods, 2008). This research, however, is concerned with the link between higher education success and transformation. To look at how higher education has the dual potential to create and inhibit transformation.

Moreover questions will be asked about the age range of participants and the rationale behind selecting participants aged between 25 and 50 years old. At the younger end of the scale the intent was to capture participants with at least a few years' experience in the workforce and not fresh university graduates, while at the older end, the intent was to include participants with many years ahead in their career and/or profession, in other words, people not in the twilight of their working lives.

The second limitation was the exploratory nature of this study. The original intent was for this research to be exploratory, but weighted more heavily towards an empirically based study, and therefore produce a more practically based research thesis. However, while the research is grounded in robust empirical evidence, the reality was that a significant chunk of theoretical groundwork needed to be covered and explored before the empirical research could take flight. This quite simply is what was needed in order to provide a strong theoretical foundation to help make sense of the data. Moreover, the exploratory nature of this topic reflected the paucity of locally based and indeed indigenous-based literature on contemporary perspectives on higher education, transformation and social class.

Therefore what is presented is a significant departure from the original intent in terms of scope and approach. 


\section{Summary}

This chapter has shown why I chose kaupapa Māori methodology, how this is coherent with the nature of the research thesis as described in the literature, and how I went about answering the research questions using a qualitative mixedmethod research approach based on document analysis and semi-structured interviews. In particular, kaupapa Māori research principles and ethics were critical to this research study because they helped to create the cultural and methodological 'space' to be able to build relationships and connect with the research participants and contribute to the overarching focus on transformation.

The importance of relationship building was fundamental to the entire research process and taking the time to do this allowed me to engage with participants in a way that was culturally safe for them as participants and me as a researcher. It also smoothed the pathway to plan, organise and carry out the interviews in a relatively short timeframe. The use of purposeful sampling or 'kumara-vine' sampling built on the strength of Māori networks and relationships across Aotearoa New Zealand and opened access to a range of diverse Māori outside of my existing professional and personal networks. This was invaluable and helped mitigate the potential academic and educationalist bias of the sample cohort.

Culturally based rituals of encounter and protocols, otherwise known as tikanga, were used to guide and contextualise the interviews within a Māori world view and provided the ethical framework for this research study. The use of tikanga involved exchanging mihimihi (initial greeting and thanks), pēpeha/whakapapa (genealogy and connections) and karakia (prayer). Enacting these rituals reminded both participants and me how we share a whakapapa connection to a collective history and ethos which spans hundreds of generations, and how important and relevant that knowledge is today. This kind of relationship invokes a level of responsibility on me as the researcher to respect, protect and honour the kōrero shared, because the relationships continue far beyond this research study. The next chapter presents the findings of this research study, based on the information captured using this methodology. The intent is to provide a rich authentic narrative account using the participants' own words. 


\section{CHAPTER SIX: FINDINGS}

\section{Introduction}

This chapter presents the findings that have emerged from the thematic analysis of participant narratives and helps to set the scene for the counter-narrative presented in the next chapter. My intent is to describe and outline what the research participants said in relation to the research question and sub-questions. The findings are presented using the participant narratives which contained a plethora of tensions and contradictions. This raised questions about how best to deal with these and, rather than hide from such complexity, I have selected specific narratives which highlight the contradictions and conundrums and speak directly to the nature and relevance of transformation and class consciousness in the life-worlds of contemporary Māori. A summary of the key findings is presented at the end of this chapter.

\section{What it Means to be Māori in Aotearoa New Zealand}

The narratives provide a rich account of the participant life-worlds and speak to their experience of what it means to be Māori within the context of Aotearoa New Zealand. Participants talked about values and dispositions instilled in the home and whānau (family) context, being Māori in te ao Māori (the Māori world) and te ao hurihuri (global world), particularly within the formal education system, and the important role education (formal and place-based) has played in their life-worlds.

\section{Values}

The values passed down within the whānau (family) context provided the foundations on which the educational and life trajectories of participants were formed. Participants were asked to describe the key values passed down within the home and the ways in which these values were practised in everyday life. The most 
common value was to work hard or have a good work ethic. This ethic was modelled by parents who spent long hours working in labouring or manual-oriented work, or who sometimes worked two jobs to provide for the family. For example, Te Kohi explains how a strong work ethic featured in his whānau:

Mum and dad both worked / and all of my brothers and sisters worked / even though they were at school / so it was common for most college kids / especially the Māori who needed the money / it was common to get up at 5 o'clock in the morning / work a couple of hours before going to school / so that ethic of work was huge.

Similarly, Teaniwa shared how her parents valued hard work over intellect:

My parents are really hard workers / and so I don't know if work ethic is a value / but it's a value in our house / you can be excused if you're not really clever / but if you're lazy / that's inexcusable / It's okay to be a thicko / but if you're lazy / well you will feel it in our house.

One consequence of such long work hours was many participants did not spend a lot of time with the primary income provider in the house, which for most was their father as demonstrated by Itiria:

They [my parents] worked 24 hours / around the clock / to pay for our fees [boarding school] / I mean / / hardly ever saw my dad as a child / really / because he was working / working / working / to try and get us ahead / and pay the bills / and do all of the rest.

Reremoana shared a similar story and highlighted the sacrifices her parents made in their own relationship to provide for the whānau:

Dad was a carpenter / he used to work long hours during the day / then dad would come home late evening / they [mum and dad] might have had like 
half an hour to see each other / then mum would be leaving / she had a night job / they just did what they had to do / to kind of get by.

Many participants described the key values instilled in the home using Māori concepts. For example, they talked about the importance of whanaungatanga (extended family relations), manaakitanga (taking care of guests, reciprocity) and tuakana/tēina (older sibling responsibilities to younger siblings) and used their own words to explain what these concepts meant. All participants were brought up in large extended whānau contexts surrounded by cousins, aunties, uncles and nannies, connected by whakapapa links. Thus, being part of and socialised into a collective ethic was the norm.

\section{Diverse Māori Identities}

At first glance the narratives did not appear to support the idea of tension and struggle growing up as Māori; however, a second and third re-examination highlighted a complex maze of dynamic tensions at play as participants navigated between te ao Māori (the Māori world) and te ao hurihuri (the global world); urban, suburban and rural identities; iwi and whānau identities; classed and stereotyped identities; prejudice and acceptance, racism and ignorance. The following narratives illustrate what it was like to grow up as Māori and the diverse ways in which being Māori was played out in a variety of social, cultural and educational contexts.

\section{Dual Identities}

Rakai, currently a lecturer in design at a New Zealand university described how he used art to explore his Māori and Pākehā identities:

The idea of dual identities / growing up in a Western urban middle class context / but engaging with a Māori world / what am I making art about? / Am I Māori purely through whakapapa / without a huge amount of knowledge and experience to back it up? / Or am I not Māori / because I don't have other things under my belt? / Creating artwork which asked what is identity? / The conclusion I came to is that the first paradigm is whakapapa / if I have 
genealogy that makes me Māori / the other stuff add to the experience / but they don't define me as Māori.

\section{Tribal Identity}

The data showed how some participants were raised with strong whakapapa links and connections to their iwi; they were iwi-centric and proudly so. For example, Ihaka discussed how he was raised and immersed in the notion of tino rangatiratanga ā iwi (tribal self-determination) and distinguished between identity ā iwi (tribal identity) and his Māori (pan-tribal) identity:

My world view / I guess / was shaped by my mother / but / was influenced by an urban upbringing / but / we were constantly going back to the coast / so / from a young age / I always knew / one / I was Māori / two / and / more importantly / I was Ngāti Porou.

Participants raised with a strong physical, spiritual and cultural connection to their iwi were confident in who they were and where they stood in the world. This tribal identity was a source of strength particularly when challenged by others about their identity as Māori, as Matariki explained:

My parents pretty much instilled within us / right from as early as I can remember / who we are / I can recall from a young age l've always known I'm Māori / I've always known who my iwi / who my people are / ...l'm quite a fair-skinned person / it was always a challenge / my own schoolmates used to challenge me / as to who I am / I clearly remember going to their homes / their parents had their own views on what Māori are and they made them quite clear by the way they treated me / but I never took any of that to heart / I was always quite confident in who I am as a Māori.

This narrative showed how a strong cultural identity ā iwi was a source of strength for Matariki in the face of overt racism and discrimination. 


\section{Racism and Prejudice}

All participants talked about their experiences of racism, prejudice and discrimination in some way, shape or form growing up as Māori in Aotearoa. Raised during the 1960s, '70s and early '80s, a defining period in New Zealand race relations history (Pollock, 2004; Spoonley, 1984), participants spoke vividly about the institutional and explicit (in-your-face) racism experienced in a range of contexts.

Almost half of the participants are children of mixed Māori and Pākehā marriages or relationships. Some participants highlighted their experience of racism, violence and prejudice directed from both Māori and Pākehā sides of their family as well as the wider community. For example, Manaakiao explained the racism he experienced within a predominantly Pākehā community:

Socially / it wasn't quite acceptable for a Pākehā man / and / for a Māori woman to be together / and / have children / One of my most vivid memories / of [suburban town] / was hearing / and / watching my dad go running out the door with a rifle / hearing gun shots outside / because / these white power types were causing strife / deliberately picking on mum and dad.

Racism experienced within whānau was described by Piata:

My mother is Pākehā / my father is Māori / they met at teachers' college / and / subsequently got married / which absolutely disgusted my mother's family / she was quite middle class / he was a Māori boy from [small rural town] / my grandfather threatened to kill my mother / my father / and / me.

Although at the extreme end of participant experiences, Piata's narrative is testament to the racial tensions prevalent in Aotearoa New Zealand during the 1970s. It was therefore no surprise that a complex web of tensions and struggles emerged in relation to identity and what it meant to be Māori.

For most participants a Māori identity was defined or judged by their physical appearance, based on skin colour (particularly those with fair skin). For example, 
Atareta's narrative highlighted what it was like to grow up with brown skin in a predominantly white community and fair-skinned family:

I went to the local school / we were one of just a handful of Māori families / so I always felt different / and very aware of being Māori / it wasn't normal / my mother is white in skin colour / my siblings have all got white skin / so mum was always reinforcing to me / you are going to have to try so much harder than your brothers and sisters because you've got dark skin / I know she meant it in a good way / but it always gave me a bit of a chip on my shoulder.

Other participants recalled what it was like to grow up as fair-skinned Māori and described how this negative experience was a key driver to prove their Māori identity in other ways like through learning te reo Māori and performing kapa haka. Meanwhile, others strong in their own identity were unfazed. The data showed how Māori identities were expressed in diverse ways, i.e. identity ā iwi (tribal identity), ā hapū (sub-tribe identity), ā whānau (family identity), identity as urban Māori, rural Māori, pale-skinned Māori and children of mixed (Pākehā/Māori) marriage or relationships.

Participants who were not raised with a strong cultural identity and lived in communities where Māori were the minority and negative attitudes about Māori dominated, more often than not struggled with their identity. For example, Pirihira spoke about having a Pākehā identity superimposed on her by the predominantly Pākehā community:

It was a very white town / I was always the only Māori kid at school [Did you feel this at school and in what ways?] Oh absolutely I felt it at school / absolutely / it was a very negative thing to be Māori / but / at the same time / I was always treated as the exception to the rule / because I was always a smart kid / and / a polite kid / so / in a way / it was like being an honorary white / terrible aye. 
In essence, the data showed how growing up Māori and expressing one's identity as Māori was fraught with challenges. The critical point is that participants navigated this relentless sea of tension and still managed to succeed educationally. This task was made easier for participants raised with a strong cultural identity. Many talked about becoming a stronger and more resilient person as a result of being exposed to these tensions growing up, while others commented on how this was the norm and the reality of growing up Māori in Aotearoa New Zealand.

\section{Role of Education}

The narratives highlighted the important role both formal and informal education played in participant life-worlds. The emphasis on formal education was evidenced by the value parents and whānau placed on formal education and academic achievement. Educational experiences were, however, not limited to the classroom and participants also expressed the critical role informal, place-based education played in shaping their consciousness and perspectives.

\section{Parents' Educational Experiences and Expectations}

All participants commented on how parents and whānau valued formal education and academic achievement despite most parents not doing well academically themselves. Thus formal education was seen as the key to making a better life, better choices and opportunities. Parents supported academic studies in a range of ways, some proactive and others not, but all participants had at least one protagonist, one parent who pushed, drove, encouraged, supported and cajoled them to do well at school. For example, Tamati commented on how strong the push for education was in his whānau:

Everything was about education / forcing you to read at night / forcing you to make sure you did everything / Everything was about getting a good education / to ensure that you get choices / and / opportunities.

Moreover, many parents held high educational aspirations in spite of their own negative experiences within the formal education system. For example, Erana 
explained the negative messages passed down by her dad as a result of his experiences at school:

I remember when I went to school for an interview with mum and dad / It was quite sad / because my dad used to say to me / things like / they think you're a dumb Māori / you have to be better than them / you have to be faster than them / so I had this really sad kind of experience at home / where / that was his experience / sadly enough / that was mum's experience too.

Erana's educational experience was markedly different from her parents'. She explained how her father's negative comments became a positive motivating force in her educational journey. Erana excelled academically and was appointed head girl at her secondary school.

\section{Place-Based Education and Cultural Wealth}

What parents did not possess in terms of formal academic qualifications was supplemented by a wealth of practical, place-based, esoteric and cultural knowledge passed down through a range of pedagogies within diverse learning contexts like the beach, the marae, the awa, the maunga (mountain), the ngāhere (bush), the garage and the hāngi pit. The importance of this cultural wealth cannot be overstated. All participants talked about how they were educated long before they entered the classroom and how the contexts within which they lived provided a rich source of cultural wealth to augment what they learnt at school. For example, Matiu explained what it was like to grow up in an isolated rural community:

We would do lots of things because it was rural / so we'd have whānau staying all of the time / which was awesome / because it was such a unique beautiful place / so we'd often all go eeling / we'd all go hunting / out in the bush together / or we'd all go to parties and play with all the other local kids.

Similarly, Teaniwa shared how her father would teach practical, place-based knowledge:

Dad didn't sit with you and say this is how you learn things / but he would do things in the outdoors with you / and teach you things like / this tree is this / and you can use that for this / or these ducks will live here because / there 
was that sort of stuff / but it wasn't $1+1=2$ / and it was more physical / like the car does this because / very practical stuff.

Teaniwa's narrative like so many speaks to the tapestry of knowledge parents and whānau possessed in the absence of formal academic qualifications.

\section{Being Māori in Formal Education}

Achieving academic success as Māori meant many participants were one of only a handful of Māori students left in the latter years of secondary school. The narratives were filled with anecdotes about compromise, sacrifice and alienation participants experienced throughout their formal education journey. All participants spoke about the high number of Māori friends who had dropped out or were kicked out of school and how only on reflection they realised these friends were never really expected to succeed. For example, Hiria highlighted how deficit theorising and privileging of Western knowledge over Māori knowledge impacted on her at secondary school:

Going into seventh form I wanted to continue te reo / and our career adviser / this middle-aged Pākehā / socks up to his knees / shorts / white t-shirt / said / oh / it's not going to get you anywhere / drop it / go and do calculus or physics / that really impacted on me / I turned to my family for support / but they said to listen to my teachers / they know best.

Hiria's narrative speaks to the implicit trust and respect many Māori parents had for teachers and the priority they placed on Western knowledge which at times was to the detriment of te reo and Māori knowledge. Similarly, Weihana talked about the scarcity of Māori students in the senior years at secondary school as well as the low expectations educators had for Māori students:

Seventh form I was the only Māori out of 75 students / I'd kind of noticed this along the way / all of my Mãori mates were disappearing / but they had the freezing works / the army / they were happy / that was what they chose to do / I see now that no-one expected them to go on to university / and my skin colour is cafe au lait / so that made things different for me. 
Weihana's narrative also speaks directly to the level of racism embedded within our schools as evidenced by differential treatment based on his lighter skin colour as opposed to his darker-skinned friends.

\section{Higher Education}

The majority of participants were the first in their immediate and extended whānau to attend university and graduate with a degree. Five participants attended university as mature students. Puawai explained her mother's tenacious approach to get her into university:

The guidance counsellor told me / I was unlikely to get into university anywhere / I said to mum / see / I can't get in / what's the point / we won't repeat what she had to say / she sort of / forced the application to university / which / I didn't really want to do / cause / I saw it as a place for nerds / so / it wasn't my plan / it was mum's.

Puawai's narrative speaks to the negative and deficit perceptions teachers and schools had for Māori students - and she was not alone in her experience. Many participants shared similar stories about how teachers steered them away from certain subjects like te reo in favour of more 'useful' subjects like physics or calculus. Participants also recalled teachers who made backhanded comments about being awarded higher grades or marks because they were 'Māori'. This impacted on the participants in a range of ways. Some spoke about how they felt confused, conflicted and hurt by such comments while for others it put fire in their belly and made them even more determined to 'succeed'.

Participants also spoke about how parents encouraged and supported higher education, but did not have the academic knowledge, networks and resources to provide support. Therefore, they actively sought support from peers, mentors and university-based Māori student support groups and associations like the Māori Law Students Association. Participants commented on how these culturally based support groups were critical to their academic success at university. 
All participants commented on how higher education success, attaining postgraduate and/or professional qualifications was critical and in most cases a prerequisite for their current professional career, as Taite explained:

I would never be able to do what I do without an education / a lawyer's degree / It's a vehicle / a medium to get you a foot in a door / and / to allow you to provide financially for your whānau / my qualifications and job allow me to do stuff.

Participants described higher education as a 'vehicle' and 'ticket' to access more choices and opportunities in the making of a materially easier life for themselves and their whānau. Moreover, higher education exposed the participants to a range of networks which they were able to utilise in both their professional and personal lives today. Matiu articulated the ways in which higher education and education in general had changed his life:

If I look back and I didn't go on and get a good education / I would hate to think what I would be doing now / honestly / education definitely has transformed me in every way / in terms of intellectually / in terms of the way that I talk to people / mix and mingle with people / my self-esteem / the way I view myself / everything / and my whole life has been education until the point I went to work / so I can't see how that process has not affected me I and / changed me hugely.

Like many others, Pirihira talked about how higher education helped to develop a critical consciousness and informed perspective particularly in regard to the position of Māori in contemporary society:

Education is the number one thing for me / it's the difference between being politicised / and / not being politicised / Being Māori defines me in terms of my identity / having access to education means that I have a good understanding about why Māori are in the situation that we're in / for example / if I wasn't well educated maybe I would buy into the stuff that 
Māori are lazy / Māori are dole bludgers / education has enabled me to understand all of those structural factors / and / who has benefitted from the resources of Māori / Education has been absolutely pivotal / giving me the outlook and approach to life that I have / and also the motivation and drive to make a difference and to contribute.

Thus, higher education success was a key enabler for transformation in terms of promoting a critical and political consciousness and providing opportunities to create material wealth and resource which enabled participants to actively contribute to transformative action and practices within their whānau.

\section{Brief Summary}

The discussion thus far has looked at what it meant to be Māori within the context of Aotearoa New Zealand. It showed how a range of values were embedded within a whānau context; the overarching value was to have a good work ethic. By this I mean an ethic of work that inculcates a particular orientation to the world, a Māori work ethic, if you will. What differentiates this Māori work ethic from a plain, old work ethic is that it was about working hard to get an equal footing and standing in life. Being Māori meant participants had to work harder and go the extra mile because they were Māori. For example, some participants were openly told by parents that they would have to work harder than others simply because they were Māori or because they had darker skin. Thus, building a Māori work ethic was also part of a journey towards social justice and tino rangatiratanga (self-determination). The next common value was whanaungatanga, being part of a collective and the implicated responsibility to support and contribute to collective wellbeing. Thus, participants were socialised into a whakapapa-based relational context where a collective ethic was embedded.

The majority of participants grew up in materially humble contexts, but were exposed to a rich cultural wealth outside the formal education system - a Māori cultural capital, if you will, comprising place-based and localised knowledge, practical skills, and cultural and esoteric knowledge. Moreover, while most parents did not succeed academically themselves, they believed in the importance of doing 
well in education to help in the making of a 'better' life (materially). The data highlighted the fluid, dynamic, complex, contradictory and challenging forces at play in the shaping of a Māori identity. Growing up as Māori more often than not meant participants experienced racism, prejudice, violence and discrimination on a range of levels. Some drew strength and resolve from their iwi identity, but most talked about how a Māori identity differentiated them physically in terms of skin colour, style of dress, speech and practices. Within an education context, growing up as Māori was filled with challenges within a system where deficit theorising, negative stereotypes and assumptions about Māori educational potential prevailed. In short, the data showed how growing up Māori within the context of Aotearoa New Zealand was a challenge as participants shifted between two worlds - te ao Māori and te ao hurihuri.

The next section looks at the material world of participants. The intent was to capture participants' understanding of their material position in the world, what they grew up with and how the material resources they possess now impacts on their responsibility and ability to contribute and effect transformation. It explores Māori perspectives on notions of class and class consciousness in contemporary Aotearoa New Zealand.

\section{Limited Material Wealth}

Almost a quarter of participants were brought up in two-income or materially comfortable contexts, but the majority grew up in materially humble or poor contexts. Most parents worked in manual labour-oriented jobs, such as factory worker, sheep shearer, dairy farmer, meat worker and mill worker, or in service and retail work. As a consequence, many parents were vulnerable to labour market changes and some participants, particularly those living in rural or semi-rural areas, talked about the negative impact government policies like 'Rogernomics' - a term coined in reference to the economic policies followed by Roger Douglas, Minister of Finance in the Fourth Labour Government characterised by market-led restructuring, deregulation and tight monetary policy (Easton, 1989) - had on families and small communities. For example, Te Kepa highlights the effects Rogernomics had on his small, predominantly Māori rural community: 
[Town] changed from the '70s to the '80s as a result of Rogernomics in the '80s / From a small provincial farmland supporting town / which in the '70s was quite good to bad in the space of a decade /... where there was once a whole street of shops in the early '80s / in the late '80s you start seeing garage roller doors on probably half of the town / the impacts were things like mill strikes / which affected a lot of people in our area.

When asked to describe their material wealth many participants used an ethnicitybased Pākehā/Māori metric whereby wealth was measured relative to Pākehā in their community as well as other Māori. Some expressed wealth using class terms, while others were unsure of what class meant.

\section{Growing up poor}

Over half of participants talked openly about what it was like to grow up poor and the struggles they experienced living in low-income, sole-income or sole-parent families, as Atareta explained:

We were very much working class poor / on the DPB / trying to stretch $\$ 250$ across three kids and a mortgage / often l'd go to school with no lunch / and I'd be hungry / but at the same time / I always knew there were people poorer then us / so we didn't feel poor / I never felt sorry for myself / it was always / I wish I had other stuff / I always knew that I was going to work hard and do well for myself / because I just hated being poor / I never felt any resentment towards my parents / but that was always something that spurred me on.

For participants like Atareta, growing up poor was a driver to succeed, but for the majority of participants growing up in materially humble contexts helped to build a level of wherewithal, perseverance, resourcefulness and resilience in that they had to make do with minimal material resources. 


\section{Growing up the same as the community}

About a quarter of participants commented how their material wealth was the same as or relative to others in their community as Terina highlighted:

In the neighbourhood we were the same as everyone else / well / we weren't poor / But / we would still be below middle class / when you're kids / you don't realise where you sit / but / when we look back / you know / it was all hand-me-downs / in a family of six.

\section{Growing up comfortable or wealthy}

About a quarter of participants grew up in materially comfortable homes where either both parents worked or one parent had a well-paid job. All commented on how privileged they were relative to extended whānau. Kapuarangi, however, defined his material wealth as 'high class' and described how cultural identity was not sacrificed as a result of growing up wealthy. His narrative stands out markedly because it openly acknowledged the level of wealth and material privilege he grew up with, brought up in his papakāinga, but more importantly how cultural identity was not lost as a result:

Oh / we were high class! / we were in families that had the flashest cars / everyone worked / and lived in beautiful homes / The stunning thing about that is / the Māori side / the tikanga side / wasn't lost / it wasn't in jeopardy / there wasn't any trade-off / You take it for granted though / and you are not aware as a young child / that not every family has those privileges.

This narrative was the exception and by far the majority of participants described their material wealth as poor, humble or relative to others in their community. But this narrative is important because it provides a new model which speaks to new possibilities for success that is inter-generational where cultural and material success go hand in hand. 


\section{Class Consciousness}

To help build an understanding of class consciousness as a lever for transformation, participants were asked about their perspectives and understanding of social class and class consciousness. Two main schools of thought emerged. The first group vehemently rejected the notion of social class and, in fact, some participants abhorred the idea. Within this group a few participants theorised class from a te ao Māori perspective. The second group was comfortable with the notion of class and described themselves in class terms. Examples of these two divergent perspectives are presented in the next section.

\section{Social Class: Te Ao Māori Perspective}

Some participants rejected social class and instead theorised the notion of social class from a te ao Māori knowledge base. For example, Manaakiao rejected the class label and focused more on his whakapapa and made a clear distinction between chiefly and commoner lines:

I wouldn't describe us as any class labels / I would probably describe myself / and / my family as / he uri nō ètahi tangata rangatira [descendants of chiefly lines] / This is whakapapa / I keep on saying / my children are not tūtūā / you are not commoners / our children are not taurekareka / this is not being whakahīhī / we're kāwai ariki / we actually are.

While Manaakiao disregarded a social class label, his narrative is very much about status and hierarchy based on whakapapa lines. Tūterangi contributed to the whakapapa analysis and asserted the idea of a Māori self-sufficiency class based on knowing one's identity:

We're part of a Māori self-sufficiency class / you should have a grounding of who you are / and where you come from / your identity / if you're going to be Māori you have to have an understanding of your own tikanga and kawa / and / what that means for you. 
Te Kohi rejected class titles based on economic wealth, but valued status and hierarchy invoked by whakapapa:

I don't like titles / I know who I am / We have been raised to know whakapapa / I expect my kids to know it / and / I expect them to act accordingly / he uri ariki / he uri rangatira / ehara i te tūtūā / Strange that I have an issue with those titles / I have an issue with them / because / they measure something that is based mainly on financial wealth.

Te Kohi's narrative highlights some interesting points. First, how important whakapapa (genealogy) and traditional stratification and hierarchy lines are within a contemporary context, as expressed through the distinction made between ariki (chiefly) and tūtūā (commoner) whakapapa. This may simply be an arbitrary separation; however, a sufficient number of participants commented on such whakapapa distinctions for it to be noteworthy. Second, perhaps wealth is fine so long as it is not 'financial wealth'. For example, wealth derived from whakapapa (genealogy) in the guise of mana (authority and agency) and rangatiratanga (status) is acceptable. To a certain extent, this idea is oppositional to Western concepts of social class whereby material wealth is the fulcrum of social class. Conversely, a te ao Māori perspective might argue whakapapa is the primary source of 'cultural wealth', power and status, which may or may not lead to 'material wealth'.

\section{Focus on non-material wealth}

Some participants rejected the idea of social class because they did not understand what it meant or its relevance to their lives. They preferred a non-materialist metric based on experiences and aspirations, understanding of mātauranga, level of happiness and knowing one's identity as well as one's ability to help others. For example, Hiria talked about being rich because of her experiences:

I find it challenging to describe myself in class terms / because / I feel that I'm rich as / and / I don't mean in material ways / I mean with all of my experiences. 
Hiria's narrative and others provide a strong counter-narrative to the Western concept of class and challenge us to rethink class and capital in a non-material way.

\section{Social Class: Te Ao Hurihuri Perspective}

Over 50 percent of participants were comfortable to describe themselves using class terms, but emphasised this did not define who they were nor was it a central part of their identity. The majority identified as middle class. These participants felt privileged because they were able to provide security for their family and had access to resources like medical care and benefits like being able to choose what to eat or buy at the supermarket. The markers of being middle class as identified by participants were the level of formal education, income, networks and the ability to have choices in one's life.

\section{Social class markers: income, education and networks}

Te Paea interpreted social class as a structural and social construct. For example, she talked about being middle class in terms of her income, education and social networks:

I'd definitely say I was middle class / because of my level of income / my education and also because of the type of people I hang out with / the type of people I'm attracted to / I generally tend to surround myself with people who are go-getters / visionary / can drive themselves / are ambitious / all of my friends look like me / I can't name one close friend who doesn't / so when I'm talking middle class / it's also about who you surround yourself with.

The majority of participants acknowledged that being middle class was a privilege. They recognised that having a relatively comfortable income is not the norm, particularly within their whānau. Some explained the sense of privilege and unease they have because of their level of material wealth relative to others in their community. 
Weihana identified as middle class, but unlike most other participants commented on middle class financial vulnerability:

I'm definitely middle class / I'll never be more / because middle class goes from about $\$ 45$ to $\$ 50,000$ a year / up to about $\$ 120$ to $\$ 140,000$ / you've got the same issues / you're not free / you're not financially secure / you lose your job / boom / it's gone / you can lose everything in a redundancy.

This point was supported by Waimarino who described herself as professional poor:

I wouldn't call us middle class / probably more like out-of-control poor class people / I read an article and they described a profile of a person / fit me to a 't' / educated / student loan / working in a good well paid job / no savings / professional poor.

Weihana's and Waimarino's narratives bring to the fore another potential attribute of this emergent middle class - not necessarily materially well off, but certainly welleducated and with status.

\section{Working class}

A few participants described themselves as working class. One of the main reasons for this was because they had to work and sell their own time, rather than choosing to work. Moreover, these participants talked about not being motivated by material wealth or the desire to 'keep up with the Joneses'. That said, financial security for their whānau was a priority, which highlights the structural importance of social class.

\section{Perceptions of Difference}

Participants were asked whether formal education and material wealth differentiated them from whānau and, if so, in what ways. The majority of participants reluctantly agreed each marker differentiated them in both positive and negative ways depending on the context. 


\section{Metrics of worth: te ao Māori and te ao hurihuri}

Most participants have professional careers and commented on how they were perceived to be or felt 'useless' in a manual labour-focused context, particularly when helping at the marae. At times, participants found it difficult to balance whānau expectations to contribute to the marae with the demands of a professional career. Moreover, the tension between having material wealth and privilege among extended whānau was managed in different ways. Some participants talked about how the perceptions of difference were mitigated because they shared the same values as their whānau. For example, they helped out at the marae, looked after nan (grandmother) and koro (grandfather), and took an interest in land issues.

While not everyone agreed with the idea of social class, most participants acknowledged they were perceived or treated differently by extended whānau because of their income, wealth, education credentials, or a combination of the three. Thus, success in te ao hurihuri did not seamlessly translate into success in te ao Māori. Differentiation by whānau was expressed in both positive and negative ways and gave rise to a range of tensions, particularly within a marae context. As a consequence, some participants felt distanced and useless on the marae because their skills were professional-based while others felt burdened by the pressure and responsibility to contribute. For example, Hiria talked about how she felt alienated at the marae because she was perceived to be good only at academic work:

I still feel that distance / and definitely perceived differently / you know l'll be in the kitchen cooking / or / doing the dishes / or / whatever and the cousins go / 'what are you doing in here? Go back to the computer' / but / you just handle it.

All participants agreed whānau had high expectations for them to lead, support and contribute in material and non-material ways. Thus, in a sense the marae acted as a mediating structure whereby achievements in te ao hurihuri were balanced in both negative and positive ways in te ao Māori. Participants managed and navigated these tensions and used a range of strategies like humour, humility, dressing differently, returning home as much as possible, helping at the marae, setting clear 
parameters about what they would do, giving money or living away from home. For example, Tamati talked about the importance of humility when returning to the marae as a way of managing perceived tensions and differences:

When you go back to the pā / you make sure that you have your swannie / you make sure you don't take your latest jacket / because / when you're working in the back / you don't see it yourself / but / others see it / and / you don't want to come across as whakahīhi / your upbringing is about being sure that you are humble / and / you stay grounded.

\section{Giving Back and Whānau Expectations}

All participants talked about how they were privileged materially and therefore felt it was important to give back and contribute to whānau, the majority of which have limited material wealth. For example, Whaiora commented on the sense of privilege she felt as well as a deep-seated commitment to take care of her parents:

I always feel privileged / So / when I'm sitting in business class going somewhere / not that I do it often / I feel privileged / it's huge for me / But / my parents remind me / don't forget all of the sacrifices you made / or / they made / to be able to do that / so / I always / always / always / look after my parents first.

Within a te ao Māori context, the importance of giving back to the marae and contributing to the collective was poignantly highlighted by Tuterangi who theorised what it meant to contribute and why he returned to the marae as much as possible:

On the marae you have to make sure your paepae [selected cohort of speakers on the marae - usually male] is onto it / your waiata [songs to support speakers] is onto it / your back is onto it / it's about being prepared / As a whānau the rewards are endless if you make sure your marae is okay / with the mindset that it can't be just for you / you have to share / Mã te iwi i whakanui i a koe [Your tribe bestows authority and power on you] / Kāore te kumara e kōrero mō tōna ake reka [The kumara does not talk of its own 
sweetness] / kei à te iwi e noho ana te mana [authority and power lies within the tribe] / mā te iwi i whakanui i a koe [your tribe has the power to uplift you] / You have no mana / it can only be given to you by the people / guess what / they can also take it away / So if you go back home and keep giving / the principle of kanohi ki te kanohi [face-to-face interactions] / they will see you.

In terms of whānau expectations, participants talked about how whānau were proud and supportive, but also had high expectations for them to take the lead in a range of contexts. Some felt pressured by the weight of expectations and talked about being viewed as 'the chosen one', the 'go-to person', the 'oracle', the 'leader', and a few commented on how this was a negative experience because of the pressure, time and monetary demands. The majority, however, talked about how high expectations were the norm and accepted such demands.

\section{Transformation at the Roots}

Participants were asked about transformation, what it meant, and how change might come about in terms of bridging the divide between Māori in privileged positions and those struggling on the margins. In short, participants overwhelmingly supported a micro-level approach to transformation starting with one's own whānau. Although most participants acknowledged a range of strategies are needed at both a macro and micro level, the most fundamental and logical place to effect change was in the whānau because of one's whakapapa (genealogy) and responsibility to contribute. Other sites of transformation identified were the community, marae/hapū and iwi.

A range of transformative strategies were identified situated at the whānau level. For example, all participants were involved in mentoring and leadership roles within their whānau, either voluntarily or because they were tasked with roles by senior whānau members for a range of reasons which included their credentials, status, occupation, resources, skills and knowledge.

The kinds of transformative strategies participants were involved in included leadership development with rangatahi (youth), promoting the benefits of education and higher education, leading and contributing to whānau reo, tikanga and 
whakapapa wānanga (workshops), organising and facilitating marae-based events and wānanga - e.g. whānau and iwi strategic planning, and supporting whānau health days, to name but a few.

Most participants lived some distance from their traditional marae and papakāinga and acknowledged how their financial resource enabled them to return home to contribute as well as coordinate whānau-based activities within their local community. Anituatua emphasised the need to never forget one's roots and to use one's material wealth to go home and support:

Do not forget whānau in all of your education / and / high-class living / don't forget where you come from / and / who your family are / make yourself available for them / for those tangihanga / and / those wānanga back home / because / we are the educated ones / because / I am the one with the good job / and / I can fill my car up easier than cuzzie can / it's on me to go home / and / you know just chill out and just be there.

At a macro level, participants talked about the need for effective leadership to better coordinate and leverage collective knowledge, skills and resources. Central to this was the need to build an overarching transformative strategy which linked material wealth with individual efforts, as highlighted by Te Kepa:

Together / anything can be done as a collective / we can rule the world / It's just whether or not we choose to act as a collective / That's the challenge for leaders / and / leadership / to bring people together / / know there's heaps of Māori middle class / and / they've got heaps of ideas / But / time's a big factor / people start having families / and / all of a sudden they've less time to contribute to the collective / It becomes transformation at a micro level / i.e. their families.

Te Kepa is one of a handful of participants to talk about social class as a lever to build cohesion and accelerate transformation. While a few participants supported kotahitanga and the creation of a shared vision to inspire and mobilise the 
collective, most cautioned against creating a Māori middle-class cohort which had to give up what it means to be Māori (for example connections back home, relationships, tikanga and reo) in order to 'succeed', as expressed by Pirihira:

It's about using the skills and resources that we have to contribute to Māori development in the right way /...being really careful that we don't want to just build up a Māori middleclass /...so we don't want people to have to give up their connections to home / We don't want them to have to give up really important things in the name of education / what we really don't want is just to be creating a whole breed of / you know / Māori lawyers / doctors / whatever / that actually are giving up a lot of what it means to be Māori in order to achieve other benefits / It's kind of a question that I struggle with / about how people can have both.

\section{Summary}

In relation to class consciousness as a potential lever for transformation, half of the participants rejected a social class identity and half accepted it as a relevant concept in their lives. Only a handful talked about building and leveraging off a class consciousness to facilitate transformation. All, however, recognised the importance of social class structurally in terms of the benefits, opportunities and privileges that come with having a certain level of material wealth. Thus, social class was important structurally, but irrelevant socially and culturally.

Higher education qualifications and income differentiated participants from whānau in both positive and negative ways depending on the context. A variety of strategies were used to navigate through this sea of tension. However, being highly educated resulted in participants having a relatively high material wealth, access to networks and resources to better support and contribute to whānau transformation. While a few participants felt burdened and pressured by familial expectations, the majority acknowledged the responsibility to contribute to whānau was the trade-off for 'success' in te ao hurihuri. Higher education success therefore was an enabler which opened doors and provided the opportunities for participants to build material wealth to contribute to whānau-based transformation. This was, however, 
complemented by a deep-seated responsibility to also contribute to the collective in non-material ways.

The critical site of transformation was whānau and the data showed how, at present, transformation is occurring in an uncoordinated way as participants work within individual whānau to effect change. Participants acknowledged how a cohesive, coordinated and strategic approach was needed in conjunction with strong leadership and a collective vision if transformation was going to become widespread and sustainable - whakapapa was the key lever to build consciousness.

\section{Key Findings}

This chapter is about the participants and giving voice to their experiences and perspectives. As a result of the thematic analysis presented in the findings, four key findings have emerged:

1. Higher education success (i.e. educational attainment) was a key enabler for transformation in that it opened doors and provided opportunities for participants to build a critical consciousness, create resources, networks and a level of material wealth at an individual level to be able to contribute to transformative strategies at the collective level (whānau, hapū and iwi).

2. Participants share a cultural wealth in te ao Māori and shaped by a collective ethic and consciousness bound by whakapapa (genealogy), a cultural wealth which provided the foundation on which transformative intent and strategies were nurtured, a cultural wealth which alongside material wealth enables participants to successfully navigate the seas of tension and conflict that emerge from both te ao Māori and te ao hurihuri.

3. Social class has resonance and relevance to the life-worlds of contemporary Māori, but it is not the whole story. Based on Western social class indicators (i.e. qualifications, status, income and occupation type), this cohort has the social, political, educational and cultural capital that says they are part of an emergent Māori middle class. However, most of the participants reject social 
class as a marker of identity and the absence of a class consciousness means this cohort sits problematically within Western ideas of social class, because social class is important structurally, but irrelevant socially and culturally. Thus, class consciousness is not a lever for transformation, rather it is at the level of whakapapa where transformative consciousness might be raised and accelerated.

4. Whānau was identified as the critical site of transformation and participants are contributing and leading transformative strategies within their respective whānau in a range of ways. However, at present this whānau-based transformative action is uncoordinated and there is much scope for collaboration in order to better leverage skills, knowledge, talent and resource (cultural and material) to find innovative ways to create and effect transformation.

A participant matrix is provided in Appendix $E$ which provides more in-depth data about who the participants are (using pseudonyms) and how they shaped and contributed to this research study.

The next chapter presents a more detailed critical discussion of these findings. It weaves together the narratives, key findings and literature to present critical Māori perspectives on higher education, transformation and social class in Aotearoa New Zealand. 


\section{CHAPTER SEVEN: MĀORI IN THE MIDDLE - CRITICAL PERSPECTIVES ON HIGHER EDUCATION, TRANSFORMATION AND SOCIAL CLASS IN AOTEAROA NEW ZEALAND}

\section{Introduction}

This chapter sets out how the data responds to and answers the research question and sub-questions. I will critically discuss the key findings, draw on the participant narratives, and link to relevant literature to develop emergent ideas. My intent is to use my participants' experiences as expressed in their narratives to present a new story, a story which runs counter to Eurocentric analyses, a story that challenges stereotypes and assumptions about contemporary Māori life-worlds.

\section{What is the Role of Higher Education Success in the Transformative Potential of Māori?}

The data indicated the critical role higher education success, that is, educational attainment, played in getting participants to where they are today in terms of career and occupational trajectory. In fact, for most, the qualifications gained at university were a pre-requisite in their profession (e.g. lawyer, doctor, accountant, lecturer, nutritionist, policy analyst) and provided the vehicle through which they gained entry into the labour market. These credentials were complemented by hard work, perseverance and the strong desire to succeed. In short, higher education success was critical in terms of exposing participants to and raising a critical consciousness, and providing opportunities for them to build material resources to be able to lead and contribute to transformation.

\section{Formal Education Experiences}

The pathway towards achieving higher education success was challenging. The formal education system was a critical site of contest and conflict as the battle 
between the legitimation of Māori and Pākehā cultural capital ensued. Being Māori within a formal education field was laden with challenges and the narratives spoke to a field that supported a Pākehā cultural capital antithetical to the cultural capital within participants' homes and communities (Tomlins-Jahnke, 2008). For most, the schooling context was completely foreign to their home environment. Within education the overarching message was Māori academic achievement was not the norm in a system that held steadfast to its negative stereotypes and beliefs about Māori academic ability and potential. Waimarino's narrative succinctly captured the tensions around being Māori, particularly during the latter years of secondary school:

I was the only Māori girl in the A stream / the only Mãori until I got to 6th form / I'd grown up at a time where the message was the education system only worked for Pākehā / they didn't say it didn't work for Māori / but / that it only worked for Pākehā / which I found made me even odder / because I liked school / I did well at school / that made me wonder if I was actually a Pākehā / So / that kind of alienated me from other Māori / That's when I really realised how different I was in a whole lot of respects / one / I liked school / two / I did well.

Waimarino touches on a common theme across the narratives, that is, the powerful impact deficit theorising, racism and discrimination has on one's identity. These experiences are equally about the racism that is embedded in our society and our schools. To be fair, not all teachers were bad and participants highlighted at least one teacher who had a positive influence and supported their educational journey. However, the data overwhelmingly spoke to the dialectics which emerged as participants strived to succeed as Māori in the formal education system. To this end, Bourdieu's analysis (Bourdieu, 1984) has currency because it illuminates the ongoing struggle between two fields - te ao Māori and te ao hurihuri - and the tension and conflict that arises in the acquisition of Pākehā cultural capital within a Māori context and vice versa. Within formal education, no participants talked about trying to transform the rules of the field. They played to the rules (whereas the majority of Māori struggle to reconcile the tension between Pākehā cultural capital and their own, and are educationally alienated or marginalised), and were able to 
enact their learnt dispositions, cultural wealth and ways of being in order to achieve academic success.

The idea of Māori achieving success as Māori within the education system is a dominant discourse in Māori education literature today (Caccioppoli and Cullen, 2006; Durie, 2003, 2011; Penetito, 2010a). The participants reflect the fruits of this discourse in action, but despite their academic success the battle between the legitimation of Māori cultural capital and Pākehā cultural capital within the field of education was relentless. Moreover, when put into the broader context of overall Māori student educational attainment and achievement, the cold, hard reality is that this cohort's success represents a small blip on the educational outcomes screen. By far the majority of Māori students drop out, fall out, or are kicked out of the education system which has, over successive generations, failed Māori students and, despite good intent, a sizeable chunk of rhetoric and politicking, continues to do so.

This tension continued within a higher education field as the university environment was foreign to most participants in a number of ways. First, Māori students were still the minority, but even more so than at secondary school. Second, academic expectations and demands were higher. Third, many participants had moved away from home for the first time to attend university. Fourth, participants talked about a concentrated cohort of academically successful Māori being strong in their identity as Māori.

So what were the critical success factors for participants in higher education? Culture counts in the classroom no matter what the context - early childhood, compulsory or higher education (Bishop and Berryman, 2006) - and the data would certainly support this statement. For example, participants emphasised the critical role Māori student support groups, associations and networks had at university in terms of providing a safe, nurturing and culturally relevant, academic-based support group. In essence, participants drew on their cultural identity and practices to realise their aspirations and dreams. These support groups reinforced their cultural capital to bolster their resilience and wherewithal to succeed. 
The important role Māori-centred support groups and networks have in terms of fostering and enhancing cultural identity within an academic setting is supported by the literature (Durie, 1994; Selby, 1996). For example, Bennett (2003) looked at the moderating effect cultural identity had on student problems and grade point average. His research findings suggested the relationship between student problems and grade point average was moderated by cultural identity. In short, among Māori students a strong cultural identity increased one's resilience to the difficulties academic life presents (2003:62). Bennett's findings are congruent with the data which also indicated how a strong work ethic, perseverance, resilience and Māori cultural capital were equally as important to Māori higher education success. Many participants talked about how they were determined to succeed, persevere and get to the end of their higher education studies - failure to finish was not an option. At this juncture it is salient to note, however, that the New Zealand education system has a long history of excluding Māori and current Māori higher education statistics suggest little has changed. Herein lies the paradox of higher education and education per se in that on one hand education can be a potential source of emancipation and transformation, while on the other it can be a source of exclusion and deprivation.

\section{What Is the Transformative Potential of This Cohort?}

This cohort provide a new perception of what is possible and achievable, not only for their whānau, hapū and iwi, but for Pākehā, Pasifika and other minorities living in Aotearoa New Zealand as well as indigenous peoples across the world. They are highly educated, well resourced and possess the requisite credentials and capital valued in a capitalist society, importantly they possess a rich cultural wealth and commitment to contribute to collective aspirations and wellbeing. This responsibility to give back was an omnipresent force in participant life-worlds. In short, this cohort possesses significant transformative potential to create both structural and culturalbased responses and strategies. 


\section{Individual Success Rooted in a Collective Ethic}

The research data indicated how the individual pursuit of academic and professional excellence was paradoxically accompanied by a deep-seated commitment to contribute to the collective. This raises interesting questions around what it means to be Māori and to be recognised as part of whānau, hapū and iwi. Can you be Māori and not feel the need to give back? Is there space for the individual within the collective? Is the collective ethos set in stone or can it be modified, adapted and transformed?

Potential answers to these complex questions might be found in Māori oral traditions. For example, the importance of individual pursuit and endeavour is eloquently illustrated in a traditional oriori (lullaby) called 'He oriori mo Tūteremoana' (Ngata, 1948). Tūteremoana was a famous descendant of Tara the eponymous ancestor of Ngāi Tara, a tribe that once held rank across the Hawkes Bay, Wairarapa, Kāpiti and Wellington regions. The lullaby was written for Tūteremoana by Tūhotoariki his grand uncle and tohunga and speaks to the power of the mind, intellect, knowledge (spiritual, physical and metaphysical) and the importance of protecting such knowledge. Moreover, the lullaby encourages the individual pursuit of knowledge, but locates the individual within a broader context of whakapapa, thereby connecting that individual to his or her ancestors, contemporary peers and progeny. The knowledge embedded within this lullaby reminds us that individual success was encouraged and indeed celebrated in traditional society, but perhaps more importantly that individual success was indelibly connected to collective wellbeing - past, present and future.

Moreover, the emerging discourse around Māori concepts of giftedness and gifted education provide further insights into this idea of individual success rooted in a collective ethic. According to McKenzie (2001), Māori view giftedness as being owned by an entire group, for the benefit of all. Webber (2011) highlights some of the indicators of giftedness, for example working cooperatively with others (Cathcar and Pōu, 1994), whānau-based achievement (Milne, 1993) and the importance of spirituality and inter-personal relationships (Niwa, 1998). She argues these indicators stem from the traditional belief that advanced ability was a gift from the 
gods, not for the individual's sake, but for the benefit of the whole of the tribe. Meanwhile, contemporary research on giftedness among Māori children indicates the obligation to serve others still exists (Bevan-Brown, 2004). Whether or not this highly educated cohort is viewed as 'gifted' or not, the key point is that in Māori lifeworlds the individual is always located within the collective. This does not diminish the pursuit of individual success and achievement, but invokes a responsibility to contribute and give back to collective aspirations. For example, Taiawhio commented on the need to create and provide opportunities for all whānau to contribute as well as challenge negative stereotypes about what it means to be Māori:

Being poor is not proxy for being more Māori / being unemployed does not make you more Māori / so long as there is intentional action to contribute / and / give back / to contribute to the greater collective / then we need to provide a range of skills and opportunities for whānau to contribute.

The tensions between the individual versus collective was one of many dialectics to emerge in the participants' life-worlds as they carved new landscapes for themselves and their whānau.

\section{Whānau Strategies}

Transformation can occur at a range of levels and the data showed how at present transformation is happening at a micro level within whānau (identified as the critical site of transformation). However, this effort and resource is uncoordinated. The range of strategies used by participants were to provide support (material, physical, cultural and spiritual), particularly to the younger generation, nurture, love and be positive and humble role models, and demonstrate ways of operating appropriately in both te ao Māori and te ao hurihuri. For example, Ihaka commented on how he is trying to create change within his whānau:

We need to look at our kids / make sure that they're doing alright I sometimes we can get a bit too macro / here I was / looking at all of these great kids that had awesome potential / but / I realised l've got nieces and 
nephews right here who are on drugs / yet / they're the brightest kids l've ever met / and / here I am focusing so much attention out there / not focusing enough attention on these kids right next to me.

A whānau-centred approach to transformation and change sits at the heart of whānau ora - a contemporary policy discourse and approach adopted by New Zealand government agencies in the delivery of health and social services to Māori (Te Puni Kōkiri, 2012). While such an approach is relatively new to the public sector, whānau has long been identified as the fulcrum of language revitalisation efforts and language protagonists argue the home is the most powerful domain through which a language can be revitalised by whānau for whānau (Fishman, 2001; Karetu, 2002; O’Regan, 2009). Thus, strong, vibrant and healthy whānau are needed to bring about structural transformation.

At a macro level, participants highlighted the need for a collective vision and strategy to create cohesion among Māori who are materially well off to prevent this cohort from unintentionally working against each other or in competition. For example, Kahukura supported kotahitanga and the creation of a shared vision to inspire and mobilise:

Now big numbers of us are coming through / we're all working at guessing what the vision is / and / if we don't have a shared vision / then it leaves it up to luck / and / if there's no coordination / no leadership / then everyone's just going to do their best / and / might be working in a competitive way / to the detriment of each other's actions / I think the strategy is to have someone lead the charge around kotahitanga - unification.

Kahukura's narrative is about strong, inspirational and connected leadership as a lever to build cohesion amongst highly educated and resourced Māori. Most participants commented on how current Māori tribal and pan-tribal leaders were disconnected from the lived realities of the whānau, hapū and iwi which made transformation for the collective difficult to realise. 


\section{Iwi (Tribal) Strategies}

Whakatupuranga Rua Mano provides one example of how a collective vision and whakapapa-based strategy can create cohesion and spark whānau, hapū and iwi transformation through the medium of education (Walker, 2011). Whakatupuranga Rua Mano was a vision created to give effect to the educational aspirations of Te Âti Awa, Ngāti Raukawa and Ngāti Toarangatira descendants (Winiata, 1978, 1988). Education sits at the heart of this vision and culminated in the establishment of Te Wānanga ō Raukawa in 1981 and Te Kura ā iwi ō Whakatupuranga Rua Mano - a composite primary school created by the iwi for the iwi. The Whakatupuranga Rua Mano model shows what can be done when education is used as the vehicle to implement a clear, planned and cohesive strategy.

Undoubtedly, it will take time to build a critical mass of highly educated Māori committed to collective aspirations, but the literature suggests that once a significant cohort is established and efforts coordinated, transformative action will have a greater chance of success and spread across whānau, hapū, iwi and communities. To this end, participants theorised transformation in a number of ways. For example, all acknowledged the need to create and effect change at a structural level, particularly for whānau living on the margins socially and economically, but how and what this change might look like proved more difficult to articulate. Moreover, participants cautioned against the creation of a large cohort of highly educated Māori disconnected from their cultural roots and all of the things that made them Māori (i.e. whakapapa, whanaungatanga, manaakitanga). Furthermore, participants insisted their educational and occupational success was just one pathway, one measure of success, and encouraged a range of pathways to achieve success, wellbeing and fulfilment in one's life.

This idea of multiple expressions of transformation is supported by Pihama (2001) who talks about transformation as one driving element in kaupapa Māori, but explains how transformation is defined and brought about is determined by how issues are understood, theorised and engaged (2001:102). 
An important point to take from Pihama's thesis is how materially wealthy Māori are resourced to contribute to transformation and provide one key to unlocking the complex jigsaw puzzle that is social inequality and racism - these are powerful ideologies deeply embedded within the structure of society.. That said, is it naive to think this cohort can lead transformation when inequalities are embedded at both a structural and ideological level? To be blunt it is unfair, but it is the reality and gravity of the situation that Māori as a collective are in today. If not this cohort, who? Clearly, there is no one simple solution or quick fix to this complex problem; however, this cohort provides one pathway towards transformation and is well positioned in terms of cultural and material wealth to be the agents of change. The other keys to dismantling ideological and structural inequality will be revealed through conversations with Māori as individuals and collectives - whether that be whānau living on the margins, working-class Māori, Māori elite, Māori living overseas - engaged in a process of sharing, talking, theorising, defining, naming, visioning and acting on and for transformation (Pihama 2001; Smith, 1997, 2003b).

\section{What Role Does Class Consciousness Play in Transformation in Contemporary Aotearoa New Zealand?}

The data showed the absence of class consciousness among this cohort. The relationship between class consciousness, class identity and class action is a key tenet of traditional social class perspectives (Devine, Savage and Crompton, 2005). Thus, the idea of class action sparked by a critical class consciousness seems less likely if people do not identify with social class. Payne and Grew (2005) suggest class at the individual level lies dormant until ignited by one of multiple expressions of class which may or may not result in action. They argue it is precisely this level of passivity that makes class action so difficult to cohere.

\section{Class Ambivalence}

At a surface level, the data pointed towards social class ambivalence among participants. Social class ambivalence can be defined as people's reluctance to use class in personal terms, but rather to use it in a wider societal context that is 'out there' rather than something close and personal (Savage, Bagnall and Longhurst, 
2001). The data reflected a lack of articulate class descriptions and analysis, outright rejection of class and reticence to even talk about class.

Payne and Grew's (2005) research on 'class ambivalence' promotes a broader interpretation of social class:

"If we escape from excessively formal theories of social class we will find more people using what 'they' mean by class, in a consistent rather than ambivalent way. Inarticulateness about complex concepts like class does not mean a lack of salience." (2005:893)

They argue when people are asked to place themselves in a social class, they find it a complex task because class is a complex concept, and respond by invoking a variety of criteria relevant to their own understandings (lbid:901). One of the key points is how class can be expressed without using the 'c' word; thus, apparent ambivalence reflects uncertainty about class in general. This point resonates with this research study. For example, most participants did not use the term 'class' or class specific terminology; however, they talked about being credentialed, educated, rich, poor, and status, power, hierarchy, networks, inequality, the system, the structure, capitalism, revolutions and the impact of strikes on rural labour markets and communities. For example, Ihaka strongly rejected class as a concept, but talked openly about growing up poor:

Oh / poor / we were / there's no doubt about it / we struggled / with a solo mum / raising three kids / without the assistance of the dads / before DPB / but / in saying that / she taught us the value of a good work ethic / that actually / you don't have a choice / you just had to work.

Ihaka's narrative highlighted the relationship most parents had with the means of production, that is, low-paid employees who worked long hours because there was no other choice. While half of the participants did not identify with social class, this does not reflect a lack of salience in their lives because class-related ideas were embedded in the participants' language without being made explicit. What it does 
mean is, at the level of social class, the absence of a class consciousness makes collective action difficult to facilitate. If, however, we are to invoke whakapapa, the potential for collective action offers exciting potential. For example, one of the unique and distinguishing features of this cohort is the inherent motivation, desire and responsibility to contribute and give back to the collective, starting within their own whānau. All are contributing to their whānau in a range of leadership, mentoring, role-modelling and financial support roles. At an iwi level, a few participants are employed, but the majority worked voluntarily. It is these whakapapa-based connections which make it possible to cohere and provide the impetus for action. In short, whakapapa is an enabler and mobiliser for action.

\section{Habitus in Te Ao Māori: Participants' Life-worlds}

The narratives spoke to the rich cultural knowledge and practices embedded in the participants' life-worlds and I will draw on Bourdieu's notion of habitus to cast a theoretical eye over these life-worlds. According to Bourdieu, habitus is "the way a culture is embedded in an individual" (Harker, 1985:65). Habitus was salient in the participants' life and educational trajectories, but not so much habitus within te ao Pākehā, rather their habitus in te ao Māori. Habitus in te ao Māori was about having a strong work ethic, whanaungatanga (interpersonal relationships), manaakitanga which can be perceived as being "outstandingly hospitable or generous"(BevanBrown, 1992; Macfarlane, 2004) or caring for and helping others and a commitment to collective aspirations. It was also about Māori parents who had high educational expectations and aspirations for their children. While this relational ethic is prominent among Māori, it is still nurtured in Pākehā society, e.g. private schools, school badge and school song, to generate a collective inspiration across generations. Within Māori habitus, however, this relational ethic is embedded the level of whakapapa (genealogy), which sits at the core of Māori identity and is the fundamental organising principle that permeates the whole of Māori culture (Barlow, 1994; Mead, 2003). This habitus is described in more detail below.

\section{Cultural knowledge and practices}

At the heart of habitus in te ao Māori were the values instilled in the home and community. Although universal, these particular values were expressed in a Māori 
way, shaped and influenced by cultural knowledge and practices. For example, a strong work ethic was modelled by parents who worked tirelessly in predominantly manual-oriented labour to provide a better life and opportunities for their children. It was about working long hours for minimal wage and making personal sacrifices for the whānau. A strong work ethic is by no means exclusive to Māori, and it could be argued this is a common feature of the 'Kiwi psyche'; however, it was about more than just working hard for hard work's sake, it was about working hard to gain an equal footing as Māori in a society where very few Māori prospered materially and where the majority of Māori were consigned to lower-paid manual labour. For example, Matiu commented on how his parents worked long hours in low-paid farm work:

The biggest value is to work hard / My parents worked extremely hard / They would work from very early in the morning / till really late at night / l'd often be home by myself after school / because they'd be at work / that's very ingrained in me / you don't get anything / unless you work for it.

Matiu's narrative highlighted a common theme, that is, how parents sacrificed time with their family in order to put food on the table. The implications of this work ethic were most participants spent limited time with the main breadwinner, which was in most instances their father. This work ethic was supported by whanaungatanga and a collective ethic whereby participants grew up surrounded by whānau and were socialised into a context that affirmed they were part of a bigger whole. The centrality of whakapapa, whānau and kinship ties in traditional and contemporary Māori society is well documented (Marsden, 2003; Metge, 2010). The data showed how whanaungatanga was an enabler for manaakitanga and tuakana tēina (rolemodelling) responsibilities and provided the context within which all participants developed a sense of contribution and commitment to collective aspirations, but perhaps more importantly it was about having a 'wealth' from which to draw on whatever the context. 


\section{Parental educational attainment aspirations}

A second critical feature of Māori habitus was the high educational expectations and aspirations parents expressed for their children, despite the negative experiences most had within the formal education system. These experiences showed a level of enculturation into a racist society from parents who wanted the best for their children. Moreover, although parents possessed minimal material wealth and academic networks to actively support academic success, they wholeheartedly supported the idea that educational attainment would help to create a better life. For example, Manaakiao commented on how strong the education ethos was in his whānau and the family history that underpinned this ethic:

Mum especially pushed us / It goes back to the dirt floor mentality [mother grew up in a traditional whare with dirt floor] / Education was always big in our family / My grandfather really pushed education / he went to Te Aute on scholarship / ...he was according to various accounts a brilliant mathematician / mum's family were very much products of that time / you got a Pākehā education to better yourself / the whole 'E tipu e rea' [shortened reference to famous proverb by Māori leader and scholar, Apriana Ngata, which encourages Māori to pursue the best in te ao Māori and te ao hurihuri] philosophy was part of their thinking / but I don't so much think it was meant to be at the expense of being Māori / it was just to get a good education.

The sentiments expressed by Manaakiao were echoed by many participants and as he pointed out this is not altogether surprising given the legacy of influential Ngāti Porou scholar, leader, politician, composer and philosopher, Tā (Sir) Apirana Ngata. In his dogmatic proverb 'E tipu e rea', Apirana encourages Māori to embrace the tools of the Pākehā, particularly education, as well as stand strong and proud in one's identity as Māori (Keelan, 2001). E tipu e rea is still widely used today as a source of inspiration and motivation for Māori young and old (Walker, 2001). Thus, education has long been viewed as a vehicle for emancipation and transformation by Māori, indigenous and marginalised peoples alike (Durie, 1998; Freire, 1972; Smith, 2000). In the United States, Gandarra (1995) highlighted how Chicana/os have the lowest educational outcomes compared to every other group in the US, but 
Chicana/os parents consistently maintained high educational aspirations for their children's futures. These parents nurtured a culture of possibility, despite having minimal material resources and networks to support such aspirations. Both Chicana/os parents and their children represented the "creation of a history that would break the links between parents' occupational status and their children's academic attainment" (Gandarra, 1995:55). This idea resonates with the data which showed most, if not all, parents expressed a high level of educational aspirations despite not having the academic credentials, networks or resources to actively support these aspirations. Moreover, most participants were the first in their whānau to attend and graduate from university, and were in this sense pioneers in higher education. Taite explained how the idea of university was instilled from a very young age by his Pākehā mother, who came from a family of educators:

Education is valued in our family / especially for mum / From a very young age / I always remember mum saying to us / what are you going to do at university? / We were always told that was where we would go / we never knew what it was exactly / but / the seed was planted.

Taite's comments were echoed by many participants who talked about how parents actively encouraged, cajoled and directed them towards a university education, despite most never having attended university themselves. Furthermore, a social class discourse tells us the link between parents' educational attainment and that of their offspring is critical (Ermisch and Francesconi, 2003). The majority of parents, however, left school without formal qualifications which was the norm during the 1950s, '60s and '70s, when jobs, particularly in urban areas were plentiful (Te Puni Kōkiri, 2007; Waitangi Tribunal, 2004; Walker, 1992). In short, parental qualifications had little bearing on participant educational attainment. This finding is supported by Gibbons (2011) who, based on his analysis of intergenerational economic mobility in New Zealand, claims parental education does not play a huge role in social mobility and labour market outcomes; rather it is the person's education that is critical (2011:58). While the research data set used in Gibbons' research is relatively small and the Māori sample size unknown, his findings raise interesting questions around how the absence of parental qualifications and formal academic knowledge might be reconciled by invoking Bourdieu's ideas around 
habitus, cultural capital and field. Moreover, it also raises the question about what then makes these participants different beyond their own educational outcomes. The data highlighted how part of the answer can be attributed to the participants' habitus in te ao Māori - another part is the rich tapestry of cultural wealth they were socialised into.

\section{Cultural Wealth: A Mãori Cultural Capital?}

Education outside the classroom played an important role in helping to shape the participants' cultural capital. For example, what parents did not possess in terms of formal academic knowledge was usurped by a rich tapestry of cultural, social, placebased and esoteric knowledge. The benefits of place-based education in terms of creating positive educational outcomes for indigenous peoples is well documented (Barnhardt, 2008; Gruenewald, 2003; Kawagley, 2000; Smith and Sobel, 2010). The analysis showed how cultural and place-based knowledge was exchanged in a range of contexts. For example, participants were immersed in esoteric knowledge (e.g. karakia and whakapapa) and mātauranga ā iwi at wānanga, marae, church and papakāinga and practical skills were exchanged in the home, community, at the beach, maunga, ngāhere and sports fields to name but a few. To this end, many participants talked about being 'educated' long before they entered the formal classroom. Within these learning contexts parents instilled and fostered a sense of curiosity, love of learning, strong work ethic, tenacity, discipline, perseverance and commitment. For example, Teaniwa shared how her father helped to lay a good foundation in the home:

My father taught us those basic fundamentals of life and identity / if you lay down a desire to learn / the education system can take over / and / transform you into productive people... / For Māori / I think the education system can partly transform / but / only if it's on a solid foundation of / I have a responsibility to my whānau / to my iwi / to contribute.

Teaniwa's narrative is about the way in which cultural knowledge, place-based knowledge and values are important not only to identity formation, but also as an 
important impetus for success and transformation. Meanwhile, Arohia commented on how she was raised by 'queens' in an inner city context:

My nan and the queens [transvestites, transgender people and transsexuals] were really resourceful / I mean if you were the outcasts of the day you knew how to make things / you knew how to gather / you knew how to weave / you knew how to survive / you knew all of those things / Even though they were men / they were also women in a sense / so as kids / we had the best of both worlds.

Arohia's narrative showed how cultural identity and practices were used to survive in an inner-city environment. It also highlights another common theme, that is, resilience. In this sense resilience means the ability to get on with life, survive and make do in the face of explicit racism and discrimination and to use one's own cultural practices to do so. This idea is also closely related to self-determination (Lavallee and Clearsky, 2006) or what Māori refer to as tino rangatiratanga or the right and freedom to choose and determine one's own destiny (Jenkins and Pihama 2001; Mutu, 2011; Pohatu, 2003, 2004).

Similarly, Te Kohi expressed how wānanga (house of learning based on traditional pedagogies and practices) helped to shape his identity:

The journey of education / knowledge / mātauranga / mohiotanga / not just through formal institutions / but / wānanga / the key thing that I always remember from wānanga is / 100 percent is a failure / 110 percent is what you're expected to get / 100 percent / you'd only just kill your opponent / my marae / my wānanga teaching / ensured that formal education would grow me in a certain way.

Te Kohi's narrative emphasised the importance of cultural wealth in te ao Māori and how this wealth shaped identity and created resilience and wherewithal, which he, like many others, applied and transferred into formal education settings in te ao hurihuri. 
Educational sociologists agree schooling and education play a pivotal role in producing and reproducing the dominant (Pākehā) cultural capital (Lauder and Hughes, 1990b; Thrupp, 2001). The data supports this idea to a certain extent. For example, all participants were exposed to negative stereotypes about what it meant to be Māori. This did not mean, however, Pākehā cultural capital superseded Māori cultural capital in the participant's life-worlds. Rather, the data revealed an abundant and rich cultural wealth existed within the home and community outside the dominant cultural capital of the school. This cultural wealth was hugely important to the participants' educational trajectories and all participants developed a cultural capital based on what was intrinsically valued in their life-worlds. This is hard to define given the diverse realities of participants; however, the narratives point toward Māori cultural capital comprising the following components: a strong work ethic; an understanding and practice of whanaungatanga and manaakitanga; some knowledge of te reo me ōna tikanga; tangible connections to one's iwi; a deepseated commitment and motivation to contribute to the collective; and place-based Māori knowledge and/or mātauranga. This is by no means an exhaustive list, but a starting point for discussion around what Māori cultural capital might look like. Indeed, there is an interesting discussion to be had here about how Māori have their own ontological precepts and do not have to rely on any imported variety (from the Pākehā world) in order to define their subjectivities or what would count as what it means to be Māori.

Nonetheless, the articulation of Māori cultural capital is evolving albeit slowly, particularly within a business context as indigenous business leaders and entrepreneurs seek new ways to analyse and explore the cultural factors which distinguish Māori businesses from others and give them a unique competitive edge (Best and Love, 2010; Robinson and Williams, 2001). Within an education context, however, the critical point is participants were socialised into their cultural capital based on their whānau background and resources learned through both social and cultural interactions. To this end, Yosso (2005) draws on critical race theory (CRT) to challenge Bourdieu's cultural capital thesis and argues Bourdieu sets white middle-class capital as the norm, the standard against which all others are judged. Conversely, she presents a new interpretation which shifts the centre of focus from notions of white, middle-class culture to the cultures of communities of colour and 
encourages us to learn from the cultural knowledge, skills, dispositions, abilities and networks possessed by these communities (2005:69). CRT in education can be defined as "a theoretical and analytical framework that challenges the ways race and racism impact educational structures, practices, and discourses" (Ibid:74). Similar to the ideas espoused by Hooks (1994), Freire (1977) and kaupapa Māori protagonists (Pihama, 2001; Wilkie, 2010), CRT is a social justice project that works towards the liberatory potential of schooling. Thus, CRT highlights the contradictory nature of education in that "schools more often than not oppress and marginalise while they also maintain the potential to emancipate and empower" (Yosso, 2005:74)

The idea of community cultural wealth is wholly relevant to this thesis in that it reframes the notion of capital within an indigenous context. For example, Yosso identified six forms of capital through which cultural wealth is nurtured: aspirational, linguistic, familial, social, navigational and resistant. Each form of capital is part of a dynamic process that intersects to shape community cultural wealth. Aspirational capital refers to the ability to maintain hopes or dreams for the future, even when faced with real and perceived barriers. Linguistic capital is about the intellectual and social skills garnered through communication experiences in more than one language or style. Familial capital refers to the cultural knowledge nurtured within the family, the sense of community, history and memory, and includes a more broad understanding of kinship. Social capital includes the networks of people and community resources. Navigational capital can be understood to be the ability to manoeuvre through social institutions not created with communities of colour in mind. Finally, resistant capital refers to the knowledge and skills acquired through oppositional behaviour that challenges inequality. This form of capital is grounded in the legacy of resistance to subordination by communities of colour.

Based on Oliver and Shapiro's (1995) work, Yosso (2005) developed a model of community wealth as presented in Table 8 below. The model shows the six forms of wealth which coalesce to shape and inform community cultural wealth. This model was used to develop the Māori cultural wealth model presented in Table 9. 
Table 8: Oliver and Shapiro Cultural Wealth Model

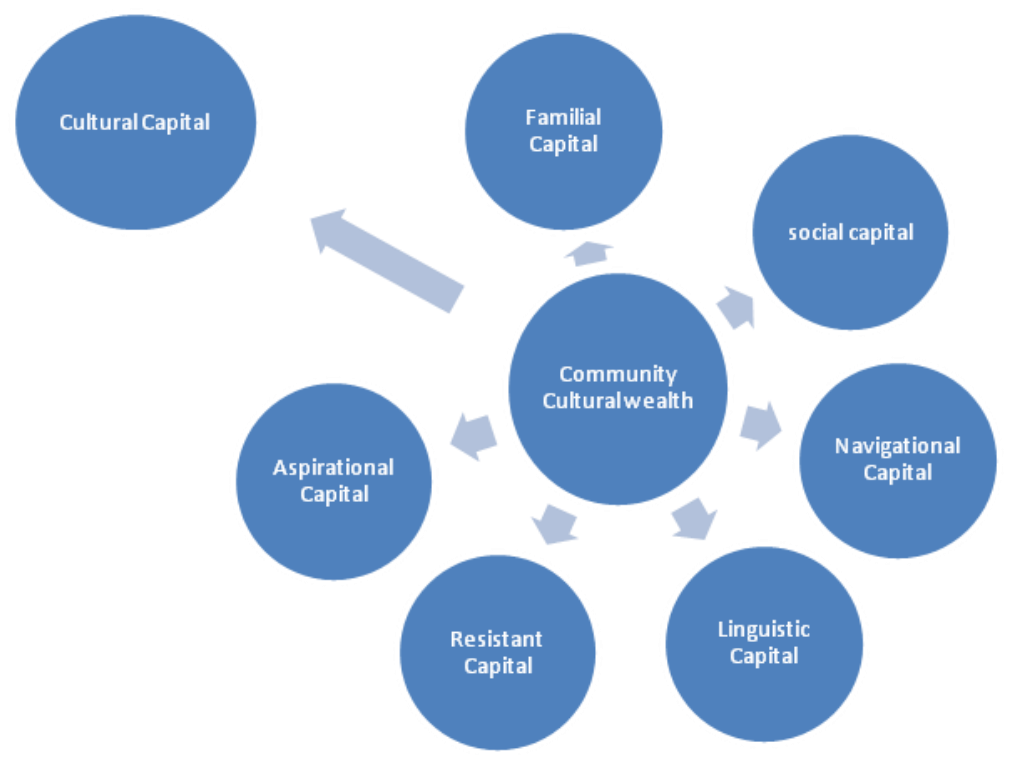

Table 9: Māori Cultural Wealth Model

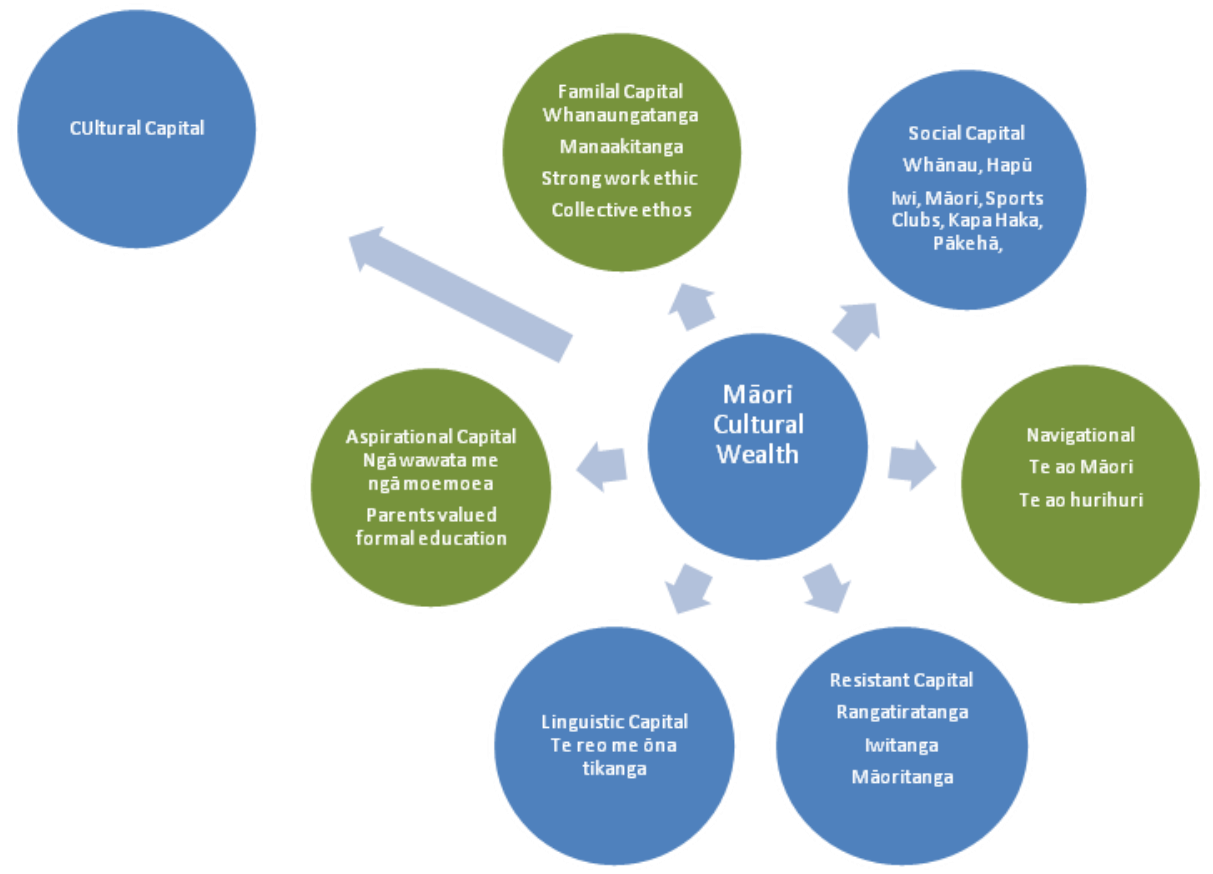


The Mãori cultural wealth model presented above maps the dimensions or cultural capital forms that featured strongly among the participants. It provides one framework for conceptualising the ways in which participants expressed their cultural wealth. While all six forms of cultural wealth were expressed, three forms stood out above the rest (as highlighted in green): familial capital; aspirational capital and navigational capital.

Familial capital was evidenced by the core values passed down in the home (whanaungatanga, manaakitanga, a strong work ethic), as well as strong kinship ties and the sense of responsibility to contribute to collective aspirations. Aspirational capital referred to the high value all parents placed on formal educational achievement, as well as their desire for participants to have a 'better life' and greater opportunities. Navigational capital was demonstrated by the resilience, wherewithal and ability to shift between two worlds and navigate the tides of discrimination, racism and prejudice in a range of contexts. Overall, the model presents a rich tapestry of cultural wealth - Māori cultural capital that coalesced to shape participants' lives and, for most, in the absence of significant levels of material wealth.

Within an African-American context, Franklin (2002) defined cultural capital as "the sense of group consciousness and collective identity aimed at the advancement of an entire group" (2002:177). Similarly, Morris (2004) explained "Black people share their cultural capital with one another and developed their social capital (Black social capital) for survival and success in a segregated world bounded by the omnipresent forces of racism and discrimination" (2004:102). Although grounded in AfricanAmerican experiences, both commentaries resonated with the data which showed how participants contributed time, resources and energies to realise collective aspirations. The important point is that in the process of identifying elements of Māori cultural wealth, we identify the levers and impetus for transformation based on the assets and resources already abundant in Māori communities. It is about rangatiratanga, that is, Māori defining and determining their own pathway to success and the strategies needed to get there. As Morris so eloquently states "it is important that social capital theory also consider the agency and sustenance that are characteristic of African American people, culture and institutions - apart from 
and in response to oppressive forces" (2004:102). Moreover, the research data validates the link between Māori cultural capital and a collective consciousness. Thus, the impetus and enabler for transformation comes from within te ao Māori.

\section{Do Māori Perceive Themselves in Social Class-based Ways?}

The data indicated the majority of this cohort does not perceive themselves in classbased ways. Based on traditional Western social class indicators (i.e. qualifications, status, income, and occupation type), they possess the social, political, educational and cultural capital that says they are part of the emergent middle class. They are highly educated, mobile, not necessarily asset rich, but wealthy in terms of income, choices and opportunities. These indicators, however, only tell part of the story. What distinguishes this emergent cohort from a traditional Western middle-class cohort is their 'cultural wealth'. It could be argued this is also the qualification for a Western middle-class cohort, i.e. socialised into a Western cultural capital and rich habitus in Western society, but the point of difference is the Māori cultural base and habitus as an enabler - which supports this cohort to navigate and shift between a Māori and Pākehā world and operate successfully in both. In short, the data showed how social class was relevant structurally, but not culturally or socially. The majority of participants were ambivalent towards social class, did not identify themselves in terms of class and consequently did not express a class consciousness. Thus class has resonance, but it is not the whole picture.

Furthermore, the data emphasised how social class perspectives do not provide the theoretical 'space' to fully capture the rich, nuanced and subtle complexities and lifeworlds of contemporary Māori. For example, Bourdieu's concept of cultural capital and social and cultural reproduction are important to understand in terms of unlocking one key to overcoming disparities; however, in the context of this thesis the data showed how these frames of analysis were not particularly useful. As highlighted by Yosso (2005), one reason for this is that the orthodox view of cultural capital privileges a white cultural capital over all others and ignores the rich cultural wealth inherent in all cultures and communities. The data showed how a humble material wealth and limited parental academic support and networks were more than adequately supported by the values and collective ethic instilled in the home 
and a rich cultural wealth - Māori cultural capital. In short, a lack of material wealth was not a barrier to achieving academic success. In fact, for some, material deprivation was a key driver for success.

Within an Australian international education context, Singh and Huang (2012) highlight how Bourdieu's theories help to maintain Anglophone education and limit the space for internationalising education for non-Anglo peoples to better reflect a diverse range of life-worlds and experiences. Similarly, Reay (2004) cautions against the habitual use of Bourdieu's concepts like habitus, and encourages ongoing critique and expansion on his ideas. Nonetheless, class perspectives have relevance because Aotearoa New Zealand is built on a Western model of capitalism. The salient point, however, is there is something more happening in Aotearoa New Zealand, something that current social class paradigm does not allow for.

\section{Why Is This Topic Important?}

The data showed how this research is important for three reasons. First, it showed the critical role higher education played in terms of building a critical consciousness and providing opportunities for participants to create a comfortable material life which enables them to lead transformative strategies, but importantly how this was supported by a rich cultural wealth which helped mitigate the absence of material wealth.

Second, this research provides empirical evidence which substantiates what is known anecdotally - an emerging Māori middle class exists that is highly educated, mobile, well paid, whānau- and action-oriented, committed to collective aspirations and successful in navigating between te ao Māori and te ao hurihuri (Harrington, 2010). This cohort is stuck in the middle somewhere between their working class roots and a Māori elite. In short, this cohort is poised and positioned to take up Gramsci's call for organic intellectuals to lead and contribute to transformation.

The third reason why this research is important is because the research data showed how a potential key to unlocking and overcoming inequalities lies in 
whakapapa as an enabler and mobiliser for action. What differentiates this emergent middle class is the paradox which Canadian legal scholar, Johnston, refers to as the 'self collective' (1989: as cited in Penetito, 2010a:269) - the pursuit of individual success rooted in a collective ethic and collective aspirations.

Discussions around Māori cultural ethics, the imperative of relationships as defined in whakapapa and an embedded responsibility to others as manifest in manaaki and aroha borrows from the scholarship of Emmanuel Levinas (1998) in his challenging and profound 'ethic' or philosophical work entitled 'Otherwise than Being or Beyond Essence'. Cohen (1998:xi as cited in Levinas, 1998) argues at the heart of Levinas' thesis is the "irreducible ethical proximity of one human being to another, morality, and through that encounter a relation to all others, justice". In short, Levinas' philosophy is about how as human beings we are ethically and morally connected, which through face-to-face encounters creates an embedded responsibility to others and a call to justice.

Hoskins' (2010) PhD thesis draws on Levinas' philosophy and ethic to consider nondominating and relational forms of authority and justice between Māori and Pākehā in the social and educational context of New Zealand. He argues how Levinas' philosophy provides a powerful theoretical framework for the creation of an ethical social relationship (and therefore ethical politics) to challenge and counter the liberal political economy - a framework that is applicable to a range of social, political and economic sites (2010:1). Furthermore, Hoskins highlights how Levinas offers "an account of the subject, in which, prior to or beyond being an autonomous ego, I am bound to the other. In being constituted heteronomously, I am, before any sense of self preservation, infinitely responsible to the other" (2010:1). This statement resonates with the data which shows how whakapapa binds and connects this cohort to the past, present and future. It tells them they are part of a bigger whole and demands they share, reciprocate and contribute to the collective. 


\section{Summary}

This thesis is focused on creating change and transformation using both cultural and structural responses. The analysis presented in this chapter shows a critical mass of highly educated contemporary Māori are taking up this challenge within their whānau, but effecting change at a structural level will require a more coordinated and strategic approach. Thus, is good will, commitment, motivation and desire enough to effect true and sustainable change at a structural level? Will this cohort, despite all of their good intent, simply contribute to maintaining the status quo? Is this emergent middle class part of the problem or the solution? Will this cohort simply close the door behind them or leave it open for others to follow? The answers to these questions are complex. While collectively Māori are still pōhara (poor), at the same time Māori are incredibly rich culturally. Kaupapa Māori and transformative theories challenge us to look at the cultural wealth within our whānau, hapū and iwi, to draw on this as a source of strength and inspiration, as well as look outside te ao Māori for solutions, tools, theories and strategies that work for and not against us as we strive for structural change. What these approaches offer will be further discussed and analysed in the next chapter which presents some concluding statements and remarks. 


\section{CHAPTER EIGHT: CONCLUSION}

\section{Introduction}

In this final chapter I weave together what I have learned from this research study. I ask: what does this research mean in terms of creating positive transformation for Māori within the context of contemporary Aotearoa New Zealand using both cultural and structural approaches and strategies?

\section{The Role of Education and Models of Transformation}

At its heart this thesis is about the power of education to transform (Penetito, 1997) and the research has shown how higher education success has played a liberating role and helped to create a cohort of highly educated organic intellectuals committed to transformative action. Smith (2006) highlights how the neo-liberal agenda wants a Māori middle class to rise in education in order to maintain the status quo, as individuals in a market-driven society. However, it has not worked out that way for two reasons. First, not enough Māori have made it through to higher education and, second, those who have are in fact committed to collective aspirations and the revitalisation of te reo me onna tikanga. The research data certainly support this thesis - participants have successfully navigated and achieved in an inherently racist education system embedded within a capitalist economy, yet remain steadfast in their commitment to a collective ethic. They are, however, the minority and the educational success of the few should not distract us from the cold, harsh reality that far too many Māori do not make it in the education system.

So how do we create change within an oppressive and racist education system? In his potent analysis of Māori education and mainstream education in Aotearoa New Zealand, Penetito (2010b) offers some revolutionary thoughts for us to consider. He posits a theoretical model based on four principles and strategies for intervention aimed at strengthening education in both mainstream and kaupapa Māori schooling. First, he argues how real change must start at the ideological level with a critique of the assumptions that underpin the education system: 
"The existing education system will never work in the real interests of Māori so long as the central philosophical assumptions of the education system remain entrenched in the Western tradition." (2010:256)

Māori are saying that being Māori does matter and the education system must do better in incorporating Māori knowledge through pedagogies based on Māori aspirations. The same can be said for the rest of the system - be it in health, social services, public policy or the political economy. The appalling statistics for Māori across a range of indices speak to an ideology, system and structure which privileges one culture and one people over all others, and Māori have maintained for many years that this simply is not good enough (Walker, 1987, 1996).

Penetito's theory is premised on the idea of an 'imbricated relationship' - one that retains the integrity of both/all parties while seeking an education in the interests of all (2010:250). The overlap or interface between Māori education and mainstream education reflects the negotiated space between te ao Māori and te ao hurihuri. Penetitio argues for a theory of schooling for mainstream education which makes explicit the educational theories that underpin the system, a mainstream theory to sit alongside a theory of schooling for Māori expressed in Te Aho Matua, the philosophy of kura kaupapa Māori (Sharples, 1988). If we are to take this idea to another level and cast it across the rest of our system, exciting potential for change emerges. Māori theories of health and wellbeing are well documented (see for example, Durie, 1999; Pere, 1988; Reid and Robson, 2006), but what does a theory of the Māori political economy look like? What does a theory of Māori economics which incorporates both material and cultural wellbeing look like?

In Māori business scholarship new kaupapa Māori models are emerging which push the boundaries of existing theories and concepts to better capture Māori contexts and world views. For example, Tapsell and Woods (2008) highlight the importance of 'pōtikitanga' in Māori entrepreneurship and argue how this is a differentiating feature which does not fit within existing models of entrepreneurship. Pōtikitanga is about the genealogical check and balance of the pōtiki (the young entrepreneur) through the tuakana or rangatira (the elder). It is about kin accountability and the relationship between the master and the apprentice, if you will. The rangatira pōtiki 
relationship has been part of the customary leadership tension within Māori society for generations and the authors argue how entrepreneurial models which fail to incorporate the pōtikitanga dynamic will likely remain limited in their application.

Thus, more theories which derive from te ao Māori and merge with te ao hurihuri theories in an imbricated relationship are needed. We must continue to push the theoretical boundaries, test and challenge and create new theoretical spaces whereby life-worlds of contemporary Māori are reflected and become a powerful vehicle for change and transformation. But theory in itself is not enough. Transformation requires action.

\section{Whakapapa (Geneology): An Enabler and Mobiliser}

The research emphasises the dynamic power of whakapapa as both an enabler and mobiliser for transformative action. Participants share a cultural wealth in te ao Māori shaped by a collective ethic and consciousness bound by whakapapa (genealogy), a cultural wealth which provided the foundation on which transformative intent and strategies were fostered and actioned. Whakapapa sits at the heart of a Māori world view, Māori cosmology and mātauranga ā iwi. It is the thread which binds the living to those passed; animate to inanimate objects; the physical to the spiritual. In te ao Māori, whakapapa is the primary source of 'cultural wealth', power and status, which may or may not lead to 'material wealth'. In te ao hurihuri, whakapapa provides a potent lever to raise and accelerate a transformative consciousness and build cohesive transformative strategies - both cultural and structural.

\section{Highly Educated and Stuck in the Middle}

This cohort is in a sense stuck in the middle between the Māori working class and the ruling Māori elite. They possess the capital and resource which could enable them to move into a Māori elite; however, participants express a reluctance about doing so and differentiate themselves from the Māori elite based on their comparatively lower levels of material wealth, power and status. For example, an interesting characteristic of this cohort is how they are not necessarily materially 
well off, but certainly well educated. They are relatively vulnerable to labour market changes, particularly within a global economic recession, and their material wealth is reliant on having a job and secure employment. Conversely, the Māori elite possess the resources and status which provide a buffer against economic and structural changes.

In short, the data shows a distinction between this cohort and the established ruling Māori elite, that is, the power brokers and spokespeople (predominantly male) in Māoridom whose faces are well known (Poata-Smith, 2004a; Sykes, 2010). But what is to stop this cohort from taking over as the ruling elite? Although there can be no guarantees this emerging cohort will not move on to replace the ruling Māori elite, the ways in which they distinguish themselves and critique the established elite may well provide a buffer against this becoming a fait accompli or at the very least delay the onset of this process.

\section{Future Research and Directions}

This research provides a much-needed empirical evidence base for further research into Māori perspectives and analyses of higher education, transformation and class consciousness in contemporary Aotearoa New Zealand. Research grounded in Māori life-worlds and the structural realities of the neo-liberal political economy. To this end, I have identified potential areas for further research, and there will undoubtedly be more.

First, research into how transformation is being enacted using whakapapa as a lever to build cohesion might provide rich data to support the evidence presented in this research. The data has shown how whakapapa is embedded in Māori cultural wealth and how this provides a rich source from which to create transformative strategies for the collective. Second, a whānau-centred longitudinal study using the same cohort might provide fertile ground for a deeper examination and critique of how transformation is being enacted by whānau. It might also highlight the structural relevance of social class and class consciousness in the life trajectories of the next generation. For example, educational strategies and aspirations for children and mokopuna were briefly touched on in this research, but many participants 
expressed anxiety about what the future holds, particularly given the unpredictable nature of the global economy and neo-liberal educational policies. Moreover, unlike their parents, the next generation has not experienced te ao Māori in the same way, nor have they been exposed to struggle and hardship - therefore material wealth is in a sense taken for granted. What does this mean in terms of work ethic, responsibilities to collective aspirations and the collective self, all of which featured so strongly among this cohort? Will the next generation be the change agents or maintain the status quo? Will they draw on whakapapa as a lever for change and transformation?

Third, further research into how higher education is complicit in both the potential to transform and constrain transformation warrants further investigation, particularly within the context of increased tertiary fees (and therefore for many students higher student loans), increased competition for placements and a shortage of jobs for new graduates. This research has shown how valuable higher education has been in terms of creating a critically conscious, well-resourced and highly educated cohort. However, the level of competition will only grow within the education marketplace and what is the likelihood that a significant number of Māori will have access to higher education, let alone make it through the higher education system?

\section{Policy Implications}

This research study has implications in three key policy areas:

- Whānau and hapū transformation;

- Post-settlement Treaty context; and

- Government educational policies and directions.

\section{Whānau and Hapū Transformation}

Penetito (2010b) promulgates four principles to underpin future whānau, hapū, iwi and education transformation: 
1. Māoridom as a whole is only as strong as its weakest links - benefits need to accrue to all iwi;

2. Whānau, hapū and iwi Māori survival depends on organisation and retention and revitalisation of mātauranga to inform future generations;

3. Community-based Māori education - focus on strengthening the sense of community, whanaungatanga; and

4. Urban-based Māori are sufficiently different from rural-based Māori, and plans must reflect this.

These principles resonate beyond the realm of education and can be applied to a range of contexts where the intent is to create positive change and transformation for Māori communities. This research shows how participants are proactive role models and leaders, connected and engaged within their respective whānau. However, transformation at the whānau and hapū level is uneven because such efforts lack cohesion - there are simply not enough highly educated Māori working towards a shared and collective vision. The maintenance and fulfilment of responsibilities to the collective is a lifetime commitment which brings many benefits, but also comes at a cost, particularly in terms of time, resources and energy.

What other models of positive whānau and hapū development can be drawn from to inform this process? What is clear is that whānau- and community-centred initiatives based on local needs and aspirations hold exciting potential for transformation. Protagonists agree that change must come from within. Communities must define their own problems and issues and articulate their own strategies and solutions for how to address these. The role of the emerging Māori middle class is to listen, share knowledge, support and empower, but above all else create, facilitate and accelerate action at both a micro whānau and macro pan-whānau level. 


\section{Post-settlement Context Framework}

This thesis raises questions about unbalanced power relationships within a neoliberal context and has direct relevance to Māori, particularly within a postsettlement context. As more iwi settle Treaty claims with the Crown and receive settlement packages, questions about mandate, representation, power, control, benefits and social justice are critical (Wickliffe, 2010). It could be argued that this is already an issue in a local context, but Māori will no doubt find themselves standing on tricky ground where key critical questions must be asked: who is mandated to speak for the collective? How was mandate achieved? Who has power and control? Who decides who benefits and how? How will such benefits be distributed fairly to whānau and hapū, particularly those on the margins?

Rata's provocative ideas about the corporatisation of iwi, identity politics and the emergence of neo-tribal capitalism provide a clear and present warning against the creation of differential power relations and class divisions within Māori society (Rata, 2000, 2004a, 2004b). She is not alone. A small but growing number of Māori and Pākehā are emerging with similar questions. Webster (2002) suggests the increasing wealth, power and influence of the Māori elite contributes to widening social class difference among Māori (2002:341). Moreover, Waymouth (2003) explores how traditional tribal identity based on whakapapa (genealogy) within Ngāi Tahu is being challenged by new frameworks of identification and governance imposed by the lure of financial prosperity within a post-settlement framework. She posits how the bureaucratisation of iwi is a direct threat to whakapapa and has significant implications on the capacity of Māori societies to maintain their cultural uniqueness (2003:18). In her critical analysis of the Māori elite, Sykes (2010) calls for a process to take on the "entrenched power and influence of the finance elite and others who have hijacked our nation" (Sykes, 2010:36). Thus, if Māori are to move forward towards a shared vision where benefits are distributed to all - rich, poor, privileged and marginalised - the systems, processes and power relations within a post-settlement context must be vigorously critiqued. 


\section{Government Educational Policies and Directions}

Neo-liberal, market-driven education policies which undermine the role of whānau and community ignore the unequal power relations embedded within the education system, and the cultural wealth within te ao Māori will exacerbate inequalities.

Similarly, culture-based policies which ignore the realities of the neo-liberal political economy, the interconnectedness of the economy to the social and cultural, the structural nature of inequalities, will fail. What is needed is an imbricated relationship between the two. Kawharu (2001:11) posits that in order for disparities to be overcome, a detailed analysis of social, cultural and economic needs at a community level is required. This process includes developing ground-up policies based on research into the particular histories of kin groups. While Māori communities have experienced similar experiences of colonisation and neoliberalism, responses will differ in scale and emphasis.

\section{Summary}

Education has been a powerful liberating vehicle and ally in the emergence of this highly educated cohort. The challenge ahead lies in opening the benefits of these experiences, outcomes and perspectives to the masses. An education which nurtures and promotes Māori cultural wealth and the benefits of material wealth as well as developing a critical consciousness to expose the structural nature of inequalities and how to overcome them is much needed. In the search for answers, one point becomes crystal clear: the pathway forward requires huge shifts at a systemic and ideological level from tangata Māori, tangata Pākehā, tangata Pasifika and tangata nō tā wāhi (peoples of other lands).

A continual concern that emerges in this research is how to empower marginalised whānau. How do we connect with and engage those members of whānau who live on the poverty line and experience hardship in their daily lives? Māoridom has a long history of resilience and resistance, but the impact of structural inequalities within the current neo-political economy, and how these inequalities are now perpetuated from within, is testing this resilience and resolve in an unprecedented way. In terms of action, one potential solution is to use whakapapa as a lever to 
cohere a mass movement driven by organic intellectuals. A movement which works alongside Māori elite, working class, and marginalised whānau, Pākehā and others - equal participants committed to a sustained struggle, to creating solutions from within, accountable to the very communities from whence these policies and programmes are designed. This movement must include education, participation, engagement, organisation, action and reflection (Sykes, 2010:36).

While the inherently racist and oppressive institutions, mechanisms, structures and apparatus of the state and the neo-liberal political economy continue to produce negative statistics, skewed viewpoints and portrayals of Māori culture and society, we must build our own analyses of the contemporary Māori realities in Aotearoa New Zealand to challenge, contest and disrupt. We must hold fast to our rangatiratanga, the right to articulate and determine our own aspirations, pathways and solutions, but work alongside tangata Pākehā and others to achieve these. We must hold fast to principles of social justice, equality and fairness, principles which our tīpuna (ancestors) fought so courageously for in an enduring struggle without end (Walker, 1990). We must project our mind's eye to the future, the world of our mokopuna (grandchildren) and successive generations, and develop policies and practices which will support and enable them all to look back on our actions with pride. Transformation is not about positive change for the few, it is about the health, wellbeing and prosperity of the many.

This highly educated cohort plays an important role in the future process of transformation. They are leaders, role models, change agents, organic intellectuals working to effect positive change within their whānau - but more are needed to help build a sustainable and cohesive critical mass. In his potent analysis of the dilemma of the black intellectual, influential African-American scholar and professor, Cornel West, articulates a sense of hope and a pathway forward for black intellectuals to create change and transformation. The following quote poignantly gets to the heart of this matter:

"The predicament of the black intellectual need not be grim and dismal. Despite the pervasive racism of American society and anti-intellectualism of the black community, critical space and insurgent activity can be expanded. 
This expansion will occur more readily when black intellectuals take a more candid look at themselves, the historical and social forces that shape them, and the limited though significant resources of the community from whence they come. A critical self inventory that scrutinizes the social positions, class locations, and cultural socializations of black intellectuals is imperative... this self inventory should embody the sense of critique and resistance applicable to the black community, American society and Western civilisation as a whole." (West, 1985:67)

Grounded in the black/African-American experience in America, West's ideas resonate with the Māori organic intellectual experience and dilemma in Aotearoa New Zealand. In short, a critical self-inventory is long overdue to help build and cohere transformation. The analytical tools used in this process must include a vigorous critique of Māori social, cultural and structural locations within both te ao Māori and te ao hurihuri. This process could be whakapapa-based, actioned within whānau, hapū and iwi, to capture the diverse life-worlds and realities of Māori living within the context of contemporary Aotearoa New Zealand. This is about drawing on whakapapa and cultural wealth to create cultural- and structural-based responses to effect transformation for the individual and the collective. I conclude with a whakataukī (proverb) from my papakāinga (tribal homeland) which brings together four strands that have weaved seamlessly throughout this thesis - Whakapapa, Māori strength, Māori resilience and Māori futures.

'Pōu tū pōu hinga, pōu hinga pōu tū, tū tonu.'

Our strength and resilience will grow future generations. 


\section{Karakia Whakamutunga}

Kia tau ngā manaakitanga a te mea ngaro

Ki runga ki tēnā, ki tēnā o tātau

Kia mahea te hua mākihikihi

Kia toi te kupu, toi te reo, toi te hauora, toi te aioi

Kia tūtūrū o whiti whakamaua kia tīna, haumi e, hui e, tāiki e

Let the blessings of the universe be bestowed upon us all.

So that all evils pass us by.

So that the permanence of authority, language, wellbeing and peace remains.

So that it has certainty and is maintained and it will be secure. 


\section{Glossary²}

\begin{tabular}{|c|c|}
\hline ahi kaa & home fires, occupation of tribal lands \\
\hline aroha & love \\
\hline atua & God \\
\hline awhi & care, support, help \\
\hline hapū & sub-tribe \\
\hline hinengaro & intellect, consciousness, awareness \\
\hline hui & meeting \\
\hline iwi & tribe \\
\hline kanohi kitea & face-to-face, in person \\
\hline karakia & to recite ritual chants \\
\hline kaumātua & elder/s \\
\hline kaupapa & subject, topic \\
\hline kāwai ariki & royal lineage \\
\hline kāwai rangatira & chiefly lineage \\
\hline kuia & elderly woman \\
\hline kura kaupapa Māori & $\begin{array}{l}\text { primary school operating under Māori custom using Māori } \\
\text { as the medium of instruction }\end{array}$ \\
\hline MAI Network & Māori and Indigenous Graduate Studies support network \\
\hline mana & $\begin{array}{l}\text { a principle denoting status, prestige, authority and } \\
\text { leadership }\end{array}$ \\
\hline manaakitanga & hospitality, kindness \\
\hline MANUAO & $\begin{array}{l}\text { national inter-university Māori academy for academic and } \\
\text { professional advancement }\end{array}$ \\
\hline marae & $\begin{array}{l}\text { a traditional meeting centre often comprising a main house } \\
\text { and forecourt }\end{array}$ \\
\hline māramatanga & enlightenment \\
\hline mātauranga & knowledge, education \\
\hline maunga & mountain \\
\hline mihi & greeting \\
\hline mohiotanga & knowledge \\
\hline mokopuna & grandchild \\
\hline Ngaitai & a tribe in Eastern Bay of Plenty \\
\hline Ngā Pae o Te Maramatanga & centre of research excellence \\
\hline Ngāti Porou & a tribe on the East Coast of New Zealand \\
\hline Ōpotiki & a place \\
\hline oriori & lullaby \\
\hline Pākehā & New Zealanders of European descent \\
\hline papakāinga & extended family housing collective \\
\hline pēpeha & tribal saying \\
\hline pōhara & be poor, broke, poverty stricken \\
\hline pōtiki & youngest child \\
\hline pōtikitanga & Māori entrepreneurship model \\
\hline pūkenga tukutuku & directory of indigenous research capability \\
\hline rangatahi & youth \\
\hline
\end{tabular}

${ }^{2}$ Definitions are given in the context of this thesis and may not be generally applicable 


\begin{tabular}{|l|l|}
\hline rangatira & leader \\
\hline reo & language \\
\hline Ruatoria & a place \\
\hline taurekareka & captive, slave \\
\hline Te Aho Matua & founding document and driving force for Kura Kaupapa \\
& Māori \\
\hline te ao Māori & Māori world \\
\hline te ao hurihuri & wider society, global world \\
\hline tēina & younger siblings, of a junior descent line \\
\hline Te Puni Kōkiri & Ministry of Māori Development \\
\hline te kōhanga reo & Māori language preschool \\
\hline Te Tiriti o Waitangi & Treaty of Waitangi \\
\hline Te Whakatōhea & a tribe \\
\hline Te Whānau a Apanui & a tribe \\
\hline Tuparoa & a place \\
\hline tikanga & Māori process \\
\hline tino rangatiratanga & self-determination \\
\hline Titahi Bay & a place \\
\hline tohunga & a Māori specialist in a particular field \\
\hline Torere & a place \\
\hline tuakana & older siblings, of a senior descent line \\
\hline tūrangawaewae & a place to stand, tribal homeland \\
\hline tūtūā & person of low birth, commoner \\
\hline utu & reciprocity, repay \\
\hline waiata & song \\
\hline wairua & spirit \\
\hline wairuatanga & spirituality \\
\hline wānanga & Māori institution of higher learning \\
\hline ware & low rank \\
\hline whakapapa & genealogy \\
\hline whakatau & official welcome \\
\hline whakataukī & proverb \\
\hline whānau & family \\
\hline whanaungatanga & kin relations \\
\hline & \\
\hline
\end{tabular}




\section{References}

Alfred, T., and Corntassel, J. (2005). Being Indigenous: Resurgences Against Contemporary Colonialism, Government and Opposition, 40 (4), 597-614.

Apple, M. W. (1992). Education, culture and class power: Basil Bernstein and the neo-Marxist sociology of education. Educational Theory, 42(2), 127-145.

Apple, M. W. (2001). Educating the "right way": Markets, standards, god, and inequality. New York: Routledge Falmer.

Awatere, D. (1984). Māori sovereignty. Broadsheet.

Ball, S. J. (2003). Class strategies and the education market. The middle classes and social advantage. London: Routledge Falmer.

Ballara, A. (1982). The pursuit of mana? A re-evaluation of the process of land alienation by Māoris, 1840-1890. The Journal of the Polynesian Society, 519541.

Ballara, A. (1998). Iwi: The dynamics of Māori tribal organisation from c.1769 to c. 1945. Wellington: Victoria University Press.

Barcham, M. (1998). The challenge of urban Māori: reconciling conceptions of indigineity and social change. Asia Pacific Viewpoint, 39(3).

Bargh, M. (2002). Re-Colonisation and Indigenous Resistance: Neoliberalism in the Pacific (Unpublished PhD thesis). Australian National University, Canberra, Australia.

Bargh, M. (2007). Resistance: an indigenous response to neoliberalism. Wellington: Huia Publishers.

Barlow, C. (1994). Tikanga whakaaro: Key concepts in Māori culture. Auckland: Oxford University Press.

Barnhardt, R. (2008). Creating a place for indigenous knowledge in education: The Alaska native knowledge network. Place-based education in the Global Age (pp. 113-136). New York: Lawrence Erlbaum Associates.

Barnhardt, R., \& Kawagley, A. O. (1999). Education indigenous to place: Western science meets indigenous reality. In G. Smith \& D. Williams (Eds.), Ecological Education in Action (pp. 117-140). Albany: State University of New York Press.

Barnhardt, R., \& Kawagley, A. O. (2004). Culture, chaos and complexity: catalysts for change in indigenous education. Cultural Survival Quarterly, 27(4), 59-64. 
Barnhardt, R., \& Kawagley, A. O. (2005). Indigenous knowledge systems and Alaska native ways of knowing. Anthropology and Education Quarterly, 36(1), 8-23.

Barnhardt, R., \& Kawagley, A. O. (2008). Indigenous knowledge systems and education. Yearbook of the National Society for the Study of Education, 107(1), 223-241.

Barrington, J. (2008). Separate but equal: Māori schools and the crown - 18671969. Wellington: Victoria University Press.

Battiste, M. (2002). Indigenous knowledge and pedagogy in First Nations education: A literature review with recommendations. Ottawa.

Bawden, R. (1991). Praxis: The essence of systems for being. In A. R. Viskovic (Ed.), Research and development in higher education (Vol. 14, pp. 1-7).

Bedggood, D. (1980). Rich and poor in New Zealand. A critique of class, politics and ideology. Auckland: Allen \& Unwin.

Belich, J. (1989). The Victorian interpretation of racial conflict: The Māori, the British, and the New Zealand wars. Montreal: McGill-Queen's University Press.

Belich, J. (2001). Paradise reforged: A history of New Zealanders from the 1880s to the year 2000. Auckland: Penguin Books Limited.

Belich, J. (2007). Making peoples: A history of the New Zealanders (2nd ed.). Auckland: Penguin Books Limited.

Bell, A., \& Carpenter, V. (1994). Education's role in (re)producing social class in Aotearoa. In E. Coxon, K. Jenkins, J. Marshall, \& L. Massey (Eds.), The Politics of Learning and Teaching in Aotearoa: Historical Perspectives on Education in New Zealand (pp. 112-147). Palmerston North: The Dunmore Press Ltd.

Bennett, S. (2003). Cultural identity and academic achievement among Māori undergraduate university students. In L. W. Nikora, M. Levy, B. Masters, W. Waitoki, N. Te Awekotuku, \& R. J. M. Etheredge (Eds.), The Proceedings of the National Māori Graduates of Psychology Symposium 2002: Making a Difference. Proceedings of a symposium hosted by the Māori \& Psychology Research Unit at the University of Waikato, Hamilton, 29-30 November 2002. Hamilton, New Zealand: Māori and Psychology Research Unit, University of Waikato.

Benton, N. (1989). Education, language decline and language revitalisation: The case of Māori in New Zealand. Language and Education, 3(2), 65-82.

Bernstein, B. (1975). Class, codes and control: Towards a theory of educational transmissions. Routledge and Kegan Paul. 
Bernstein, B. (1977). Class, codes and control (Volume 3.). London: Routledge and Kegan Paul.

Best, E. (1924). The Māori as he was. Wellington: Dominion Museum.

Best, E. (1941). The Māori (Vols 1 and 2.). Wellington: The Polynesian Society.

Best, P., \& Love, M. (2010). Māori values for Māori business: Cultural capital in indigenous organisations. Victoria Management School Working Paper Series, Victoria University: Wellington.

Bevan-Brown, J. (1992). Special abilities: A Māori perspective. Wellington, New Zealand: He Pārekereke, Dept. of Education, Victoria University of Wellington.

Bevan-Brown, J. (2004). Gifted and talented Māori learners. In D. McAlpine \& R. Moltzen (Eds.), Gifted and talented: New Zealand perspectives. Palmerston North: Kanuka Grove Press.

Bishop, R. (1996). Collaborative research stories: whakawhanaungatanga. Palmerston North: Dunmore Press.

Bishop, R. (1998). Freeing ourselves from neo-colonial domination in research: a Māori approach to creating knowledge. Qualitative Studies in Education.

Bishop, R. (1999). Kaupapa Māori research: An indigenous approach to creating knowledge. In N. Robertson (Ed.), Māori and psychology: research and practice - The proceedings of a symposium sponsored by the Māori and Psychology Research Unit. Hamilton.

Bishop, R, \& Berryman, M. (2006). Culture speaks: cultural relationships and classroom learning. Wellington: Huia Publishers.

Bishop, R, Berryman, M., \& Richardson, C. (2002). Te toi huarewa: Effective teaching and learning in total immersion Māori language educational settings. Canadian Journal of Native Education, 26, 44-61.

Bishop, R, \& Glynn, T. (1999). Culture counts: Changing power relations in education. Palmerston North: Dunmore Press.

Bishop, Russell, \& Berryman, M. (2006). Culture speaks: Cultural relationships and classroom learning. Wellington: Huia Publishers.

Black, J. (2005). Class facts. New Zealand Listener. Retrieved from http://www.listener.co.nz/issue/3394/features/4077/class_facts.html

Blossfeld, H., \& Shavit, Y. (1992). Persistent inequalities: Changes in educational opportunities in thirteen countries. Boulder: Westview. 
Borland, E. (2008). "Class consciousness". In Parrillo, Vincent N (Ed.), Encyclopedia of Social Problems, Vol.1, 134-135. Sage.

Bottero, W. (2004). Class identities and the identity of class. Sociology, 38(5), 9851003.

Bourdieu, P. (1973). Cultural reproduction and social reproduction. In R. Brown (Ed.), Knowledge, Education and Cultural Change (pp. 71-112). London: Tavistock.

Bourdieu, P. (1984). The market of symbolic goods. The Field of Cultural Production: Essays on Art and Literature. Columbia University Press.

Bourdieu, P. (2000). Acts of resistance: Against the new myths of our time. Cambridge: Polity Press.

Boyatzis, R. E. (1998). Transforming qualitative information: Thematic analysis and code development. California: Sage.

Braun, V., \& Clarke, V. (2006). Using thematic analysis in psychology. Qualitative Research in Psychology, 3(2), 77-101.

Brosnan, P. (1987). Māori occupational segregation. Journal of Sociology, 23(1), 89-103.

Broughton, J., Fergusson, D. M., Rimene, C., Horwood, L. J., \& Sporle, A. (2000). Ngā tini aho o te ao hōu. The many strands of contemporary Māori society: Māori ethnicity and identity in the Christchurch health and development study. Dunedin: NTMHRU. Dunedin.

Brown, P. (1995). Cultural capital and social exclusion: Some observations on recent trends in education, employment and the labour market. Work, Employment \& Society, 9(1), 29-51.

Buck, P. (1987). The coming of the Māori (2nd ed.). Wellington: Māori Purposes Fund Board.

Caccioppoli, P., \& Cullen, R. (2006). Māori education. Auckland: Kotahi Media Limited.

Caldwell, J., \& Brown, C. (2007). 8 Tribes: The hidden classes of New Zealand. Wellington: Wicked Little Books.

Campbell, C. (2007). Class and competition. In R. Connell, C. Campbell, M. Vickers, A. Welch, D. Foley, \& N. Bagnall (Eds.), Education, Change and Society. Oxford University Press.

Carey, M. (2008). Indigenising the curriculum: Centre for Aboriginal studies position paper. Bentley: Centre for Aboriginal Studies and Curtin University. 
Cathcart, R., \& Pou, N. (1994). The gifted child who is Māori. New Zealand Association of Gifted Children, 17(3), 13-17.

Certeau, M. (1984). The practice of everyday life. Berkeley: University of California Press.

Chapple, S. (2000). Māori socio-economic disparity. Political Science, 52, 101-115.

Chapple, S., Jefferies, R., \& Walker, R. (1997). Māori participation and performance in education. A literature review and research programme. Wellington: Ministry of Education (Vol. 63). Wellington.

Codd, J. (1999). Educational reform, accountability and the culture of distrust. New Zealand Journal of Educational Studies, 34(1).

Cohen, R. A. (1998). Foreword. In E. Levinas (Ed.), Otherwise than being or beyond essence. Pittsburgh: Duquesne University Press.

Cole, M. (1989). "Race" and "class" or "race", class, gender and community? A critical appraisal of the radicalised fraction of the working-class thesis. The British Journal of Sociology, 40(1), 118-129.

Cole, M. (2008). Marxism and educational theory: Origins and issues. Cole, Mike. (2008). Marxism and Educational Theory: Origins and Issues. New York: Routledge.

Conway, D. (1987). A farewell to Marx: An outline and appraisal of his theories. New York: Penguin Books.

Courtney, C. (2008, June). Māori in the middle. North and South, 36-46.

Cowan, J., \& Pomare, M. (1977). Legends of the Māori (Vol.1). Wellington: AMS Press.

Cram, F. (2006). Kaupapa Māori research: The importance of relationships. Retrieved from http://www.rangahau.co.nz/methodology/124/

Cram, F., \& Pipi, K. (2000). Māori/lwi provider success: Report on the pilot project. Tamaki Makaurau.

Creswell, J. W. (2009). Research design. Qualitative, quantitative and mixedmethod approaches ( $3^{\text {rd }}$ ed.). Sage.

Crompton, R. (1996). The fragmentation of class analysis. British Journal of Sociology, 47(1), 56-67.

Cunningham, C. (1998). A framework for addressing Māori knowledge in research, science and technology. In Te Pumanwa Hauora (Ed.), Proceedings of Te Ora 
Rangahau Māori Research \& Development Conference (pp. 1-6). School of Māori Studies, Massey University, Palmerston North.

Cunningham, C. (2000). A framework for addressing Māori knowledge in research, science and technology. Pacific Health Dialog, 7(1), 62-69.

Cunningham, C., Stevenson, B., \& Tassell, N. (2005). Analysis of the characteristics of whānau in Aotearoa. Wellington: Ministry of Education. Retrieved from http://www.educationcounts.govt.nz/publications/maori_education

Czarniawska, B. (2004). Narratives in social science research. London: Sage Publications Ltd.

Dale, R. (2000). Social class and education in Aotearoa/New Zealand. In James Marshall, E. Coxon, K. Jenkins, \& A. Jones (Eds.), Politics, Policy and Pedagogy (pp. 107-137). Palmerston North: The Dunmore Press Ltd.

Darwin, C. (1859). On the origin of species: The preservation of favoured races in the struggle for life. London: John Murray.

David, G. (1990). Review: A farewell to Marx: An outline and appraisal of his theories. By David Conway. New York: Penguin Books, 1987. The Review of Austrian Economics, 4, 234-40.

David, M., \& Sutton, C. D. (2004). Social research: the basics. London: Sage Publications Ltd.

Davis, P., McLeod, K., Ransom et al. (1997). The New Zealand Socioeconomic Index of Occupational Status (NZSEI). Wellington: Statistics New Zealand.

Denscombe, M. (2004). The good research guide: for small-scale research projects (2nd ed.). Open University Press.

Denscombe, M. (2010). The good research guide. Open University Press.

Department of Labour. (2009). Māori in the New Zealand labour market. Wellington: Department of Labour. Retrieved from http://www.dol.govt.nz/publications//mr/maori/in-the-labour-market-2009/fullreport.pdf

Department of Marketing Massey University. (1992). New Zealanders' attitudes to social inequality: International social survey programme 1992. Palmerston North: Massey University.

Devine, F, \& Savage, M. (2000). Renewing class analysis. In R. Crompton, F. Devine, M. Savage, \& J. Scott (Eds.), Renewing Class Analysis (pp. 184-199). Blackwell. 
Devine, F, Savage, M., Crompton, R., \& Scott, J. (2005). Rethinking class: Identities. cultures and lifestyles. (F Devine, M. Savage, R. Crompton, \& J. Scott, Eds.). London: Palgrave.

Devine, Fiona. (1998). Class analysis and the stability of class relations. Sociology, 32(1), 23-42.

Dewes, K. (1975). The case for oral arts. In M King (Ed.), Te Ao Hurihuri. Wellington: Hicks Smith \& Sons.

Durie, A. (1998). Emancipatory Māori education: Speaking from the heart. Language, Culture and Curriculum, 11(3), 297-308.

Durie, M. (1995). Ngā matatini Māori: Diverse Māori realities. Paper to Wānanga Pūrongo Kōrero: Māori Health Framework Seminar, 14-17 February, Department of Māori Studies, Massey University, Palmerston North.

Durie, M. (1997). Identity, access and Māori advancement. New Zealand Journal of Educational Administration, 12, 41-45.

Durie, M. (1998). Te mana me te kāwanatanga: The politics of Māori selfdetermination. Auckland: Oxford University Press.

Durie, M. (1999). Mental health and Māori development. Australia and New Zealand Journal of Psychiatry, 33(1), 5-12.

Durie, M. (2001). The hui taumata mātauranga: Progress and platforms for Māori advancement. Hui Taumata Mātauranga Tuarua, Taupo, 11 November. Taupo.

Durie, M. (2003). Ngā kāhui pōu: Launching Māori futures. Wellington: Huia Publishers.

Durie, M. (2004). Exploring the interface between science and indigenous knowledge. Paper presented at the 5th APEC research and development leaders forum: Capturing value from science. Christchurch.

Durie, M. (2005). Ngā tai matatū: tides of Māori endurance. Oxford University Press.

Durie, M. (2006). Whānau, education, and Māori potential. Paper presented to hui taumata V, October 2006. Taupo.

Durie, M. (2011). Ngā tini whetū: Navigating Māori futures. Wellington: Huia Publishers.

Easton, B. H. (Ed.). (1989). The making of Rogernomics. Auckland: Auckland University Press. 
Edwards, W. J. W. (2009). Taupaenui: Māori positive ageing (PhD thesis, Massey University, Palmerston North, New Zealand). Retrieved from http://mro.massey.ac.nz/handle/10179/1331

Elley, W., \& Irving, J. (1976). Revised socio-economic index for New Zealand. New Zealand Journal of Educational Studies, 11, 25-36.

Ermisch, J., \& Francesconi, M. (2003). Family matters: Impacts of family Background on educational attainments. Economica, 68, 137-156.

Evans, R. (1994). The negation of powerlessness: Māori feminism, a perspective. Hecate, 20(2), 53-65.

Every Child Counts. (2011). New report reveals brown social underclass in New Zealand [Press Release]. Retrieved from http://www.everychildcounts.org.nz/news/new-report-reveals-brown-socialunderclass-in-new-zealand/.

Fanon, F. (1963). The wretched of the earth (C.Farrington, Trans.). New York: Grove Press.

Firth, R. (1959). Economics of the New Zealand Māori. London: George Routledge \& Sons.

Fishman, J. A. (Ed.). (2001). Can threatened languages be saved? Reversing language shift revisited: A 21st century perspective. Clevedon: Multilingual Matters Ltd.

Fitzgerald, T. K. (1974). The Māori University graduate and the sentiment system. Anthropological Quarterly, 47(2), 169-181.

Fitzgerald, T. K. (1977). Education and identity: a study of the New Zealand Māori graduate. Wellington: New Zealand Council for Educational Research.

Fitzsimons, P. (2000). Neoliberalism and "social capital": Reinventing community.

Foucault, M. (1980). Power/knowledge - Selected interviews and other writings 1972-1977. (C. Gordeon, Ed.). Brighton: Harvester Press.

Foucault, M. (1982). The subject and power. Critical Inquiry, 8, 777-95.

Franklin, V. (2002). Introduction cultural capital and African-American education. The Journal of African-American History, 87, 175-181.

Freire, P. (1973). Education for critical consciousness. Vol. 1. Continuum International Publishing Group.

Freire, P. (1977). Pedagogy of the oppressed. Harmondsworth: Penguin. 
Freire, P. (2000). Pedagogy of the oppressed. 30th anniversary edition. The Continuum International Publishing Group.

Friedman, M. (1962). Capitalism and freedom. Chicago: The University of Chicago Press.

Fuli, E. (1994). Whaia te iti kahurangi: Māori women in higher education: The educational experiences of five Māori women at Victoria University of Wellington. Victoria University of Wellington.

Gandarra, P. C. (1995). Over the ivy walls: The educational mobility of low-income Chicanos. SUNY Press.

Gibbons, M. (2011). Intergenerational economic mobility in New Zealand. Policy Quarterly, 7(2), 53-60.

Gibbs, M. (2001). Towards a strategy for undertaking cross cultural collaborative research. Society and Natural Resources, 14, 673-687.

Giddens, A. (1997). Sociology (3rd ed.). Cambridge: Polity Press.

Gilbert, D. (1998). The American class structure. New York: Wadsworth Publishing.

Giroux, H. (1982). Power and resistance in the new sociology of education: Beyond theories of social and cultural reproduction. Curriculum Perspectives, 2(3), 113.

Gitlin, T. (1980). The whole world is watching: Mass media in the making and unmaking of the new left. Berkeley: University of California Press.

Given, L. M. (Ed.). (2008). The SAGE encyclopaedia of qualitative research methods. Thousand Oaks: SAGE Publications.

Glaser, B. (1992). Basics of grounded theory. Mill Valley: Sociology Press.

Gordon, L., \& Whitty, G. (1997). Giving the "hidden hand" a "helping hand". The rhetoric and reality of neoliberal education reform in England and New Zealand. Comparative Education, 33(3).

Grace, P., Ramsden, I., \& Dennis, J. (2007). The silent migration: Ngāti Pōneke young Māori club, 1937-1948. Wellington: Huia Publishers.

Gramsci, A. (1971). Selections from the prison notebooks. London: Lawrence and Wishart.

Gramsci, A. (2005). The intellectuals. In S. P. Hier (Ed.), Contemporary Sociological Thought: Themes and Theories (pp. 49-58). Toronto: Canadian Scholars Press Inc. 
Gruenewald, D. (2003). Critical pedagogy of place. Educational Researcher, 32(4), 3-12.

Hall, S. (1980). Cultural studies: Two paradigms. Media, culture and society, 2, 5772.

Hall, S. (1992). The question of cultural identity. In S. Hall, D. Held, \& A. McGrew (Eds.), Modernity and Its Futures (pp. 274-316). Cambridge: Polity Press.

Hall, S. (1996). Critical dialogues in cultural studies. (D. Morley \& K.-H. Chen, Eds.). London: Routledge.

Hall, S. (1997). Cultural identity and diaspora. Framework, 36, 222-237.

Hall, S., \& Du Gay, P. (1996). Questions of cultural identity. London: Sage.

Hargreaves, A. (1982). Resistance and relative autonomy theories: problems of distortion and incoherence in recent Marxist analyses of education. British Journal of Sociology of Education, 3(2), 107-126.

Harker, R. (1985). Schooling and cultural reproduction. In J. Codd, R. Harker, \& R. Nash (Eds.), Political Issues in New Zealand Education. Palmerston North: Dunmore Press.

Harker, R. (1990). Schooling and cultural reproduction. In John Codd, R. Harker, \& R. Nash (Eds.), Political Issues in New Zealand Education. (2nd ed., pp. 2542). Dunmore Press.

Harker, R., \& May, S. A. (1993). Code and habitus: comparing the accounts of Bernstein and Bourdieu. British Journal of Sociology of Education, 14(2), 169178.

Harmsworth, G. (2010). 'Respecting Māori world views'. Presentation to Integrated Catchment Management Annual General Meeting, April, Nelson.

Harrington, T. A. (2010). Māori role models: Inspirational kōrero from inspirational Māori. Palmerston North: Te Kiko Charitable Trust.

Harris, A. (2004). Hīkoi: Forty years of Māori protest. Wellington: Huia Publishers.

Hatton, E. (Ed.). (1998). Understanding teaching: Curriculum and the social context of schooling. Marrickville: Harcourt Brace.

Henare, M., Puckey, A., \& Nicholson, A. (2011). He ara hou: The pathway forward: Getting it right for Aotearoa New Zealand's Māori and Pasifika children. Auckland.

Hickox, M. S. (1982). The Marxist sociology of education: a critique. British Journal of Sociology, 563-578. 
Hill, D. (2001). State theory and the neo-liberal reconstruction of schooling and teacher education: a structuralist neo-marxist critique of postmodernist, quasi postmodernist and culturalist neo-marxist theory. British Journal of Sociology of Education, 22(1), 135-155.

Hokowhitu, B. (2012). Producing elite indigenous masculinities. settler colonial studies, 2(2), 23-48.

Hook, G. (2009). "Warrior genes" and the disease of being Māori. MAl Review, 2 , $1-11$.

Hooks, b. (1994). Teaching to transgress: education as the practice of freedom. New York: Routledge.

Hoskins, T. K. (2010). Māori and Levinas: kanohi ki te kanohi for an ethical politics (PhD thesis, University of Auckland, New Zealand). Retrieved from https://researchspace.auckland.ac.nz/bitstream/handle/2292/6089/Whole.pdf?s $\underline{\text { equence }=5}$

Hudson, M. (2004). He matatika Māori: Māori and ethical review in health research (Master's thesis, Auckland University of Technology, New Zealand). Retrieved from http://aut.researchgateway.ac.nz/handle/10292/151

Hudson, M., Ahuriri-Driscoll, A., Lea, M., \& Lea, R. (2007). Whakapapa - a foundation for genetic research? Journal of Bioethical Inquiry, 4(1), 43-49.

Hughes, D., \& Lauder, H. (1991). Human capital theory and the wastage of talent in New Zealand. New Zealand Journal of Educational Studies, 26(1), 5-35.

Ip, M. (2008). Being Māori Chinese: mixed identities. Auckland: Auckland University Press.

Irwin, K. (1990). Challenges to Māori feminists. Broadsheet, 20-23.

Irwin, K. (1992). Towards theories of Māori feminisms. In R. Du Plessis \& P. Bunkle (Eds.), Feminist Voices. Oxford University Press.

Irwin, K. (1994). Māori research methods and processes: An exploration and discussion. Sites 28, 28, 25-43.

Jackson, M. (1993). Land loss and the Treaty of Waitangi. In W. Ihimaera (Ed.), Te Ao Marama: Regaining Aotearoa. Māori Writers Speak Out, vol. 2. Auckland: Reed Publishing.

Jackson, M. (1997). "Intellectual property rights and implications for Māori: An interview with Moana Jackson" in Cultural and intellectual property rights: Economics. Politics and Colonisation (Vol. Two). Auckland: Moko Productions/International Research Institute for Māori and Indigenous Education. 
James, D., Reay, D., Crozier, G., Beedell, P., Hollingworth, S., Jamieson, F., \& Williams, K. (2010). Neoliberal policy and the meaning of counterintuitive middle-class school choices. Current Sociology, 58(4), 623-641.

Jarden, K. (1992). Education: Making a Māori underclass. Race, Gender, Class, 20-25.

Jenkins, K., \& Pihama, L. (2001). Mātauranga wahine: Teaching Māori women's knowledge alongside feminism. Feminism and Psychology, 11(3), 293-303.

Jenkins, R. (1997). Rethinking ethnicity. arguments and explorations. London: Sage.

Jensen, J., Krishnan, V., Hodgson, R., Sathiyandra, S., Templeton, R., Jones, D., Goldstein-Hawes, R., et al. (2006). New Zealand living standards 2004: Ngā āhuatanga noho o Aotearoa. Wellington: Centre for Social Research and Evaluation, Ministry of Social Development.

Jiang, X. (2011). Why interculturalisation? A neo-Marxist approach to accommodate cultural diversity in higher education. Educational Philosophy and Theory, 43(4), 387-399.

Johnston, D. M. (1989). Native rights as collective rights: A question of group selfpreservation. Canadian Journal of Law and Jurisprudence, 2(1), 19-34.

Jones, A., \& Jenkins, K. (2011). He kōrero - words between us: First Māori-Pākehā conversations on paper. Wellington: Huia Publishers.

Jones, C. P. (2000). Levels of racism: A theoretic framework and a gardener's tale. American Journal of Public Health, 908, 1212-1215.

Jones, F., \& Davis, P. (1988a). Class structuration and patterns of social closure in Australia and New Zealand. Sociology, 22(2), 271-291.

Jones, F., \& Davis, P. (1988b). Closure and fluidity in the class structure. Australia and New Zealand Journal of Sociology, 24(2), 226-247.

Kaomea, J. (2004). Decolonizing research in cross cultural contexts - critical personal narratives, Edited by K. Mutua and B. Blue-Swadener (pp 27-44). Albany: State University of New York Press.

Karetu, T. (1992). Language and protocol of the marae. In Michael King (Ed.), Te Ao Hurihuri: the world moves on: aspects of Māoritanga (pp. 28-42). Auckland: Reed.

Karetu, T. (2002). Māori: New Zealand Latin? In B. Burnaby \& J. Reyhner (Eds.), Indigenous Languages Across the Community (pp. 25-29). Flagstaff, AZ: Northern Arizona University. 
Katene, S. (2010). Modelling Māori leadership: What makes for good leadership? MAI Review, 2, 1-16.

Kawagley, O. A. (1995). A Yupiaq worldview: A pathway to ecology and spirit. Prospect Heights IL: Waveland Press.

Kawagley, O. A. (2000). Remembering place. Voice of the drum: Indigenous Education and Culture (pp. 101-120). Manitoba: Kingfisher Publications.

Kawharu, M. (2001). Local Māori development and government policy. Social Policy Journal of New Zealand, (16), 1-16.

Keelan, T. (2001). E tipu e rea: A framework for taiohi Māori development. Wellington.

Kidman, J. (2007). Engaging with Māori communities: An exploration of some tensions in the mediation of social sciences research. Tihei Oreore Series. New Zealand: University of Auckland.

Kidman, J., Abrams, E., \& McRae, H. (2011). Imaginary subjects: school science, indigenous students, and knowledge-power relations. British Journal of Sociology, 32(2), 203-220.

King, Michael. (1996). Māori: A photographic and social history (2nd ed.). Auckland: Reed Publishing.

King, Michael. (2003). The Penguin history of New Zealand. Auckland: Penguin Books Limited.

Klees, S. J. (2008). A quarter century of neoliberal thinking in education: misleading analyses and failed policies. Globalisation, Societies and Education, 6(4).

Kraus, M. W., Piff, P. K., \& Keltner, D. (2011). Social class as culture. Current Directions in Psychological Science, 20(4), 246-250.

Krishnan, V., Jensen, J., \& Ballantyne, S. (2002). New Zealand living standards 2000: Ngā āhuatanga noho o Aotearoa. Wellington.

Lankshear, C. (1987). Literacy, Schooling and Revolution. New York: The Falmer Press.

Lash, S., \& Urry, J. (1987). The end of organized capitalism. Cambridge: Polity.

Lather, P. (2006). Paradigm proliferation as a good thing to think with: teaching research in education as a wild profusion. International Journal of Qualitative Studies in Education, 19(1), 35-37. 
Lauder, H., \& Hughes, D. (1990a). Social origins, destinations and educational inequality. In John Codd, R. Harker, \& R. Nash (Eds.), Political Issues in New Zealand Education. (2nd Ed., pp. 43-60). Dunmore Press.

Lauder, H., \& Hughes, D. (1990b). Social inequalities and differences in school outcomes. New Zealand Journal of Educational Studies, 25(1), 37-60.

Lauder, H., Hughes, D., Watson, S., Waslander, S., Thrupp, M., Strathdee, R., Simiyu, I., et al. (1999). Trading in futures: Why markets in education don't work. Buckingham: Open University Press.

Lauder, H., \& Wylie, C. (Eds.). (2011). Towards successful schooling. Falmer Press.

Laugesen, R., \& Black, J. (2010). All things being equal. New Zealand Listener, Vol. 223. Retrieved from

http://www.listener.co.nz/issue/3651/features/15346/all_things_being_equal,2.h tml

Lavallee, B., \& Clearsky, L. (20006). From woundedness to resilience: A critical review from an Aboriginal perspective. Journal of Aboriginal Health, 3(1), 6-14.

Lawson, T., \& Garrod, J. (1994). The complete A-Z sociology handbook. London: Hodder and Stoughton Educational.

Levinas, E. (1998). Otherwise than being: or beyond essence. (Trans. A. Lingis). Pittsburgh: Duquesne University Press.

Lopez, G. R. (1998). Reflections on epistemology and standpoint theories: a response to "a Māori approach to creating knowledge". International Journal of Qualitative Studies in Education, 11(2), 225-231.

Lynch, K., \& O'Neill, C. (1994). The colonisation of social class in education. British Journal of Sociology of Education, 15(3), 307-324.

Macfarlane, A. H. (2004). Kia hiwa ra: Listen to culture: Māori students' plea to educators. Wellington, NZ: New Zealand Council for Educational Research.

Mahuika, A. (1992). Leadership: Inherited and achieved. In Michael King (Ed.), Te Ao Hurihuri: Aspects of Māoritanga. Auckland: Reed.

Mahuika, R. (2008). Kaupapa Māori theory is critical and anti-colonial. MAI Review, 3(4).

Mannheim, K. (1936). Ideology and utopia, trans. L. Wirth and E. Shils (p. 121). New York.

Marie, D., Fergusson, D. M., \& Boden, J. M. (2008). Educational achievement in Māori: The roles of cultural identity and social disadvantage. Australian Journal of Education, 52(2), 183-196. 
Marsden, M. (1992a). God, man and universe. In Michael King (Ed.), Te Ao Hurihuri: Aspects of Māoritanga (p. 134).

Marsden, M. (2003). The woven universe: Selected writings of Rev. Māori Marsden. (T. A. C. Royal, Ed.). The Estate of Rev. Māori Marsden.

Marsden, M., \& Hēnare, T. A. (1993). Kaitiakitanga: A definitive introduction to the holistic world view of the Māori. Unpublished report.

Marshall, J, Peters, M., \& Smith, G. H. (1991). The business roundtable and the privatisation of education: Individualism and the attack on Māori. Education Policy and the Changing Role of the State. Delta, Massey University, Palmerston North.

Marshall, M. N. (1996). Sampling for qualitative research. Family Practice, 13(6), $552-525$.

Martinez Cobo, J. (1986). Study of the Problem of Discrimination Against Indigenous Populations. Final Report Submitted to the Special Rapporteur. Department of Economic and Social Affairs, Division for Social Policy and Development. Secretariat of the Permanent Forum on Indigenous Issues. New York: United Nations.

Massey University. (1999). Social inequality in New Zealand: international social survey programme 1999 (pp. 1-25). Palmerston North: Massey University.

Massey University. (2010). Social inequality in New Zealand: International social survey programme. School of Communication, Journalism and Marketing, Palmerston North: Massey University.

Mataira, K. (1980). The effectiveness of the silent way method in the teaching of Māori as a second language (Unpublished master's thesis). University of Waikato, Hamilton, New Zealand.

Mataira, P. J. (2000). Ngā kai arahi tutui Māori - Māori entrepreneurship: The articulation of leadership and the dual consistency arrangements associated with Māori enterprise in a capitalist economy. Massey University Albany, Auckland.

Maxwell, J. (2005). Qualitative research design. An interactive approach. ( $2^{\text {nd }}$ ed.). Sage Publications Ltd.

Mayo, P. (1999). Gramsci, Freire and adult education: Possibilities for transformative action. Palgrave Macmillan.

McCormack, D. (2010). Opening address at the New Zealand higher education summit, 15 March 2010, Auckland.

McGregor, C. (1997). Class in Australia. Ringwood: Penguin. 
Mckenzie, J. (2001). Māori children with special abilities: taking a broader perspective. NZ Principal.

McKinley, E. (2001). Cultural diversity: Masking power with innocence. Science Education, 85(1), 74-76.

McKinley, E. (2005). Locating the global: culture, language and science education for indigenous students. International Journal of Science Education, 27(2), 227-241.

McKinley, E., Grant, B., Middleton, S., Irwin, K., \& Williams, L. (2007). Teaching and learning in the supervision of Māori doctoral students: Project outline. MAI Review, 2 (Research note 1), 1-6.

Mcleod, R. (2004, Nov). Closing the employment gap. re-think: Waikato Management School's Newspaper For Business., p. 6. Retrieved from http://wms-soros.mngt.waikato.ac.nz/NR/rethink/RethinkNovFinal.pdf

McNeill, H. (2008). A critical reflection of ethical issues in Māori research. Te Kaharoa, 1, 18-49.

Mead, H. (2003). Tikanga Māori: Living by Māori values. Wellington: Huia Publishers.

Mead, H. (2004). Whakapapa and te ira tangata. Wellington: Toi Te Taiao BioEthics Council.

Meadmore, D. (1999). Class counts! Social class and education. In D. Meadmore, B. Burnett, \& P. O'Brien (Eds.), Understanding education: contexts and agendas for the new millennium (pp. 56-63). Sydney: Prentice Hall.

Mercier, O. (2007). Indigenous knowledge and science. A new representation of the interface between Indigenous and Eurocentric ways of knowing. He Pūkenga Kōrero, 8(2), 20-28.

Metge, J. (1976). Rautahi (2nd ed.). Oxfordshire: Routledge.

Metge, J. (2010). Tuamaka: The challenge of difference in Aotearoa New Zealand. Auckland: Auckland University Press.

Meyer, L, H., Penetito, W., Hynds, A., Savage, C., Hindle, R. \& Sleeter, C. (2010). Evaluation of Te Kotahitanga: 2004-2008. Report to the Ministry of Education. Wellington: Victoria University of Wellington.

Meyer, M. A. (2001). Our own liberation: Reflections on Hawaiian epistemology. The Contemporary Pacific, 13(1), 124-148.

Middleton, S., Codd, J., \& Jones, A. (Eds.). (1990). New Zealand education policy today: Critical perspectives. Wellington: Allen \& Unwin. 
Middleton, S., \& McKinley, E. (2010). The gown and the korowai: Māori doctoral students and the spatial organisation of academic knowledge. Higher Education Research \& Development, 29(3), 229-243.

Mikaere, A. (2001). "Racism. Alive and kicking in the colony - an examination of racism and colonisation in Aotearoa/New Zealand. Faculty of Law Seminar Series on Racism. University of British Columbia.

Miles, R. (1980). Class, race and ethnicity: a critique of Cox's theory. Ethnic and Racial Studies, 3(2).

Miles, R. (1982). Racism and migrant labour. London: Routledge and Kegan Paul.

Milne, A. (1993). Ngā tamariki Māori āta mohio: Gifted Māori children. The Proceedings of the New Zealand Council for Gifted Education (pp. 47-61).

Ministry of Education. (2005). Economic outcomes for Māori from tertiary education. Wellington.

Ministry of Education. (2006). Māori in doctoral study. Wellington: Ministry of Education. Retrieved from

http://www.educationcounts.govt.nz/publications/tertiary_education

Ministry of Education. (2007a). Māori participation in tertiary education 2005. Wellington: Ministry of Education.

Ministry of Education. (2007b). Māori in postgraduate study 2005. Wellington: Ministry of Education.

Ministry of Education. (2008). Hei titiro anō i te whāinga: Māori achievement in bachelors degrees revisited. Wellington: Ministry of Education.

Ministry of Education. (2009). Profile and trends 2008: New Zealand's tertiary education sector. Wellington: Ministry of Education.

Ministry of Education. (2010). Ngā Haeata Mātauranga - The Annual Report on Māori Education 2008/2009. Wellington: Ministry of Education.

Ministry of Education. (2013). Effective Governance: Supporting Education Success as Māori. Information for School Boards of Trustees. Wellington: Ministry of Education. Retrieved from http://www.minedu.govt.nz/ /media/MinEdu/Files/Boards/EffectiveGovernance/ SupportingEducationSuccessAsMaori.pdf

Ministry of Health. (2010). Quick facts about the regulated Māori health workforce. Retrieved from http://www.maorihealth.govt.nz

Ministry of Justice. (2001). He hīnātore ki te ao Māori: A glimpse into the Māori World. Wellington. 
Ministry of Social Development. (2010). The social report 2010. Wellington. Retrieved from http://www.socialreport.msd.govt.nz/documents/the-socialreport-2010.pdf

Mitchell, D., Phillips, T., Evans, A., Reed, K., Mateju, P., Krejci, J., Smith, M., et al. (2008). International social survey programme 2009 social inequality: Final questionnaire. Tel Aviv.

Moewaka-Barnes, H. (2000). 'Kaupapa Māori: explaining the ordinary', a report prepared for Whāriki Research Group, Alcohol and Public Health research Unit, Auckland. Retrieved from http://www.kaupapamaori.com/assets/explaining the ordinary.pdf

Moon, P. (1993). Māori social and economic history to the end of the Nineteenth Century. Wellington: Huia Publishers.

Morris, J. E. (2004). Can anything good come from Nazareth? Race, class and African American schooling and community in the urban south and midwest. American Educational Research Journal, 41(1), 69-112.

Morris, L., \& Scott, J. (1996). The attenuation of class analysis: some comments on G.Marshall, S.Roberts and C.Burgoyne, "Social class and the underclass in Britain in the USA". The British Journal of Sociology, 47(1).

Mosco, V. (2009). The political economy of communication (2nd ed.). Sage Publications Ltd.

Mutu, M. (2011). The state of Māori rights. Wellington: Huia Publishers.

Nash, R. (1986). Educational and social inequality: the theories of Bourdieu and Boudon with reference to class and ethnic differences in New Zealand. New Zealand Sociology, 1(2), 121-137.

Nash, R. (1997). Inequality/difference (2nd Ed.). Palmerston North: ERDC Press.

Nash, R. (1999a). Realism in the sociology of education: "Explaining" social differences in attainment. British Journal of Sociology, 20(1), 107-125.

Nash, R. (1999b). Social capital, class identity, and progress at school: case studies. New Zealand Journal of Education Studies, 34(2), 267-280.

Nash, R. (1999c). School learning: Conversations with the sociology of education. Palmerston North: Delta.

Nash, R. (2001). Models of Māori educational attainment: beyond the "class" and "ethnicity" debate. Waikato Journal of Education, 7, 23-36.

Nash, R. (2010). Explaining inequalities in school achievement. (H. Lauder, Ed.). Surrey, England: Ashgate Publishing Limited. 
Nash, R., \& Harker, R. (1992). Working with Class: The educational experiences and practices of class-resourced families. New Zealand Journal of Educational Studies, 27(1), 3-20.

Nash, R., \& Harker, R. (1997). 'Progress at school': Final report to the Ministry of Education. Massey University.

Nepe, T. (1991). Te toi huarewa tīpuna: Kaupapa Māori an educational intervention system (Master's thesis, University of Auckland, New Zealand). Retrieved from https://researchspace.auckland.ac.nz/handle/2292/3066

New Zealand Treasury. (2010). Monthly economic indicators: May 2010. Wellington.

New Zealand Vice-Chancellor's Committee. (2008). New Zealand university graduate statistics. Wellington: New Zealand Vice-Chancellors Committee. Retrieved from http://www.nzvcc.ac.nz/files/u10/NZUniGradStats3.pdf

Ngata, A. T. (1948). Ngā moteatea (Vol.3): Supplement. Journal of the Polynesian Society, 57, 257-296.

Ngā Kaitatau Māori o Aotearoa. (2007). Ngā kaitatau Māori o Aotearoa: National Māori accountants network. He Mihi. Retrieved from http://www.nzica.com/AM/Template.cfm?Section=National Maori Accountants Network

Ngā Pae o te Maramatanga (2012). Annual Report. Indigenous Transformation through Research Excellence. Ngā Pae o Te Maramatanga, University of Auckland: Auckland.

Ngugi Wa Thiong'o. (1986). Decolonising the Mind. The Politics of Language in African Literature. Portsmouth: Heinemann.

Niwa, T. (1998). Māori students with special abilities. APEX, 11/12(1), 3-8.

Oliver, M., \& Shapiro, T. (1995). Black wealth/White wealth a new perspective on racial inequality. New York: Routledge.

Olssen, M., Codd, J., \& O’Neill, A.M. (2004). Educational Policy: Globalisation, Citizenship, Democracy. London: Sage.

Openshaw, R., \& Rata, E. (2008). Flax rope or iron fetter? How cultural essentialism threatens intellectual freedom in the New Zealand Tertiary Education Sector. New Zealand Journal of Tertiary Education Policy.

Orange, C. (1987). The Treaty of Waitangi. Wellington: Allen and Unwin \& Port Nicholson Press. 
Organisation for Economic Co-operation and Development (OECD). (2008). Growing unequal? Income distribution and poverty in OECD countries. Paris. Retrieved from www.oecd.org/els/social/inequality/GU

Ortner, S. B. (1991). Reading America: Preliminary notes on class and culture. Recapturing Anthropology: Working in the Present. Santa Fe, NM: School of American Research Press.

Owen, W. (1984). Interpretive themes in relational communication. Quarterly Journal of Speech, 70, 274-287.

O’Regan, H. (2001). Ko Tahu, Ko Au. Christchurch: Horomaka Publishing.

O'Regan, H. (2009). Toitū te iwi - A journey in the evolution of cultural identity. Te Kaharoa, 2.

Pahl, R. (1993). Does class analysis without class theory have a future? Sociology, 27, 253-258.

Patton, M. (1990). Qualitative research and evaluation methods (pp. 169-186). Beverly Hills, CA: Sage.

Patton, Michael. (2002). Qualitative research and evaluation methods (3rd Ed.). Thousand Oaks: California: Sage Publications Inc.

Payne, G., \& Grew, C. (2005). Unpacking "class ambivalence”: Some conceptual and methodological issues in accessing class cultures. Sociology, 39(5), 893910.

Pearsall, J. (Ed.). (1999). The concise Oxford dictionary (10th Ed.). Oxford University Press.

Pearson, D., \& Thorns, D. (1983). Eclipse of equality: social stratification in New Zealand.

Penehira, M., Cram, F., \& Pipi, K. (2003). Kaupapa Māori governance: Literature review and key informant interviews. Wellington.

Penetito, W. (1984). Taha Māori and the core curriculum. Delta, 34, 35-43.

Penetito, W. (1988). Māori education for a just society. In Royal Commission on Social Policy (Ed.), The April Report - Social Perspectives, Vol. IV (pp. 91114). Wellington: Royal Commission on Social Policy.

Penetito, W. (1997). Visions for Māori education. In V. Tapine \& D. Waiti (Eds.), He tirohanga ki mua: Visions for Māori education. Wellington: New Zealand Council for Educational Research. 
Penetito, W. (2002). Research and context for a theory of Māori schooling. McGill Journal of Education, 37(1), 89-109.

Penetito, W. (2005a). A Sociology of Māori Education - Beyond Mediating Structures (Unpublished PhD thesis). Victoria University of Wellington, New Zealand).

Penetito, W. (2005b). Scenario for a Māori education authority: Mainstreaming or Māori control. In John Codd \& K. Sullivan (Eds.), Education policy directions in Aotearoa New Zealand (pp. 141-160). Palmerston North: Dunmore Press.

Penetito, W. (2006). Kaupapa Māori: Tikanga in research. Retrieved January 10, 2012, from http://www.rangahau.co.nz/methodology/125/

Penetito, W. (2010a). Kaupapa Māori research methodologies. Presentation to the Faculty of Education on 4 June, 201. Wellington.

Penetito, W. (2010b). What's Māori about Māori education? Wellington: Victoria University Press.

Penetito, W., Yates, B., Selby, M., Wikaira, R., Reid, S., Higgins, T., Taipana, B., et al. (2001). Te kāwai ora. Report of the Māori Adult Literacy working party. Unpublished Paper. Wellington.

Pere, R. (1979). Taku taha Māori: My Māoriness. He Matapuna: some Māori perspectives. New Zealand Planning Council, Wellington.

Pere, R. (1988). Te wheke: Whāia te maramatanga me te aroha. In S. Middleton (Ed.), Women and education in Aotearoa (Volume 1, pp. 6-19). Wellington: Port Nicholson Press.

Pere, R. (1994). Ako: Concepts and learning in the Māori tradition. Wellington: Kōhanga Reo National Trust.

Peters, M., Fitzsimons, P., \& Marshall, J. (1999). Education and managerialism in a global context. In C. A. Torres \& N. Burbules (Eds.), Education and Globalization: Critical Concepts. New York/London: Routledge.

Phillips, H. (2003). Te reo karanga o ngā tauira Māori: Māori students, their voices, their stories at the University of Canterbury 1996-1998 (Unpublished PhD thesis, University of Canterbury, New Zealand). Retrieved from http://hdl.handle.net/10092/2700

Phillips, H., \& Mitchell, M. (2010). "It is all about feeling the aroha": Successful Māori and Pasifika providers. EEL Research Report No. 7. EEL Research Report (Vol. 7). Lincoln, New Zealand. 
Pihama, L. (2001). Tihei mauri ora honouring our voices: Mana wahine as a kaupapa Māori theoretical framework (Unpublished PhD thesis). University of Auckland, New Zealand.

Pihama, L., Cram, F., \& Walker, S. (2002). Creating methodological space: A literature review of kaupapa Māori research. Canadian Journal of Native Education, 26, 30-43.

Pipi, K., Cram, F., Hawke, R., Hawke, S., Huriwai, T. M., Mataki, T., Milne, M., et al. (2004). A Research ethic for studying Māori and Iwi Provider Success. Social Policy Journal of New Zealand, (23).

Pitcher, B. (2012). Race and capitalism redux, Patterns or Prejudice, 46 (1), pp 115.

Poata-Smith, E. T. A. (1996). He pokeke uenuku i tū ai: The evolution of contemporary Māori protest. In P. Spoonley, D. Pearson, \& C. Macpherson (Eds.), Ngā Pātai: Racism and Ethnic Relations in Aotearoa/New Zealand (pp. 97-116). Palmerston North: The Dunmore Press Ltd.

Poata-Smith, E. T. A. (2004a). Ka tika a muri, ka tika a mua? Māori protest politics and the Treaty of Waitangi settlement process. In P. Spoonley, C. Macpherson, \& D. Pearson (Eds.), Tangata Tangata The Changing Ethnic Contours of New Zealand (pp. 59-88). Victoria: Thomson/Dunmore Press.

Poata-Smith, E. T. A. (2004b). The changing contours of Māori identity and the treaty settlement process. In J. Hayward \& N. Wheen (Eds.), The Waitangi Tribunal (pp. 168-183). Wellington: Bridget Williams Books.

Pohatu, T. W. (2003). Māori world views: Sources of innovative choices for social work practice. Te Komako, 16-24.

Pohatu, T. W. (2004). Āta: Growing respectful relationships. He Pūkenga Kōrero, $8(1), 1-8$.

Pollock, J. (2004). 'We don't want your racist tour': The 1981 springbok tour and the anxiety of settlement in Aotearoa/New Zealand. Graduate Journal of Asia Pacific Studies, 2(1), 32-43.

Popper, K. (1977). The open society and its enemies, Vol 2, The high tide of prophecy: Hegel, Marx, and the aftermath. London: Routledge and Kegan Paul.

Power, S. (2000). Educational pathways into the middle class(es). British Journal of Sociology of Education, 21(2), 133-145.

Power, S., Edwards, T., Whitty, G., \& Wigfall, V. (2003). Education and the middle class. Open University Press. 
Power, S., \& Whitty, G. (2002). Bernstein and the middle class. British Journal of Sociology of Education, 23(4), 595-606.

Prandy, K., \& Jones, F. (2001). An international comparative analysis of marriage patterns and social stratification. International Journal of Sociology and Social Policy, 21(4/5/6), 165-183.

Procter, J. (2004). Stuart Hall. London: Routledge Critical Thinkers.

Puckey, A. (2006). The substance of the shadow: Māori and Pākehā political economic relationships 1860-1940. Auckland University.

Ramsay, P. (1983). Fresh perspectives on the school transformation. Reproduction Debate: A Response to Anyon from the Antipodes. In Curriculum Inquiry, Vol 13 (3), pp 295-320.

Rangihau, J. (1977). Being Māori. In Michael King (Ed.), Te Ao Hurihuri: The world moves on - aspects of Māoritanga. Wellington: Hicks Smith.

Rata, E. (1991). Māori survival and structural separateness: The history of Te Rūnanganui o Ngā Kura Kaupapa Māori o Tamaki Makaurau, 1987-89 (Unpublished Master's thesis). University of Auckland, New Zealand.

Rata, E. (2000). A political economy of neo-tribal capitalism. New York: Lexington Books.

Rata, E. (2004a). The capitulation of the left. Red \& green: the New Zealand journal of left alternatives, 4(13-32).

Rata, E. (2004b). Leadership ideology in neo-tribal capitalism. In D. E. Davis (Ed.), Political Power and Social Theory (16th ed., pp. 43-71). Emerald Group Publishing Limited.

Rata, E. (2004c). Kaupapa Māori education in New Zealand. In J. Demaine (Ed.), Citizenship and Political Education today (pp. 59-74). London: Palgrave Macmillan.

Rata, E. (2005). The rise and rise of the neo-tribal elite. Retrieved from http://tazi.net/JFriedman/IMG/pdf/RataSS 20Address12Feb05.pdf

Rata, E. (2010). Localising neoliberalism: Indigenous brokerage in the New Zealand university. Globalisation, Societies and Education, 8(4), 523-538.

Reay, D. (1991). Intersections of gender, race and class in the primary school. British Journal of Sociology of Education, 12(2), 163-182.

Reay, D. (1998). Rethinking social class: Qualitative perspectives on class and gender. Sociology, 32(2), 259-275. 
Reay, D. (2004). 'It's all becoming a habitus': Beyond the habitual use of habitus in educational research. British Journal of Sociology of Education, 25(4), 431444.

Reay, D. (2005). Thinking class, making class. British Journal of Sociology of Education, 26(1), 139-143.

Reay, D. (2006). The zombie stalking English schools: social class and educational inequality. British Journal of Educational Studies, 54(5), 288-307.

Reid, P. (2006). Kaupapa Māori research: Analysis. Retrieved from http://www.rangahau.co.nz/methodology/123/

Reid, P., \& Robson, B. (2006). The state of Māori health. In M. Mullholland (Ed.), State of the Māori Nation: twenty-first century issues in Aotearoa (pp. 15-27). Auckland: Reed Publishing.

Reweti, D. (2006). Māori and broadcasting. In M. Mullholland (Ed.), State of the Māori Nation: twenty-first century issues in Aotearoa (pp. 179-186). Auckland: Reed Publishing.

Riessman, C. K. (1993). Narrative analysis. Thousand Oaks, California: Sage.

Robbins, D. (2000). Bourdieu and culture. Sage Publications Ltd.

Robinson, D., \& Williams, T. (2001). Social capital and voluntary activity: Giving and sharing in Māori and non-Māori society. Social Policy Journal of New Zealand, December(17).

Robson, B. (2007). Economic determinants of Māori health and disparities. In M. Bargh (Ed.), Resistance: An Indigenous Response to Neoliberalism (pp. 4564). Wellington: Huia Publishers.

Robson, B., \& Reid, P. (2001). Ethnicity matters: Review of the measurement of ethnicity in official statistics. Wellington.

Roper, B. (1997). The changing class structure. In C Rudd \& B. Roper (Eds.), The Political Economy of New Zealand. Auckland: Oxford University Press.

Royal, Teahukaramu Charles. (1998). Te ao marama - A research paradigm. In Te Pumanawa Hauora (Ed.), Proceedings of Te Ora Rangahau Māori Research \& Development Conference (pp. 79-87). School of Māori Studies, Massey University, Palmerston North.

Royal, Teahukaramu Charles. (2002). Indigenous worldviews: A comparative study. A report of research progress. Otaki.

Royal, Teahukaramu Charles. (2005). Exploring indigenous knowledge. Paper delivered to "The indigenous knowledges conference - reconciling academic 
priorities with indigenous realities", Victoria University, Wellington, 25 June 2005.

Royal, Teahukaramu Charles (Ed.). (2003). The woven universe: Selected writings of Rev. Māori Marsden. The Estate of Rev. Māori Marsden.

Rudd, Chris, \& Roper, B. (Eds.). (1997). The political economy of New Zealand (2nd ed.). Oxford University Press.

Said, E. (1978). Orientalism. London: Vintage Books.

Salmond, A. (1991). Two worlds: first meetings between Maori and Europeans, 1642-1772. Auckland: Viking.

Savage, M, Bagnall, G., \& Longhurst, B. (2001). Ordinary, ambivalent and defensive: Class identities in the northwest of England. Sociology, 35(4), 875892.

Savage, Mike. (2000). Class analysis and social transformation. Open University Press.

Savage, Mike. (2003). A new class paradigm? British Journal of Sociology of Education, 24(4), 535-541.

Scott, D. (2004). Ask that mountain: The story of Parihaka (3rd Ed.). Raupo.

Selby, R. (1996). A study of the factors that contribute to success for Māori women in tertiary education. He Pārekereke, Department of Education, Victoria University of Wellington.

Sharp, R. (1980). Knowledge, ideology and the politics of schooling: towards a Marxist analysis of education. London, Boston and Henley: Routledge \& Kegan Paul.

Sharples, P. (1988). Kura kaupapa: Recommendations for policy. Access: Critical Perspectives on Education Policy, (8).

Shaull, R. (2000). Foreword: Pedagogy of the oppressed (pp. 29-34). New York: Continuum International Publishing Group.

Sibley, C. G., Harre', N., Hoverd, W. J., \& Houkamau, C. A. (2011). The gap in the subjective wellbeing of Māori and New Zealand Europeans widened between 2005 and 2009. Social indicators research, 104(1), 103-115.

Silverman, D. (2000). Analysing talk and text. In N. K. Denzin \& Y. S. Lincoln (Eds.), Handbook of Qualitative Research (2nd ed., pp. 821-834). London: Sage.

Simon, J. (1990). The place of schooling in Māori-Pākehā relations. University of Auckland. 
Simon, J. (1998). Ngā kura Māori - The native schools' system 1867-1969. (J. A. Simon, Ed.). Auckland: Auckland University Press.

Simon, J, \& Smith, L. T. (2001). A civilising mission? Perceptions and representations of the New Zealand native schools system. Auckland: Auckland University Press.

Simon, Judith. (1986). Ideology in the schooling of Māori children. Delta Research Monograph (Delta Rese., Vol. No.7). Palmerston North: Massey University.

Singh, M., \& Huang, X. (2012). Bourdieu's lessons for internationalising Anglophone education: declassifying Sino-Anglo divisions over critical theorising. Compare: A Journal of Comparative and International Education, 1-21.

Skeggs, B. (2004). Class, self, culture. London: Routledge.

Small, D. (2009). 'Neoliberalism's fate: Implications for education'. Paper presented to 37th annual conference of ANZCIES, 24-27 November, University of New England, Armidale, Australia.

Smith, G. H. (1999). Reform of the New Zealand education system and response by indigenous Mãori of New Zealand. Journal of Educational Studies, 60-72.

Smith, G.A., \& Sobel, D. (2010). Place- and community-based education in schools. Taylor \& Francis.

Smith, Graham Hingangaroa. (1990). The politics of reforming Māori education: The transforming potential of Kura Kaupapa Māori. In H. Lauder \& C. Wylie (Eds.), Towards Successful Schooling. London: Falmer Press.

Smith, Graham Hingangaroa. (1997). The development of kaupapa Māori: theory and praxis (Unpublished PhD thesis). University of Auckland, Auckland, New Zealand).

Smith, Graham Hingangaroa. (2000). Māori education: Revolution and transformative action. Canadian Journal of Native Education, 24(1), 57-72.

Smith, Graham Hingangaroa. (2003a). Indigenous struggle for the transformation of education and schooling. Keynote address to the Alaskan Confederation of Natives Convention, October 2003.

Smith, Graham Hingangaroa. (2003b). Kaupapa Māori theory: Theorizing indigenous transformation of education and schooling. Presentation to the "Kaupapa Māori Symposium" NZARE / AARE Joint Conference. Auckland.

Smith, Graham Hingangaroa. (2004). Mai i te maramatanga, ki te pūtanga mai o te tāhuritanga From conscientization to transformative praxis. Educational Perspectives: Journal of the College of Education, 37(1), 46-52. 
Smith, Gregory A, \& Sobel, D. (2010). Place and community based education in schools. New York: Routledge.

Smith, L.T. (1992). 'Kura Kaupapa Māori and the implications for curriculum' In G. Mcculloch (Ed.), The School Curriculum in New Zealand: History, Theory, Policy and Practice. Palmerston North: Dunmore Press.

Smith, L. T. (1999). Decolonizing methodologies: Research and indigenous peoples. London: Zed Books.

Smith, L. T. (2005). Building a research agenda for indigenous epistemologies and education. Anthropology and Education Quarterly, 36(1), 93-95.

Smith, L. T. (2006). Fourteen lessons of resistance to exclusion: learning from the Māori experience in New Zealand over the last two decades of neo-liberal reform. In M. Mullholland (Ed.), State of the Māori Nation: twenty-first century issues in Aotearoa (pp. 247-260). Auckland: Reed Publishing.

Smith, L. T. (2008). On tricky ground: Researching the native in the age of uncertainty. In N. K. Denzin \& Y. S. Lincoln (Eds.), The Landscape of Qualitative Research (3rd ed., pp. 113-144). Thousand Oaks: California: Sage Publications Ltd.

Spoonley, P. (1984). Tauiwi: racism and ethnicity in New Zealand. Auckland: Dunmore Press.

Spoonley, P., \& Pearson, D. G. (2004). Tangata tangata: The changing ethnic contours of New Zealand. (P. Spoonley, Ed.). Cengage Learning Australia.

Statistics New Zealand. (2007). Quickstats about Māori. Wellington. Retrieved from http://www.stats.govt.nz/Census/2006CensusHomePage/QuickStats/quickstats -about-a-subject/maori.aspx

Statistics New Zealand. (2008). National ethnic population projections: 2006 (base) - 2026. Wellington.

Statistics New Zealand. (2009a). Household labour force survey: September 2009 quarter. Wellington: Statistics New Zealand.

Statistics New Zealand. (2009b). New Zealand income survey: June 2009 quarter.

Statistics New Zealand. (2009c). Implementing ANZSCO in the household labour force survey. Retrieved from www.stats.govt.nz

Strathdee, R. (2005). Globalization, innovation, and the declining significance of qualifications led social and economic change. Journal of Educational Policy, 20(4), 437-456. 
Strathdee, R. (2013). Neo-tribal capitalism, socio-economic disadvantage and educational policy. New Zealand Journal of Education Policy, 28 (4), 501-516.

Strauss, A. L., \& Corbin, J. M. (1990). Basics of qualitative research: grounded theory procedures and techniques. Sage Publications Ltd.

Stokes, E. (2008). Māori geography or geography of Māoris. New Zealand Geographer, 43(3), 118-123.

Sykes, A. (2007). Blunting the system: The personal is political. In M. Bargh (Ed.), Resistance: An Indigenous Response to Neoliberalism: An Interview with Annette Sykes (pp. 115-124). Wellington: Huia Publishers.

Sykes, A. (2010). 'The politics of the brown table'. Paper presented at the Bruce Jesson Lecture, 27 October, Madiment Theatre, University of Auckland.

Tapine, V., \& Waiti, D. (1997). He tirohanga ki mua: Visions for Māori education. Wellington: New Zealand Council for Educational Research.

Tapsell, P., \& Woods, C. (2008). Pōtikitanga: Indigenous entrepreneurship in a Māori context. Journal of Enterprising Communities: People and Places in the Global Economy, 2(3), 192-203.

Te Awekotuku, N. (1991). Mana wahine Māori: Selected writings on Māori women's art, culture and politics. Auckland: New Women's Press.

Te Huinga Roia Māori. (2010). About us: Te Huinga Roia Māori ō Aotearoa. Retrieved from http://www.maorilawsociety.co.nz/

Te Punga Somerville, A. (2007). "If I close my mouth I will die": Writing, resisting, centring. In M. Bargh (Ed.), Resistance: An Indigenous Response to Neoliberalism (pp. 85-114). Wellington: Huia Publishers.

Te Puni Kōkiri. (1992). Ngā toka tū Moana: Māori leadership and decision making. Wellington.

Te Puni Kōkiri. (1998a). Progress towards closing social and economic gaps between Māori and non-Māori: A report to the Minister of Māori Affairs. Wellington: Te Puni Kōkiri.

Te Puni Kōkiri. (1998b). Progress towards closing social and economic gaps between Māori and non-Māori: A report to the Minister of Māori Affairs. Wellington.

Te Puni Kōkiri. (2006). Ngā pukenga mātauranga Māori: Māori graduates. Wellington: Te Puni Kōkiri.

Te Puni Kōkiri. (2007). Historical influences: Māori and the economy. Wellington. 
Te Puni Kōkiri. (2009a). Whakawhiwhinga whaiaro a ngāi Māori: Māori personal income. Wellington: Te Puni Kōkiri.

Te Puni Kōkiri. (2009b). The implications of a recession for a Māori economy. Wellington.

Te Puni Kōkiri. (2009c). Mahi Māori: Māori employment. Wellington: Te Puni Kōkiri.

Te Puni Kōkiri. (2009d). Moni utunga Māori: Māori earnings. Wellington: Te Puni Kōkiri.

Te Puni Kōkiri. (2010). Ngai Māori me ngā hua o te mātauranga. Benefits of education for Māori. Wellington: Te Puni Kōkiri.

Te Puni Kōkiri. (2011). Māori: Demographic dividend for economic return - Ko te whakatipu tāngata hei huanga ohanga. Wellington.

Te Puni Kōkiri. (2012). Every Māori counts: Ko te tatau i a ngai Māori. Wellington: Te Puni Kōkiri.

Te Rito, J. S. (2007). Whakapapa: A framework for understanding identity. MAI Review, 2, 1-10.

The New Zealand Institute. (2010). A report card of New Zealand's social, economic, and environmental wellbeing. Wellington: The New Zealand Institute. Retrieved from www.nzahead.com

Thrupp, M. (2001). Education policy and social class in England and New Zealand: an instructive comparison. Journal of Educational Policy, 16(4), 297-314.

Thrupp, M. (2007). Education's "inconvenient truth": Part one - persistent middle class advantage. New Zealand Journal of Teachers' Work, 4(2), 77-88.

Thrupp, M. (2008). Education's “inconvenient truth": Part two - the middle classes have too many friends in education. New Zealand Journal of Teachers' Work, 5(1), 54-62.

Tiakiwai, S. (2001). Māori participation in higher education. Tainui graduates from the University of Waikato, 1992-1997 (Unpublished PhD thesis). University of Waikato, New Zealand.

Tiakiwai, S., \& Teddy, L. (2003). Collaborating for efficiency: Report of the responsiveness to Māori sub-group. Wellington: Tertiary Education Commission.

Tomlins-Jahnke, H. (2008). The Place of Cultural Standards in Indigenous Education in MAI Review, 1 (Article 1). Retrieved from http://review.mai.ac.nz/index.php/MR/article/viewFile/100/107 
United Nations. (2010). State of the world's indigenous peoples. Retrieved from http://www.un.org/esa/socdev/unpfii/documents/SOWIP web.pdf

United Nations Development Programme. (2009). Human development report: New Zealand - human development index. New York: UNDP. Retrieved from http://hdrstats.undp.org/en/countries/country fact sheets/cty fs NZL.html

Urciuoli, B. (1993). Representing class: Who decides? Anthropological Quarterly, 66(4), 203-210.

Waitangi Tribunal. (2004). Mohaka ki Ahuriri report. WAI 201. Wellington: Waitangi Tribunal.

Waitangi Tribunal. (2012). Matua Rautia: The Report on the Kōhanga Reo Claim. Wellington, Waitangi Tribunal.

Waitere-Ang, H. (1998). Methodological vertigo: the researcher as a sociohistorically constructed phenomenon. Proceedings of Te Ora Rangahau Māori Research \& Development Conference (pp. 224-230). Palmerston North: Massey University.

Walker, P. (2011). Whakatupuranga rua mano 1975-2000. He tirohanga whakamuri. Otaki, Aotearoa: Te Takapu, Te Wānanga o Raukawa.

Walker, R. J. (1987). Ngā tautohetohe - Years of anger. Auckland: Penguin.

Walker, R. J. (1990). Ka whawhai tonu mātou: The struggle without end. Auckland: Penguin.

Walker, R. J. (1991). Liberating Māori from educational subjection. Auckland: International Research Institute for Māori and Indigenous Education, University of Auckland.

Walker, R. J. (1992). The relevance of Māori myth and tradition. In Michael King (Ed.), Te Ao Hurihuri: Aspects of Māoritanga (pp. 170-182). Auckland: Octopus Publishing.

Walker, R. J. (1996). Contestation of power and knowledge in the politics of culture. He Pūkenga Kōrero, 1(2), 1-7.

Walker, R. J. (1999). The development of Māori studies in tertiary education in Aotearoa/New Zealand. In M. Peters (Ed.), After the Disciplines. The Emergence of Culture Studies (pp. 187-198). Connecticut: Bergin and Garvey.

Walker, R. J. (2001). He tipua: The life and times of Sir Apirana Ngata. Auckland: Viking Press/Penguin Books. 
Walker, R. J. (2007). Ōpotiki mai tawhiti - Capital of Whakatōhea: The story of Whakatōhea's struggle during the nineteenth and twentieth centuries. Auckland: Penguin.

Walker, S., Eketone, A., \& Gibbs, A. (2006). An exploration of kaupapa Māori research, its principles, processes and applications. International Journal of Social Research Methodology, 9(4), 331-344.

Wanhalla, A. (2009). In/visible sight. Wellington: Bridget Williams Books Ltd.

Watkins, P. (1992). The transformation of educational administration: The hegemony of consent and the hegemony of coercion. Australian Journal of Education, 36(3), 237-259.

Waymouth, L. (2003). The bureaucratisation of genealogy. Ethnologies comparees, 6.

Webber, M. (2009). The multiple selves and realities of a Māori researcher. MAI Review, 1(1), 1-8.

Webber, M. (2011). Look to the past, stand tall in the present: The integral nature of positive racial-ethnicity identity for the academic success of Māori students. In W. Vialle (Ed.), Giftedness from an indigenous perspective (pp. 100-110). Australian Association for the Education of the Gifted and Talented.

Webster, S. (2002). Māori retribalization and treaty rights to the New Zealand fisheries. The Contemporary Pacific, 14(2), 341-376.

West, C. (1985). The dilemma of the black intellectual. Cultural Critique, (1), 109124.

Wickliffe, T. (2010). Lifting the veil of secrecy. Koha, (7), 4-6.

Wilkie, M. (2006). Kaupapa Māori intervention in post-graduate education: Ko te pae tawhiti arumia kia tata: Seek to bring the distant horizons closer. New Zealand Annual Review of Education, 15, 45-63.

Williams, D. V. (1999). Te Kooti Tango Whenua: The Native Land Court 1864-1909. Wellington: Huia Publishers.

Williams, R. (1983). Keywords - a vocabulary of culture and society (Revised Ed.). New York: Oxford University Press.

Winiata, W. (1978). Whakatupuranga rua mano, generation 2000: An experiment in tribal development. New Zealand Planning Council, 4.

Winiata, W. (1988). Hapū and iwi resources and their quantification. Government Print, Wellington. 
Wright, E. (2005). Foundations of a neo-Marxist class analysis. In E. O. Wright (Ed.), Approaches to Class Analysis (pp. 4-30). Cambridge University Press.

Wright, E. O. (2000). Class counts. Cambridge University Press.

Wylie, C. (1988). Fair enough. Set, 1(Item 9).

Yosso, T. (2005). Whose culture has capital? A critical race theory discussion of community cultural wealth. Race, Ethnicity and Education, 8(1), 69-91.

Young, M. (1975). Knowledge and control: New directions for the sociology of education. London: Collier-Macmillan.

Zizek, S. (1997). Multiculturalism, or, the cultural logic of multinational capitalism, New Left Review, Series 1 (225) September, 28-51. 


\section{Appendix A: Participant Interview Schedule}

\section{Research: Higher Education Success and the Emergence of a Māori Middle Class}

The primary questions are numbered, with prompts shown in the bullet points below.

\section{Section A: Background information}

[Transition: Let me begin by asking you some brief background questions]

1. Where are you from?

- Hapū, iwi, whānau, awa, maunga, waka, papakāinga

2. Where do you currently live?

3. Are you married, single, in a relationship, divorced, separated?

4. Do you have children?

5. What is your date of birth?

6. How would you describe your reo proficiency?

7. What is your highest qualification?

8. What is your gross annual income? 


\section{Section B: Whānau and upbringing}

[Transition: Now l'd like to ask you about your whānau and your upbringing to get a sense of where you've come from]

9. Describe your whānau background and upbringing?

10. Where did you grow up? Describe the community.

11. How many people were in your nuclear whānau?

12. Who brought you up/were your primary caregivers?

\section{Section C: Whānau material wealth}

[Transition: The next few questions are focused on the jobs and income in your whānau to help me understand the material resources that you grew up with]

13. What jobs/occupation/s did your mother, father or primary caregiver/s have?

14. What qualification/s did your mother, father or primary caregiver/s have?

15. How would you describe the material wealth of your whānau as you were growing up?

16. Although not a commonly used term in Aotearoa, some people see themselves as belonging to a social class, what class do you see your whānau as being while you were growing up (i.e. working class, lower middle class, middle class, upper middle class)? 


\section{Section D: Whānau and education}

17. What did education mean to your whānau as you were growing up and in what ways was this reflected?

18. What values and/or dispositions did you learn within the whānau which helped you throughout your educational journey?

19. What everyday practices did your family get into (as you were growing up) related to education in the broader sense (e.g. kapa haka, music lessons, sports etc)?

20. What school-related practices did your family undertake (as you were growing up) at home (e.g. reading, homework, tutoring etc)?

\section{Section E: Personal education}

21. Describe your personal educational journey, experiences and outcomes?

22. What influence did your whānau have upon your education choices and outcomes?

23. In what ways do you think the material wealth of your whānau impacted upon or influenced your education choices, destinations and outcomes?

24. Why did you pursue higher education qualifications?

25. What were the critical success factors? 


\section{Section F: Educational aspirations and strategies}

26. Based on your personal journey, what aspirations do you have for your tamariki, mokopuna, nieces' and/or nephews' education?

27. What values and dispositions have you or will you pass on to support their education?

28. What everyday practices does your family do related to education in the broader sense (e.g. kapa haka, music lessons, sports etc)?

29. What kinds of school-related practices does your family do at home (e.g. reading, homework, tutoring etc)?

\section{Section G: Work and effecting change}

30. What work are you currently doing?

31. In what ways has your education led to or contributed to the work you are doing today?

32. How influential is this work in effecting change for yourself (i.e. income and rewards) and also to wider Māori society?

\section{Section H: Connectedness to te ao Māori}

33. In what ways do you connect with te ao Māori? In particular, whānau, hapū, iwi, kaupapa Māori organisations, government policy, knowledge production etc.

34. Does your work relate to these connections and, if so, in what ways? 


\section{Section I: Social class and educated identities}

35. What does it mean to you to be Māori and highly educated?

36. In what ways does being highly educated differentiate you from other members of your whānau and/or other Māori who are not highly educated?

37. How would you define yourself in social class terms? For example, what class do you see yourself in today (i.e. working class, lower middle class, middle class, upper middle class, upper class)?

38. Why do you place yourself in this particular group?

39. Based on your selection, what does being Māori and being in this particular group mean to you?

40. If you don't define yourself in terms of social class, what are your reasons?

\section{Section J: Transformation aspirations}

41. What does transformation mean to you?

42. What aspirations do you have for your whānau, hapū, iwi, Māori whānui?

43. There are stark social inequities between working-class and middle-class Māori, as well as between Māori and non-Māori. What do you think can be done by middle-class Māori to help bridge this gap? 


\section{Appendix B: Information Sheet for Interview Participants}

\section{Research Project: Higher Education Success and the Emergence of a Māori Middle Class.}

Tēnā koe,

He uri ahau nō Ngaitai me Ngāti Porou me Te Whānau-a-Apanui me Te Whakatōhea me Te Arawa hoki. Ko Chelsea Grootveld tōku ingoa. E mihi kau ana tēnei i runga i te kaupapa o te rangahau nei. Nō reira kei te mihi.

The purpose of this letter is to invite you to participate in my doctorate (PhD) research. The study involves investigating the role of higher education success in the emergence of a Māori middle class and the transformative potential of this highly educated cohort. This research has been approved by the Victoria University of Wellington Faculty of Education Ethics Committee.

I have worked in education policy, research and evaluation for the past 10 years and I'm interested in finding out how and in what ways being highly educated, that is, having a postgraduate qualification, honors, masters, doctorate degree, or professional qualification, makes a difference to material lives. In particular, I want to explore whether at the end of the day Māori are becoming highly educated and creating a middle class which maintains the status quo, or are we in fact building a highly educated force with the drive to advance Māori aspirations and effect change for the benefit of the collective.

I would like to interview a range of highly educated Māori to share your perceptions, views, and stories about your personal educational pathways and occupational destinations as well as your aspirations and strategies for the future. The interview will be audio-taped, will take approximately 60-75 minutes and will be carried out at a location most convenient to you. Following the interviews, you will be offered the opportunity to view a transcript of your interview to check for accuracy. You can also request a copy of your transcript to keep. 
Your name will remain confidential to my supervisors and I. You can choose to withdraw consent to participate in this research and/or some or all of your information without having to give a reason, up to and including the final point of data collection (31 March, 2011). All data collected will only be seen by my supervisors, a typist and I, and will be kept on password protected computers in secure offices.

If you would like to participate in this research please reply via email (contact details below) and send me your contact phone number. Please also let me know a convenient time to call. Alternatively, if you have any questions or would like to talk about the research you can call me directly on my mobile or landline at anytime. Please note that you are not obliged to participate in this research. If you choose not to participate you may know of other friends, whānau and/or colleagues who may be interested in this research. If so, please feel free to email me any suggestions you might have and/or forward this information sheet to them.

Thank you for your time. Kia piki te ora

Chelsea Grootveld

Work: 6442982944

Mob: 021911854

Email: chelsea.grootveld@vuw.ac.nz

Supervisors:

Professor Wally Penetito, PhD Hazel Phillips, PhD

Te Kura Māori, VUW College of Education Research Consultant

Email: wally.penetito@vuw.ac.nz $\quad$ Email: $\underline{\text { hazel@kotuku.net.nz }}$ 


\section{Appendix C: Consent form for Interview Participants}

\section{Research Project: Higher Education Success and the Emergence of a Māori Middle Class.}

Please tick the boxes below each statement to signal your agreement. I have read Chelsea Grootveld's introductory letter which explains this research project and I agree to participate in the project. I understand that:

- My name will remain confidential to the researcher and PhD supervisors.

- I can choose to withdraw my consent to participate in this research and/or some or all of my information without having to give a reason, up to and including the final point of data collection (31 March, 2011).

- The interviews will be audio-taped and then written-up.

- Following the Interviews I will be offered the opportunity to view my own transcript to check for accuracy.

- I may request a copy of my own transcript.

- Data collected will be seen only by the researcher, the PhD supervisor and a typist, and will be stored securely in a locked cabinet in a locked room at Victoria University, and destroyed after five years.

- Research findings may be published in academic or professional journals, disseminated at academic or professional conferences and deposited in the University Library, but I will not be identifiable.

- The outcomes of the research will be shared with me.

Name: (please print):

Signature: Date $(\mathrm{d} / \mathrm{m} / \mathrm{y})$ :

Supervisors:

Professor Wally Penetito, PhD Hazel Phillips, PhD

Te Kura Māori, VUW College of Education Research Consultant 


\section{Appendix D: Transcriber Confidentiality Form}

\section{Research Project: Higher Education Success and the Emergence of a Māori Middle Class.}

Please tick the boxes below each statement to signal your agreement. I have read Chelsea Grootveld's introductory letter which explains this research project and I agree to transcribe the interview audiotapes. I agree to:

- $\quad$ keep the names of all participants and their information confidential;

- keep all the data and transcriptions securely stored while I have them.

- When the transcriptions are completed and sent I will also send the audiotapes back to the researcher; and

- destroy all computer and hard copies of the transcript once sent.

Name: (please print):

Signature: Date $(\mathrm{d} / \mathrm{m} / \mathrm{y})$ :

Supervisors:

Professor Wally Penetito, PhD Hazel Phillips, PhD

Te Kura Māori, VUW College of Education Research Consultant 


\section{Appendix E: Participant Matrix}

The next few pages present a participant matrix which outlines who the participants were (using pseudonyms), iwi affiliations, level of education, upbringing - both economic and cultural - occupational connection to te ao Māori and major contribution to this thesis. My intent is to paint a picture of the participants, who they are and how they shaped this research study, while still protecting their anonymity and confidentiality.

The upbringing economic indicators were based on the participant class locations growing up. Most identified themselves as poor or working class. Three indicators were used to denote this: 1) working class, 2) middle class and 3) upper class. Cultural indicators were based on participant descriptions of their connection to te ao Māori growing up. Three indicators were used to denote this connectivity: 1) strong connection, 2) connected or 3) weak connection.

The occupation connection to te ao Māori was included to emphasise how the professional careers of this cohort connect and engage with te ao Māori on a range of levels. Many participants are employed in kaupapa Māori organisations or businesses guided by kaupapa Māori values and practices. Most, however, are employed in Māori-focused roles within mainstream (non-Māori) organisations. A handful of participants work in mainstream organisations where their role includes aspects of connection and engagement with te ao Māori. Finally, the unique way each participant has contributed to this thesis is outlined in the last matrix column. For brevity, I have only included short descriptors. 
Table 10: Participant Matrix: An Overview of Key Indicators and Major Contributions to Thesis

\begin{tabular}{|l|l|l|l|l|l|}
\hline Participant & Iwi Affiliation & $\begin{array}{l}\text { Level of } \\
\text { Education }\end{array}$ & $\begin{array}{l}\text { Upbringing- Economic } \\
\text { (Class) and Cultural } \\
\text { (Connection to te ao } \\
\text { Māori) }\end{array}$ & $\begin{array}{l}\text { Occupation } \\
\text { Connection to } \\
\text { Te Ao Māori }\end{array}$ & Major Contribution to Thesis \\
\hline Anituatua & Ngāti Kere & $\begin{array}{l}\text { MA (Mātauranga } \\
\text { Māori) }\end{array}$ & $\begin{array}{l}\text { Working class } \\
\text { Strong connection }\end{array}$ & Kaupapa Māori & $\begin{array}{l}\text { Wānanga graduate, gained higher education } \\
\text { as adult, grounded in iwitanga }\end{array}$ \\
\hline Arohia & $\begin{array}{l}\text { Ngāti Ngātū, Ngāti } \\
\text { Tamatoa }\end{array}$ & BA (Hons) & $\begin{array}{l}\text { Working class } \\
\text { Connected }\end{array}$ & Māori-focused & $\begin{array}{l}\text { Raised by queens in urban city setting, } \\
\text { independent and resourceful }\end{array}$ \\
\hline Atareta & $\begin{array}{l}\text { Tūhourangi, Ngāti } \\
\text { Wahiao }\end{array}$ & $\begin{array}{l}\text { LLB (B\&S of High } \\
\text { Court of NZ) }\end{array}$ & $\begin{array}{l}\text { Working class } \\
\text { Weak connection }\end{array}$ & Māori-focused & $\begin{array}{l}\text { Grew up in racist community, religious } \\
\text { boarding school }\end{array}$ \\
\hline Erana & $\begin{array}{l}\text { Ngāti Kahungunu, } \\
\text { Ngāti Rangi }\end{array}$ & LLB & $\begin{array}{l}\text { Working class } \\
\text { Strong connection }\end{array}$ & Kaupapa Māori & $\begin{array}{l}\text { Entrepreneur, grounded in iwitanga, raised } \\
\text { on papakāinga }\end{array}$ \\
\hline Hiria & Ngāti Kahungunu & $\begin{array}{l}\text { MSc (Marine } \\
\text { Biology) }\end{array}$ & $\begin{array}{l}\text { Middle class } \\
\text { Connected }\end{array}$ & Māori aspects & $\begin{array}{l}\text { Strong connection to iwitanga, educated in } \\
\text { predominantly Pākehā secondary school }\end{array}$ \\
\hline Hirini & Ngāti Porou & MSc (Nutrition) & $\begin{array}{l}\text { Working class } \\
\text { Weak connection }\end{array}$ & Māori aspects & $\begin{array}{l}\text { Top sportsman, gained higher education as } \\
\text { adult }\end{array}$ \\
\hline
\end{tabular}




\begin{tabular}{|l|l|l|l|l|l|}
\hline Participant & Iwi Affiliation & $\begin{array}{l}\text { Level of } \\
\text { Education }\end{array}$ & $\begin{array}{l}\text { Upbringing- Economic } \\
\text { (Class) and Cultural } \\
\text { (Connection to te ao } \\
\text { Māori) }\end{array}$ & $\begin{array}{l}\text { Occupation } \\
\text { Connection to } \\
\text { Te Ao Māori }\end{array}$ & Major Contribution to Thesis \\
\hline Ihaka & Ngāti Porou & $\begin{array}{l}\text { LLB (B\&S of High } \\
\text { Court of NZ) }\end{array}$ & $\begin{array}{l}\text { Working class } \\
\text { Strong connection }\end{array}$ & Kaupapa Māori & Grounded in iwitanga, raised by sole parent \\
\hline Itiria & $\begin{array}{l}\text { Ngāti Raukawa, Ngāti } \\
\text { Porou }\end{array}$ & $\begin{array}{l}\text { MD (Doctor of } \\
\text { Medicine) }\end{array}$ & $\begin{array}{l}\text { Working class } \\
\text { Connected }\end{array}$ & Kaupapa Māori & $\begin{array}{l}\text { Started higher education journey as teenage } \\
\text { mother, Māori girls' boarding school }\end{array}$ \\
\hline Kahukura & $\begin{array}{l}\text { Taranaki, Ngā } \\
\text { Ruahine, Tāngahoe }\end{array}$ & PhD & $\begin{array}{l}\text { Working class } \\
\text { Connected }\end{array}$ & Māori-focused & $\begin{array}{l}\text { Strong Catholic upbringing, living on } \\
\text { papakāinga }\end{array}$ \\
\hline Kapuarangi & $\begin{array}{l}\text { Ngāti Porou } \\
\text { Mpper class } \\
\text { Strong connection }\end{array}$ & Kaupapa Māori & $\begin{array}{l}\text { Grounded in iwitanga, high class, } \\
\text { educationalist }\end{array}$ \\
\hline Manaakiao & $\begin{array}{l}\text { Ngāti Kahungunu ki } \\
\text { Te Wairoa, Ngāti } \\
\text { Ruapani }\end{array}$ & $\begin{array}{l}\text { MA (Hons) Māori } \\
\text { Studies }\end{array}$ & $\begin{array}{l}\text { Middle class } \\
\text { Connected }\end{array}$ & Kaupapa Māori & $\begin{array}{l}\text { Whānau leader, grounded in iwitanga, living } \\
\text { in tribal home-town }\end{array}$ \\
\hline Matariki & Te Āti Awa & BA (Hons) & $\begin{array}{l}\text { Working class } \\
\text { Connected }\end{array}$ & Kaupapa Māori & $\begin{array}{l}\text { Grounded in iwitanga, passion for } \\
\text { mātauranga ā iwi }\end{array}$ \\
\hline Matiu & $\begin{array}{l}\text { Ngāti Raukawa, Ngāti } \\
\text { Toa, Te Āti Awa }\end{array}$ & $\begin{array}{l}\text { BCA/Chartered } \\
\text { Accountant }\end{array}$ & $\begin{array}{l}\text { Working class } \\
\text { Weak connection }\end{array}$ & Māori aspects & $\begin{array}{l}\text { Raised in small non-Māori rural community, } \\
\text { struggled with Māori identity }\end{array}$ \\
\hline
\end{tabular}




\begin{tabular}{|c|c|c|c|c|c|}
\hline Participant & Iwi Affiliation & $\begin{array}{l}\text { Level of } \\
\text { Education }\end{array}$ & $\begin{array}{l}\text { Upbringing- Economic } \\
\text { (Class) and Cultural } \\
\text { (Connection to te ao } \\
\text { Māori) }\end{array}$ & $\begin{array}{l}\text { Occupation } \\
\text { Connection to } \\
\text { Te Ao Māori }\end{array}$ & Major Contribution to Thesis \\
\hline Piata & $\begin{array}{l}\text { Ngāti Kahungunu, Ngā } \\
\text { Rauru }\end{array}$ & BA (PG Dip) & $\begin{array}{l}\text { Middle class } \\
\text { Connected }\end{array}$ & Māori-focused & $\begin{array}{l}\text { Strong whānau unionist and education } \\
\text { background }\end{array}$ \\
\hline Pirihira & Whakatōhea & $\mathrm{PhD}$ & $\begin{array}{l}\text { Working class } \\
\text { Weak connection }\end{array}$ & Māori-focused & $\begin{array}{l}\text { Success whānau norm, raised in racist } \\
\text { community, struggled with Māori identity }\end{array}$ \\
\hline Puawai & $\begin{array}{l}\text { Ngāti Maniapoto, } \\
\text { Tainui, Ngāti Porou }\end{array}$ & $\begin{array}{l}\text { BCA/Chartered } \\
\text { Accountant }\end{array}$ & $\begin{array}{l}\text { Middle class } \\
\text { Strong connection }\end{array}$ & Māori aspects & $\begin{array}{l}\text { Strong whānau background in education, } \\
\text { grounded in iwitanga }\end{array}$ \\
\hline Rakai & Ngāi Tūhoe & $\begin{array}{l}\text { MA (Māori Visual } \\
\text { Arts) }\end{array}$ & $\begin{array}{l}\text { Middle class } \\
\text { Connected }\end{array}$ & Māori-focused & $\begin{array}{l}\text { Strong Catholic upbringing, passion for } \\
\text { Māori design }\end{array}$ \\
\hline Reremoana & $\begin{array}{l}\text { Ngāti Tūwharetoa, } \\
\text { Ngāi Tūhoe }\end{array}$ & BA (Hons) & $\begin{array}{l}\text { Working class } \\
\text { Connected }\end{array}$ & Kaupapa Māori & $\begin{array}{l}\text { Catholic upbringing, learnt te reo at } \\
\text { university, children at Kura Māori }\end{array}$ \\
\hline Taiawhio & $\begin{array}{l}\text { Ngāti Awa, Ngāitai, } \\
\text { Ngāi Tūhoe }\end{array}$ & LLM (Hons) & $\begin{array}{l}\text { Working class } \\
\text { Strong connection }\end{array}$ & Māori-focused & $\begin{array}{l}\text { Strong whānau education background, } \\
\text { grounded in iwitanga }\end{array}$ \\
\hline Taite & $\begin{array}{l}\text { Ngāti Kahungunu ki } \\
\text { Te Wairoa }\end{array}$ & $\begin{array}{l}\text { LLB/BA (B\&S of } \\
\text { High Court of NZ) }\end{array}$ & $\begin{array}{l}\text { Working class } \\
\text { Connected }\end{array}$ & Kaupapa Māori & $\begin{array}{l}\text { Strong Catholic upbringing, Māori boarding } \\
\text { school }\end{array}$ \\
\hline Tamati & Tainui, Ngāti Porou & BSocSci (Hons) & $\begin{array}{l}\text { Working class } \\
\text { Connected }\end{array}$ & Māori-focused & Nomadic upbringing, Māori boarding school \\
\hline
\end{tabular}




\begin{tabular}{|c|c|c|c|c|c|}
\hline Participant & Iwi Affiliation & $\begin{array}{l}\text { Level of } \\
\text { Education }\end{array}$ & $\begin{array}{l}\text { Upbringing- Economic } \\
\text { (Class) and Cultural } \\
\text { (Connection to te ao } \\
\text { Māori) }\end{array}$ & $\begin{array}{l}\text { Occupation } \\
\text { Connection to } \\
\text { Te Ao Māori }\end{array}$ & Major Contribution to Thesis \\
\hline Te Kepa & $\begin{array}{l}\text { Ngāitai, Whakatōhea, } \\
\text { Te Ati Haunui-a- } \\
\text { Pāpārangi }\end{array}$ & $\begin{array}{l}\text { LLM/BCA (B\&S of } \\
\text { High Court of NZ) }\end{array}$ & $\begin{array}{l}\text { Working class } \\
\text { Strong connection }\end{array}$ & Māori-focused & $\begin{array}{l}\text { Whānau leader, raised in small Māori rural } \\
\text { community }\end{array}$ \\
\hline Te Kohi & $\begin{array}{l}\text { Ngāti Rangi, } \\
\text { Whanganui }\end{array}$ & BA (Hons) & $\begin{array}{l}\text { Working class } \\
\text { Strong connection }\end{array}$ & Kaupapa Māori & $\begin{array}{l}\text { Iwi leader, grounded in iwitanga, Catholic } \\
\text { upbringing }\end{array}$ \\
\hline Te Paea & Ngāti Whātua & $\begin{array}{l}\text { LLM/BA (B\&S of } \\
\text { High Court of NZ) }\end{array}$ & $\begin{array}{l}\text { Working class } \\
\text { Strong connection }\end{array}$ & Kaupapa Māori & $\begin{array}{l}\text { Whānau and iwi leader, grounded in } \\
\text { iwitanga, raised in urban Pasifika suburb }\end{array}$ \\
\hline Teaniwa & $\begin{array}{l}\text { Ngāti Kahungunu, Te } \\
\text { Âti Awa }\end{array}$ & MA (Linguistics) & $\begin{array}{l}\text { Working class } \\
\text { Strong connection }\end{array}$ & Māori-focused & $\begin{array}{l}\text { Raised in urban Māori and Pasifika suburb, } \\
\text { youngest of six children }\end{array}$ \\
\hline Terina & $\begin{array}{l}\text { Ngāiterangi, } \\
\text { Whakatōhea }\end{array}$ & $\begin{array}{l}\text { BTSM/BCA } \\
\text { (Hons) }\end{array}$ & $\begin{array}{l}\text { Working class } \\
\text { Connection }\end{array}$ & Kaupapa Māori & $\begin{array}{l}\text { Strong Catholic upbringing, raised in family } \\
\text { of six children }\end{array}$ \\
\hline Tūterangi & $\begin{array}{l}\text { Ngāti Manawa, Tainui, } \\
\text { Ngāi Tūhoe }\end{array}$ & $\begin{array}{l}\text { MSocSci } \\
\text { (Applied) }\end{array}$ & $\begin{array}{l}\text { Working class } \\
\text { Strong connection }\end{array}$ & Kaupapa Māori & $\begin{array}{l}\text { Native speaker, raised on papakāinga, } \\
\text { gained higher education as adult }\end{array}$ \\
\hline Waimarino & Taranaki & MA & $\begin{array}{l}\text { Working class } \\
\text { Weak connection }\end{array}$ & Māori aspects & $\begin{array}{l}\text { Raised in sole parent family with no connect } \\
\text { to iwi, struggled with Māori identity }\end{array}$ \\
\hline Weihana & $\begin{array}{l}\text { Ngāti Ruapani, Ngāi } \\
\text { Tūhoe }\end{array}$ & $\mathrm{PhD}$ & $\begin{array}{l}\text { Middle class } \\
\text { Weak connection }\end{array}$ & Māori-focused & $\begin{array}{l}\text { Fair-skinned Māori, strong whānau } \\
\text { educational background }\end{array}$ \\
\hline Whaiora & Waikato, Ngā Puhi & LLB/BA & $\begin{array}{l}\text { Working class } \\
\text { Strong connection }\end{array}$ & Māori aspects & $\begin{array}{l}\text { Raised in urban setting, studied } \\
\text { internationally }\end{array}$ \\
\hline
\end{tabular}


